\title{
The politics of the evolution of global tobacco control: The formation and functioning of the Framework Convention on Tobacco Control (FCTC)
}

Hadii M. Mamudu

West Virginia University

Follow this and additional works at: https://researchrepository.wvu.edu/etd

\section{Recommended Citation}

Mamudu, Hadii M., "The politics of the evolution of global tobacco control: The formation and functioning of the Framework Convention on Tobacco Control (FCTC)" (2005). Graduate Theses, Dissertations, and Problem Reports. 2316.

https://researchrepository.wvu.edu/etd/2316

This Dissertation is protected by copyright and/or related rights. It has been brought to you by the The Research Repository @ WVU with permission from the rights-holder(s). You are free to use this Dissertation in any way that is permitted by the copyright and related rights legislation that applies to your use. For other uses you must obtain permission from the rights-holder(s) directly, unless additional rights are indicated by a Creative Commons license in the record and/ or on the work itself. This Dissertation has been accepted for inclusion in WVU Graduate Theses, Dissertations, and Problem Reports collection by an authorized administrator of The Research Repository @ WVU.

For more information, please contact researchrepository@mail.wvu.edu. 
The Politics of the Evolution of Global Tobacco Control: The Formation and Functioning of the Framework Convention on Tobacco Control (FCTC)

Hadii M. Mamudu

Dissertation submitted to the Eberly College of Arts and Sciences

At West Virginia University In partial fulfillment of the requirements

For the degree of

\title{
Doctor of Philosophy \\ In \\ Political Science
}

\author{
Donley T. Studlar, Ph.D, Chair \\ Geri A. Dino, Ph.D \\ Jeffrey S. Worsham, Ph.D \\ Jamie E. Jacobs, Ph.D \\ Joe D. Hagan, Ph.D \\ Department of Political Science
}

$$
\begin{aligned}
& \text { Morgantown, West Virginia } \\
& 2005
\end{aligned}
$$

Keywords: Framework Convention on Tobacco Control (FCTC), LiberalConstructivism, Transnationalism, “Low Politics,” “Best Practices,” Diffusion, Transfer, Advocacy Coalition Framework (ACF), Transnational Advocacy Groups (TAGs), Epistemic Communities, Middle-Level Theories

Copyright 2005 Hadii M. Mamudu 


\begin{abstract}
The Politics of the Evolution of Global Tobacco Control: The Formation and Functioning of the Framework Convention on Tobacco Control (FCTC)
\end{abstract}

\title{
Hadii M. Mamudu
}

The study investigates the politics behind the evolution of tobacco as a global issue leading to adoption of the Framework Convention on Tobacco Control (FCTC) in May 2003. The study relies on liberal-constructivist perspective to analyze the transformation of tobacco control between 1960 and 2003. The study uses a combination of elite interview and content analysis. It found that the presence of an international organization with constitutional powers in tobacco control, WHO and the diffusion and transfer of knowledge, information, and ideas about tobacco use and tobacco control contributed to the emergence of tobacco control as a global phenomenon and the FCTC. 


\section{A C K N O W L E D G E E N T}

Life in the United States in general, and Morgantown, West Virginia would not have been possible without the support of countless number of people. Still, my most heartfelt thanks go to my mum, Zuwerah and my dad, Mamudu for their encouragement throughout my stay and academic work at West Virginia University (WVU). My second thanks go to my uncle, Issah for his financial support and for being there whenever I needed him.

Beyond the family members, many people at the Political Science Department of West Virginia University made my academic work fun. In this respect, I say thank you to all members of my dissertation committee - Donley Studlar (Chair), Jamie Jacobs, Jeff Worsham, Geri Dino, and Joe Hagan. I am glad that you took time out of your summer vacation schedules to ensure that this study is concluded. Also, I say thank you to the Political Science Department for giving me the opportunity to embark on this doctoral program. I appreciate the help and support of the administrative staff especially Becky, throughout my stay at the department. Finally, I cannot end this without saying thank you to all my colleagues. They made my doctoral work fun. Although it is difficult to single out any person, I cannot help but to say special thank you to Dave, Lt. Col. Kong, Kyoung, Chaun, Korok, and Teresa. I appreciate your friendliness a lot.

There is actually life beyond academic work. For this reason, I say thank you to all members of the African Students' Association and Circle-K International of WVU. I appreciate the bond we established throughout my stay in Morgantown. In addition, I say thank you Katherine Bankole, Araba and Ben Dawson for your encouragement even when the task ahead seems insurmountable. Ben Dawson, I will always remember your encouraging words: "Hard work will not kill you, but will only make you a better

person.” Also, I say thank you to Odhiambo, Fred, Yemi, Bossman, Gashew, Muriel, and Nicho for support and friendship throughout my stay in Morgantown.

Finally, thank you all the interviewees of this study. I am glad that you consented to the interviews, and shared your knowledge on the subject matter of this study with me. 
Dedicated to Jeff Worsham for bringing me to West Virginia University and Donley Studlar for the support throughout the study. 


\section{O N T E N TS}

Chapter 1: Introduction

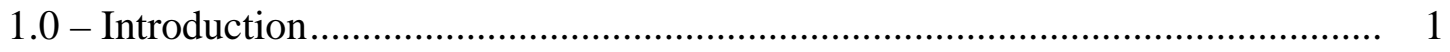

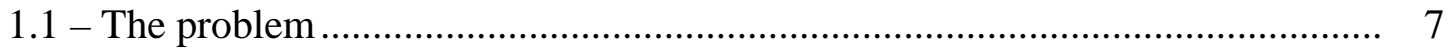

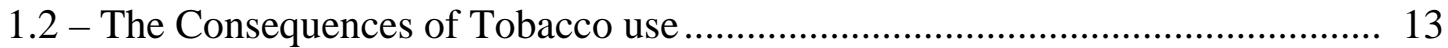

1.3 - The Framework Convention on Tobacco Control (FCTC) ........................... 17

1.3.0 - The FCTC Negotiation Process ....................................................... 18

1.4 - Overview of Chapters .................................................................... 23

Chapter 2:Theoretical Framework ..................................................................... 25

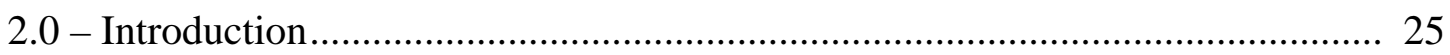

2.1 - A Review of International Relations Literature............................................ 25

2.2 - The Liberal-Constructivist Model............................................................ 29

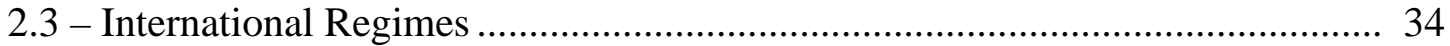

2.3.1 - The Structural Tradition.................................................................. 35

2.3 .2 - The Grotian Tradition ..................................................................... 37

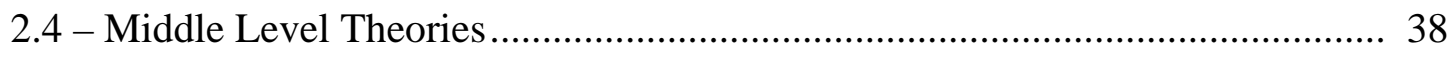

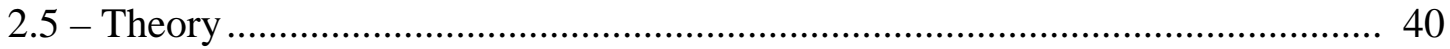

2.5.1 - Epistemic Communities ................................................................. 41

2.5.2 - Transnational Advocacy Networks................................................... 44

2.5.3 - Advocacy Coalition Framework (ACF)............................................ 47

2.6 - Concepts, Measurements, and Hypotheses ................................................. 48

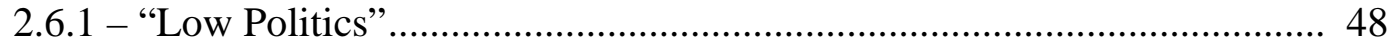

2.6.2 - Policy Transfer/Diffusion ................................................................. 51

2.6.3 - Transnationalism........................................................................ 55

2.6.4 - Globalization and Interdependence.............................................. 59

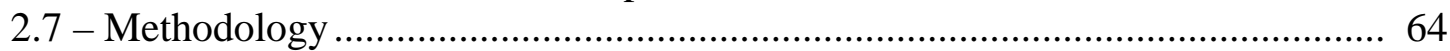

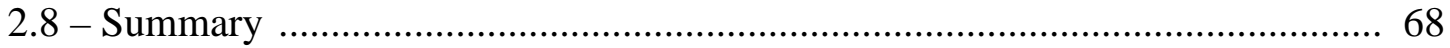

Chapter 3: Transnationalism..................................................................... 70

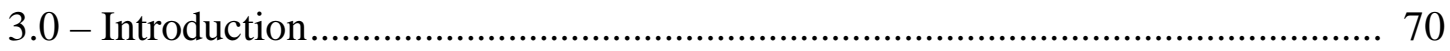

3.1 - Transnational Advocacy Groups............................................................ 71

3.1.1 - Anti-Tobacco Advocacy Groups ................................................... 73

3.1.1.0 - Anti-Tobacco Advocacy Groups and the FCTC....................... 78

3.1.1.0.0 - Working Strategies.................................................. 82

3.1.1.1 - Pro-tobacco Advocacy Groups and the FCTC......................... 86

3.2 - Transnational Tobacco Companies (TTCs) ................................................. 97

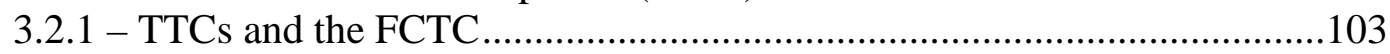

3.3 - Tobacco Policy Entrepreneurs (TPEs) and Advocates/Activists......................110

3.3.0 - TPEs and Advocates/Activists and the FCTC ......................................112

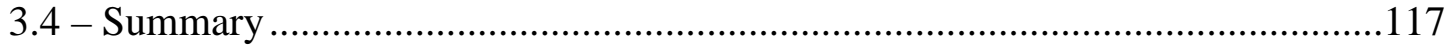


4.0 - Introduction

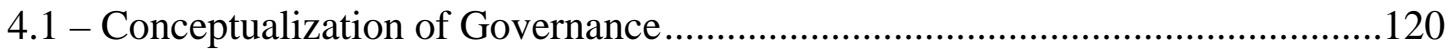

4.2 - From Uruguay Round of Talk (GATT) to FCTC .........................................123

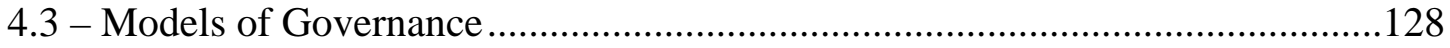

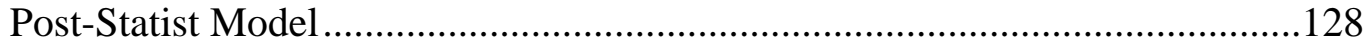

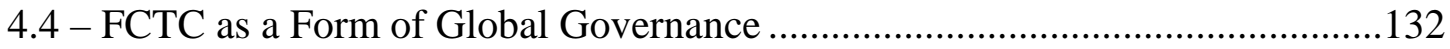

4.4.1 - The Role of States ............................................................................132

4.4.2 - The Role of the World Health Organization ...........................................138

4.4.2.1 - World Health Organization’s Partners.........................................143

4.4.2.2 - World Health Organization’s Tobacco Control Program: The Tobacco Free Initiative (TFI) ......................................... 147

4.4.2.3 - World Health Organization’s Tobacco Control Program:

"World No Tobacco Day" (WNTD).........................................150

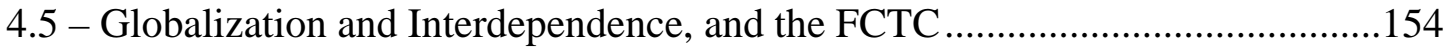

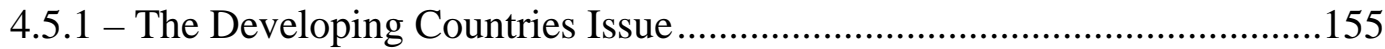

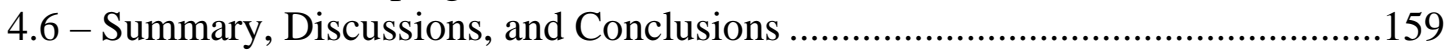

Chapter 5: Transfer/Diffusion of Best Practices in Tobacco Control....................163

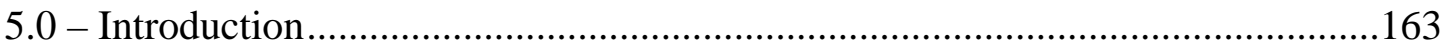

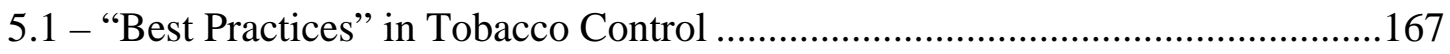

5.2 -Epistemic Community on Tobacco Control:

World Conference on Tobacco or Health .......................................................173

5.2.1 - First Phase: Tobacco as a Developed Countries Issue............................177

5.2.2 - Second Phase: Tobacco as a Worldwide Issue .......................................178

5.2.3 - Final Phase: Development of a Global Tobacco Control Regime ............186

5.2.4 - Impact of WCTOH on global Tobacco Control ....................................187

5.3 - The International Conference on Illicit Tobacco Trade...................................192

5.4 - Key Nongovernmental Organizations in the Global

Diffusion of Tobacco Control Measures........................................................199

5.4.1 - The International Union Against Cancer (UICC) ....................................200

5.4.2 - The American Cancer Society (ACS) ....................................................202

5.5 - Research Institutions in the Diffusion of Global Tobacco Control Measures ..205

5.5.1 - The U.S. Center for Diseases Control and Prevention (CDC)................205

5.5.2 - Research for International Tobacco Control (RITC), Canada ..................208

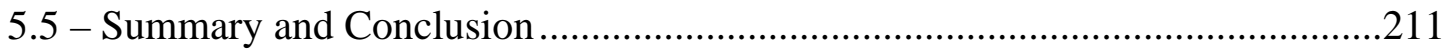

Chapter 6: Preliminary Analysis............................................................................213

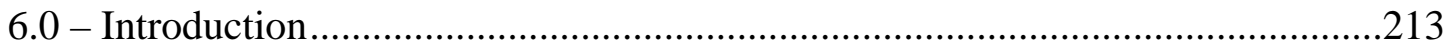

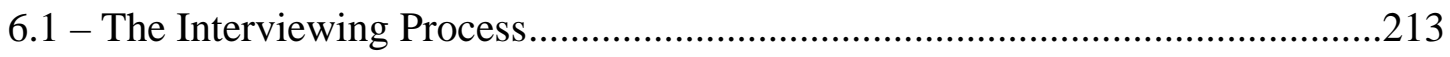

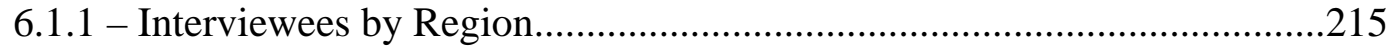

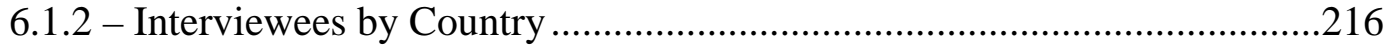

6.2 - Actors and Stakeholders in the FCTC Negotiation Process ............................217 
6.2.1 - Intergovernmental Organization (WHO) .................................................218

6.2.2 - Nongovernmental Organizations (NGOs) ..............................................2.219

6.2.3 - Business International Organizations (BINGOs).....................................219

6.2.4 - Policy Entrepreneurs and Advocates/Activists ........................................220

6.2.5 - Public/Government Officials ....................................................................221

6.2.6 - Transnational Tobacco Companies (TTCs) ……….....................................221

6.3 - Methods of Data Collection ...........................................................................222

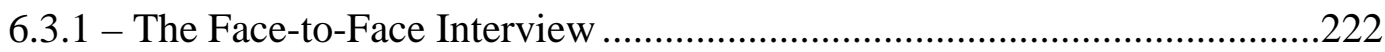

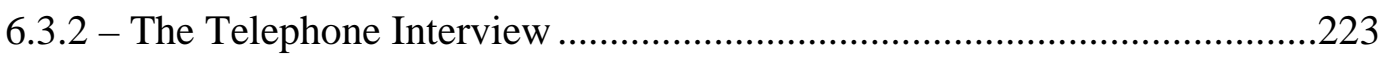

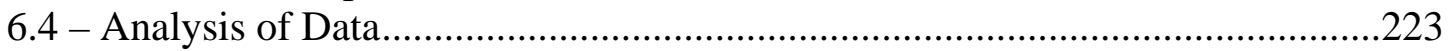

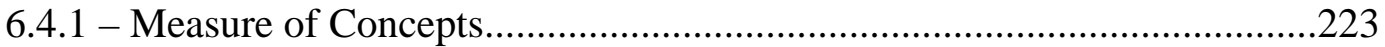

6.5 - Adoption of the FCTC: Analysis .....................................................................225

6.5.1 - FCTC and Knowledge, Information, and Ideas about

Tobacco Use and Tobacco Control......................................................228

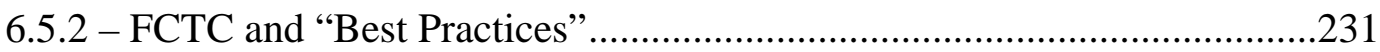

6.5.3 - FCTC and Policy Transfer/Diffusion......................................................232

6.5.4 - FCTC and Transnationalism ...............................................................237

6.5.5 - FCTC and Globalization and Interdependence.......................................239

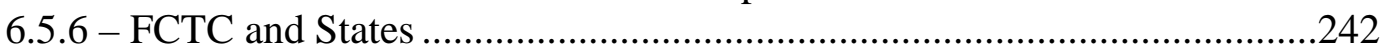

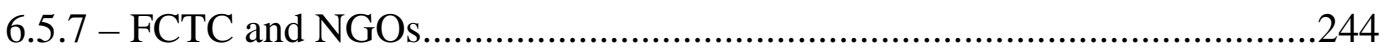

6.5.8 - FCTC and The Tobacco Industry …..................................................247

6.5.9 - FCTC and Policy Entrepreneurs and Advocates/Activists ........................248

6.5.10 - FCTC and "Low Politics" ......................................................................250

6.6 - Summary, Conclusion, and Discussion ...........................................................252

Chapter 7: Conclusion.........................................................................................................255

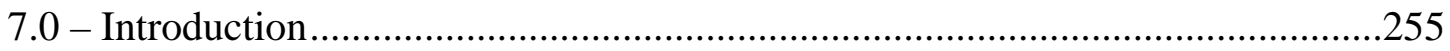

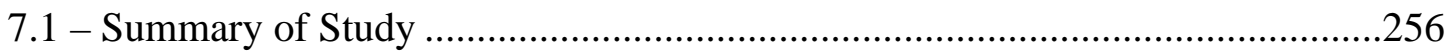

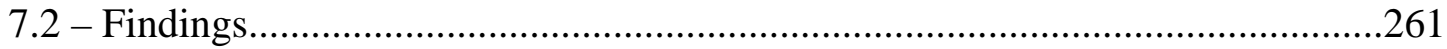

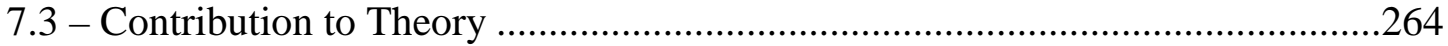

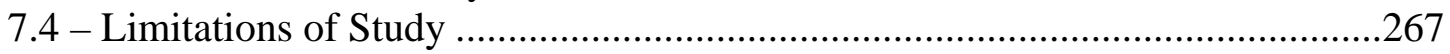

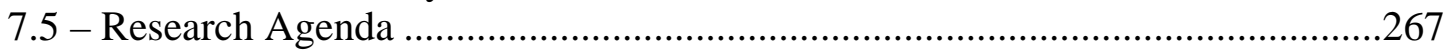

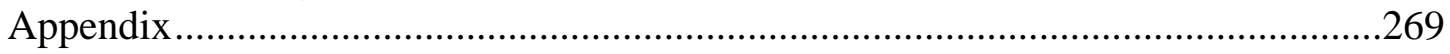

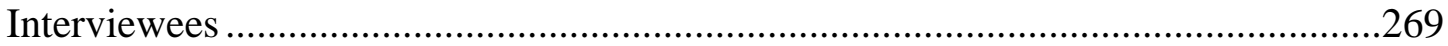

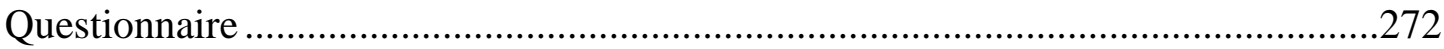

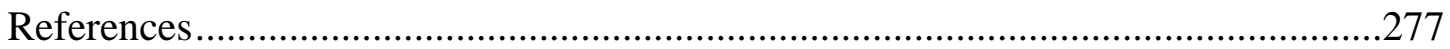


T A B L E S

1.0 - The Timeline of Global Tobacco Control, 1950s-2003.................................. 2

3.1 - Date of Establishment of Some Transnational Advocacy Groups.....................78

3.2 - Framework Convention Alliance Bulletin .......................................................83

3.3 - Tobacco Leaf Exporters ...........................................................................92

3.4 - Date of Establishment of Some Key Transnational Tobacco Companies ........102

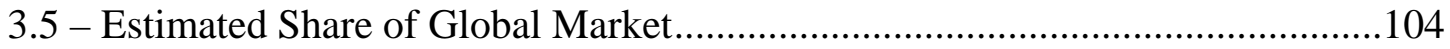

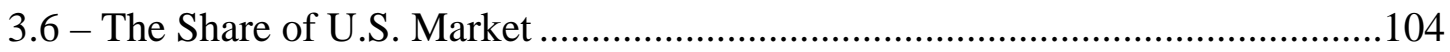

3.7 - Worldwide Activities of Major Transnational Tobacco Companies ................104

3.8 - Transnational Tobacco Companies at the FCTC Public Hearings ....................107

4.0 - Estimated Number of Smokers Globally .......................................................155

4.1 - Estimates and Trends of Cigarette Consumption per Adult

Aged 15 and Over, 1970-1972 to 1990-1992 ..................................................155

5.0 - World Conference on Tobacco or Health (WCTOH) .....................................164

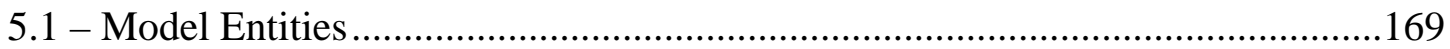

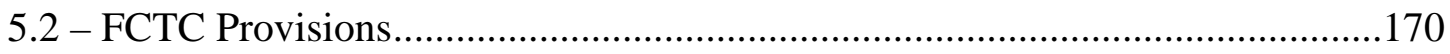

5.3 - International Strategy of Tobacco Control ....................................................187

5.4 - International Conference on Illicit Tobacco Trade and FCTC ........................198

6.0 - Interviewees by Type of Conference/Meeting.............................................215

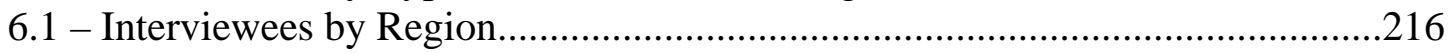

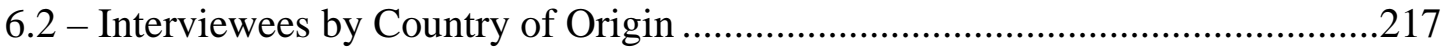

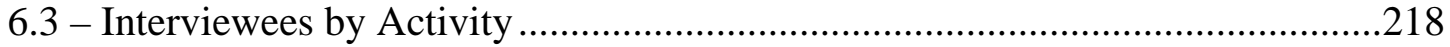

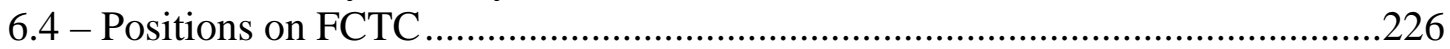

6.5 - Percentage of Interviewees on Raised Issues..............................................228 


\section{F I G U R E S}

1.0 - Institutionalization of Global Tobacco Control ............................................ 6

1.1 - Summary of the FCTC Negotiation Process...................................................21

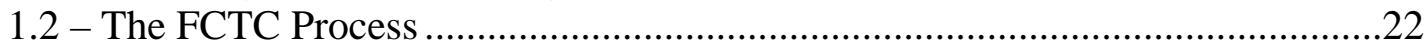

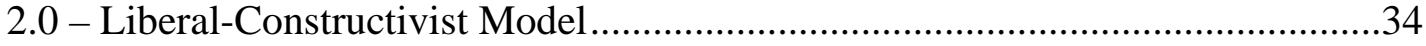

3.0 - The Growth of NGOs with Interest in FCTC, 1999-2003 ..............................81

3.1 - Pro-tobacco Groups Central Arguments .......................................................96

5.0 - Number of Countries at World Conference on Tobacco or Health,

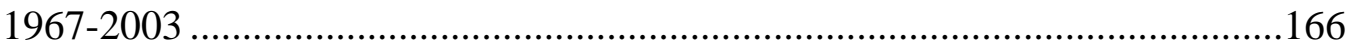

5.1 - Number of Countries at World Conference on Tobacco or Health,

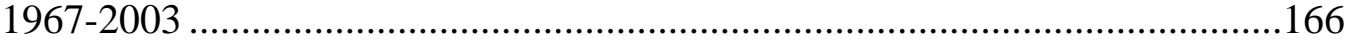

5.2 - Tobacco Control Epistemic Community: WCTOH.......................................174

5.3 - Activities of the Research International on Tobacco Control, Canada.............208

7.1 - The Evolution of Global Tobacco Control ................................................259 


\begin{tabular}{|c|c|}
\hline \multicolumn{2}{|c|}{ Abbreviations and Acronyms } \\
\hline $\mathrm{ACF}$ & Advocacy Coalition Framework \\
\hline ACLU & American Civil Liberties Union \\
\hline ACS & American Cancer Society \\
\hline ACTC & Asian Consultancy on Tobacco Control \\
\hline AFRO & World Health Organization’s African Region \\
\hline AHA & American Heart Association \\
\hline AIPMTMA & All India Pan Masala \& Tobacco Manufacturers Association \\
\hline ALA & American Lung Association \\
\hline AMA & American Medical Association \\
\hline ASH & Action on Smoking and Health \\
\hline BAT & British American Tobacco \\
\hline $\mathrm{BBC}$ & British Broadcasting Corporation \\
\hline BINGO & Business International NGO \\
\hline $\mathrm{CDC}$ & Center for Disease Control and Prevention \\
\hline CIDA & Canadian International Development Agency \\
\hline CTR & Center for Tobacco Research \\
\hline ECOSOC & Economic and Social Council \\
\hline EMRO & WHO Eastern-Mediterranean Region \\
\hline ETS & Environmental Tobacco Smoke \\
\hline EURO & World Health Organization’s European Region \\
\hline FAO & Food and Agricultural Organization \\
\hline FCA & Framework Convention Alliance \\
\hline FCTC & Framework Convention on Tobacco Control \\
\hline FDA & Food and Drug Administration \\
\hline GASP & Group to Alleviate Smoking Pollution \\
\hline GATS & General Agreement on Trade and Services \\
\hline GATT & General Agreement on Trade and Tariffs \\
\hline GYTS & Global Youth Tobacco Survey \\
\hline HEC & Health Education Council \\
\hline $\mathrm{HO}$ & Health Organization \\
\hline ICAO & International Civil Aviation Organization \\
\hline ICITT & International Conference on Illicit Tobacco Trade \\
\hline ICRC & International Committee of Red Cross \\
\hline ICOSI & International Committee on Smoking Issues \\
\hline IDRC & International Development Research Center \\
\hline IGO & Intergovernmental Organization \\
\hline ILO & International Labor Organization \\
\hline IMO & International Maritime Organization \\
\hline INB & Intergovernmental Negotiating Body \\
\hline INFOTAB & International Tobacco Information Center \\
\hline INGCAT & International Nongovernmental Coalition Against Tobacco \\
\hline $\mathrm{IO}$ & International Organization \\
\hline IOCU & International Organization of Consumers’ Unions \\
\hline ISFC & International Society and Federation of Cardiology \\
\hline ITGA & International Tobacco Growers’ Association \\
\hline
\end{tabular}




\begin{tabular}{|c|c|}
\hline ITL & Imperial Tobacco Limited \\
\hline IUATLD & International Union Against Tuberculosis and Lung Diseases \\
\hline IUF & $\begin{array}{l}\text { International Union of Food, Agricultural, Hotel, Restaurant, and Allied } \\
\text { Workers Union }\end{array}$ \\
\hline JTI & Japan Tobacco International \\
\hline MNB & Multinational Bank \\
\hline MNC & Multinational Corporation \\
\hline MSA & Master Settlement Agreement \\
\hline NATIONS & National Tobacco Information Online System \\
\hline NATT & Network Accountability for Tobacco Transnationals \\
\hline NGO & Nongovernmental Organization \\
\hline NYCCLASH & New York City Citizens Lobbying Against Smoker \\
\hline OECD & Organization for Economic Development and Cooperation \\
\hline OLAF & European Union Anti-Fraud Office \\
\hline PAHO & Pan American Health Organization \\
\hline RCP & Royal College of Physicians \\
\hline RITC & Research International for Tobacco Control \\
\hline SAP & Structural Adjustment Program \\
\hline SDA & Seventh Day Adventist \\
\hline SEARO & World Health Organization’s Southeast Asian Region \\
\hline Sida & Swedish International Development Cooperation Agency \\
\hline SSA & Sub-Saharan Africa \\
\hline TAG & Transnational Advocacy Group \\
\hline TAN & Transnational Advocacy Network \\
\hline TBT & Technical Barriers to Trade \\
\hline TFI & Tobacco Free Initiative \\
\hline TIRC & Tobacco Institute Research Center \\
\hline TMA & Tobacco Merchants Association \\
\hline TNB & Transnational Bank \\
\hline TNC & Transnational Corporation \\
\hline TNO & Transnational Organization \\
\hline ТРC & Technical Preparatory Committee \\
\hline TRIPS & Trade-Related Aspect of International Property Rights \\
\hline TTC & Transnational Tobacco Company \\
\hline UICC & International Union Against Cancer \\
\hline UK & United Kingdom \\
\hline UN & United Nations \\
\hline UNCTAD & United Nations Conference on Trade and Development \\
\hline UNEP & United Nations Environmental Program \\
\hline UNRRA & United Nations Relief and Rehabilitation Administration \\
\hline UIA & Union International Association \\
\hline U.S. & United States \\
\hline USDA & The U.S. Department of Agriculture \\
\hline USDHHS & The U.S. Department of Health and Human Services \\
\hline WCCO & World Conference for Cancer Organizations \\
\hline WCO & World Customs Organization \\
\hline
\end{tabular}




$\begin{array}{ll}\text { WG } & \text { Working Group } \\ \text { WPRO } & \text { World Health Organization's Western Pacific Region } \\ \text { WCTOH } & \text { World Conference on Tobacco or Health } \\ \text { WHA } & \text { World Health Assembly } \\ \text { WHO } & \text { World Health Organization } \\ \text { WNTD } & \text { World No Tobacco Day } \\ \text { WTO } & \text { World Trade Organization } \\ \text { WWI } & \text { World War I } \\ \text { WWII } & \text { World War II } \\ \text { ZTA } & \text { Zimbabwe Tobacco Association }\end{array}$




\section{Chapter 1}

\section{Introduction}

On May 21, 2003, a unanimous decision at the World Health Assembly (WHA) brought the Framework Convention on Tobacco Control (FCTC) into being. It became enforceable on February 27, 2005 after minimum of forty countries ratified it. It is the first global treaty negotiated through the World Health Organization (WHO). Tobacco control is one of the few issue areas within the international system and the only international public health issue that has resulted in a successful collective action by states in the form of a treaty. All the 192 member states of WHO came together at the $56^{\text {th }}$ World Health Assembly (WHA) to combat an emerging global public health problem. Within two years, 168 countries had signed the document, and as at July 2005, 74 countries had ratified. The alacrity with which the FCTC came into being has made it a unique international public health regime.

Since Ruggie (1975) introduced the concept of regime into the lexicon of international relations literature, wide range of authors have identified regimes in different issue areas including telecommunication, food, trade, money, and oceans (Smith, 1987; Kranser, 1983). However, little is known about this new tobacco control regime, FCTC. This longitudinal study analyzes the evolution of tobacco control into a global regime between 1960 and 2003 [See Table 1.0]. It analyzes why tobacco control took about four decades before it bubbled up as an international regime, a bottom-up analysis. The analysis of this regime is important because it is the first time the World 
Health Organization used its constitutional powers to lead the development of a global regime since it came into being in 1948. Moreover, the FCTC is one of the few regimes that emerged in the form of a treaty hence the importance of exploring why states came together to embark on such collective action. Also, the analysis of this global regime brings not only the fields of Public Health and Political Science together in one study but also it bridges the gap between International Relations and Comparative Public Policy sub-fields in Political Science. Furthermore, as a number one preventable cause of death that affects millions of people worldwide, tobacco brings actors of diverse interest together. As such, analysis of how these different actors around the globe collaborated to establish this regime is important. This helps in the understanding of how and why rational-egoists could cooperate within the international system. Finally, there is a multibillion-dollar transnational corporate agent involved in worldwide spread of the habit, making a multi-fields approach to analysis of the regime important.

Table 1.0 The Timeline of Global Tobacco Control, 1950s to 2003

1950s - The peak of scientific evidence on health hazards of tobacco use

1962 - Publication of British Royal College of Physicians’ Report acknowledging the link between tobacco use and health

1964 - The U.S. Surgeon General's Report on Smoking and Health acknowledged the hazards of tobacco use

1967 - The First World Conference on Tobacco or Health (WCTOH), New York. The American Cancer Society and the Seventh Day Adventist (SDA) church sponsored it. Tobacco use is treated as an international issue among developed countries.

1970 - World Health Organization (WHO) publicly acknowledged the hazards of tobacco use 
1975 - $\quad$ Publication of International Union Against Cancer (UICC) Manual on tobacco control under the chairmanship of Nigel Gray. The manual highlighted tobacco control policies for worldwide adoption

1979 - $\quad$ World Conference on Tobacco or Health, Stockholm, Sweden. Recognition that the extension of activities of the tobacco industry in developing world and associated increase in tobacco consumption is part of the international tobacco problem

1983 - $\quad$ Resolution at the $5^{\text {th }}$ WCTOH at Winnipeg, Canada that recommended policies of WHO, the UICC, and International Union Against Tuberculosis (IUAT) were comprehensive program for adoption

1986 - $\quad$ WHO resolution WHA39.14 urged member states to take steps to reduce tobacco use.

1988 - $\quad$ First "World No Tobacco Day.”

1988 - $\quad$ UICC and WHO published guidelines for primary health care teams on smoking cessation

$1992 \quad$ - $\quad 8^{\text {th }}$ World Conference on Tobacco and Health, Buenos Aires, Argentina. The first conference held in a developing country. The World Bank, United Nations' Children Fund (UNICEF) and United Nations Education, Scientific, and Cultural Organization (UNESCO) attended the conference for the first time.

1992 - $\quad$ Allyn Taylor publishes an article in the Journal of Law and Medicine illuminating the constitutional powers of WHO to establish a regime

1993 - $\quad$ Allyn Taylor, Ruth Roemer, and Judith Mackay discuss the need for an international convention on tobacco control at a meeting in San Francisco

1994 - $\quad$ Resolution at the $9^{\text {th }}$ World Conference on Tobacco or Health urged WHO to develop an international convention on tobacco control

1994 - International Nongovernmental Coalition Against Tobacco (INGCAT) was formed

1995 - $\quad$ WHO adopts the $9^{\text {th }}$ WCTOH resolution on international strategy for tobacco control, resolution WHA48.11

1998 - $\quad$ The Master Settlement Agreement in the U.S. 
1998 - Gro Harlem Brundtland ascended to the position of Director-General of WHO on July 21. She made global tobacco control one of the priorities of WHO

1998 - Establishment of WHO Tobacco Free Initiative (TFI), another recommendation of the $9^{\text {th }}$ WCTOH

1999 - Beginning of the FCTC negotiation process

1999 - Publication of Centers for Diseases Control and Prevention's (CDC) manual on "best practices" in tobacco control

1999 - The Network for Accountability of Tobacco Transnationals emerged

2000 - FCTC public hearings in Geneva. It provided opportunity for the civil society to participate in the negotiation process

2000 - The Framework Convention Alliance came into being

2002 - International Conference on Illicit Tobacco Trade (ICITT), New York. Conference resolutions were integrated into the negotiation of FCTC.

2000/2003 Two Intergovernmental Working Group (WG) meetings and six Intergovernmental Negotiating Body meetings on FCTC

2003 - May 21 - the 192 members of WHO unanimously adopted the FCTC

2004 - June - signature for the FCTC was closed after 168 countries had signed

2005 - February 27 - FCTC became an enforceable international treaty after 40 countries had ratified. As at July, 74 countries had ratified the treaty

The key question the study seeks to analyze is that there are several issue-areas within the global system in general and many public health issues, why has tobacco control been institutionalized in the name of the FCTC? The main purpose of this work is to analyze the forces and rationales behind the adoption and the functioning of the FCTC. For many years tobacco control was deemed a domestic issue and as such, it belonged to the realm of national governments. However, over time, the issue evolved to encompass entire globe. Tracing the evolution of the issue to include the global dimension is the key 
concern of this study. As such, it is a bottom-up (inside-out) approach to the study of the emergence of international norms. Hence, it recognizes the importance of agents ${ }^{1}$ as norm makers, and thereby overcomes Checkel's (1999) concern that constructivist analysis usually assumes that agents are passive norm takers.

This study tries to establish that when an issue is recognized not only as a domestic issue but also transnational and global issue, the spread of knowledge, information, and ideas about the issue to other geographic and political jurisdictions, and the commitment on the part of those interested in the issue is more likely to lead to the development of international norms in the area and the ultimate development of a global regime. In addition, if the issue is crosscutting in the sense that it affects everyone or every state regardless of race, religion, creed, national origin or economic status, it serves as impetus for cooperation and collective action.

Theoretically, this work uses a liberal-constructivist perspective to analyze the transformation of tobacco control into a global phenomenon. This is the key contribution to the theory of social movement and analysis of international regimes. Under this approach, not only does the spread of knowledge, information, and ideas about a phenomenon through the international system help states to define their interests and priorities, but it also helps transnational actors to become advocates of certain kinds of policies and behaviors throughout the international system. In confronting the activities of a transnational enterprise - the tobacco industry around the world - actors interested in tobacco control transformed the issue from a national issue into a transnational issue in order to harmonize policies of states globally, so as to limit the flexibility of the tobacco enterprise. Familiarity with the knowledge of tobacco use and tobacco control, and the

\footnotetext{
${ }^{1}$ It refers to individuals, groups, and organizations within states.
} 
existence of an international organization with constitutional powers in the issue area acted as catalyst for individuals, states, governmental and nongovernmental organizations to collaborate and cooperate, leading to the emergence of a global institution. This is represented as:

\section{Figure 1.0 Institutionalization of Global Tobacco Control}

Knowledge $\longrightarrow$ Collaboration and Cooperation $\longrightarrow$ Institutionalization (FCTC) [Unit level] [Advocacy Coalitions; Transnational Networks;

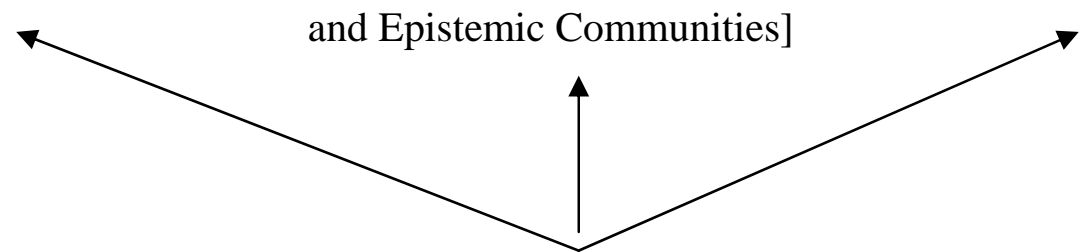

Transnational Actors

[Individuals, bureaucrats of international organizations, NGOs, IGOs, IOs, TTCs, states etc. - international subsystem]

On the other hand, compliance to the norms and principles of the Convention is a function of domestic politics and the role of the established institution [FCTC] and other transnational activities. Examination of compliance requires analysis of the unique socioeconomic and political circumstances of each state. In effect, similar to Coleman and Perl (1999), Moravcsik (1997), Rogowski (1989), Putnam (1988), and Gourevitch (1978), this study attempts to bridge the gap between comparative politics and international relations by answering several questions: How do domestic norms evolve to become a global institution? What role does an established international organization with constitutional powers in the issue area play in the diffusion and transfer of norms to different political and geographic jurisdictions in the international system? Countries around the world had 
experienced public health problems such as polio, small pox, cholera, malaria, and

HIV/AIDS, so, why should tobacco control develop into a global regime?

This study uses a triangulation method that combines qualitative and quantitative approaches to analyze how the spread of knowledge about the hazards of tobacco use and other transnational activities contributed to the adoption of the FCTC. Specifically, this work uses a mixture of content analysis and elite interviews of participants around the world who were directly or indirectly involved in the negotiation of the FCTC between 1999 and 2003 to analyze the processes and motivations behind such a global collective action.

\subsection{The Problem}

The issue of tobacco use and tobacco control can be traced as far back as the Fifteenth Century (Borio, 2001). However, the historic juncture of contemporary phenomenon can be traced to the early 1960s with the publication of the Royal College of Physicians (RCP) Report of 1962 in the United Kingdom (UK) and the United State (U.S.) Surgeon General's Report in 1964 (Nathanson, 1999). Although knowledge about the hazards of tobacco use emerged in the $1950 \mathrm{~s}^{2}$ or even earlier, these two reports were the first official recognition of the link between tobacco use and health (Proctor, 1999; Farquharson 2003; Collin et al., 2002). The two reports of the early 1960s are widely recognized and acknowledged as the most important documents on tobacco use, setting in

\footnotetext{
${ }^{2}$ Research that report that smoking and lung cancer appeared to be causally linked include: Doll, Richard, and A. Bradford Hill, 1950, "Smoking and Carcinoma of the Lung. Preliminary Report,” British Medical Journal 2:739-748; Wynder, Ernst L. and Evarts A. Graham, 1950, “Tobacco Smoking as Possible Etiology in Bronchogenic Carcinoma,” Journal of the American Medical Association, 143:329-336; Levin, Morton, Hyman Goldstein, Paul R. Gerhardt, 1950, "Cancer and Tobacco Smoking. A Preliminary Report,” Journal of the American Medical Association, 143:336-338; Schreck, Robert et al, 1950, “Tobacco Smoking as an Etiologic Factor of Disease. I. Cancer,” Cancer Research 10:49-58.
} 
motion a new era of tobacco control (USDHHS, 2000; Nathanson, 1999). The issue in the aftermath of the publication of the reports was not whether tobacco use was harmful or not, but rather how to combat the use and spread of tobacco domestically and internationally (WCTOH, 1967). The emphasis shifted from trying to establish the scientific basis of hazards of tobacco use to the issue of preventing the harm caused by it.

Since early 1960s, the linkage between tobacco use and health hazards has been firmly established. Cigarette smoking is the greatest cause of preventable deaths in many countries, and it is also linked to premature death of millions of people each year (Jha and Chaloupka, 2000; Glantz et al, 1996;Taylor, 1985). For many years, it was tackled at the unit level of the nation-state. Individual countries were responsible for dealing with the issue of tobacco control. However, over time, individual state efforts proved unable to combat the spread and use of tobacco. Whether the issue should be recognized as an international problem was deliberated at the Second World Conference on Tobacco and Health (WCTOH) held in London in 1971. After several years of authoritative recognition of the hazards of tobacco use, it was eventually resolved at the Ninth WCTOH in Paris in 1994 that individual state-level action alone could not combat the tobacco epidemic. The Ninth WCTOH recommended to WHO and its member states the importance of the development of an international convention on tobacco control. This recommendation was subsequently adopted at the $48^{\text {th }}$ WHA in 1995 . This began the process towards the development of an international regime on tobacco control. This is an attempt to harmonize the policies of countries caught up in globalization of tobacco use and the tobacco industry. 
The contemporary globalization process has facilitated the gradual emergence of public health issues as concern for many states (Taylor, 2002; Yach and Bettcher, 1998), as many of these issues (including tobacco use) have become global in nature. According to the World Health Organization’s Director-General Gro Harlem Brundtland, globalization of the tobacco industry's marketing strategies has contributed to breakdown in national cultural boundaries to tobacco use (Satcher, 2001). Satcher also argues that tobacco use is truly a global health problem because it transcends national borders and as such, it requires countries to cooperate in strong international action even as they tailor their tobacco control efforts to their own unique circumstances. The globalization of tobacco use is regarded as a key rationale for collective action in tobacco control (Yach and Bettcher, 2000).

Since the early 1960s, tobacco consumption has bubbled up to become an international public health issue. An issue that was primarily the concern of developed industrialized countries, as evidenced by the theme of the first WCTOH in 1967 in New York, has emerged as a global issue in the last 40 years leading to the adoption of the FCTC in 2003. Currently, there are about 1.3 billion smokers around the world, the majority of them living in China (WHO, 2003). This number is expected to increase to about 1.7 billion by 2020 if the trend continues (WHO, 2003). It is estimated that consumption of tobacco products caused at least 3.5 million deaths worldwide in 1998 and 4.9 million premature deaths in 2000 (WHO, 2000). On average, tobacco kills about five million people annually (WHO, 2005). It may cause about 10 million deaths per annum by $2020^{3}$ (WHO, 2005), 70 percent of which will occur in developing countries, an increase of about 50 percent from current rate (WHO, 1999; Jha and Chaloupka, 
1999). Countries in the developing world, therefore, face bleak public health problems if the current pattern of tobacco use continues unabated. The increasing trend of tobaccorelated diseases and deaths, with socio-economic ramifications globally, suggests a comprehensive and immediate action to combat the epidemic is necessary.

Whereas tobacco use has been decreasing gradually in developed countries, consumption in developing countries has been rising, notes the WHO Expert Committee on Smoking Control and Strategies in Developing Countries (Sklair, 2002; Frey, 1997; WCTOH, 1983). In an opening address of the Ninth WCTOH in Paris, the DirectorGeneral of WHO Hiroshi Nakajima pointed out "In the developed countries, per capita cigarette consumption has fallen by $10 \%$ since 1970 . In the developing countries it has gone up by 67\% over the same period” (WCTOH, 1994:2). With increasing tobacco and other regulations in developed countries since the 1960s, the market for tobacco products has been on the decline. As a result, developing countries have become the target of the tobacco industry's marketing practices, a concern that has been expressed since the Third WCTOH (Sklair, 2002; Jha and Chaloupka, 2000; Yach and Bettcher, 2000; Frey, 1997). For instance, in July 1992, Margaret Thatcher, a former Prime Minister of Britain, accepted a contract with Philip Morris to advise the company on its strategy in the developing world and in Eastern Europe (ASH).

The rising trend of tobacco consumption in the developing world despite the scientific evidence about the hazards of tobacco use demands the attention of not only policymakers in specific countries but also the world. Tobacco products on sale in developing countries have high yields of tar and nicotine. In addition, vast proportion of these populations are neither aware of the dangers of tobacco use, nor are educational,

\footnotetext{
${ }^{3}$ This is the revised date. The original date in many scholarly materials is 2030.
} 
legislative and other measures being taken to combat the smoking epidemic $\left(3^{\text {rd }}\right.$ WCTOH, 1975: 894). Moreover, the Expert Committee noted the double standard in the tobacco business, that is, cigarettes of the same brand carrying health warnings in developed countries are sold without these warnings in developing countries. All these raise the concern that tobacco control should be handled globally.

In spite of the fact that tobacco has been scientifically proven to be a hazardous product, tobacco is a commodity that is traded on the world market. As highlighted by the Uruguay Round of talk under the General Agreement on Trade and Tariff (GATT), tobacco is an integral part of international trade. The inclusion of tobacco in world trade and its protection by international trade rules has been a key concern of public health advocates around under world, emerging as one of the major themes of the WCTOH. Trade liberalization has led to increases in both the volume of tobacco traded on the world market and the level of tobacco consumption, especially in developing countries, raising public health concerns around the world (Jha and Chaloupka, 2000). As a global phenomenon, it requires global concerted efforts to combat it.

WHO is the primary international organization charged with addressing national and international disparities in health standards and health services through the right to health (Taylor, 1992). It was the first intergovernmental institution to adopt the term "world" because it wanted to stress that, "Problems which are no longer purely national must of necessity be solved not only by international action merely, but by world-wide action. Disease knows no frontiers and anything less than world action may not only deprive one nation of the benefits of the organization but may endanger the health of all member states” (WHO, 1947:13). The Preamble of WHO’s Constitution emphasizes this 
phenomenon of internationalism by pointing out that "The health of all peoples is fundamental to the attainment of peace and security and is dependent upon fullest cooperation of individuals and states" (cited in WHO, 1947:13). Also, the Preamble goes further to assert "Unequal development in different countries in the promotion of health and control of disease, especially communicable disease, is a common danger" (cited in WHO, 1947:14). WHO was adopted under the conviction that public health issues (including tobacco use) should be tackled through global collective action. In effect, WHO provides a forum where tobacco issues are deliberated and legitimacy is gained for efforts to curb tobacco use worldwide.

Taylor (1992) points out that WHO has the authority and legitimacy in the establishment of a framework for international public health, and argues that it can promote global public health through multilateral agreements by developing a legal framework. Taylor's argument suggests that WHO can be a conduit for the creation of an international regime. The ability of WHO to establish a global health regime is compared with other regimes such as the United Nations Environmental Program (UNEP), and the International Maritime Organization (IMO) (Taylor, 1992). Like UNEP and IMO, WHO can forge an international consensus under circumstances posing global crisis in a realm that would, at first, appear to be of more universal concern than health status of domestic populations (Taylor, 1992). As a result of interdependence of global health conditions, “The health status of a nation's domestic populations cannot be isolated from that of other nations; universal health is a global concern that necessitates multilateral action” (Taylor, 1992:335). In this sense, WHO can bridge the gap between international politics and domestic politics through the cultivation of global support, or international public 
opinion (Taylor, 1992). This suggests that through international collaboration with others, WHO can be an advocate of development of a global regime on tobacco use and tobacco control. "Cultivating public support for national and multilateral action and publicizing nation's compliance and noncompliance with the rule of law have been key ingredients in the successful lawmaking activities of other international organizations” (Taylor, 1992:336-337). This is because public support of an international collective action motivates statesmen to be part of it (Putnam, 1988). Thus, in 1994 after many years of transformation of tobacco use into a global phenomenon with the spread of the practice into developing countries, a consensus resolution at the Ninth WCTOH called on WHO to take steps to develop a global convention, ultimately leading to the FCTC.

\subsection{The Consequences of Tobacco Use ${ }^{4}$}

Scientific evidence on the health hazards of tobacco use had been established even before the First World Conference on Tobacco and Health (WCTOH) in 1967. Thus, William Stewart, the U.S. Surgeon General, pointed out at the First WCTOH "the proposition that cigarette smoking is hazardous to human health is no longer controversial” (WCTOH, 1967: IX). The 1962 and subsequent RCP reports have recognized the health hazards of tobacco use. In the U.S. alone, between 1964 and 2004, there have been 34 Surgeon General's Reports acknowledging the poisonous nature of tar and the addictive nature of nicotine and associated tobacco-related-diseases to smokers, non-smokers, fetus, children, and women (Studlar, 2002). The 2004 U.S. Surgeon General's Report indicates that tobacco use is harmful to virtually all parts of the human 
body. Similarly, at the global level, the WHO passed 19 Resolutions $^{5}$ between 1970 and 2003 acknowledging the health, social, and economic hazards of tobacco use. Other international institutions such as the World Bank, International Monetary Fund (IMF), and the United Nations Conference on Trade Adjustment (UNCTAD) have all examined the health, social, and economic consequences of tobacco use. Furthermore, there have been 12 WCTOH between 1967 and 2003, highlighting the consequences of tobacco use and how to combat the tobacco epidemic. The Fifth WCTOH in Winnipeg - Canada (1983) in particular, extensively deliberated on the social, economic and environmental implications of tobacco use. In effect, besides health, it has been established scientifically that tobacco use has socio-economic, psychological, and environmental consequences.

Tobacco contains harmful substances - tar and nicotine. Tar contains carcinogenic chemicals and nicotine contains toxic that causes cardiovascular diseases (WCTOH, 1967). Nicotine is recognized to be addictive, not only by international medical organizations and other health organizations such as International Union Against Cancer (UICC) and the American Cancer Society (ACS), but also by medical experts such as the U.S. Surgeon General, and international health agencies such as WHO. Tobacco dependence is listed in the International Classification of Diseases. Nicotine fulfills the key criteria for addiction or dependence, including compulsive use, despite the desire and repeated attempts to quit; psychoactive effects produced by the action of the substance on the brain; and behavior motivated by the "reinforcing" effects of the psychoactive substance. Cigarettes enable nicotine to reach the brain rapidly, within a

\footnotetext{
${ }^{4}$ Most of the information for this section of the study is from World Bank's Publication, Economics of Tobacco Control. Website: http://www1.worldbank.org/tobacco/book/html/chapter2.htm. (Accessed 10/08/04)
} 
few seconds of inhaling smoke, and the smoker can regulate the dose puff by puff. Thus, the nature of tobacco itself account for the inclination towards collective action in tobacco control.

Tobacco use causes diseases. However, it takes a long time for the symptoms of the disease to mature. In a longitudinal study by American Cancer Society ${ }^{6}$ involving one million U.S. adults, it was concluded that smokers in the United States are 20 times more likely to die of lung cancer in middle age than nonsmokers. Smokers are three times more likely to die in middle age of vascular diseases, including heart attacks, strokes, bronchitis, emphysema, and other diseases of the arteries or veins. At the First WCTOH in 1967 it was established that the life expectancy of male cigarette smokers is 3.4 years shorter than that of nonsmokers ( $1^{\text {st }}$ WCTOH, 1967). Also, the lifespan of a two-pack-aday smoker is reduced by 8.3 years $\left(1^{\text {st }}\right.$ WCTOH, 1967). Scientific evidence has demonstrated that tobacco use shortens the lifespan of users.

All the commonly used indexes of degree of exposure to cigarette smoke ${ }^{7}$ indicate that death rates of current cigarette smokers increase with degree of exposure (Hammond, 1967). It is estimated that tobacco related deaths will ultimately emerge as the single most preventable cause of death of millions, more than any other cause and more than the projected death tolls from pneumonia, diarrhea diseases, tuberculosis, and the complications of childbirth for that year combined. Currently, it kills about 430,000 people annually in the U.S. (CDC, 1999) and about five million people globally. If current trends persist, about 500 million people alive today will eventually be killed by

\footnotetext{
${ }^{5}$ All the WHO resolutions on Tobacco Control since 1970 are accessible at http://www.who.int/tobacco/framework/wha_eb/wha_resolutions/en/ [accessed 10/08/04]

${ }^{6}$ Second Cancer Prevention study (Cited in Curbing the Epidemic, World Bank, 1999)
} 
tobacco, half of them in productive middle age, losing 20 to 25 years of life (World Bank, 1999). In effect, tobacco use is deadly to one's health.

The problems with tobacco use include long delay between exposure and disease, the fatal aspect, association between smoking and the existing health disadvantages of the poor, and passive smoking. For instance, it takes decades for diseases and disabilities caused by tobacco use to emerge. Smoking affects not only the smoker but also those around them (secondhand smoking) (WHO, 2004). All these make smoking over time not only hazardous and deadly to smokers themselves but also to those around them. In this regard, tobacco use is an issue of importance not only for the user but also the non-user. The idea of innocent-victim, in particular, is very important in comprehending the success of tobacco control movement in places such as the U.S. (Studlar, 2002; Nathanson, 1999).

Besides the health hazards, tobacco use has social, economic, and environmental consequences. According to Jha and Chaloupka (2000), the World Bank, WHO, and UNCTAD, tobacco use has a negative impact on an economy as a whole. For WHO, in addition to the high public health costs of treating tobacco-related diseases, tobacco kills people at the height of their productivity. This deprives families of breadwinners and nations of a healthy workforce. Also, tobacco users are less productive while they are alive due to increased sickness. Annually, tobacco use costs about US\$40-US\$73 billion in medical expenses in the U.S. alone (CDC, 1999:3). Globally, a 1994 report estimated that the use of tobacco resulted in an annual global net loss of US\$ 200 billion, a third of this loss being in developing countries (Barnum, 1994). A group of 22 organizations and

\footnotetext{
${ }^{7}$ Indexes: (a) number of cigarettes smoked per day; (b) depth of inhalation of the smoke; and (c) years of smoking (or age at start of cigarette smoking).
} 
individuals concluded at a meeting at the Rockefeller Foundation's Bellagio Study and Conference Center in Italy, June 26-30, 1995 that tobacco is a major threat to sustainable and equitable development. Environmentally, increase in tobacco use leads to increase in tobacco leaf production, which cause problems such as deforestation. Knowledge about the consequences of tobacco use is one of the catalysts behind the adoption of the FCTC (WHO, 2005b). This is the underlying logic of the liberal-constructivist perspective of this study because it emphasizes on the transformational effects of knowledge, information and ideas on actors in the tobacco control policy arena.

\subsection{The Framework Convention on Tobacco Control [FCTC]}

After about a decade of preparation and four years of active negotiations among governmental and non-governmental actors and organizations under the auspices of WHO, ${ }^{8}$ the FCTC was established under Resolution WHA56.1 in 2003. It is a legally binding treaty, negotiated by the 192 member states of WHO. Although the original idea is attributed to Allyn Taylor's publication in 1992 and a tobacco advocates' meeting in San Francisco involving Judith Mackay and Ruth Roemer in 1993, the idea was also raised at the Ninth WCTOH at Paris, France in 1994. The WHO’s Director-General, Nakajima, subsequently set up a body in 1995 to investigate its Substance Abuse Program. In the same year, the World Health Assembly passed Resolution WHA48.11, outlining the concept of international strategies for tobacco control. The World Health Assembly adopted resolution WHA49.17 in 1996, requesting the Director-General to initiate the development of a WHO Framework Convention on Tobacco Control (WHO, 
2003). This marked the genesis of the formal WHO process. The ascension of Dr. Gro Harlem Brundtland to the post of Director General of WHO made the issue of tobacco control a major priority for WHO. In May 1999, the World Health Assembly provided a mandate for negotiations on the FCTC to begin, leading to its adoption in 2003 (PAHO, 2003).

\subsubsection{The FCTC Negotiation Process}

From WHO documents on the FCTC, interviews with participants, and published first-hand accounts of the negotiation process, ${ }^{9}$ the structure of the FCTC negotiation between 1999 and 2003 is illustrated as Figure 1.1 below. This helped in the selection of interviewees.

At the bottom of the process were country-level conferences and meetings. These conferences allowed interested parties and the general public within countries to express their opinion and to help countries formulate policy positions on the FCTC. For instance, in the U.S. three conferences on FCTC were held in California, Tennessee, and Washington, D.C. Also, in places like Canada and New Zealand, meetings among stakeholders - public health ministries, TTCs, and anti-tobacco NGOs - were held for the development of country's position on FCTC. At this level, individuals, domestic groups, public officials, and TTCs were the main participants.

\footnotetext{
${ }^{8}$ Kapur, Atul, op. cit. from World Health Organization, the Framework Convention on Tobacco Control: A Primer, Geneva: The Organization; 2003. Available: www5. who.int/tobacco/page.cfm?sid=41 (accessed April 22, 2003)

9 Jacob, Gregory F. 2004. “Without Reservation.” Chicago Journal of International Law. Summer. Jacob was a member of the U.S. delegation of the Intergovernmental Negotiation Body meeting and he gives account of his experience in the FCTC negotiation process.
} 
The next level was the regional conferences. The World Health Organization has six regions. Some regions held conferences and inter-session meetings on the FCTC. Participants in the regional conferences were states (countries). For instance, the African region (AFRO) held three conferences in Lome, Algiers, and Johannesburg to develop a common position on the proposed FCTC. Although states were the focus in these regional conferences and inter-session meetings in Geneva, NGOs and other individual advocates influenced the process by helping states to understand the FCTC drafted text (Jacob, 2004). An interviewee from Action on Smoking and Health (ASH), Australia indicated that they were involved in helping the states from the Western Pacific Region (WPRO) to develop a common stand on the FCTC. They even provided $\$ 70,000$ to sponsor delegates from the region. Also, Laurent Hubert of Framework Convention Alliance (FCA) was regarded more as an interpreter and translator for delegates from Western Africa during AFRO inter-session meetings, an interviewee pointed out.

The third level is the global meetings and public hearings in Geneva, Switzerland. The FCTC public hearing was meant to solicit the opinion of individuals, groups, organizations, and firms from around the world. The WHO Tobacco Free Initiative (TFI) organized this program to get the global civil society involved in the FCTC process. Everyone was given the opportunity to participate in the process. While some actors traveled directly to participate in the hearings in Geneva, others made their submissions through e-mail, fax, and regular mail. In the end, over 500 submissions were made and WHO has compiled them in a single database accessible through the Internet. Participants in this process were primarily non-state actors. At this level, coalition and alliances of groups around the world started to emerge. 
Finally, the Working Group meetings in Geneva prepared the technical background for the INB meetings, the highest negotiating body. A lot of activities among different actors occurred at this level. As Jacob (2004) points out, there were the INB meetings of the 192 WHO member states, meetings of the different WHO regions, and NGOs activities throughout the negotiating process. It was at this level that the text of the FCTC was negotiated. After the INB6, the drafted text was submitted to the $56^{\text {th }}$ World Health Assembly, the ultimate decision-making body whose members are states, for approval. In this sense, the influence of non-state actors in the negotiation of the FCTC was limited to the drafting of the text and lobbying states to support it. States were the ultimate decision-makers. 
Figure 1.1: Summary of the FCTC Negotiating Process

\section{Framework Convention on Tobacco Control}

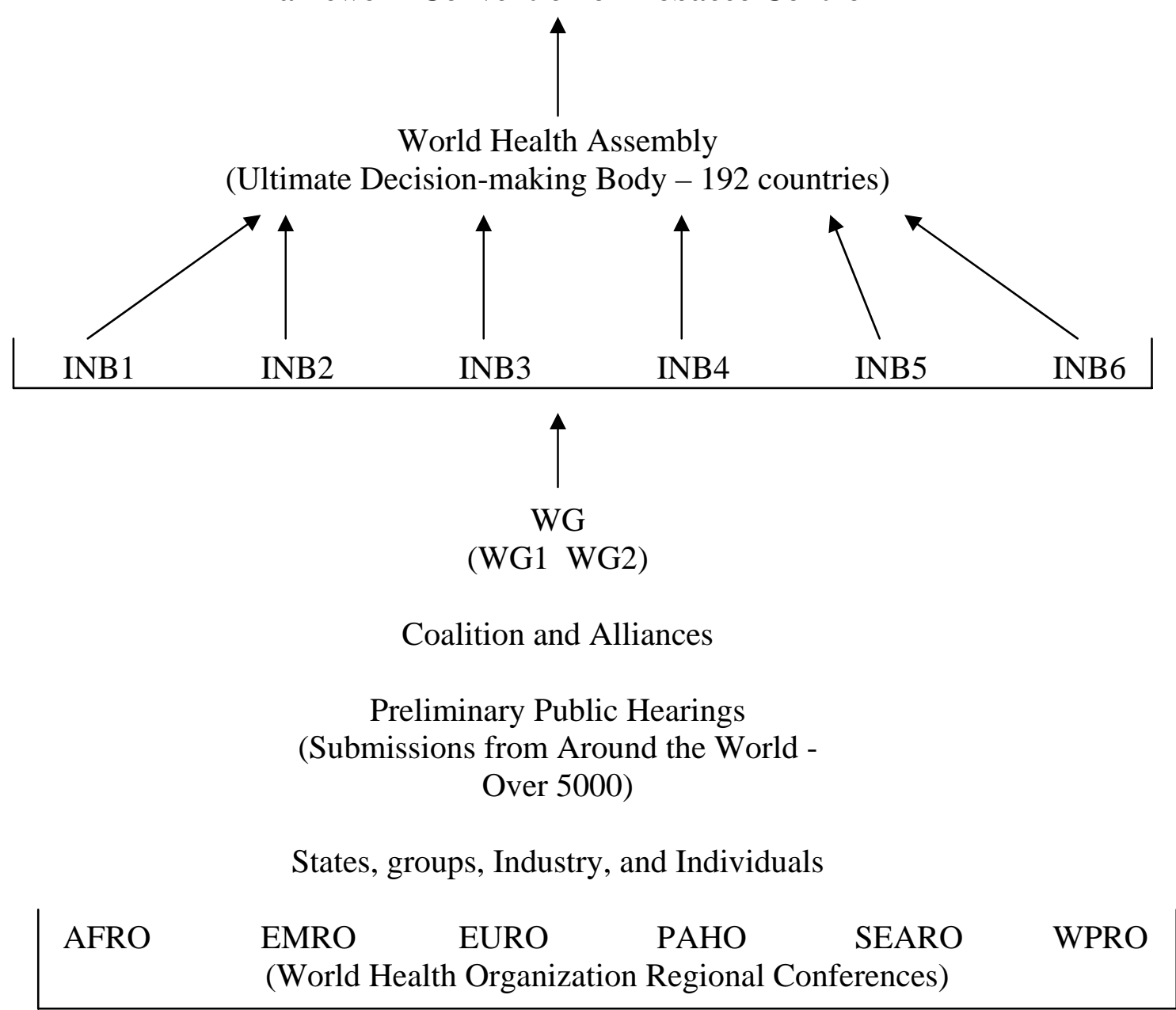

Domestic Groups

Individual Country Level Conferences

and Meeting.

The key provisions [See Table 5.2] encourages countries to (a) enact a comprehensive ban on tobacco advertising, promotion, and sponsorship; (b) obligate the placement of rotating health warnings on tobacco packaging that covers about 30 percent 
of principal display areas and can include pictures and pictograms; (c) ban the use of misleading and deceptive terms such as "light" and "mild"; (d) protect citizens from exposure to tobacco smoke in workplaces, public transport and indoor public places; (d) combat smuggling, including the placing of final destination markings on packs; and (e) increase tobacco taxes. The FCTC also contains measures designed to promote and protect public health, such as mandating the disclosure of ingredients in tobacco products, providing treatment for tobacco addiction, encouraging legal action against the tobacco industry, and promoting research and the exchange of information among countries. Lastly, it encourages efforts to find alternatives to tobacco production. This is an attempt to find alternative sources of livelihood for those dependent on tobacco production.

After the unanimous adoption by the World Health Assembly on May 21, 2003, the FCTC was opened for signature. A minimum of 40 countries had to sign and ratify the FCTC before it entered into force, at which time the FCTC formally became an international agreement. Within a year of entering into force, a subsidiary body - the Conference of the Parties - will begin meeting to review national reports, provide further guidance on proper implementation of the FCTC, initiate protocol negotiations, and promote the mobilization of financial resources. The entire FCTC process is illustrated below:

Figure $1.2 \quad$ The FCTC Process

Adoption $\longrightarrow$ Signature $\longrightarrow$ Ratification $\longrightarrow$ Compliance 
Prior to the emergence of the idea in 1993, there was a handful of independently functioning international and regional NGOs devoted to tobacco control (Mackay, 2003). However, the NGO community embraced the idea. Eventually, the FCTC brought the tobacco control NGO community together. This resulted in the birth of an international tobacco control alliance, Framework Convention Alliance (FCA). This alliance and coalition became actively involved in the negotiation of the FCTC. The FCA is recognized as the mouthpiece of a coalition of over 200 international NGOs that pushed

for a strong treaty (Kampala, 2004). Other important tobacco coalitions include Network for Accountability of Tobacco Transnationals (NATT) and the International Nongovernmental Coalition Against Tobacco (INGCAT). In general, members of the NGO community communicate through an Internet network called GLOBAlink. The NGO community has been involved in the issue of tobacco control and institutionalization of the issue area. Thus, this work analyzes the contribution of these transnational actors to the spread of knowledge and information about tobacco use and tobacco control and the adoption of the FCTC.

\subsection{Overview of Chapters}

The rest of this study is divided into three main parts. The first part (chapter two) lays out the theoretical foundation of the entire work. The chapter discusses where this work fits within Political Science and previews the main hypotheses.

The second part of the work is made up of descriptive analyses of the key issues. Chapter three describes and analyzes the issue of transnationalism with focus on the contribution of key transnational actors - states, advocacy groups, tobacco companies, 
and individuals towards the development of the FCTC. To varying degrees, all these actors were influential in the negotiation of the FCTC. The fourth chapter analyzes the issue of tobacco control as a form of global governance. Tobacco control as a form of global governance is linked to Uruguay Round of talks on the General Agreement on Trade and Tariff (GATT) that succeeded in liberalizing international trade in agricultural commodities, including tobacco. This made tobacco an international phenomenon and created the need for some form of international regulation. The role of WHO in this governance process is extensively analyzed in this chapter. Finally, chapter five analyzes the issue of "best practice" in tobacco control. Using publications from world conferences on tobacco, the chapter analyzes how empirically proven tobacco control policies in some states, primarily developed states, gradually spread to other geographic and political jurisdictions, primarily developing states through conferences and research institutions. With the quest to harmonize tobacco control policies to limit the flexibility of the tobacco industry, the conference resolutions and recommendations have been integrated into WHO policies and programs and spread worldwide. The world conference on tobacco was a catalyst for the development of the FCTC.

The third and final part of this work is made up of two chapters. Chapter six uses elite interviews to analyze the rationales behind the collective action. Chapter seven offers concluding remarks and suggestions on how issues at domestic level can transform into global issues over time. 


\section{Chapter 2}

\section{Theoretical Framework}

\subsection{Introduction}

The study draws heavily from liberal international relations theory and constructivism. This is because the FCTC is a form of collective action undertaken by states around the world and as such, it is about the behavior of states in the international system. However, societal and transnational societal interaction helped shape the preferences of state in favor of a global regime on tobacco control hence the unanimous adoption of the FCTC. These theories contribute to our understanding of world affairs by trying to explain the behavior of states (Moravcsik, 1997; Lumsdaine, 1993). They help

us to comprehend why and how states decided to form a global regime on tobacco control after the issues has been treated as a domestic matter for many years. The liberal international relations theory, in particular, is relevant to this study because it rests on a "bottom-up" view of politics in which the demands of individuals and societal groups are treated as analytical prior to politics (Moravcsik, 1997:517). This chapter reviews the major literature on liberalism, explain the model of this study, sets up the underlying hypotheses of this study, and discusses the methodology of the study.

\subsection{A Review of International Relations Theory}

The liberal international analyzes how state-society relations have a fundamental impact on the behavior of states in international affairs (Moravcsik, 1997:513). It examines how forces within states shape their policies within the international system and their interaction with others. "Societal ideas, interests, and institutions influence state 
behavior by shaping state preferences” (Moravcsik, 1997:513; Wendt, 1987). In this respect, liberal international relations theory is relevant in analyzing issues of foreign policy and international relations.

The core premise of the liberal international relations theory is that the relationship between states and the surrounding domestic and transnational society in which they are embedded shapes the state behavior by influencing the social purpose underlying state preferences (Moravcsik, 1997:516). It considers how societal forces and transnational societal interaction influence the behavior of states. The core assumptions emerging from the premise according to Moravcsik (1997) include: (a) the fundamental actors in international politics are individual private groups, who are on the average rational and risk-averse and who organize exchange and collective action to promote differentiated interests under constraints imposed by material scarcity, conflicting values, and variation in societal influences (p.516); (b) states (or other political institutions) represent some subset of domestic society, on the basis of whose interests state officials define state preferences and act purposively in world politics (p.518); and (c) the configuration of interdependent states preferences determines state behavior (p.520). The relevance of this theory is its applicability to wide variety of issues including liberal and non-liberal states, the behavior of individual states (foreign policy) and aggregation of states (international relations) (Moravcsik, 1997:515).

Liberals believe that cooperation under anarchy is still possible (Moravcsik, 1997’ Oye, 1986). ${ }^{1}$ They reject assumption that states are the only important actors in the

\footnotetext{
${ }^{1}$ It is different from trade/commercial liberalism (Richard Cobden, 1956, in Arnold Wolfers and Lawrence W. Martins, eds. The Anglo-American Tradition in Foreign Affairs, New Haven: Yale University Press, 192-205; or Cobden and Richard Bright in Waltz, Man, State, and War, 98-99, 103-107); democratic structural/republican liberalism (Immanuel Kant and Woodrow Wilson in Waltz, Man, State, and War,
} 
international system (Moravcsik, 1997; Ruggie, 1983, 1982; Grieco, 1990; Keohane and Nye, 1972). They believe that beyond states, other societal and transnational actors play important and influential role in international relations. Some of these other actors in world politics include specialized international agencies and their technical experts; ${ }^{2}$ labor unions, political parties, trade associations, and supranational bureaucracies; ${ }^{3}$ and multinational corporations (MNCs), transnational social movements; and transnational governmental and nongovernmental coalitions ${ }^{4}$ (Moravcsik, 1997; Grieco 1990; Keohane and Nye, 1972). Liberals also reject the view that states are unitary or rational agents (Moravcsik, 1997; Coleman, 1990). For instance, according to interdependence theorists, 'multiple channels of access' have weakened the grip on foreign policy previously held by central decision makers (Grieco 1990; Keohane and Nye 1977 and 1972; Cooper 1972; Morse 1970; Haas 1968; Mitrany 1966). Moreover, as Moravcsik (1997) has shown, societal forces influence the decision-making processes of states. Socially differentiated individuals define their material and ideational interests independently of politics and then advance those interests through political exchanges and collective action and as such, they shape the behavior of states in the international system. (Moravcsik, 1997; Coleman, 1990). These societal actors are assumed to be rational in the pursuit of material and ideational welfare hence states preferences may reflect patterns of transnational societal interaction (Moravcsik, 1997:517, 522). In essence, not only do we

101-3, 109-11, 117-19; Michael Doyle, 1986, “Liberalism and World Politics,” World Politics, 80:1151-69; Bruce Russett..); liberal transactions approach (Karl Deutsch et al., 1957, Political Community and the North Atlantic Area, Princeton: Princeton University Press; Bruce Russett, 1963, Community and Contention: Britain and America in the Twentieth Century, Cambridge, MIT Press); and ideational liberalism (Andrew Moravcsik, 1997).

${ }^{2}$ Mitrany, Working Peace System, 17, 85-87, 133-34; Haas, Beyond the Nation-State, 32-40

${ }^{3}$ Haas, Uniting of Europe, 16-31, 113-239, 283-340 [see note 35]

${ }^{4}$ Keohane and Nye, “"'Introduction” and "Conclusion” in Keohane and Nye, eds., Transnational Relations and World Politics, ix-xxix, 371-98 
have multiple actors in the international system but also activities of diverse actors within states influence their policy outcomes.

Liberals are also interested in situations where interdependence leads to cooperation among states. Interdependence in this case refers to interdependence of state policies. Policy interdependence is the set of costs and benefits created for foreign societies when the dominant societal groups in a society seek to realize their preferences, that is, the pattern of transnational externalities resulting from attempts to pursue distinctive national purposes (Moravcsik, 1997:520). The pattern of interdependence of states preferences imposes a binding constraint on states (Moravcsik, 1997). The pattern of state preferences is a determinant of both individual state foreign policies and system outcomes. Thus, the depth of cooperation in any issue area within the international system depends on the nature of these patterns of preferences (Moravcsik, 1997). For instance, contemporary issues of interdependence and globalization have created a situation in which many issues have become transnational in nature. Such issues require mutual cooperation among states. These developments in the international system have resulted in a situation whereby states are more inclined to cooperate with one another. In this respect, transnational societal interaction can shape the preferences of states, and lead to international collective action in certain issue areas. As such, there is no strict line between domestic and transnational levels of analysis (Moravcsik, 1997; Gourevitch, 1978).

One form of international collective action is the formation of institutions. Institutions refer to "persistent and connected sets of rules (formal and informal) that prescribe behavioral roles, constrain activity, and shape expectations” (Keohane, 1989:3). 
They may be in the form of formal intergovernmental or cross-national nongovernmental organizations (NGOs), ${ }^{5}$ international regimes, ${ }^{6}$ or conventions ${ }^{7}$ (Keohane, 1989). These forms of institutions are interrelated. Whilst international regimes depend on the existence of conventions that makes such negotiation possible, regimes cannot adapt or transform in absence of an international organization. That is, you need an international organization with legitimate constitutional powers in an issue-area to facilitate the development of an international regime. Similarly, an international regime is established on certain core principles, norms, and conventions. Thus, Keohane (1989) argues that the distinction among conventions, regimes, and organization is not clear in reality.

\subsection{The Liberal-Constructivist Model}

This perspective combines aspects of liberal international theory and constructivism because of the relevance of societal actors, transnational societal interaction, WHO, and knowledge, information, and ideas in shaping the preferences of states and a systemic outcome, FCTC. Institutions affect incentives facing states as well as the understanding that states' leaders have of the roles they should play and their assumptions about others' motivations and perceived self-interest (Keohane, 1989). Thus, they have constitutive as well as regulative aspects: they help define how interests are defined and how actions are interpreted (Cook, 1996; Keohane, 1989; Giddens, 1984).

\footnotetext{
${ }^{5}$ They are purposive entities. They are capable of monitoring activity and of reacting to it, and are deliberately set up and designed by states. They are bureaucratic organizations, with explicit rules and specific assignment of rules to individuals and groups. An example is the United Nations system (Keohane, 1989: 3-4).

${ }^{6}$ They are institutions with explicit rules, agreed upon by governments that pertain to particular sets of issues in international relations. An example is the international monetary regime established at Bretton Woods, New Hampshire in 1944 (ibid).
} 
The constitutive aspect of institutions underlies Wendt’s (1987) “agent-structure problem.” That is, to what extent are agents of international institutions "constituted" or "generated" by the international system? This is the essence of constructivism or Keohane (1988) refers to as "reflectivist” theory.

More specifically, constructivism is the social construction of subjectivity that minimizes image problems (Finnemore, 1996; Wendt, 1992; Onuf, 1989). The central concern of constructivism is the issue of identity and interest formation of states (Wendt 1992; Finnemore, 1996). In this case, constructivists are interested in how states define their interests, identities, and priorities. The concern is with the impact of cultural practices, norms of behavior, and social values on political life (Finnemore, 1996). Constructivists investigate how principles, norms, conventions, among others affect the behavior of states. For instance, Katzenstein (1996) investigates the role of norms, identities, and social relations in weapons acquisition patterns, weapon taboos, humanitarian intervention, the dynamic of specific alliances, and military posture in specific countries. For Haas (1990 and 1983), shared experiences and commonly held understandings developed within international institutions determine the outcome of states’ behavior. Wendt (1992) also asserts that international institutions can transform state identity and interests. Thus, the situation where states cooperate to form institution such as WHO, and the institution's ability collaborate with societal and transnational actors to transform the preferences of the states - liberal-constructivism - is the underlying theory of this study.

\footnotetext{
${ }^{7}$ They are informal institutions with implicit rules and understandings that shape the expectation of actors. They enable actors to understand one another and without explicit rules, to coordinate their behavior. An example is the traditional diplomatic immunity (ibid)
} 
Knowledge, information and ideas are vital to the comprehension of the global tobacco control issue. Accumulated scientific knowledge on tobacco use up to the early 1960s in particular, and beyond was a source of motivation for not only to mobilize for domestic action against the habit but also to mobilize for international action to combat the use and spread of tobacco around the world (Wolfson, 2001; Nathanson, 1999). Thus, venues such as world conferences on tobacco and health served as forums for the spread of knowledge, information, and ideas about tobacco use and tobacco control as well as mobilization for action against the use and spread of tobacco domestically and internationally. As Nathanson (1999) illustrates, the social construction of the tobacco issue has impact on the adoption of the tobacco control policies as well as the emergence of a social movement in the policy arena. Knowledge about the impact of passive smoking (innocent victims) and tobacco industry awareness of addictive nature of nicotine and poisonous nature of tar contributed to change the identity and interest of states and other organizations to join the tobacco control movement (Studlar, 2002; Nathanson, 1999).

Tobacco control was initially the concern of developed countries because as Eyestone (1977) points out, leaders innovate because they are the first to experience the negative impact of a phenomenon. That is, high tobacco consumption rate and associated consequences led some developed countries to innovate ideas about tobacco control. However, it became global as the transnational tobacco companies extend their activities into other countries, transnational externalities (Moravcsik, 1997:520). This resulted in the need for diffusion and transfer of information on tobacco controls to parts of the world where tobacco control is non-existing. Over time, the activities of transnational 
actors and WHO contributed to the diffusion and transfer of information about tobacco control to different geographic and political jurisdiction, helping to shape states preferences to embark on an international collective action [See Chapter 3 and 4].

Underlying this process of evolution from a domestic issue to an issue with global dimension is the idea of "best practices." This is the idea that states should simply adopt and adapt already innovated tobacco control policies instead of designing novel ones. Since 1970, the WHO has been instrumental in the gathering of model tobacco control policies and programs for emulation. In essence, not only the spread of knowledge, information, and ideas about tobacco use and tobacco control helped states to define their interests and priorities, but also the activities of WHO contributed to the modification of states' interests and identities.

In a nutshell, knowledge, information, and ideas about tobacco use and tobacco control originated in developed countries. However, the activities of individuals, states, IOs, IGOs, NGOs, and WHO facilitated the spread of these innovated tobacco control policies to other parts of the world due to phenomena such as transnationalism, interdependence, and globalization. Also, international conferences on tobacco contributed to the spread of this knowledge. Familiarity with the knowledge about tobacco use and tobacco control by countries around the world (developed and developing) acted as catalyst for the adoption of the FCTC. The FCTC also operates to modify the interests and priorities of all countries globally. The FCTC operates in such a way that it urges states to make tobacco use and tobacco control one of their top public health priorities. That is, combating the use and spread of tobacco should be a central 
concern of all states. This is the essence of the "Liberal-constructivist Model" underlying this work, and it is represented in Figure 2.0 below. 
Figure 2.0: Liberal-constructivist Model

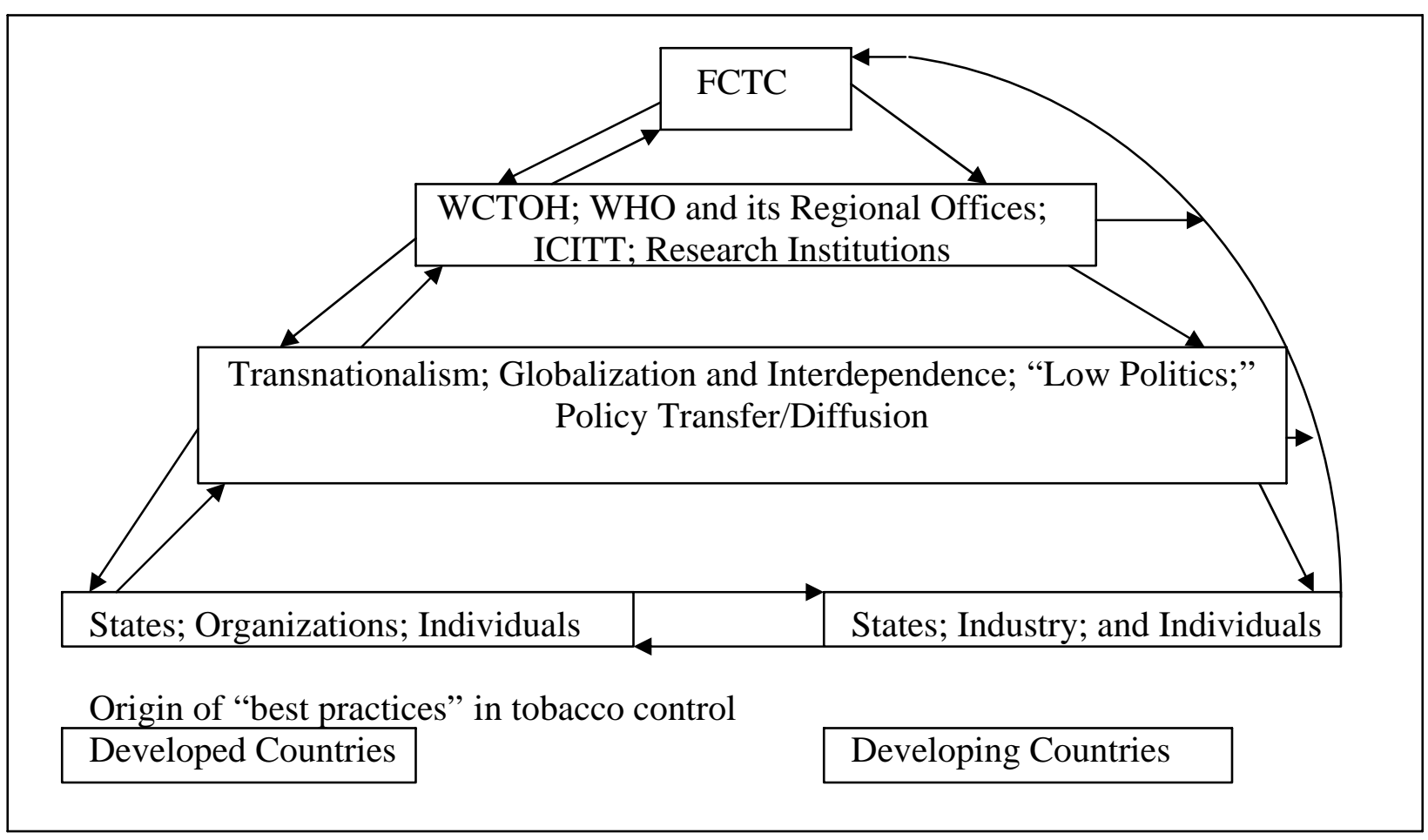

\subsection{International Regimes}

The relevant institution to this study is international regimes. The emphasis is on

the institutionalization of global tobacco control as an international regulatory regime

(Studlar, 2002; Taylor, 1996; Nadelman, 1990). As defined by Krasner (1983:2) and in

conformity with the definition of Keohane (1989, 1984), Keohane and Nye (1977),

Haggard and Simmons (1987), among others, regime in this study refers to

Sets of implicit or explicit principles, norms, rules, and decision-making procedures around which actors' expectations converge in a given area of international relations. Principles ${ }^{8}$ are beliefs of facts, causation, and rectitude. Norms are standards of behavior defined in terms of rights and obligations. Rules are specific prescriptions or proscriptions for action. Decision-making procedures are prevailing practices for making and implementing collective choice.

\footnotetext{
${ }^{8}$ An important principle shared almost all regimes is what Jervis refers to as 'reciprocation': the belief that if one helps others or fail to hurt them, they will reciprocate when the tables are turned (1982:180)
} 
Regimes are arrangements that facilitate agreement among different actors. Thus, for Jervis (1983:173) regime "implies not only norms and expectations that facilitate cooperation, but a form of cooperation that is more than following short-run selfinterest.” In this respect, regimes are not temporary phenomena in the international system.

The key elements of international regimes are principles, norms, rules, and procedures that govern the relationship among states within any issue area. Principles and norms are foundations of regimes, and as such, they cannot be easily altered. They are the basic characteristics of a regime (Smith, 1987; Jervis, 1983; Krasner, 1983; Ruggie, 1975). On the other hand, rules and decision-making procedures are malleable as long as the changes are consistent with the principles and norms underlying the regime (Krasner, 1983:3). Changes in rules and procedures do not necessarily change a regime. However, changes in norms and principles alter the foundation of a regime. Regimes can occur in any issue area (including tobacco). From Keohane (1989), the issue area could be monetary, trade, the environment, human rights, or tobacco control, among others, as long as states cooperate to solve a collective problem. The two broad traditions in analysis of international regimes are the structural and Grotian traditions (Krasner, 1983).

\subsubsection{The Structural Tradition}

Although this work acknowledges the existence of other structural theories in international relations such as World-Systems and Dependency theory, the discussion in this work is limited to structural theory of international regimes. The two sub-traditions in this structural tradition are the conventional structural perspective and the modified 
structural perspective (Krasner, 1983). The conventional structural perspective is consistent with the structural orientations of international relations that conceptualize a world of rational self-interested actors. The actors function in a system that is defined by their own interests, power, and interaction. Such a view does not recognize the independent impact of principles, norms, rules, and decision-making procedures on outcomes and behavior (Krasner, 1983). In effect, this orientation does not recognize the importance of regimes. For instance, Susan Strange argues that the concept is pernicious because it obfuscates and obscures the interests and power relationships that are the proximate cause of behavior in the international system (Krasner, 1983; Strange, 1983). For structural realists such as Waltz, regime can only be a small step removed from the underlying power capability that sustains them (Waltz, 1979; Krasner, 1983). This perspective does not take regimes seriously (Krasner, 1983).

The modified structural perspective accepts the fundamental assumption of the conventional structural perspective, that is, believes that world is composed of states seeking to maximize their interests and power. This view relies heavily on rational-choice analysis. An example of this view is Keohane's (1983) assertion that in the international system, regimes derive from voluntary agreements among juridically equal actors. Stein (1983) also subscribes to similar conception of regimes. However, the distinguishing feature of the modified structural perspective is the recognition of the importance of regimes under certain circumstances.

Adherents of this perspective argue that regimes can coordinate state behavior to achieve desired outcomes in a particular issue-area (Krasner, 1983). An example of this 
perspective is the "theory of hegemonic stability." 9 Stein (1983) and Keohane (1983)

argue that regimes can have an impact when Pareto-optimal outcomes could not be achieved through uncoordinated individual calculation of self-interest (Krasner, 1983).

The Prisoners’ Dilemma or the game of chicken is usually used in this analysis. For Haas (1983), regimes may have significant impact in a highly complex world in which ad hoc, individualistic calculations of interest could not possibly provide the necessary level of coordination. In spite of this, some adherents of this perspective argue that regimes cannot be relevant in zero-sum situations such as security issues because states act to maximize the difference between their utilities and those of others (Krasner, 1983). Yet, Jervis (1983) notes the dearth of regimes in the security area. In essence, regimes matter only when independent decision-making leads to undesired outcomes (Krasner, 1983). This perspective sees regimes as situational phenomena.

\subsubsection{The Grotian Tradition}

This perspective views the world differently from any of the structural perspectives. Proponents of this perspective see regimes as pervasive phenomenon of all political systems (Krasner, 1983). It is argued, “regimes exist in all areas of international relations.... Statesmen nearly always perceive themselves as constrained by principles, norms, and rules that prescribe and proscribe varieties of behavior" (Puchala and Hopkins, 1983:86). The concept moves beyond the realist perspective, which is "too

\footnotetext{
${ }^{9}$ The view that concentration of power in one dominant state facilitates the development of strong regimes, and the fragmentation of power is associated with regime collapse. [Robert O. Keohane, 1980, "The Theory of Hegemonic Stability and Changes in International Economic Regimes, 1967-1977," in Ole R. Holsti, Randolph Siverson, and Alexander George, eds., Changes in the International System, Boulder: Westview; Also in Keohane, 1989, International Institutions and State Power, pp.74-100; Duncan Snidal, 1985, “Limits of Hegemonic Stability,” International Organization, 39:579-614; Joanne Gowa, 1989, "Rational
} 
limited for explaining an increasingly complex, interdependent, and dangerous world” (Puchala and Hopkins, 1983:61). In Young’s (1983) view, patterned behavior generates convergence of expectations around new institutional arrangements. This perspective rejects the argument that the international system is made up of only sovereign states. Rather, it emphasizes the importance of transnationalism as well as different venues for communication within the international system, such as with Keohane and Nye’s (1977) idea of Complex Interdependence. ${ }^{10}$ This view rejects the conventional power-oriented theory (Krasner, 1983). In effect, the Grotian perspectives accept regimes as a fundamental part of all patterned human interaction (Krasner, 1983). However, according to Krasner (1983), the basic causal variables for the emergence of regime in general are egoistic self -interest, ${ }^{11}$ political power, ${ }^{12}$ norms and principles, usage and custom, ${ }^{13}$ and knowledge. ${ }^{14}$ In effect, regime formation is the result of conglomeration of many factors.

\subsection{Middle-level Theories}

These are attempts to explain states' behavior within the international system by linking international politics and domestic politics (Coleman and Perl, 1999; Caporaso, 1997; Rogowski, 1989; Putnam, 1988; Wendt, 1987 \& 1992; Gourevitch, 1978).

\footnotetext{
Hegemons, Excludable Goods, and Small Groups: An Epitaph for Hegemonic Stability Theory,” International Organization, 307-324]

${ }^{10}$ Its is the idea that relations among states are characterized by multiple-channels of communication, multiple objectives, and reject the primacy of force as well as issue hierarchy, Keohane and Nye, Power and Interdependence, 1977

${ }^{11}$ It refers to the desire to maximize one's own utility function where that function does not include utility of another party (Krasner, International Regimes, p.11)

${ }^{12}$ Cosmopolitan power - power in service of common good or instrumental power - power in service of particular interests (ibid, pp.13-16)

${ }^{13}$ Usage refers to regular patterns of behavior based on actual practice; Custom - long standing practice (Ibid, pp.18-19)

${ }^{14}$ The sum of technical information and theories about that information which commands sufficient consensus at a given time among interested actors to serve as a guide to public policy designed to achieve some social goal (Ibid, pp.19-20; Haas, 1980:367-368)
} 
Coleman and Perl (1999) argue that many public policy domains increasingly feature institutionalized connections between sub-national, national, regional, and international levels. The importance of horizontal coordinating governance arrangements in internationalized policy domains that occur more frequently in the present globalizing era justifies building further on middle-level theories (Coleman and Perl, 1999). Tobacco control, an issue originating from the state-level is now an international issue institutionalized as FCTC. Underlying the FCTC are protocols, principles, and conventions that must be implemented at the state-level. This blurs the distinction between domestic politics and international politics hence the importance of middle-level theories to this study.

As Singer $(1969,1961)$ argues, analysis of state behavior that relies only on systemic explanation or domestic explanation is likely to miss some important variables. The importance of the middle-level theories is the attempt to bridge this gap. Gourevitch (1978) examines both international economic theories that account for systemic influences on domestic politics and theories of the international system doing likewise. Similarly, he examines the domestic structures that account for a state's behavior in the international arena. Gourevitch (1978) argues that

The international system is not only a consequence of domestic politics and structure but a cause of them. Economic relations and military pressures constrain an entire range of domestic behaviors, from policy decisions to political forms. International relations and domestic politics are therefore so interrelated that they should be analyzed simultaneously, as a whole (p.911).

Wendt (1987) builds on Gourevitch’s (1978) conclusion in the analysis of 'agentstructure problem'. Subsequent works in this area - Putnam’s Two-Level Games (1988 \& 
1993), Rogowski’s Commerce and Coalitions (1989), Evans et al's Double-Edged

Diplomacy (1993), and Caporaso's Across the Great Divide illustrate the close

interrelationship between domestic politics and international relations. In essence, this

work is meant to analyze how forces within the international system as a whole (domestic and international) led to the emergence of the FCTC.

\subsection{Theory}

Attempts to explain the adoption of an international convention like FCTC as well as ratification and possible compliance with the tenets of the convention brings in Wendt's (1987) 'agent-structure problem.' How does an international concern expressed in conventions become policy of a state, defined as governmental outcomes? This becomes a level of analysis issue. What is the appropriate level to analyze the forces behind the adoption of an international convention as well as the ratification and compliance with its principles and norms? Is it the individual, the state, the international system as a whole or an amalgamation of all levels of analysis? The "discussion of levels of analysis, and the research programs associated with these levels, quickly gets involved with ontological questions” (Caporaso, 1997:565). An attempt to answer these questions demands consideration of the main theories under the various levels of analysis.

Within the international politics arena, scholars have identified different levels of analysis. For instance, Caporaso (1997) points out a categorization of the levels of analysis as interest groups, bureaucratic politics, and intergovernmental and nongovernmental organizations. The levels of analysis that emerged in the aftermath of the publication of Waltz's (1959) Man, the State and War are the individual, state, and 
international system. However, this study encompasses multiple levels of analysis. It is an analysis of how individuals, states, and governmental and nongovernmental organizations collaborated to transform a domestic phenomenon into institutionalized global one. Such an analysis demands not only understanding systemic explanations of states' behavior but also looking into the domestic environment or the "black box" hence the relevance of foreign policy and comparative politics.

Theoretical approaches to analyses involving interaction of individuals, groups, states, and international governmental and nongovernmental organizations, include transnationalism (advocacy networks and social movements) (Stone, 2003; Pertschuk, 2001; Wolfson, 2001; Keck and Sikkink, 1998; Meyer et al, 1997; Keohane and Nye, 1972), Advocacy Coalition Framework (ACF) (Sabatier and Jenkins-Smith, 1999, 1993; Farquharson, 2003), and epistemic communities (Haas, 2001, 1992, 1989; Meyer et al 1997). Under these theories, explanation of an international phenomenon such as the adoption of FCTC requires examination of the activities of individuals, states, and intergovernmental and nongovernmental organizations. Thus, the theory of this study is that the globalization of the tobacco epidemic, the interdependent nature of public health, the activities of transnational advocacy groups, the role of tobacco epistemic communities, and the "low politics" nature of tobacco control contributed to the adoption of the FCTC.

\subsubsection{Epistemic Communities}

Epistemic communities refer to "a network of professionals with recognized expertise and competence in a particular domain and an authoritative claim to policy 
relevant knowledge within that domain or issues-area” (Haas, 1992:3; Alder and Haas, 1992). Such communities share a set of normative and principled beliefs, causal beliefs, notion of validity, and common policy enterprise (Haas, 1992). These are Haas’ (1992) criteria for the identification of an epistemic community. First, the shared set of normative and principled beliefs provide a value-based rationale for the social action of the community. Second, shared causal beliefs derived from analysis of practices serve as basis for the determination of linkages between policy action and desired outcomes. Third, the shared notion of validity is based on intersubjectivity and internally defined criteria for weighing and validating knowledge in the domain of expertise. Finally, the common policy enterprise is based on set of common practices associated with a set of problems to which the competence of the community is directed with the conviction the human welfare will be enhanced.

The core beliefs of members of such a community usually are based on science. As such, they share common understanding of the problem, causes, and solutions. The key motivation underlying the activities of epistemic communities is translation of authoritative knowledge in the area of expertise into policy. Thus, the goal of an epistemic community is policy-oriented. In addition, policymakers at times defer to epistemic communities as a result of the expansion and professionalization of the modern administrative state as well as complexity and uncertainty in decision-making (Haas, 1992; Alderman and Haas, 1992). This phenomenon deals with how socially constructed ideas that have become consensual knowledge among a community of experts are transnationally transmitted and ultimately adopted by states. Haas (1989) uses this 
approach to the study of regimes to analyze the emergence of the Mediterranean Pollution Control Regime, the Med Plan.

The most important way of thinking about epistemic communities is that of evolution (Alderman and Haas, 1992:372). The process of evolution under this approach refers to evolutionary changes to structures that are largely irreversible and virtually determine the array of available choices, once in place (Alder and Haas, 1992:372). The key elements of this evolutionary process are policy innovation, diffusion, selection, and persistence (Alderman and Haas, 1992; Alder, 1991; Krasner, 1988). Under this approach, foreign policy of states is view as a process by which intellectual innovations produced through the help of epistemic communities are carried by domestic and international organizations (in which epistemic communities may reside) and are selected by political process to become the basis of new or transformed national interests (Alder and Haas, 1993:373). Also, international politics can be viewed as the process by which the innovations of epistemic communities are diffused nationally, transnationally, and globally to become basis of new or changed international practices and institutions (Alder and Haas, 1993:373). The domestic and international steps could be understood through Putnam’s “two-level games” (Alder and Haas, 1992; Putnam, 1988). The role of the WCTOH in the innovation of tobacco control policies, and the diffusion of these policies domestic and internationally since its inception in 1967, makes this approach appropriate in an analysis of politics behind the evolution of tobacco control into an international regime.

The primary purposes of WCTOH include updating worldwide knowledge on tobacco use, identifying effective ways of combating the habit ("best practices”), and 
exchanging information and ideas on tobacco use and tobacco control. These are issues underlying epistemic communities and evolution of international policies (Haas, 1992; Alderman and Haas, 1992). Those within the tobacco control community share a fundamental belief that tobacco use is harmful to the human body. Many members within the worldwide tobacco control community that congregate during conferences are currently linked with each other through GLOBALink, an Internet community. Also, the aim of the international conference on tobacco has been policy-oriented, that is, the adoptions of tobacco control policies by countries around the world. These tobacco control policies, known as "best practices" in tobacco control have been scientifically proven to be effective within certain political and geographic jurisdictions and as such, appropriate for emulation by others around the globe. Thus, considering the criteria for the existence of epistemic communities, and their roles in domestic and international policy transformation, this work identifies epistemic communities on tobacco control called World Conferences on Tobacco or Health (Haas, 1992; Alderman and Haas, 1992).

\subsubsection{Transnational Advocacy Networks}

Transnationalism is "the movement of tangible or intangible items across state boundaries when at least one actor is not an agent of a government or an international organization” (Keohane and Nye, 1972: xii). It involves the movement of information, money, physical objects, people, or other tangible or intangible items across state boundaries (Keohane and Nye, 1972). Governmental or nongovernmental actors may initiate this interaction. Individuals and organizations play roles in world politics through 
participation as members of a coalition that control or affect their governments or direct roles vis-à-vis foreign governments or foreign societies and thus bypass their own government ${ }^{15}$ (Keohane and Nye, 1972). Among the effects of transnationalism are transnational promotion of attitudinal change, international pluralism, dependence and interdependence, and the presence of transnational autonomous or quasi-autonomous organizations, among others (Keohane and Nye, 1972).

It is within the broad framework of transnational activities that Keck and Sikkink (1998) analyze the importance of transnational advocacy networks in policy making in human rights, the environment, and women's rights. A transnational advocacy network includes those relevant actors working internationally on an issue, who are bound together by shared values, a common discourse, and dense exchanges of information and services (Keck and Sikkink, 1998). Also using event history analysis in an examination of the world environmental regime (UNEP), Meyer et al (1997) find the activities of NGOs and the spread of knowledge and norms about the environment as pivotal in the emergence of the regime. The emphasis on transnational advocacy networks and actors makes this approach the foundation of the entire study.

Also, underlying transnationalism is social movement. For instance, Nathanson (1999), Pertschuk (2001), and Wolfson (2001) have analyzed the tobacco control social movement in the U.S. One theory of social movement is resource mobilization (Gamson, 1990; Jenkins, 1983; McCarthy and Zalad, 1977). The emphasis here is that the availability of resources such as money, expertise, and volunteers act as a function for the emergence of a social movement. Another theory of social movements is on political

\footnotetext{
${ }^{15}$ The distinction was provided by J. David Singer, 1969, "The Global System and its Subsystems: A Developmental View,” in James N. Rosenau, ed., Linkage Politics: Essays on the Convergence on National
} 
process (McAdam, 1996). The argument is that political opportunities provided by issues such as focusing events serve as catalyst for a social movement to emerge. A third theory of social movement is issue definition (Benford and Snow, 2000; Nathanson, 1999; Gamson and Meyer, 1996). In this case, how a problem is defined or framed can be a source for the emergence of social movement. For instance, Nathanson (1999) argues that the issue of "innocent victim" with regards to passive smoking was a strong source of mobilization for the tobacco control social movement in the U.S. A fourth theory on social movements is about the shift in Western countries from industrial to post-industrial economy (Pichardo, 1997; Buechler, 1995). This shift in Western societies has shifted concern for material things to issues such as the environment. Finally, some analytical work synthesizes the various theories on social movements (Wolfson, 2001; McAdam et al., 1996).

These theories explain the origin of social movements and they are relevant to this work. This is because social movement theories emphasis the importance of individuals and groups in the mobilization for collective action. In fact, WHO's constitution allows the involvement of NGOs in its policy-making process. Since it was resolved at the Ninth WCTOH in France in 1994 that individual country effort was not enough to combat the tobacco epidemic and as such the need for an international convention, the WHO and other NGOs made conscious effort to mobilize support for the FCTC. An example is the formation of the Framework Convention Alliance. Although Nathanson (1999) identified the emergence of a social movement in tobacco control in the aftermath of the 1960s authoritative recognition of the hazards of tobacco use, the movement at the global level has become more visible since the 1990s. Thus, the importance role of transnational 
actors in the adoption of FCTC makes transnationalism the theoretical foundation of this study.

\subsubsection{Advocacy Coalition Framework (ACF)}

Sabatier and Jenkins-Smith’s $(1999,1993)$ ACF has become an important framework in the analysis of policy networks. An advocacy coalition refers to a coalition composed of people from various governmental and private organizations that share a set of normative and causative beliefs and engage in a nontrivial degree of coordinated activity over time (Sabatier and Jenkins-Smith, 1999, 1993). The ACF requires that theories of the policy process or change need to address the role played by technical information, time frame of about a decade, policy subsystem as unit of analysis, and going beyond the notion of iron triangles (Sabatier and Jenkins-Smith, 1999, 1993). In

essence, the ACF focuses on groups of people and/or organizations interacting regularly over periods of a decade or more to influence policy formulation and implementation in a given policy area (Sabatier and Jenkins-Smith, 1999, 1993). The underlying belief systems of the ACF are deep core, policy core, and secondary aspects. Whereas the policy core and secondary aspects beliefs are susceptible to change, the deep core beliefs are resistant to change (Sabatier and Jenkins-Smith, 1999, 1993).

Although the ACF was primarily meant to analyze domestic policies, Farquharson (2003) uses this approach to provide insight on a transnational advocacy network, the tobacco advocacy networks at the international level. Her work illustrates how transnational pro-tobacco and anti-tobacco advocacy network groups work assiduously to influence global tobacco control policy. Important advocacy groups in the area of tobacco 
control are the Framework Convention Alliance (FCA), International Non Governmental Coalition Against Tobacco (INGCAT), and Network Accountability of Tobacco Transnationals (NATT). These are conglomerations of pro-tobacco control groups from around the globe that worked assiduously to ensure a strong FCTC text and continue to work for compliance. In effect, there has been a tobacco control coalition that has existed over a decade. The emphasis on a coalition of actors within a policy area suggests that the approach is also relevant to this study.

\subsection{Concept, Measurements, and Hypotheses}

\subsection{1 “Low Politics"}

“Low politics” is usually contrasted with "high politics," such as the politics of peace and security in which executive branch foreign and national security policy managers are in charge of policy-making (national security and foreign relations). "Low politics” refers to the politics of social welfare in which sub-governments involving lower-level executive branch officials, legislative committees and subcommittees, and nongovernmental actors have a greater role in policy-making (HIV/AIDS, environment, women’s right, and demographic issues) (Kegley and Wittkopf, 2004; McCormick and Wittkopf, 1992; Underhill, 2000). For Barnett (1990), “high politics” refers to a state’s security relationship with other states in the international system and "low politics" refers to societal pressures and domestic political economy. Both "high politics" and "low politics” issues involve the relationship between states in the international system and as 
such, transnational in nature. However, "high politics" concerns issues that affect the sovereignty and survival of the state within the international system. It is difficult for states to cooperate on such issues (Jervis, 1983). These issues affect the security of states in the international system and they usually require self-help. This is why cooperation in these issue-areas is difficult to attain. On the other hand, in many cases "low politics" issues do not affect the security or survival of states within the international system. Due to this reason, collective action among states is usually possible. Thus, liberals acknowledge the ease with which nation-states cooperate within the areas of "low politics” (Keohane, 1984; Krasner, 1983; Jervis, 1983). In “low politics” arenas, the propensity for collective action is greater.

Tobacco control can be categorized as a "low politics” issue. Allyn Taylor (1992) compares tobacco control to issues such as the environment and HIV/AIDS. These issues cut across national border hence they are transnational in nature. For instance, with regards to tobacco, the industry is a transnational enterprise. The operation of the industry is not limited to any single country. Also, tobacco is an international commodity governed by international trade rules under GATT and WTO. Furthermore, as a result of technological advancements, marketing activities of the tobacco industry such as advertising cut across national boundaries. Moreover, issues involved in the tobacco business such as cross-border smuggling do not affect only a single country. From these, tobacco control can be classified as a "low politics" issue. It is an issue that is transnational in scope hence it requires collective action of states to deal with it. Even in the midst of the Cold War when states were preoccupied with "high politics," "low 
politics” issues were still recognized. However, the end of the Cold War facilitated cooperation in such arenas (including tobacco control) (Gordenker and Weiss, 1995).

Moreover, following Lowi's (1964) categorization of policy into distributive, regulatory, and redistributive types, one can infer that states are more likely to cooperate on the issue of tobacco control. This is because regulatory policies seek to proscribe and prescribe certain kind of behaviors; tobacco control can perhaps be described as a regulatory policy (Studlar, 2004 and 2002, Nadelman, 1990). Such policies do not "rob Peter to pay Paul.” That is, they do not take resources from the rich and give to the poor. They are meant to prohibit a certain form of behavior that affects both the rich and the poor as well as developed and developing countries. Thus, unlike redistributive issues in North-South relations, countries are more inclined to cooperate on the issue of tobacco control because of its regulatory nature. Tobacco control is not a zero-sum issue where the propensity for disagreement is high (Krasner, 1983; Jervis, 1982 and 1983). It is not an issue area where one state's gain is at the expense of another state. This fosters cooperation among states.

Tobacco use is a pandemic that is global in nature, requiring countries to cooperate in strong international action even as they tailor their control efforts to their own unique circumstances (Satcher, 2001). Borrowing from functionalists, WHO, like other specialized agencies promote cooperation in tobacco control, since the FCTC does not challenge state sovereignty (Mitrany, 1968; Haas, 1964). The FCTC does not constrain states on how to control their own population. It does not seek to undermine the survival of any particular states. However, armed with accumulated scientific knowledge about the hazards of tobacco use and effective ways of combating the problem ("best 
practices”), it urges states to take action to combat the use and spread of tobacco.

Tobacco control is based on a mountain of scientific evidence about the hazards of tobacco usage. It is familiarity with knowledge on tobacco use and tobacco control that served as catalyst for the adoption of the FCTC. How the knowledge about this evidence gradually spread through the international system, culminating into a regime - FCTC - is an essence of this work. The primary hypothesis emerging from the above is that The low politics nature of tobacco control facilitated the adoption of the FCTC.

\subsubsection{Policy Transfer/Diffusion}

As Studlar (2002) points out, policy transfer falls into the family of lesson drawing, policy copying, policy emulation, policy borrowing, and diffusion. Despite that one can make some conceptual distinctions, they all involve political jurisdictions countries states, provinces, and localities, as well as learning from others - horizontally or vertically (Studlar, 2002). Policy transfer and lesson drawing are usually used synonymously (Dolowitz, 2003; Rose, 2005, 1993). Furthermore, lesson-drawing, policy convergence, policy diffusion, and policy transfer are all concerned with a similar process in which knowledge about policies, administrative arrangements, institutions and ideas in one political setting (past or present) is used in the development of policies, administrative arrangements, institutions and ideas in another political setting (Dolowitz and Marsh, 2000). Thus, policy transfer (Dolowitz, 2003; Dolowitz and Marsh, 2000 and 1996), lesson drawing (Rose, 1993), policy learning (Sabatier and Jenkins-Smith, 1993) and diffusion (Walker, 1969; Gray, 1973) are closely connected. 
The essence of these phenomena is that lessons ${ }^{16}$ are learned from another geographical jurisdiction or from the past (Rose, 1993). Although this is an old phenomenon, it has gained prominence because of the awareness of the potential influence of foreign ideas and models on the changing world of modern governance (Rose, 2005; Dolowitz, 2003). Thus, as far as countries do not exist in isolation, they are more likely to become aware of ideas and information for solving problems through contact with other countries or interactions within international institutions.

Policy transfer refers to the process by which policies and/or practices of one political system are fed into and utilized in the policy-making arena of another political system (Dolowitz, 2003; Dolowitz and Marsh, 1996). The salient questions asked with respect to this phenomenon are: Why do actors engage in transfer? Who are the key actors? What is transferred? From where are lessons drawn? What are the different degrees of transfer? What restricts or facilitates the policy transfer process and how is the process of policy transfer related to policy ‘success' or policy ‘failure’? (Dolowitz and Marsh, 2000). The key political actors involved in policy transfer include: elected officials, political parties, bureaucrats/civil servants, pressure groups, policy entrepreneurs and experts, transnational corporations, think tanks, and supra-national governmental and nongovernmental institutions and consultants (Dolowitz and Marsh, 2000). In this sense, actors other than states play relevant roles in the diffusion or transfer of knowledge, information, and ideas from one jurisdiction to the other.

Policy transfer at the global level can take place through different mechanisms. Rose (1993) discusses voluntary lesson drawing whereby due to different reasons,

\footnotetext{
${ }^{16}$ Program(s) of action based on a program(s) undertaken in another city, state, or a nation or by the same organization in the past (Rose, 1993:21).
} 
particularly, policy failures, countries borrow successful policies from different jurisdictions. However, using the transfer of privatization policies to developing countries through international financial institutions (World Bank and International Monetary Fund) Dolowitz and Marsh (1996) point out that policy transfer could be either voluntary or coercive. They developed a model of policy transfer across a spectrum of voluntary to coercive transfer (Dolowitz, 2003; Dolowitz and Marsh, 2000 and 1996). In certain cases, countries are coerced through different mechanisms to adopt policies against their will. In such a situation, they adopt policies out of necessity. A typical example is the adoption of privatization by many developing countries (Dolowitz and Marsh, 1996).

There are many agents involved in the process of policy transfer across national borders. For Studlar (2004, following Bennett 1992), agents of transfer of information can occur through a variety of mechanisms such as technological determinism, epistemic communities, direct lesson drawing by independent governments, international networks based on NGOs and IGOs, harmonization (authoritative action by IOs) and penetration (international coercion). The actors involved in this process range from individual policy entrepreneurs to supranational organizations. Thus, although, "best practices" in tobacco control originated at the unit-level, through the activities of transnational actors they have been institutionalized as a tobacco control regime (FCTC). The FCTC, an international regime, has in turn becomes a key actor in the diffusion of "best practices" in tobacco control.

Evidence of policy transfer or lesson drawing or diffusion of policy across different jurisdictions is abundant within the literature, particularly among countries (Bennett 1992; Studlar, 2002; Dolowitz, 1997; Nadelman, 1990). For instance, while 
Studlar (2002) found that Canada and the United states learned from each other in the area of tobacco control policies, Dolowitz (1997) concluded that the policy of welfare to work was transferred from the United States to the United Kingdom in the 1980s. Nadelman (1990) also demonstrates how policies on certain prohibitory practices ranging from piracy, slavery, cross-border crimes, and drug trafficking to environmental policies developed in the West gradually evolve to become global policies. Finally, in a review of the policy transfer literature, Dolowitz and Marsh (1996) point out how the World Bank transferred the policy of privatization to parts of the developing world via structural adjustment programs (SAPs). In effect, policies could be transferred from one jurisdiction to another or from one jurisdiction to supra-national institutions and vice versa.

Technological advancements and the process of globalization facilitate these processes (Dolowitz and Marsh, 2000; Dolowitz, 1997).

In tobacco control, policies to combat tobacco consumption ("best practices”) originating primarily from core countries evolve into a global regime (FCTC) in 2003. Like the World Bank, the FCTC facilitates the transfer of "best practices" in tobacco control to the peripheral areas (medium and low income countries) where tobacco consumption is on the rise, and policies to combat the scourge are non-existing. Thus, a central concern of this paper is how "best practices" in tobacco control innovated in some developed countries, over time, are diffused or transferred to different jurisdictions (primarily, developing ones), and eventually become an international institution (FCTC).

The emergence of "best practices" in tobacco control and the diffusion and transfer of these practices facilitated the adoption of the FCTC. 


\subsubsection{Transnationalism}

Richard Cooper (1968 and 1972) earlier pointed out the issue of interdependence in the area of national economic policies. Subsequently, Keohane and Nye (1977) argue that emerging complexity of the world as a result of multiple channels of communication, equally competing national goals, and limited importance of military power and the threat of use of force has increased the importance of transnational actors. The state is no longer the sole actor on the international arena. On the contrary, Crane and Amawi (1997:14) point out the limitation of complex interdependence in explaining North-South relations. ${ }^{17}$ In spite of this criticism, it is still relevant in understanding international tobacco policy because of its emphasis on the importance of transnational actors.

The two key transnational actors are international nongovernmental organizations (INGOs or NGOs) and transnational organizations (TNOs) (Kowalewski, 1992). The conception of NGOs ranges from organizations with purely private actors, those with at least one private (non-state) actor, to hybrid ones having both governmental and private organizations. Kowalewski (1992) argues that the salient feature of this sort of interaction is that these organizations are associational, not centrally directed by citizens of only one country (Kowalewski, 1992). One type of tobacco control NGOs consists of those formed with primary focus on curbing tobacco use, such as Action on Smoking and Health (ASH) and Group to Alleviate Smoking Pollution (GASP). The other groups such as American Medical Association (AMA) added tobacco control to its areas of concern as

\footnotetext{
${ }^{17}$ See also Michael Doyle, 1983, "Stalemate in the North-South Debate: Strategies and the New International Economic Order," World Politics 35, 3; Vincent Mahler, 1984, "The Political Economy of North -South Commodity Bargain: The Case of International Sugar Agreement,” International Organization 38, 4; John Ravenhill, 1984, "What is to Be Done for Third World Commodity Exporters? Evaluation of STABEX Scheme,” International Organization 38, 3
} 
evidence on the linkage between tobacco use and health became apparent (Nathanson, 1999). [See Table 3.5 for tobacco NGOs].

Nongovernmental organizations (NGOs) have generally emerged as important transnational actors in international issues. They are important component of the international system. The United Nations (UN) recognize NGOs, defined by the UN's Economic and Social Council (ECOSOC) Resolution 288 (x) of February 27, 1950, ${ }^{18}$ as any organization not established by intergovernmental agreement (UIA, 1983/84). Members of such organizations are primarily private groups and individuals. The aim of such organization must be international in character. They operate across national borders in not-for-profit activities (Mingst and Karns, 1995). They are recognized as an integral part of the UN system. Article 71 of the UN Charter provides consultative status to NGOs. Resolution 1296 categorizes NGOs into three. Category I consists of those with multifaceted goals and activities involving areas of ECOSOC responsibilities; Category II consists of those specialized in a particular area of economic and social activities; and Category III consists of those that may have occasional interest in UN activities (Mingst and Karns, 1995). These provisions suggest that NGOs are legitimate actors in the international system. Such organizations are herein referred to as Transnational Advocacy Groups (TAGs).

Transnational organizations, on the other hand, refer to those organizations with special ties of authority to one single country (Kowalewski, 1992). These organizations originate in one country but they extend their operations into other countries. Among

\footnotetext{
${ }^{18}$ ECOSOC Resolution 288(x) states "Any international organization which is not established by intergovernmental agreement shall be considered as non-governmental organization for the purpose of this arrangement” [Source: Union of International Associations (ed.), 1984/85 Yearbook of International Organizations, New York: K.G. Saur Munchen
} 
these organizations are not-for-profit ones such as transnational religions and transnational foundations like Ford or Rockefeller. The other transnational organization is made up of business international nongovernmental organizations (BINGOs) such as transnational corporations (TNCs) or Multinational Corporations (MNCs) and transnational banks (TNBs) or multinational banks (MNBs). They are engaged in forprofit business transactions and operations (Mingst and Karns, 1995). The contemporary globalization process has facilitated the operation of these TNOs. Rapid technological advancement has increased the volume and intensity with which these actors are able to extend their activities into other countries. They have been recognized as significant international actors since the 1970s (Mingst and Karns, 1995). The hallmark of these organizations is that they have their headquarters in a mother country and subsidiaries in other countries. The transnational enterprise of importance to this study is the tobacco industry. This is because it remains the main agent involved in the spread of tobacco use worldwide.

Lastly, policy entrepreneurs have emerged as very important transnational actors. Individual citizens have become one of the important actors in the international system. Personal transnational interaction may change attitudes of individuals and cause them to exert accommodative influence upon governmental policy makers (Bennett, 1980). Individual actors within the international system can be norm makers. Just like previous literature, policy entrepreneurs refer to people who seek to initiate dynamic change in certain policy areas whether domestically or globally (Mintrom, 1997; Baumgartner and Jones, 1993; Kingdon, 1984). They are particularly important in setting global agendas for states. Policy entrepreneurs or advocates are relevant in pushing ideas and issues on 
the global systemic agenda unto the global institutional agenda. These "policy entrepreneurs can play key roles in identifying policy problems in ways that both attract the attention of decision makers and indicate appropriate policy responses” (Mintrom, 1997:739; Polsby, 1984). These transnational actors are herein referred to as Transnational Policy Entrepreneurs (TPEs).

Associated with this idea is tobacco control advocates or activists (Pertschuk, 2001; Wolfson, 2001). These are consultants and or leaders of anti-tobacco groups and institutions. For instance, individuals such as Stan Glantz in the United States (Wolfson, 2001) or Clive Bates, formerly of Action on Smoking and Health - United Kingdom fall into this group. Wolfson (2001) and Pertschuk (2001) demonstrate that the individual's policy orientations and visions of such people are relevant in understanding the general spread of knowledge, information, and ideas about tobacco use and tobacco control domestically and internationally.

The analysis of the activities of these transnational actors in the global tobacco control policy arena will draw upon some of the underlying ideas of the Transnational Advocacy Network (TAN) and Advocacy Coalition Framework (ACF). The NGOs phenomenon is measured as the cumulative number of pro-tobacco and anti-tobacco control NGOs. MNCs on the other hand, refer to tobacco companies and their subsidiaries around the globe. This is considered collectively as the tobacco industry. The argument is that the growth of these transnational actors in the midst of accumulated evidence on the hazards of tobacco use is one of the rationales behind the adoption of the FCTC. 
The emergence of transnational actors in the tobacco control policy arena facilitated the adoption of FCTC.

\subsubsection{Globalization and Interdependence}

Held (1995:20) defines globalization as "the stretching and deepening of social relations and institutions across space and time such that, on the one hand, day-to-day activities are increasingly influenced by events happening on the other side of the globe and, on the other hand, the practices and decisions of local groups or communities can have significant global reverberations.” The rapid technological advancement has shrunk distance around the world. As a result, knowledge, information, and ideas about an issue are quickly spread around the world. Societies around the world have become more interconnected, leading to increase in the volume and intensity of interactions. Keohane and Nye (2001) prefer to call the process "globalism” and say it involves issues ranging from military to environmental interactions and interconnectedness. This process has created a situation such that in many issue areas, states must cooperate with one another for collective action. This is because issues (including tobacco) spill over national boundaries hence requiring a transnational collective action.

Indicators of globalization include the number of subsidiaries of tobacco companies, the number of tobacco factories around the world, the number of markets tobacco companies operate in, and number of tobacco leaf producing countries around the world. The emphasis in this work is on the extension of the tobacco industry activities around the world and associated public health problems. The central focus is on the extension of the tobacco industry marketing and other activities into developing 
countries. It is the knowledge about these phenomena that contributed to the adoption of FCTC. This is an attempt to test the assertion of individuals like WHO Director-General Gro Harlem Brundtland and scholars such as Taylor et al. (2003) and Collin et al (2002) that the main rationale behind the adoption of the FCTC is the spread of knowledge about the activities of the tobacco industry and associated health problems.

Emerging from the process of globalization with regard to policy are two phenomena - convergence and global governance. Convergence simply refers to the existence of similar policies in an issue area among two or more countries (Kerr, 1983). Some of the important issues Studlar (2002) notes are that the phenomenon is a process rather than condition (Bennett, 1992), evidence must demonstrate that it takes place across time and space (Bennett, 1992; Rose, 1993; Seeliger, 1996), and one must be able to find change in differences over time to determine convergence (Seeliger, 1996). In addition, Studlar (2002) points out that there must be a reference point for each country, one must be able to tell which country adopted the policy first, and one must be able to demonstrate that over time the policies of the countries have moved closer. Explanation of convergence ranges from technological determinism, that is, states at the same level of development face similar problems will enact similar policies; emulation, that is, copying and adaptation of legislation passed elsewhere; elite networking, that is, convergence through the common perception and interaction of cross-national policy community; harmonization, that is, through authoritative action by international organization; and penetration, that is, a more coercive process where states are forced to conform to a legislative action taken elsewhere (Bennett, 1992, 1991). In this case, transnational actors can facilitate the convergence of policies of states in an issue area. 
In an elaborate analysis of convergence among OECD countries, Castles (1998) finds several factors that account for why policies of different countries move closer together in an issue area. Using a quantitative approach, Castles examines the causes of 'big government' or the welfare state in 21 OECD countries during the post-World War Two (WWII) era - 1960-1995 - with combination of economic, social, and political variables. For instance, he finds that left leaning government, corporatism, union density, and ageing population is associated with higher government expenditure (Castles, 1998). Also, using a case study approach, Studlar (2002) examines convergence between United States and Canada in tobacco control policies. Studlar, (2002) concludes that "in the third period, 1994-2001, the two countries converged in their policies at both the federal and lower levels, with both having achievements and failures” (p.125). Similarly, using case study approach to examine convergence between the U.S. and Canada in social and environmental policies, Hoberg et al. (1999) find considerable amount of convergence in environmental policies and policies relating to equality of rights. Still, they find divergence in some social policies. On the other hand, in an investigation into the assertion that international capital mobility creates substantial pressure for all democratically elected government to decrease the tax burden on business using 17 OECD countries, Swank (1998) finds little evidence to support the thesis.

The argument from these works is that the adoption of the FCTC is the result of the globalization of the tobacco industry. The emphasis is the extension of the activities of transnational tobacco companies around the world. For instance, currently the British American Tobacco (BAT) Group operates in about 180 markets worldwide and it has 81 factories in 64 countries (BAT, 2005). Similarly, Philip Morris International has more 
than 50 factories worldwide and it operates in over 160 markets around the globe (PMI, 2004). [See Table 3.7]. The growth and extension of the tobacco industry across the globe made states to realize that tobacco control is not an issue meant for a specific domestic population but the world in general hence the need for global concerted effort in tobacco control. As Young (1983) argues, patterned behavior generates convergence of expectation and new institutional arrangements. In essence, globalization of the tobacco industry led to harmonization in tobacco control policies among states.

Emerging also from globalization is the issue of global governance. Under the globalization phenomenon, events at in one country echoes in other parts of the world. The emergence of global issues suggests the need for some form of governance in such issue areas. Held (1992), Held et al (2001), and Keohane and Nye (2001) note that globalization leads to common problems, hence the need for a concerted effort or collective action. One of the means for achieving this from a neoliberal perspective is the establishment of regimes. However, as Keohane (1989) points out, institutions have both regulative and constitutive aspects, Wendt’s (1987) ‘agent-structure problem’. Thus, for the neoinstutionalists, while individuals participating in institutions influence the institutions on one hand, on the other hand, institutions help to mold the preferences of these individuals (March and Olson, 1984). New institutionalism conceives of relative autonomy of institutions. A key concern in new internationalism in international relations is about institutional arrangement whose members are states and whose operations center on issues arising within international society (Young, 1999). The issue in this case is tobacco control. The extension of the activities of the tobacco industry into places where 
tobacco use was not a problem led to concern over the spread and use of tobacco worldwide hence the need for an institution on tobacco control.

The constitutive aspect of institutions suggests that institutions have formative effects on their members rather than only the other way round (Wendt, 1987 and 1992). In this respect, participation in institutions can affect the way members define their interests and identify their identities even though they may have begun with different identities (Wendt, 1994). The functions of IGOs in the development of regimes include the facilitation of agreements, the altering of states' and nongovernmental actors' influence in the formation and implementation of regimes and promotion of compliance with regime rules (Cassese and Clapham, 2001). From this, the first indicator of global governance is WHO itself. The mere existence of WHO with the constitutional powers to influence international public health issues facilitated the emergence of global governance in tobacco control.

Scholars such as Held et al (2001), Wapner (1997), Lipschutz (1996), Young (1999 and 1994), and Rosenau and Ernst-Otto (1992) analyze the issue of global governance in certain issue-areas. Even in 1995, a Commission on Global Governance investigated the issue of global governance. Taylor's (1992) argument on WHO’s ability to establish a regime in the area of public health was coined in terms of the globalization of public health issues. She subsequently wrote on issues of global governance in the area of international public health (Taylor et al, 2003; Taylor, 2002). The argument is that WHO provided the framework for negotiation of the convention among governmental and nongovernmental actors. WHO provided a venue for anti-tobacco advocacy groups to press their case for global tobacco control. 
On the other hand, the FCTC itself is a symbol of global governance in the area of tobacco control. Its articles highlight what some scholars refer to as global "best practices” in tobacco control (WCTOH, 2000). As a form of governance, it aims at modifying the behavior of states in the area of tobacco control, an idea consistent with neoinstitutionalism (March and Olson, 1984). The FCTC prescribes certain kind of behaviors and proscribe others. In this respect, it is hypothesized that

The extension of the activities of the tobacco industry across the globe and the evolution of tobacco control as a global issue facilitated the adoption of the FCTC.

\subsection{Methodology:}

The qualitative research method is used to analyze the hypotheses of this study. This is an appropriate methodology for addressing issues in social science (Patton, 2002; Merriam, 1998; Peters, 1998; King et al., 1994; Maanen et al. 1982). For instance, Patton (2002:96-103) has elaborately discussed how one can use qualitative research to explore constructivist issues such as this study. Specifically, this is a single case study approach to analysis of the development and behavior of a global regime on tobacco control - the FCTC. This approach involves an intensive, holistic description and analysis of a phenomenon (Merriam, 1998:27). As such, the emphasis is more on processes and procedures that led to the ultimate outcome (Merriam, 1998:19). In essence, the central concern is on analysis of the politics behind the development of the FCTC.

The two key approaches to qualitative research work are the insider and the outsider perspective (Maanen, 1982). Whereas the insider approach compels a researcher 
to enter the world of the studied and attempt to come forth with a close reading of that world in terms of the interpretative standards found there, the outsider perspective seeks to describe aspects of the studied world about which members of these worlds are presumably unaware (Maanen, 1982:17-18). This study took an outsider perspective on the development of global norms on tobacco use and tobacco control in a bottom-up fashion. For this reason, it draws on data and summarizing information as well as the knowledge of people who have been directly or indirectly involved in tobacco control at the global level since the early 1960s.

In general, the study used a combination of content analysis using written documents or archival data and interview. These mulltimethods of data collection have been identified as appropriate forms of qualitative research work (Patton, 2002; Maanen et al., 1982:15). This is because qualitative research is marked by reliance on multiple sources of information to determine consistency in an argument. The importance of interviewing is that it strengthens the "actor viewpoint” (Faulkner, 1982:81; Lofland, 1971:7). In this case, the interviews were meant to understand the role(s) of actors and their influence(s) in the creation of global norm on tobacco use and tobacco control. This method allowed quick responsiveness to decisions to move between more or less focused types of questions (Faulkner, 1982:81-82). The process was characterized by high degree of flexibility in the choice of questions. However, interviewees were directed toward specific questions. 
The study relied on two kinds of interview - telephone and face-to-face after review of literature ${ }^{19}$ on interviewing. This was a semistructured or focused form of interview where the topic was introduced and the discussion was guided with specific questions (Patton, 2002; Fontana and Frey, 2000; Rubin and Rubin, 1995; Merton et al., 1990). The face-to-face interviews in particular, induced an appreciation of the people being interviewed, and at the same time, it permitted a wide range of issues and questions to emerge (Faulkner, 1982:82). The interviews were supplemented with information that has been accumulated on tobacco control since the 1960s.

The selection of interviewees was based on Rubin and Rubin’s (1995:66) criteria. The criteria include interviewees (a) should be knowledgeable about the situation or experience being studied; (b) willing to talk; and (c) should represent the range of points of view. Interviewees were selected based on their involvement in the negotiation of the FCTC either at the country, regional, and global levels, or a combination of them. The important elements in the selection of interviewee were accessibility and convenience. Emphasis was laid on the ease with which an interviewee could be contacted. In addition, in order to ensure variety of opinions and to meet the methodological condition of adequate variance in the data (Peters, 1998:30), the interviewees included public/government officials, anti-tobacco NGOs, Business International NGOs (BINGOs), individuals who have been working in the tobacco control policy arena, and experts from World Health Organization from different regions and countries around the world, but were all involved in the FCTC negotiation process [See Table 6.1, 6.2, and

\footnotetext{
${ }^{19}$ I consulted Rubin and Rubin's (1995) Qualitative Interview, Biagi’s (1986) Interview that Works, Patton's Qualitative Research and Evaluation Methods and Merriam's (1998) Qualitative Research and Case Study Applications in Education for guidance in the conduct of elite interview.
} 
6.3]. In effect, I talked to a different actors and stakeholders whose activities resulted in the transformation of tobacco control into a global institution.

The interviews were recorded so that the written report will be based on accurate rendition of what was said (Patton, 2002; Rubin and Rubin, 1995:125; Biagi, 1986:17). Recording of the interviews helped to get the material down in an accurate and retrievable form (Rubin and Rubin, 1995:126; Biagi, 1986). For instance, an interviewee said, "I actually prefer that you record the interview because if there is any doubt you can go back to it, and not rely on your memory.” In this regard, Patton (2002:380) asserted, "As a good hammer is essential to carpentry, a good tape recorder is indispensable to fine field work.” Also, tapes can be kept until one has chance to transcribe them (Rubin and Rubin, 1995:126; Biagi, 1986). Finally, interviewees appreciated being recorded because the tape was perceived as a symbol of the ability to get their message accurately (Rubin and Rubin, 1995:126). However, public officials in particular and business groups did not like to be recorded (Rubin and Rubin, 1995; Biagi, 1986). For instance, an interviewee from a business advocacy group indicated that recording should pause for the personal position on tobacco control during one face-to-face interview session. The person said,

“There is no question about the scientific basis of the linkage between tobacco use and health. Actually, I don’t think that any person will allow his or her child to smoke because the person will eventually get cancer or some diseases like that. It may be extreme, but I personally support an absolute ban on cigarette smoking.”

This is an illustration of how interviews were intertwined with note taking. Also, it tells the degree of flexibility interviewees had during interviews. 


\subsection{Summary:}

The idea of tobacco control originated from developed countries because they were the first to experience the health consequences of tobacco use. The accumulation of scientific knowledge linking tobacco use to health hazards and authoritative recognition of this relationship resulted in the need for solution to the problem. The innovated policies ("best practices”) in some developed countries diffused or were transferred to other political and geographic regions of the world. Knowledge, information, and ideas about tobacco use and tobacco control to curb the activities of the tobacco industry spread around the world. Over time, tobacco control evolved to encompass an international dimension, eventually developing into a global regime - FCTC. This chapter set up the theoretical foundation of the study and describes the methodology for analysis for the adoption of the FCTC.

The underlying theory of this work is liberal-constructivism. The essence of this theory is that the transnational nature of tobacco control, the "low politics" nature of tobacco control, the extension of the activities of the tobacco industry worldwide, and the diffusion and transfer of tobacco control policies worldwide facilitated the adoption of the FCTC. In addition, due to the spread and use of tobacco around the global, tobacco control has emerged as a form of global governance. This study draws on theories of regime formation and transnationalism. The activities of transnational actors around the world, international conferences on tobacco control, and WHO facilitated the adoption of the FCTC. Underlying all these processes is the spread of knowledge, information, and ideas about tobacco use and tobacco control. Familiarity with the science and evidence on tobacco use and tobacco control motivated states and other transnational actors to work 
collectively toward the institutionalization of global tobacco control. On the other hand, the international regime created - FCTC exists to facilitate the spread of this knowledge to other political and geographic jurisdictions, so that countries around the world would take tobacco control as one of their priorities. The FCTC puts tobacco control on the agenda of parties to the treaty in particular, and states within the global system in general. 


\section{Chapter 3}

\section{Transnationalism: Advocacy Groups, the Tobacco Industry and Policy Entrepreneurs or Advocates}

\subsection{Introduction:}

The underlying phenomenon in this study is transnationalism and how tobacco use and tobacco control spilled over national borders. The activities of transnational actors produced authoritative recognition of the linkage between tobacco use and health hazards. Transnational actors in the area of tobacco control include individual advocates or policy entrepreneurs, advocacy groups, nongovernmental organizations, and transnational tobacco companies. This chapter briefly reviews activities of these transnational actors from the early 1960s to the early 1990s, their involvement in the FCTC negotiation process, and their impact on the institutionalization of global tobacco control. The emphasis, however, is on the activities of transnational actors from the beginning of the negotiation in 1999 to the adoption of the FCTC in 2003. This chapter argues that the emergence of tobacco use and tobacco control as a transnational phenomenon can be linked to activities of these transnational actors. The chapter analyzes WHO documents and submissions these actors made during the October 2000 FCTC public hearings to determine motivations behind their positions on the FCTC and the strategies they used to mobilize worldwide support for their positions. 


\subsection{Transnational Advocacy Groups (TAGs)}

Societal groups have been important part of the efforts to curb the use and spread of tobacco at both domestic and international levels. For instance, in the U.S. groups such as the American Anti-Tobacco Society, the Chicago Anti-Cigarette League, and Nonsmokers' Protective League of America had been in existence since the midnineteenth century. Still, there were little transnational advocacy groups in the tobacco control policy arena until the official recognition of the hazards of tobacco use in the early 1960s [See Table 3.1]. In the U.S., Nathanson (1999) shows that these official publications succeeded in dramatically transforming the advocacy groups' activities in the tobacco arena. Since then there has been proliferation of TAGs with both domestic and international focus [See Table 3.1].

Internationally, advocacy groups such as the American Cancer Society (ACS), International Union Against Cancer (UICC), International Union Against Tuberculosis and Lung Diseases (IUATLD), International Society and Federation of Cardiology (ISFC), International Organization of Consumers Union (IOCU), and International Union for Promotion of Health and Education (IUPHE) have been involved in research on tobacco use, and mobilization of collective action against tobacco use. Between 1960 and the beginning of the FCTC negotiations in 1999, these groups have been working either solely or in collaboration with other organizations and WHO to spread knowledge and information about tobacco use and tobacco control worldwide. They have helped to transform tobacco control into a global issue. For instance in 1988, the UICC and WHO published guidelines for primary health care teams on smoking cessation (Ramstrom et 
al., 1988). These actors have been involved in global tobacco control since the 1960s, but they became more visible with the onset of the FCTC negotiations in 1999.

The $53^{\text {rd }}$ Session of WHA in 1999 established two bodies under Resolution WHA52.18 - the Intergovernmental Working Group (WG) and the Intergovernmental Negotiating Body (INB) - to prepare the grounds for the establishment of an international tobacco control regime (FCTC). The WG was responsible for working out the technical elements of FCTC. World Health Organization document A/FCTC/WG1/7 suggests that at the first meeting of the WG it was recognized that combating the global tobacco epidemic required an inclusive, comprehensive, multisectoral approach with the involvement of member states, private entities, nongovernmental organizations, and civil society. The INB was also responsible for negotiating the text of the FCTC and related protocols. After two meetings (October 25-29, 1999 and March 27-29, 2000), the WG developed a draft of the FCTC and submitted it to the fifty-third session of WHA in May 2000. Resolution WHA53.16 paved the way for the negotiation of the FCTC.

The INB began negotiation of the treaty at its first meeting in October 2000. The INB held a public hearing prior to the first meeting, giving a forum to advocacy groups, tobacco companies, public health officials, and ordinary individuals to voice their opinion on the FCTC. Over 500 submissions were made during the pre-negotiation public hearings. The submissions and the public hearings were indications of the importance of NGOs in the effort to negotiate a global convention on tobacco control and to encourage states to adopt the FCTC. In comments on the relevance of NGOs to the FCTC process, Derek Yach (2001), Executive Director, Noncommunicable Disease and Mental Health, WHO and Project Manager of TFI, admitted, "Now more than ever, we need the broad- 
based support of civil society." ${ }^{11}$ Public advocacy has become a strong part of the FCTC process.

Today, tobacco advocacy involves raising awareness about the importance of tobacco use prevention; advocating for governments to include tobacco prevention in national, provincial, and local policies; securing technical and financial support for implementation; educating leaders and community members about the importance of tobacco prevention efforts; promoting public awareness of the need for school based tobacco prevention initiatives; advocating for the provision of training for education personnel; establishing coordinated training programs with national institutions; and joining forces with other international, national, governmental, and non governmental (FCTC). ${ }^{2}$ TAGs worked alongside WHO and other IGOs to ensure the emergence of the FCTC and they continue to work diligently to ensure that the norms, principles, and protocols underlying the FCTC are implemented.

\subsubsection{Anti-Tobacco Advocacy Groups}

Anti-tobacco advocacy groups continued to emerge gradually in the first half of the twentieth century [See Table 3.1]. Until the 1960s, these groups were primarily domestically oriented. They were concerned with tobacco control in their home countries. However, the official recognition of the harmful effects of tobacco use in the 1960s changed this dynamic. The Royal College of Physicians and the U.S. Surgeon General reports were distributed worldwide and attracted attention of the media. The 1964

\footnotetext{
${ }^{1}$ Derek Yach, January 31, 2001, ““In their own words...” Using Tobacco Industry Documents to Advance the Truth"; http://www.who.int/tobacco/dy_speeches1/en/ [accessed 03/22/04]

${ }^{2}$ This information is available at http://www.who.int/school_youth_health/media/en/453.pdf [accessed $11 / 15 / 2004]$
} 
publication of the Surgeon General's Report in particular, "Marked the beginning of a revolution in attitudes and behaviors relating to cigarettes” (Brandt, 1990:156; cited in USDHHS, 2000:40; Nathanson, 1999). Similarly, the Food and Allied Workers' Union noted in their submission to the October 2000 FCTC public hearings that the 1964 U.S. Surgeon General's Report was the starting point for global debate on smoking and health. ${ }^{3}$ The image of tobacco as a socially acceptable commodity started to change. In 1965, just about a year after publication of the Surgeon General's report, the British parliament banned cigarette advertising on television. In the same year, the U.S. Congress passed the Federal Cigarette Labeling Law, requiring tobacco companies to put health warnings on cigarette packs. The scientific publications helped the anti-tobacco control movement to gain more momentum.

In addition, the emergence of more official and authoritative scientific evidence linking tobacco use to health impact on the non-user galvanized different advocacy groups to campaign against tobacco use in different geographic and political jurisdictions and globally (Studlar, 2002; Nathanson, 1999). The construction of the idea of innocentvictim (non-tobacco users) as a result of scientific evidence on passive smoking contributed to the proliferation of nonsmokers and other tobacco control groups (Nathanson, 1999). Moreover, tobacco use is a practice promoted by the tobacco industry. This made it easier for groups to mobilize to halt the perpetuation of this habit by the tobacco industry (Nathanson, 1999).

In the light of accumulating evidence on the hazards of tobacco use, the first World Conference on Smoking and Health was held in New York in 1967, followed by

\footnotetext{
${ }^{3}$ This assertion was made in their submission to the October 2000 FCTC preliminary public hearings, http://www3.who.int/whosis/FCTC/submissions/F2680262.pdf
} 
WHO's acknowledgement of the hazards of tobacco use in 1970. These two events set the foundation for the contemporary tobacco control movement, a movement that depends on the collaboration and cooperation between states, IGOs, WHO, TAGs, and individual advocates and activists. Under the contemporary era, tobacco use and tobacco control are predominantly perceived as transnational issues. It requires the concerted effort of different actors within the international system to bring the tobacco epidemic under control. For this reason, the activities of tobacco control advocates and groups have become transnational in scope. However, a formalized "Blueprint for Action" drafted in 1981 by more than 200 smoking control experts attending a National Conference on Smoking or Health in USA, is often identified as the catalyst for a dramatic change in anti-smoking activity - the Anti-Smoking Movement (Borio, 2001). The blueprint serves as guidance for anti-tobacco groups around the world.

Evidence as to the global nature of tobacco control was presented at different World Conferences on Smoking and Health. Tobacco control was deemed more as a global problem than as a domestic problem. At different WCTOH participants were consciously educated on how to form tobacco advocacy groups and to be involved in global advocacy against tobacco use. Also, since WHO publicly acknowledged the health hazards of tobacco use in 1970, various resolutions had urged member states to involve advocacy groups in the campaign against tobacco use. Throughout the 1980s and 1990s, WHO passed resolutions to deliberately involve civil society groups in the global campaign against tobacco use. Specifically at the $9^{\text {th }}$ WCTOH at Paris, France in 1994, the Tobacco Free Initiative (TFI) was launched to find a global approach to combat the 
tobacco epidemic. This approach demands the involvement of advocacy groups and other transnational actors around the world in the effort to combat tobacco use globally.

Another phenomenon in the evolution of global tobacco control movement is sponsorship of advocacy groups in developing countries by similar groups in developed countries. This observation is discerned from the sources of funding of developing countries advocacy groups that made submission to the FCTC pre-hearings. Those groups are usually funded and supported by similar groups from the developed world. In addition, funds were provided for groups in developing countries to enable them to send participants to global tobacco conferences such as the WCTOH. For instance, at the Fourth WCTOH in Stockholm, Sweden in 1979, funds were provided purposefully for the sponsorship of participants from developing countries. Also, the UICC sponsorship of tobacco control workshops in Africa in the 1980s and early 1990s resulted in the formation of smoking control groups in different countries $\left(8^{\text {th }}\right.$ WCTOH, 1992). These conscious efforts by groups in developed countries to finance those in developing countries to participate in global tobacco control activities greatly contributed to the emergence of the global tobacco control movement [See chapter 6].

Finally, pre-existing groups and organizations included tobacco control in their areas of concern as more convincing scientific evidence on the hazards of tobacco use emerges. For instance, professional health organizations such as American Medical Association (AMA) and public health charities such as American Lung Association (ALA), American Heart Association (AHA), American Cancer Society (ACS), International Union Against Cancer (UICC), and International Union Against Tuberculosis and Lung Disease (IUATLD) exemplify this set of groups. For instance, it 
took the AMA a long period before joining the tobacco control movement. Even after the 1964 U.S. Surgeon General's report, the AMA was reluctant to include tobacco control issues in its agenda (USDHHS, 2000; Nathanson, 1999). These associations and organizations absorbed tobacco control into their agenda.

Some of the leading transnational advocacy groups involved in the global campaign against tobacco use are below: 
Table 3.1: Date of Establishment of some Transnational Advocacy Groups (TAGs)

\begin{tabular}{|l|l|l|}
\hline Key Transnational Advocacy Groups (TAGs) & $\begin{array}{l}\text { Date of } \\
\text { Creation }\end{array}$ & $\begin{array}{l}\text { Country } \\
\text { of Origin }\end{array}$ \\
\hline American Anti-Tobacco Society & 1849 & USA \\
\hline $\begin{array}{l}\text { Chicago Anti-Cigarette League. It became the Anti- } \\
\text { Cigarette League of America in 1911 and Anti-Cigarette } \\
\text { League of the World in 1919 }\end{array}$ & $\begin{array}{l}1899 \text { by Lucy } \\
\text { Payne Gaston }\end{array}$ & USA \\
\hline Nonsmokers' Protective League of America & 1911 & USA \\
\hline $\begin{array}{l}\text { American Society for the Control of Cancer. It later } \\
\text { became American Cancer Society }\end{array}$ & 1913 & USA \\
\hline National Cancer Institute at Bethesda, Maryland & 1937 & USA \\
\hline $\begin{array}{l}\text { Federation of German Women launched a campaign } \\
\text { against tobacco }\end{array}$ & 1942 & Germany \\
\hline Action on Smoking and Health (ASH) & January 1968 & UK \\
\hline $\begin{array}{l}\text { Group Against Smokers' Pollution (GASP) - Clara Gouin } \\
\text { founded the first group in Maryland }\end{array}$ & 1970 & USA \\
\hline $\begin{array}{l}* \text { Action Group to Halt Advertising and Sponsorship by } \\
\text { Tobacco (AGHAST) }\end{array}$ & June 1984 & UK \\
\hline Coronary Prevention Group & November 1979 & UK \\
\hline Artists' Campaign against Tobacco Sponsorship (ACTS) & April 1985 & UK \\
\hline Public Health Alliance & 1987 & UK \\
\hline British Thoracic Society & December 1990 & UK \\
\hline International Agency on Tobacco and Health (IATH) & January 1991 & UK \\
\hline Doctors for Tobacco Law (DFTL) & June 1991 & UK \\
\hline Nurses Against Smoking & April 1994 & UK \\
\hline Public Health Services (PHS) & 1965 & USA \\
\hline GASP group in Maryland- founded by Clara Gouin & 1970 & USA \\
\hline GASP group in Berkeley - founded by Helen Story & 1971 & USA \\
\hline $\begin{array}{l}\text { MASH, an affiliate of ASH founded by MIT Professor } \\
\text { David Wilson }\end{array}$ & 1972 & USA \\
\hline Canadian Council on Smoking and Health & 1974 & Canada \\
\hline BUGAUP & 1979 & Australia \\
\hline The Advocacy Institute & 1984 & USA \\
\hline John Tung Foundation founded by David Yen & 1984 & \\
\hline
\end{tabular}

Source: Borio (2001); http://www.tobacco.org/History/Tobacco_History.html

\subsubsection{Anti-Tobacco Advocacy Groups (TAGs) and The}

\section{FCTC}

Working closely with the WG and INB, the NGO community on tobacco control actively participated in the negotiation of the FCTC. Due to the fact that tobacco control 
groups are dispersed around the globe, a key strategy used in the mobilization of support for the FCTC was the formation of alliances and coalitions. This confirms the importance of the Advocacy Coalition Framework in this analysis. This is consistent with Farquharson's (2003) conclusion that the ACF and TANs are applicable and observable in the adoption of the FCTC. Still, the TAGs are qualitatively different from the TANs because they are not loose networks of organizations around the world, but rather they are organizations on their own. Although they are conglomerations of different organizations around the world, they have their own structures like any organization. Examples include the FCA and the NATT. Membership organizations of these TAGs act on their own, but at the same time, they speak with one voice on many issues through the TAGs. In this respect, TAGs are new phenomena in the literature of social movements in general, and tobacco control in particular.

The deep core believe of these anti-tobacco groups around the world is that the evidence on hazards of tobacco use is a scientific fact. A review of the submissions made by anti-tobacco groups around the world to the October 2000 WHO’s TFI preliminary public hearings showed that the primary reason why many of them supported the FCTC is the linkage between tobacco use and health hazards. These groups also believe that innovative tobacco control measures are efficient and effective in curbing the spread and use of tobacco around the world. The effective approach to combat the use and spread of tobacco from the perspective of these groups is a comprehensive tobacco control program that encompasses individual, community, country, regional and global programs, and that the FCTC is very important for combating the tobacco epidemic. For instance, Oluwafemi Akinbode of Nigeria's Environmental Rights Action said in his testimony at 
the public hearings that "It is our belief that this forum would further strengthen the resolve of organizations and individuals of conscience worldwide to pursue an international instrument and multilateral actions that would curtail the globalization of disability, poverty and death which the tobacco industry symbolizes” (WHO, 2000c). This is a summation of the position of many of the anti-tobacco individuals, groups, and organization that made submission during the FCTC public hearings.

One of the leading anti-tobacco coalitions is the International NonGovernmental Coalition Against Tobacco (INGCAT). The UICC, IUATLD, and World Heart Foundation at the Ninth WCTOH in 1994 formed this coalition with an aim of promoting tobacco control at the global level. Subsequently, after WHO endorsed the idea of an international convention on tobacco control, the Framework Convention Alliance (FCA) emerged with the aim of mobilizing civil society support for the Convention and educating state delegates to the FCTC negotiating sessions on the dangers of tobacco use and the importance of a global collective action to combat the problem. Also, in 1999 the Network for Accountability of Tobacco Transnationals (NATT) was formed by over 75 NGOs from more than 50 countries to work for strong, enforceable FCTC and tobacco control worldwide. During the negotiations, the NATT played a key role in exposing and challenging attempts of the giant tobacco corporations and their political allies to derail the FCTC (PR Newswire, 2003). These coalitions, alliances, and networks were involved in the FCTC negotiating process. For instance, INGCAT made a submission during the public hearings and presented papers on the effects of tobacco use at the INB sessions. Membership of some of these coalitions grew with time, as more groups around the world became familiar with the FCTC process. 
Membership of FCA increased from about 25 during the first INB session in 2000 to over 195 during the sixth (last) INB session in February 2003 [See Figure 3.0]. Closely working with the FCA, INGCAT, and NATT is GLOBALink, ${ }^{4}$ the international tobacco control network and a cyber base community. From the British based Action for Smoking or Health (ASH), ${ }^{5}$ there is a list of over 395 tobacco control NGOs and individual actors across the world interested in the emergence of a global convention on tobacco control. Similarly, Tobacco.org ${ }^{6}$ has a list of over 383 NGOs and individuals with domestic, regional and international tobacco control concerns. It must, however, be noted that memberships of these groups overlap as some individuals and NGOs belong to more that one coalition or alliance. Below is a graphic representation of the trend in the growth of the NGO community ${ }^{7}$ interested in a global regime on tobacco control between 1999 and 2003.

Figure 3.0: The Growth of NGOs with Interest in the FCTC, 1999-2003

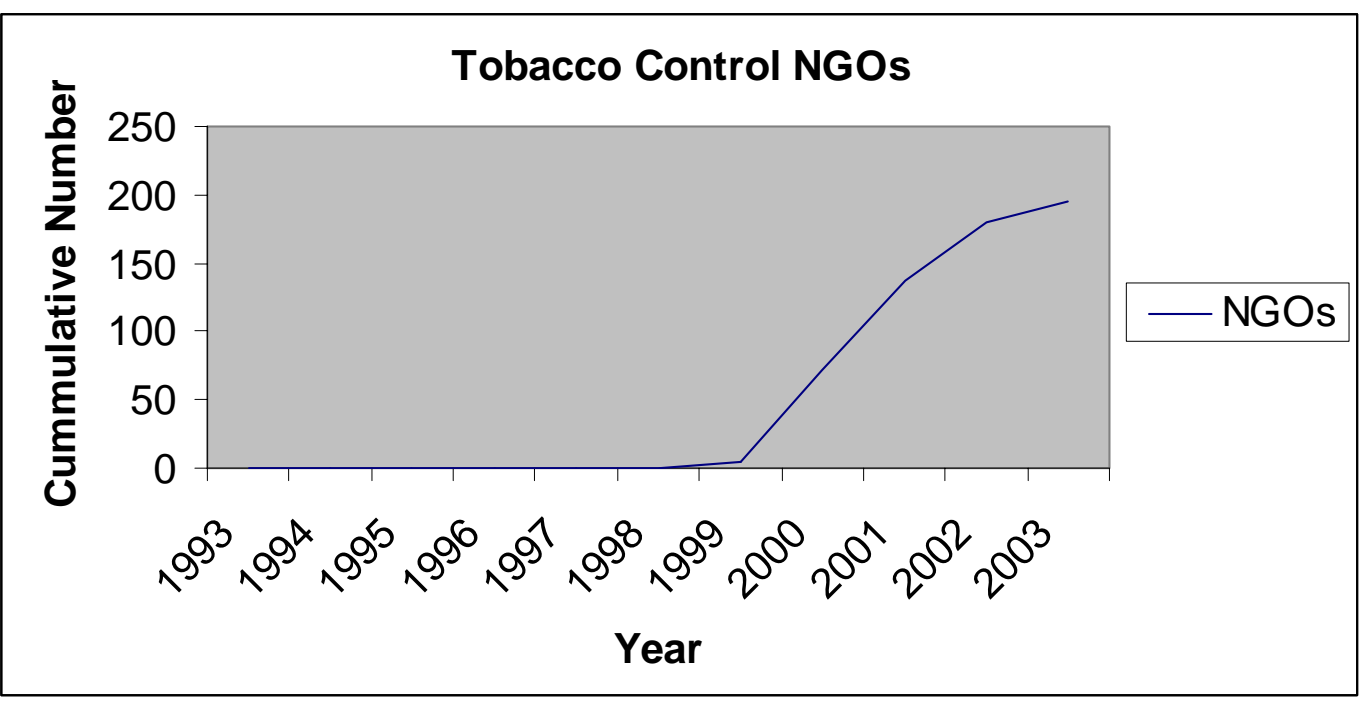

Source: Framework Convention Alliance

\footnotetext{
${ }^{4}$ http://www.globalink.org/ [accessed 03/23/04]

${ }^{5}$ http://ash.org/foreignorgintro.html [accessed 02/20/04]

6 http://www.tobacco.org/resources/general/tob_adds.html [accessed 02/20/04]

${ }^{7}$ Data from World Health Organization and Framework Convention Alliance
} 


\subsection{Working Strategies:}

Throughout the INB negotiation process (October 2000- February 2003), the FCA, in conjunction with other members within the international civil society, developed strategies for encouraging states to adopt, sign, and ratify the FCTC (UICC, 2003). The activities of the FCA during the negotiation process included press club debates, briefings of delegates, production of a daily bulletin, NGO press conferences, letter writing, and meetings (FCA, 2001). During the first INB session, the FCA organized a public debate between representatives of the tobacco industry and the tobacco control NGO community represented by Yussuf Salooje of National Council Against Smoking (South Africa) and Clive Bates of Action on Smoking and Health (UK) on tobacco advertising. In addition, the FCA conducted technical briefings of delegates. For instance, during the first FCTC negotiation the FCA conducted briefings on smuggling, advertising, the Kessler report on tobacco industry infiltration of WHO, and the World Bank report on the economics of tobacco control. Moreover, the alliance usually published a daily Newsletter - Alliance Bulletin - highlighting important issues in tobacco control and proceedings at the INB meetings. Over the course of negotiation, the alliance published 45 issues of the daily bulletin. The FCA also produced a position paper and three issues of their Newsletter during the International Conference on Illicit Tobacco Trade in July/August 2002 to educate participants on the impact of smuggling of tobacco products worldwide on tobacco control and the necessity for a global collective action to combat the phenomenon. 
Table 3.2:

Framework Convention Alliance Bulletin

\begin{tabular}{|l|c|}
\hline $\begin{array}{l}\text { Intergovernmental Negotiation } \\
\text { Board Meetings (INB) }\end{array}$ & $\begin{array}{c}\text { Issues of } \\
\text { Alliance Bulletin }\end{array}$ \\
\hline INB-1 - October 16-21, 2000 & 5 \\
\hline INB-2 - April 30- May 5, 2001 & 6 \\
\hline INB-3 - November 22-28, 2001 & 6 \\
\hline INB-4 - March 18-23, 2002 & 6 \\
\hline $\begin{array}{l}\text { International Conference on } \\
\text { Illicit Tobacco Trade - July 30- } \\
\text { August 1, 2002 }\end{array}$ & 3 \\
\hline INB-5 - October 14-25, 2002 & 9 \\
\hline INB-6 - February 18-27, 2003 & 10 \\
\hline
\end{tabular}

Source: Framework Convention Alliance, 2003

Furthermore, NGOs used press conferences to air their opinions on the FCTC negotiation. For instance, U.S. Public Health Groups ${ }^{8}$ at the first session of the INB held a joint press conference, calling on the U.S. to support the FCTC. In addition, the FCA held meetings among it members to discuss the most effective way of participating in the process. Also, the Commonwealth ${ }^{9}$ Medical Association and Commonwealth Secretariat held meetings with Commonwealth NGOs and Commonwealth delegations. For instance, at the first INB session, delegations from South Africa, Canada, Britain, Australia, and Zimbabwe voiced their support for a strong FCTC. Finally, FCA member organizations used letters to inform and encourage delegates from their respective countries to support the FCTC. Notable were letters sent to politicians in the U.S., ${ }^{10}$ the US president, ${ }^{11}$ letters

\footnotetext{
${ }^{8}$ The American Lung Association, American Medical Association, American Public Health Association and the Campaign for Tobacco-Free Kids

${ }^{9}$ It specifically refers to the Commonwealth, an association of about 54 English speaking countries across the globe

${ }^{10}$ Letter from Campaign for Tobacco Free Kids to US Secretary of State Colin Powell, June 25, 2001, http://fctc.org/archives/news170.shtml; Letter from ASH (USA) to the Honorable Hillary Rodham Clinton, June 5, 2001, http://fctc.org/archives/news149.shtml [accessed 03/19/04]

${ }^{11}$ Letter from Campaign for Tobacco Free Kids to the President of the United States, June 25, 2001, http://fctc.org/archives/news171.shtml; Letter from the Anti-Smoking Coalition, Papua New Guinea to
} 
to the U.S. bureaucratic agencies, ${ }^{12}$ and letters to agencies in other countries. ${ }^{13}$ Based on minutes of meetings revealing the U.S. attempt to weaken or eliminate key provisions of the FCTC during the second session of the INB, a U.S. member of Congress, Henry Waxman (Democrat, California) wrote a letter on August 2, 2001 to President W. Bush protesting the action of the U.S. delegation. In effect, the NGO community used primarily the traditional strategies of interest groups in pluralist political systems to influence states to support the convention.

The question is: how effective were these strategies in persuading states to adopt the FCTC? The countries whose positions were critical to the adoption of the FCTC were China, Japan, Germany, and the U.S. These countries wanted a watered down version of the convention. For instance, in spite of the fact that states in the U.S. such as California and Massachusetts have relatively strong comprehensive tobacco control programs, the U.S. cited constitutional and free trade concerns as hindering its acceptance of a stronger version of the treaty. However, participants involved in the negotiation process realized the importance of the U.S.' support if the FCTC was to be successful. The Lancet, (2003:1575) pointed out that "failure of the USA to sign up to the FCTC will be a major blow to the treaty’s power.” In a later letter to President Bush, Congressman Waxman said, "the position of the U.S. has been in virtual lockstep with the tobacco industry

the US President, May 7, 2001, http://fctc.org/archives/news146.shtml Letter from Rep. Henry Waxman to the President of the United States, August 2, 2001 [accessed 03/19/04]

${ }^{12}$ Letter from Campaign for Tobacco Free Kids to the U.S. Department of Health \& Human Services, June 25, 2001, http://fctc.org/archives/news172.shtml; Letter from the American Lung Association to the US Department of Health and Human Services, June 4, 2001, http://fctc.org/archives//news145.shtml; Letter from the American Medical Association to the US Department of Health and Human Services, May 23, 2001, http://fctc.org/archives/news144.shtml [accessed 03/19/04]

${ }^{13}$ Letter from ACASH (India) to the Indian Minister of Health and Family Welfare, May 25, 2001, http://fctc.org/archives/news150.shtml [accessed 03/19/04] 
throughout the treaty negotiation” (The Lancet, May 10, 2003:1575). The U.S. was criticized for the preference of a watered-down convention on tobacco control.

Unlike states such as Canada and those in Scandinavia that traditionally support systems of governance at the global level, the U.S. was generally seen as an obstructionist. For instance, in a joint statement, the American Lung Association and Campaign for Tobacco-Free Kids said "The US... has repeatedly made proposals that will weaken critical provisions of the draft convention and severely undermine potential efforts to reduce the death and disease caused by tobacco around the world” (Weissman, 2001). Also, in denouncing U.S. obstructionism, Clive Bates of ASH UK said “The U.S. contribution has been entirely negative: weakening, and deleting anything that might have substance” (Weissman, 2001). Thus, the U.S. position drew more criticisms from tobacco control activists than did those of Japan and Germany because its support for the convention was deemed as a more significant boost for the success of FCTC.

In spite of the position of these countries on the FCTC, they eventually voted for its adoption. EU health ministers reached a compromise, allowing Germany to sidestep some of the provisions of the FCTC (Kapp, 2003). However, in the case of the US, the Oncology Nursing Society (ONS) of USA, for instance, concluded "Because of the overwhelming advocacy of its members, ONS, along with others in the tobacco-control community, helped the Bush administration to support the Framework Convention on Tobacco Control (FCTC)”,14. This is a direct claim that NGOs' involvement in the FCTC process proved effective in swaying states to adopt it. White (2004) also chronicles the effectiveness of the strategies used by various pro-tobacco control groups in securing the

\footnotetext{
${ }^{14}$ The Editor, 2003, “ONS Advocacy Involvement Proves Effective Once Again,” ONS News, Vol. 18 Number 7
} 
adoption of the FCTC. Thus tobacco control advocacy groups' activities at domestic, regional, and international levels immensely contributed to the adoption of the FCTC. Anti-tobacco groups and activists were at the forefront of the promotion of the FCTC during the negotiating phase. This confirms the assertion that the activities of these transnational actors during the negotiating phase of the FCTC facilitated its adoption [See Chapter 6 for evidence].

\subsubsection{Pro-Tobacco Advocacy Groups and the FCTC}

Unlike tobacco control that did not gain momentum until advances in science, tobacco promotion has been defended on several grounds ranging from medicinal and ceremonial to economic purposes. In 1560, Jean Nicot de Villemain, France's ambassador to Portugal, wrote of tobacco's medicinal properties, describing it as a panacea. He sent rustica plants to the French court. He also sent snuff to Catherine de Medici, the Queen Mother of France, to treat her son Francis II's migraine headaches in 1561. The Queen Mother later decreed tobacco should be termed as Herba Regina. Also, in 1571, Monardes, a doctor in Seville, reported on the latest craze among Spanish doctors - the wonders of the tobacco plant, which herbalists are growing all over Spain (Borio, 2001). He listed thirty-six maladies that he believed could be cured by tobacco. Frampton translated Monardes’ report into English in 1577. Subsequently, European doctors searched for new cures, and tobacco was recommended for toothache, falling fingernails, worms, halitosis, lockjaw and cancer.

Besides the medicinal purpose of tobacco use, tobacco was and is deemed as a commercial plant. In 1531, European cultivation of tobacco began in Santa Domingo. In 
1548, Portuguese cultivated tobacco in Brazil for commercial export. In 1612, John Rolfe raised Virginia's first commercial crop of "tall tobacco." The first shipment of Rolfe's tobacco arrived in 1613. The year 1614 marks the first sale of native Virginia tobacco in England. Virginia colony entered the world tobacco market under English protection. However, a trade agreement between the Crown and Virginia Company banned commercial tobacco growing in England in 1620. The ban remained in place until 1911, when tobacco -growing was allowed in England for the first time in more than 250 years. In 1631, European-style cultivation of tobacco began in Maryland. In 1635, the first tobacco farms began in Clairac. George Washington harvested his first tobacco in 1759. In 1800, tobacco begins being commercially grown in Southern Ontario, Canada. Increasingly, production has moved to developing countries (Frey, 1997). This remains one of the main arguments of tobacco growers in particular, during the FCTC public hearings in October 2002. The defense of tobacco as a commercial plant has continued since its discovery in 1492.

The emergence of manufactured cigarette in 1860 and the tobacco industry bolstered the economic argument of tobacco use. The term "cigarette” appeared in English in the 1840s (Apperson, 1916; USDHHS, 2000). The popularity of cigarettes was based on certain distinctive features: (a) its mildness and inexpensiveness; (b) its relative convenience and disposability; and (c) its cultural connotation as a minor moral transgression (USDHHS, 2000). The invention of the Bonsack machine by James Albert Bonsack in 1881 - firs mass production replaced roll-your-own and single cigarette production, and at a lesser cost (Kluger, 1996; Chandler, 1977; Tennant, 1950). The aggressive business practices of people like James Buchanan Duke, and cheapness and 
portability of cigarettes led to soaring cigarette output (Chandler, 1977). The emergence of cigarettes led to increases in tobacco use. Yet, individuals and groups protested against cigarettes use either on religious or on grounds of hygiene and illness. For instance, Ellen Gould Harmon, the founder of the Seventh-day Adventist Church, was strongly against tobacco (Borio, 2001).

Throughout the history of tobacco, pro-tobacco groups can be categorized as farmers/growers' groups; tobacco industry interest groups and research institutions; tobacco trade associations; smokers rights' groups; and groups affiliated to the hospitality and advertising industry. Farmers' groups are usually formed to protect the interests of tobacco farmers. One of the foremost pro-tobacco groups emerged in Kentucky, USA. In 1904, Kentucky tobacco farmers formed a violent "protective association” to protect themselves against rapacious tactics of large manufacturers (Borio, 2001). They destroyed tobacco factories, crops, and even murdered other planters. The group was disbanded in 1915. In the U.S. for instance, interests of farmers (including tobacco farmers) are usually protected and promoted through the U.S. Department of Agriculture (USDA) and congressional committees (Baumgartner and Jones, 1993). This government protection of farmers' interests is a common phenomenon in other political and geographical jurisdictions where tobacco is grown, such as Malawi. In such countries, tobacco farmers constitute a strong lobby group. For instance, Malawi included farmers’ groups in its delegation to the FCTC negotiating sessions. The primary concern of these groups is the revenue and employment that tobacco generates.

For many years tobacco farmers' groups or associations were confined to different jurisdictions with very limited interactions. Often, the interests of tobacco 
farmers collided with that of manufacturers. However, as tobacco control evolved to encompass an international dimension, tobacco farmers around the world felt threatened. For this reason, in 1984, the International Tobacco Growers’ Association (ITGA) was formed. Currently with 25 countries as members, the ITGA is an organization with the purpose of presenting the course of millions of tobacco farmers to the world. It has a strong link to the tobacco industry through INFOTAB (Yach and Bettcher, 2000). Although other domestic farmers' associations have been in existence for many years, the ITGA has emerged as a strong representative of tobacco growers at different international tobacco forums.

The second set of pro-tobacco groups is usually tied to the tobacco industry. These are groups formed by tobacco companies or are groups that work in close collaboration with tobacco companies to either defend tobacco use or lobby against the regulation of tobacco use. For instance, in 1949 the Tobacco Tax Council was established in the U.S. to lobby for lower tobacco taxes. The most important activities of these groups are that they seek to undermine anti-tobacco use arguments and to carry industry programs to the grassroots. The leading association in this respect is the International Tobacco Information Center (INFOTAB), originally known as International Committee on Smoking Issues (ICOSI). Six tobacco companies - BAT, Philip Morris, Reemtsa, R.J. Reynolds, and Rothman's International established INFOTAB in 1978 in Switzerland to serve as an information clearinghouse that collects articles and legislative information. It was reorganized in 1980/81. It must be noted that in 1987, BAT and Brown and Williamson gave a notice of withdrawal from the institute. The main goal of INFOTAB is to establish an "early warning" system for anti-smoking initiatives worldwide, to "track 
activities of pressure groups and international consumer unions" and "to take industry programs to the grass roots and municipal levels" to help the industry to prevail over public health (Yach and Bettcher, 2000). The efforts to realize these goals usually lead to conflict with public health organizations such as WHO.

A third set of groups is trade associations of tobacco companies. The leading association in this respect is Tobacco Merchants Association (TMA). The Tobacco Merchants Association (TMA) was founded in 1915 to manage information of vital interest to the worldwide tobacco industry. Virtually all companies in all sectors of the tobacco business support it. A prominent tobacco trade association that operates within a particular country is Tobacco Manufacturers Association (TMA) of UK. Its principal members are: British American Tobacco UK Ltd, Gallaher Ltd, Imperial Tobacco Ltd. Philip Morris International and JT International S.A. are associate members. ${ }^{15}$ In addition, some governments such as those in China, Japan, and some developing countries have their own tobacco companies. Currently, many of these groups are located in India, Bangladesh, Pakistan, and Brazil. These groups work to promote the interests of tobacco companies. The general rationale for the promotion of tobacco is usually economic. A review of the submissions made by these groups to the FCTC public hearings revealed that the emphasis in this case is on the revenue and employment that tobacco generates [See Figure 3.1]. However, for particularly those in developing countries, the emphasis is on lack of alternative sources of livelihood for tobacco farmers. Another set of groups is smokers' rights groups and groups affiliated to the hospitality and advertising industry. They are those that defend tobacco use on grounds of

\footnotetext{
${ }^{15}$ The information is available from TMA of UK website: http://www.the-tma.org.uk/default.aspx. [accessed on 03/04/05]
} 
individual rights. Most of the groups in this set are domestically-oriented. The prominent ones are American Civil Liberties Union (ACLU), Forest of UK (founded in 1979), Friends of Tobacco (USA), New York City Citizens Lobbying Against Smoker Harassment (NYC CLASH), Smokers United Against Discrimination, National Smokers Alliance of USA, German Smokers' Club, and International Union of Food, Agricultural, Hotel, Restaurant, and Allied Workers' Association (IUF). Many of these groups are located in developed industrial democracies. However, a few are internationally oriented. An example of international pro-tobacco group is Forces International. The primary argument is that individuals have the right to smoke and any regulation of tobacco use is against such right [See Figure 3.1]. These groups argue that the FCTC encroaches on the right of the individual adult to choose.

A core argument common to pro-tobacco groups is that the FCTC undermines the sovereignty of states. For instance, in their submission to the FCTC public hearing, All India Pan Masala \& Tobacco Manufacturers Association (AIPMTMA) concluded that "it is impractical to come up with a solution that will not be a violation of the right of self governance and as long as any viable alternate is not found this industry should not be killed with a single stroke but in a plan which has a proper time frame” (WHO, 2000c). They perceive any attempt at global tobacco control as tantamount to overriding the concept of sovereignty hence their objection to such idea. For the German Smokers' club (WHO, 2000c),

The political system as a whole as well as the individual political sectors therein reflects the specific values and priorities of such a society. This is true also for national tobacco control policies. We cannot see any merit to impose a global one-fits-all-solution and weaken political self-governance in the name of health 
Tobacco is a commodity of economic importance not only to individuals whose livelihood depends on it but also states that perceive tobacco as source of employment and revenue. The leading exporters of tobacco leaf are shown in the table below.

Table 3.3: Tobacco Exporters (2001)
\begin{tabular}{|l|l|}
\hline Country & Share \\
\hline Brazil & $17 \%$ \\
\hline USA & $10 \%$ \\
\hline Zimbabwe & $9 \%$ \\
\hline China & $6 \%$ \\
\hline India & $5.6 \%$ \\
\hline Others & $52.4 \%$ \\
\hline Source: Borio (2001); $h$ htp://www.tobacco.org/History/Tobacco_History.html
\end{tabular}

Although pro-tobacco groups have adversarial relations with WHO, they presented their positions on the FCTC at the public hearings. For this reason, Judith Mackay (2003) contends that all voices were heard despite the complaint of some protobacco groups and TTCs about limited involvement in the FCTC process. From over 500 submissions made during the public hearings, over 60 diverse pro-tobacco groups from around the world were counted. However, for the most part of the actual negotiation process (WB and INB), such groups did not actively participate in the negotiation of the FCTC. In spite of this, some pro-tobacco groups directly participated in the negotiation process as state delegates of countries such as Malawi and Zimbabwe. This limited involvement of pro-tobacco groups in the FCTC negotiating process is consistent with Studlar (2002) and others assessment that the pro-tobacco groups were not active participants in the negotiation of the FCTC. Yet still, groups such as the ITGA continually debated with other anti-tobacco groups over the need for the FCTC during the public hearings, throughout the negotiating phase, and beyond. 
Using content analysis, the arguments of proto-tobacco groups for their positions on the FCTC were categorized as economic, social, environmental, price hikes, smuggling, rights, no alternative sources of livelihood, sovereignty, and WTO. The percentage of the pro-tobacco groups emphasizing on these arguments was derived using the submissions [See Figure 3.1] made these groups during the October 2000 public hearings on the FCTC (WHO, 2000c). The outcome of the analysis is shown in Figure 3.1 below.

The content analysis showed that the main rationale for their pro-tobacco stance has been economic. About 22 percent of the total arguments were expressions of economic concerns about the impact of the FCTC. They argue that tobacco is a source of employment and revenue for many people in the industry. For instance, many of the groups from India pointed out that about 30 million Indians depend on tobacco for survival. A Majority of pro-tobacco groups from developing countries in particular expressed concern about the FCTC because of lack of alternative crop for tobacco. This argument constitutes twelve percent of the total number of pro-tobacco arguments. The emphasis here is not mere absence of alternative crops, but rather unavailability of crops with comparable economic value.

Another reason for concern and opposition to some of the underlying policies of the FCTC is social. The social argument also constitutes 18 percent of the total number of pro-tobacco arguments. Some argue that tobacco businesses in their countries are familyowned. Thus, tobacco supports the family and other social structures of their countries. They argue that any immediate and dramatic decline in demand for tobacco leaf will affect the social set up of many communities whose life depends on tobacco production. 
Related to this is that some of the groups express the cultural and traditional value of tobacco in their country. This argument constitutes five percent of the total arguments. They believe that any attempt to regulate tobacco infringes on their cultural practices.

Some also offered environmental reasons for their position. The environmental argument constitutes six percent of the total arguments. The environmental argument is that tobacco grows very well on soils not conducive for many commercial crops. For this reason, tobacco production does not reduce lands available for the growth of other crops.

Others argue that the FCTC provision will rather lead to price hike for tobacco products and increase in smuggling. Concerns over price hikes constitute four percent of the total argument. Some groups and individuals feared that taxation in particular, will lead to higher prices for tobacco products, a situation they think is not in the interest of the consumer. On the other hand, five percent of the arguments are about concerns over increased smuggling as a result of price hikes. They argue that higher prices, due to higher taxes in particular, will boost the black market for tobacco products and thereby increasing the rate of smuggling.

For smokers' rights and consumer groups in particular, argue that the FCTC is against individual rights to choose. About ten percent of the entire arguments are expression over issues of rights. In this case, the FCTC is deemed as undermining the rights of farmers to grow their crops and the right of adult consumers to choose what they want. Many believed the provisions of the FCTC regulating tobacco use are against the democratic principle of freedom of choice. 
Furthermore, four percent of the arguments express concern that the provisions of the FCTC are against the spirit of free trade. They point out that provisions such as subsidies for alternative crops contravene World Trade Organization principles.

Finally, 14 percent of the arguments are on the concern that the FCTC infringes on the sovereignty of countries. Many believe that countries have the ability to formulate their own tobacco control policies; hence attempts at regulating tobacco at the international level encroach on the autonomy of countries. They argue that the one-fits-all approach of the FCTC undermines the principle of self-governance.

In addition to all the above, bidi ${ }^{16}$ producers in Indian and cigar producers in Europe prefer their products to be categorized differently from smoked tobacco or cigarettes. They think that their product should be differentiated from manufactured cigarettes, hence should not be a subject under the FCTC.

\footnotetext{
${ }^{16}$ It is a kind of traditional cigarette manufactured primarily in India
} 


\section{Figure 3.1: Pro-Tobacco Groups Central Arguments}

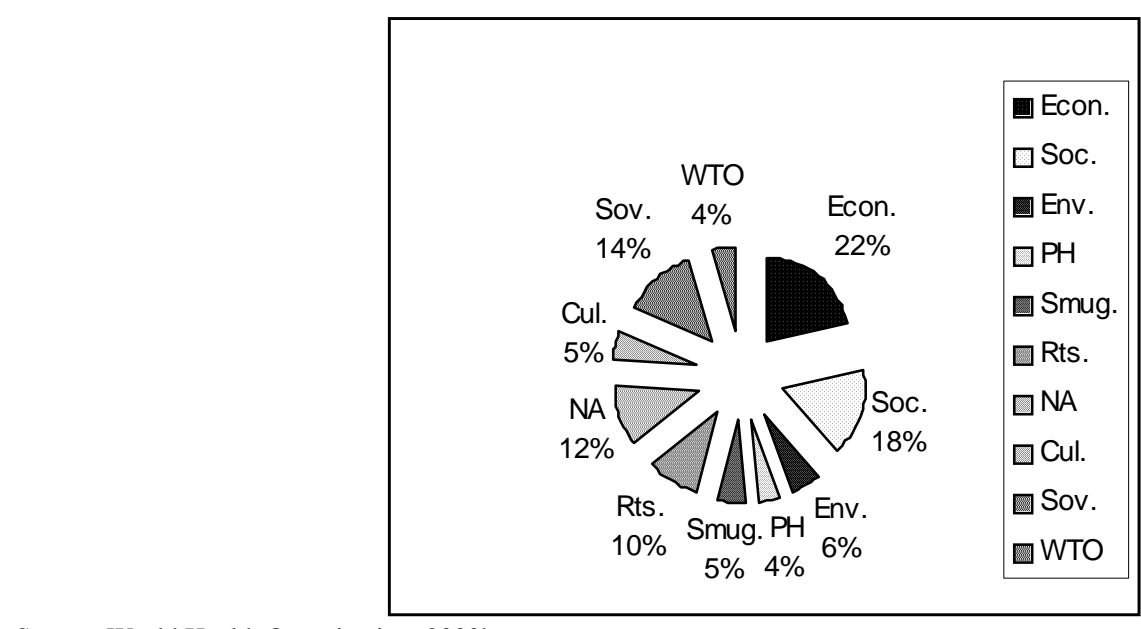

Source: World Health Organization, 2000b

Where Econ. - Economic; Soc - Social; Env. - Environmental; PH - Price Hike; Smug. - Smuggling; Rts. - Rights; NA - No Alternative; Cul. - Cultural; Sov. - Sovereignty; and Wto - World Trade Organization.

From this analysis of the central arguments of pro-tobacco groups, it can be

deduced that the key argument is economic. WHO has been considering these arguments in the effort to institutionalize global tobacco control. The WHO Expert Committee on Smoking Control Strategies in Developing Countries has long debunked this argument. The Committee asserts that

The Committee has carefully examined the case sometimes presented for tobacco cultivation and production and also the evidence presented by FAO on the role and scale of tobacco production worldwide. It concluded that while action is primarily on health grounds, even economic argument militate against tobacco production and cannot logically - and should not - be used to oppose implementation of smoking control programs (cited in WCTOH, 1983:2-3).

The consensus within the international public health community and empirical evidence has shown that overall; the costs of tobacco use outweigh the benefits (Jha and 
Chaloupka, 2000; WCTOH, 1983). Also, after considering the issue of infringement on individual liberties, the Expert Committee concluded that tobacco control policies do not infringe on any liberty other than that of the tobacco manufacturer to sell and promote an avoidable cause of diseases (WCTOH, 1983). The problem is how to reconcile these two conflicting concerns about tobacco. Thus, a key impediment to the implementation of the FCTC is more likely to be economic concerns and the issue will be how to surmount the economic concerns expressed in the submissions of these pro-tobacco groups at the FCTC public hearings.

\subsection{Transnational Tobacco Companies (TTCs)}

A key actor at the center of tobacco control politics is the tobacco industry. The tobacco industry consists of tobacco cultivation, processing, and manufacturing. It does not include wholesalers and retailers. However, the emphasis in this study is on manufactured tobacco. Since the discovery of tobacco, the industry has grown to such an extent that its wealth is far greater than many countries in the developing world. The tobacco industry has historically been a sporadic target of government regulations. Until recently, the industry has been able to resist attempts at governmental regulations. However, the discovery of nicotine in tobacco as an addictive substance, and the admission of the tobacco industry that promoted tobacco use even though it has been aware of the addictive nature of nicotine, has tarnished the image of the tobacco industry (Nathanson, 1999). As a result, the tobacco industry has also emerged as target of tobacco control activities and not just a normal commercial enterprise (Studlar, 2002; Nathanson, 1999). This is what scholars such as Studlar (2002) refer to as the 
denormalization of the tobacco industry. Tobacco control policies are not only geared toward the tobacco user but also the tobacco industry.

In the early phase of the spread and use of tobacco after its discovery in 1492, the tobacco industry was primarily an agricultural enterprise. Beginning with Europeans' cultivation of tobacco in Santo Domingo, Cuba in 1531, tobacco continued to spread across Europe and elsewhere and by 1600, the European style of tobacco cultivation had spread to Brazil. Tobacco farming spread to other continents and by 1894, Zimbabwe began tobacco farming. In 1915, bright leaf tobacco seeds and growing methods were first transported to China. The spread and innovation of tobacco farming continued to spread across the globe [See Table 3.4]. Agriculture has traditionally and historically remained the foundation of the tobacco industry. However, in recent times while output in the developed countries is declining due to tobacco regulations and cheaper prices in developing countries, that of the developing countries is on the upsurge (Sklair, 2002, 1998; Frey, 1997; Ravenholt, 1990).

The emergence of manufactured cigarette strengthened the tobacco industry. In 1860 the first manufactured cigarettes appeared. In 1864, the first American manufactured cigarette factory was opened. The invention of the Bonsack machine was the genesis of the emergence of "big" transnational tobacco companies. In addition, the invention of the cigar-rolling machine by Oscar Hammerstein in 1883 contributed to the expansion of the tobacco industry (Borio, 2001).

The invention of the Bonsack machine attracted aggressive tobacco entrepreneurs such as James Buchanan (“Buck”) Duke of the U.S and Philip Morris of England. In 1881 as Philip Morris went public, Duke entered the manufactured cigarette business. In 
1884, Duke bought two Bonsack machines, greatly increasing the production of manufactured cigarettes. Duke eventually founded the U.S. Tobacco Company, a conglomerate of the five leading American tobacco companies in 1889. In 1901 Duke went to England and bought the Ogden tobacco firm. This aggressive tactic attracted reaction in England. British companies came together to counter Duke's takeover, leading to the formation of Imperial Tobacco. However, in 1902 American and British tobacco companies came to an agreement: Imperial and American agreed to stay in their countries and united to form the British American Tobacco Company (BAT) to sell both companies' brand abroad. In the same year, Philip Morris set up a corporation in New York to sell its British brand. Still, by 1911, Duke’s American Tobacco Company controls 92 percent of world's tobacco business (Borio, 2001). However, U.S. Supreme Court ruled on May 29, 1911 dissolved Duke's trust as a monopoly and in violation of the Sherman Anti-Trust Act of 1980, leading to the emergence of American Tobacco Company, R.J. Reynolds, Liggett and Myers Tobacco Company, Lorillard, and British American Tobacco (Borio, 2001). The tobacco industry reached its peak in number of plants in 1914 [See Table 3.4 for date of establishment of key tobacco companies]. There were 24,000 cigarette factories in the U.S. alone (Borio, 2001).

The tobacco industry received strong governmental support, especially during the two World Wars. In 1917/1918, the U.S. entered World War I and it made cigarettes part of the rations for the military men. The result, according to Borio (2001), is that virtually an entire generation of men returned from the war addicted to cigarettes. Cigarette consumption doubled during the war (Ravenholt, 1990:221). World War I marks perhaps the first great expansion in at least cigarette use. Also, between 1939 and 1945 (World 
War II), Franklin D. Roosevelt, the President of the U.S., made tobacco a protected crop as part of the war efforts and they were included in soldiers' rations, almost doubling the rate of cigarette smoking (Ravenholt, 1990:221). Also, the U.S. government in particular, and other governments around the world subsidized the growth of tobacco. Governmental policies during the two World Wars and the activities of tobacco companies during the period contributed to expansion in tobacco use.

The entire history of the tobacco industry has been a history of mergers, takeovers, and expansion into other political and geographical regions ${ }^{17}$ (Sklair, 2002, 1998; Callard et al., 2001; Yach and Bettcher, 2000; Frey, 1997). For instance, in 2002 Imperial Tobacco of UK acquired Reemtsa of Germany to make it the fourth largest tobacco company in the world. Thus, it is argued that "Mega mergers and acquisition have dramatically changed the face of worldwide cigarette industry" (cited in Yach and Bettcher, 2000:207) Although Duke was more aggressive in the late ninetieth century, Philip Morris remained more aggressive throughout the twentieth century. In this respect, although the aggregate number of tobacco companies worldwide has declined, the industry has become wealthier and more extensive than before [See Table 3.7].

The tobacco industry adopted different strategies in the expansion of the business across the world. This began with the targeting of minors in the later nineteenth century, the targeting of women in the 1920s, and the targeting of developing countries since the 1960s. Advertising has been the strongest tool in the arsenal of the tobacco industry for the promotion of tobacco use. In 1919, Lorillard targeted women with its Helmar and Murad brands. In the 1920s Philip Morris' Marlboro was targeted at women. Until the

\footnotetext{
${ }^{17}$ International Union of Food, Agricultural, Hotel, Restaurant, Catering, Tobacco and Allied Workers' Associations (IUP) http://www3.who.int/whosis/fctc/submissions/F2990292.pdf (accessed 12/20/2004)
} 
1920s, women who smoked were deemed to have dubious morals. Other tobacco companies followed Philip Morris's lead. With the help of the Tobacco Institute Research Center (TIRC) established in 1958, and later renamed the Center for Tobacco Research (CTR), the tobacco industry pursued very aggressive advertising and research policies. However, as Nathanson (1999) points out, not until the discovery of nicotine as addictive tar as poisonous, and effects of secondhand smoke, the emphasis of tobacco control was on the individual user. With more conclusive evidence about nicotine and tar, the tobacco industry also became a target of tobacco control activities and policies (Studlar, 2002; Nathanson, 1999). This has even become more pronounced with the industry's own admission about addictiveness of tobacco use.

The Table 3.4 below shows the date of establishment of key tobacco companies. Others have absorbed some of these companies through outright purchase and mergers. Even in closed markets such as China where the state owns the tobacco company, others have recently been able to acquire shares in them. 
Table 3.4: Dates of Establishment of Some Key Tobacco Companies

\begin{tabular}{|c|c|c|}
\hline Tobacco Company & Activities & Year of Establishment \\
\hline Tabacalera & $\begin{array}{l}\text { Oldest tobacco company } \\
\text { was created in Spain }\end{array}$ & 1636 \\
\hline Miflin Marsh & $\begin{array}{l}\text { Begins Marsh Wheeling } \\
\text { Cigars in his Wheeling, } \\
\text { West Virginia, home (USA) }\end{array}$ & 1840 \\
\hline $\begin{array}{l}\text { Service d’Exploitation } \\
\text { Industrielle des Tabacs } \\
\text { (SEITA) Monopoly }\end{array}$ & $\begin{array}{l}\text { It began manufacture of } \\
\text { cigarettes in France }\end{array}$ & 1843 \\
\hline Philip Morris & $\begin{array}{l}\text { Opened a shop; sold hand- } \\
\text { rolled Turkish cigarettes in } \\
\text { London [it went public in } \\
1881 \text { ] }\end{array}$ & 1847 \\
\hline J.E. Liggett and Brother & $\begin{array}{l}\text { Established in T. Louis, } \\
\text { Missouri, by John Edward } \\
\text { Liggett in USA } \\
\text { [incorporated as Liggett and } \\
\text { Myers in 1885] }\end{array}$ & 1849 \\
\hline Philip Morris & $\begin{array}{l}\text { Began making his own } \\
\text { cigarette England }\end{array}$ & 1854 \\
\hline Gallaher & $\begin{array}{l}\text { Founded in Londonderry by } \\
\text { Tom Gallaher }\end{array}$ & 1857 \\
\hline $\begin{array}{l}\text { Indonesian Tobacco } \\
\text { Industry }\end{array}$ & $\begin{array}{l}\text { Dutch businessman Jacobus } \\
\text { Nienhuys attempt to rectify } \\
\text { the growth and production } \\
\text { of tobacco in Sumatra led to } \\
\text { its establishment }\end{array}$ & 1863 \\
\hline $\begin{array}{l}\text { R.J. Reynolds Tobacco } \\
\text { Company }\end{array}$ & $\begin{array}{l}\text { Richard Joshua Reynolds } \\
\text { founded the company } \\
\text { [incorporated in 1899] }\end{array}$ & 1875 \\
\hline America Tobacco Company & $\begin{array}{l}\text { James Buchanan Duke } \\
\text { made his tobacco business } \\
\text { national and formed a cartel } \\
\text { with } 5 \text { leading cigarette } \\
\text { firms in USA in } 1889 . \text { It } \\
\text { was break up in } 1911\end{array}$ & 1884 \\
\hline Brown \& Williamson & $\begin{array}{l}\text { Formed as partnership in } \\
\text { Winston-Salem, North } \\
\text { Carolina. It became a } \\
\text { company in } 1906\end{array}$ & 1894 \\
\hline $\begin{array}{l}\text { Korean Tobacco and } \\
\text { Ginseng (KTG) }\end{array}$ & $\begin{array}{l}\text { Founded as a state } \\
\text { monopoly }\end{array}$ & 1899 \\
\hline
\end{tabular}


Table 3.4 (Continued)

\begin{tabular}{|l|l|l|}
\hline Imperial Tobacco Company & $\begin{array}{l}\text { Incorporation of Imperial } \\
\text { Tobacco Company of Great } \\
\text { Britain and Ireland Ltd. }\end{array}$ & 1901 \\
\hline British American Company & $\begin{array}{l}\text { Imperial Tobacco (UK) and } \\
\text { American Tobacco } \\
\text { Company unite to form } \\
\text { joint venture }\end{array}$ & 1902 \\
\hline Souza Cruz & $\begin{array}{l}\text { Founded in Brazil but was } \\
\text { acquired by BAT in 1914 }\end{array}$ & 1903 \\
\hline $\begin{array}{l}\text { American-Chinese Tobacco } \\
\text { Company }\end{array}$ & $\begin{array}{l}\text { Formed with the purpose of } \\
\text { buying tobacco in the US } \\
\text { and selling it to China }\end{array}$ & 1918 \\
\hline $\begin{array}{l}\text { Thailand Tobacco } \\
\text { Monopoly }\end{array}$ & $\begin{array}{l}\text { Cigarette production is } \\
\text { made a state monopoly }\end{array}$ & 1943 \\
\hline $\begin{array}{l}\text { PT Hanjay Mandala (HM) } \\
\text { Sampoerna }\end{array}$ & Established in Indonesia & 1963 \\
\hline Pakistan Tobacco Board & Established & 1968 \\
\hline $\begin{array}{l}\text { The China National } \\
\text { Tobacco Corporation }\end{array}$ & $\begin{array}{l}\text { A state monopoly } \\
\text { established }\end{array}$ & $\begin{array}{l}\text { Shares began trading in } \\
\text { Paris and Madrid }\end{array}$ \\
\hline Altadis & 1999 \\
\hline Source Borio (2001) & & \\
\hline
\end{tabular}

\subsubsection{TTCs and the FCTC}

Beside the state monopolies, there are about 21 tobacco $\mathrm{MNCs}^{18}$ around the world (Weissman, 1998). However, about five MNCs dominate the international tobacco market. These companies control over 40 percent of global market share of tobacco trade [See Table 3.5]. In the U.S., Philip Morris controls about 50 percent of the market share [See Table 3.6]. As a whole, the tobacco industry has an annual turnover of over US\$400 billion, more than the GNP of almost any country in the developing world (Yach and Bettcher, 2000). These tobacco MNCs have extended their activities across the globe through the establishment of numerous subsidiaries in different countries, and they sell

\footnotetext{
${ }^{18}$ ITGA, http://www.tobaccoleaf.org; GLOBALink, http://www.GLOBALink.org [accessed 03/07/04]
} 
their products in different markets around the world [See Table 3.7]. The tables 3.5, 3.6, and 3.7 illustrate some salient information about the leading tobacco companies.

Table 3.5: Estimated Share of Global Market

\begin{tabular}{|l|c|}
\hline Company & $\begin{array}{l}\text { Percentage of Global } \\
\text { Market Share }\end{array}$ \\
\hline $\begin{array}{l}\text { Philip Morris } \\
\text { (a division of the Altria Group) }\end{array}$ & 16.4 \\
\hline BAT & 14.6 \\
\hline JTI & 7.2 \\
\hline Imperial Tobacco, UK) & 7 \\
\hline Source: & Altadis \\
\hline
\end{tabular}

Table 3.6: The Share of U.S. Market

\begin{tabular}{|l|l|}
\hline Company & Share \\
\hline Philip Morris Inc. & $50 \%$ \\
\hline R.J. Reynolds & $24 \%$ \\
\hline Brown and Williamson Tobacco Corporation & $13 \%$ \\
\hline Lorillard Tobacco Co. & $10 \%$ \\
\hline Liggett Group Inc. & $1 \%$ \\
\hline Others & $2 \%$ \\
\hline
\end{tabular}

Source: "Defendants in Florida Smokers’ Trial” Associated Press, July 14, 2000; Borio (2001);

http://www.tobacco.org/resources/history/Tobacco_History21.html

Table 3.7: Worldwide Activities of Leading Tobacco Companies

\begin{tabular}{l|l|c|}
\hline Company & Number of Markets & Number of Factories \\
\hline Philip Morris & $160+$ & $50+$ \\
\hline BAT & $180+$ & $81+$ \\
\hline JTI & $120+$ & $50+$ \\
\cline { 2 - 4 } Imperial Tobacco, UK & $130+$ & 33 \\
\hline
\end{tabular}

As one of the main targets of FCTC, the tobacco industry remains at the center of resistance of global attempts to curb tobacco use. The central argument of advocates for global tobacco control policies and the need for global collective action such as the Director General of WHO, Gro Harlem Brundtland, is the increasing globalization of the tobacco industry. For Callard et al. (2001) the tobacco epidemic is a problem of globalization. The industry has extended its activities around the world. In recent times, 
the industry has purposefully and consciously targeted medium and low-income countries as its market share declines in developed countries (Callard et al., 2001; Satcher, 2001; Frey, 1997; WCTOH, 1983). This has contributed to the rising trend of tobacco consumption in these countries (Akinbode, 2003; Jha and Chaloupka, 2000; Taylor et al., 2000).

The relevance of the tobacco industry to tobacco control lies in its attempts over the years to use its resources and political connection to deny the health hazards of smoking and efforts to undermine tobacco control policies domestically (Ling and Glantz, 2002), regionally (Ashraf, 2002; Neuman et al., 2002) and globally (Weissman, 1998). They question the scientific evidence on addiction and effects of tobacco. A 1999 letter from the chairman of BAT to the Director-General of WHO, for instance, maintained that tobacco was addictive only in the sense that chocolate was addictive (cited in Yach and Bettcher, 2000). However, such a claim contradicts the industry's internal documents (Yach and Bettcher, 2000). As a result, the WHO Expert Committee on Smoking Control Strategy in Developing Countries recommended "WHO should not engage in a dialogue with the international tobacco industry until the latter publicly accepts the scientific fact that smoking is "a major avoidable cause of death and disease”" (cited in WCTOH, 1983:4). The industry uses its own line of research to undermine tobacco research of WHO and others that reveal findings the industry deems as adverse to its interests. WHO has published a volume on the industry's attempt to undermine its global tobacco control activities (WHO Committee of Experts on Tobacco Industry 
Documents, 2000). Since "Operation Berkshire"19 in 1977 that resulted in the creation of the International Committee on Smoking Issues (ICOSI) and INFOTAB, the tobacco industry has coordinated their actions to retard tobacco control measures worldwide. Tobacco companies lobby politicians at all levels of governance. For example, they lobby the World Bank and develop agricultural lobbies such as the ITGA and the Zimbabwe Tobacco Association (ZTA) (Yach and Bettcher, 2000). For instance, in 1998 an INFOTAB document lists the following suggestions to board members in the pursuit of establishing an agricultural lobby:

- $\quad$ "We need to develop the agricultural lobby.

- We must ensure growers stick to politics and do not seek to use the global organization to gang on manufacturers.

- The nearest thing to a 'global' organization is the International Flue-Cured Tobacco Growers' Association. It is poorly run ... but it contains the core of a genuine 'ITGA' - with full geographical spread.

- $\quad$ ITGA might get fully accredited observer status at the FAO.

- $\quad$ INFOTAB should assist the formation of ITGA ... with initial funding of US400,000.

- ITGA would have the clout to combat idiotic crop substitution programs.

- ITGA could 'front' for our third world lobby activities at WHO” (cite in Yach and Bettcher, 2000:210).

They also infiltrate into the camps of anti-tobacco groups. For instance, they infiltrated into the organization of the World Conference on Tobacco and Health in Tokyo, Japan. The power of the tobacco industry has been a concern of many tobacco control

\footnotetext{
${ }^{19}$ This was found in a file called Operation Berkshire. It was a name the tobacco industry executives gave to a series of meetings held in the mid-1970s between the tobacco companies whereby they agreed to unite and fight against tobacco control policies worldwide.
} 
advocates. In effect, the tobacco industry has adversarial relations with WHO and other anti-tobacco groups.

In spite of the adversarial relations with WHO and other pro-tobacco control groups, the tobacco industry played a limited role in the negotiation of the FCTC. On May 27, 2000, the Director-General of WHO, Brundtland, called for a public hearing on the issues surrounding the FCTC (Ahmad, 2000). All interested parties (including the tobacco industry) were invited to participate in the hearing in Geneva, Switzerland (Ahmad, 2000). Some of the tobacco companies made submissions during the October 12-13, 2000 public hearings in Geneva, Switzerland. While some heeded to the call for participation, others decided to sit on the fence. Also, during the first INB session, a debate was held between representatives of the tobacco industry and tobacco control activists. Below is a list of tobacco companies that made submissions during the October 2000 FCTC public hearings.

\begin{tabular}{|c|c|}
\hline & TTCs \\
\hline & British American Tobacco \\
\hline & Imperial Tobacco Limited (ITL) \\
\hline & Japan Tobacco \\
\hline & $\begin{array}{l}\text { Phillip Morris International \& Philip } \\
\text { Morris USA }\end{array}$ \\
\hline & R.J. Reynolds Tobacco Company \\
\hline & Reemtsa Cigarettenfabriken GmbH \\
\hline
\end{tabular}

From a review of the submissions made by tobacco companies, although there is no argument that profit dictates the operation of the tobacco industry, they argue that employment and revenue generation underlie their operations. Thus, in spite of the 
consensus within the tobacco industry is that tobacco is a controversial product, they argue that it is a legal product and the choice should be left to the adult individual. Also, they argue that the global effort at tobacco control undermines the sovereignty and autonomy of states. From their perspective, tobacco is a legal commodity and its regulation should be left to the various states. In addition, they expressed the concern that the FCTC is an affront to international trade rules. Thus, they see the FCTC as a challenge to the survival of the industry.

The tobacco companies participated in only the public hearings and debates. They did not have official negotiating capacity throughout the WG and the INB negotiation processes. It is of little wonder that some companies within the tobacco industry still complained that they were not given much opportunity to contribute to the tobacco control debate during the FCTC negotiation process. For instance, BAT complained in its submission (WHO, 2000c) at the intention of WHO to ignore the tobacco companies and their allies during the FCTC negotiation process. Similarly, Philip Morris complained in its submission (WHO, 2000c) that

...we know that, in the past, Philip Morris and WHO have at times had an adversarial relationship. We are convinced that we should not allow the past to lock us into an endless cycle of contentiousness and acrimony, or stand in the way of making progress now on issues that are legitimately of concern to governments and consumers around the world.

In general, the tobacco companies accepted in their submissions that tobacco is a “controversial” product. They do not explicitly deny that there is a link between tobacco use and health. For instance, Japan Tobacco pointed out in its submission (WHO, 2000c) that 
We believe in our brands. We believe in our product. Yet it is a controversial product. People smoke for pleasure, but there are risks that come with that pleasure. These risks distinguish tobacco from most consumer goods and they place upon us a real burden of responsibility. It's a responsibility we expect to be held accountable for, together with governments and the rest of society.

A review of company stands on the health effects of tobacco use from their Internet websites reaffirmed their position during the public hearings. Since the 1998 Master Settlement Agreement made the tobacco industry’s internal documents public, some tobacco companies had admitted that their products could have harmful effects. For instance, BAT acknowledges “[a]long with the pleasures of cigarette smoking come real risks of serious diseases such as lung cancer, respiratory and heart disease. We also recognize that, for many people, it is difficult to quit smoking." ${ }^{20}$ In a commentary on the 'World No-Tobacco Day,' the British Broadcasting Corporation (BBC) contends that pro-tobacco groups' arguments have been weakened in the face of accumulating scientific evidence on the hazards of smoking (BBC, March 9, 2004; Walker, 2004). The influence of the tobacco industry on the recent creation of institutions for global tobacco control is limited, given what has been referred to as "admission of guilt" after the 1998 Master Settlement Agreement in the US. The industry unequivocally admitted that tobacco is harmful, ending many years of efforts at undermining such scientific evidence.

Finally, some of the companies in the tobacco industry support the FCTC. Most importantly, the largest tobacco company, Philip Morris, declared support for the FCTC.

\footnotetext{
${ }^{20}$ Dr. Chris Proctor, Head of Science and Regulation, BAT http://www.bat.com/oneweb/sites/uk 3mnfen.nsf/vwPagesWebLive/ED9E7B3E9270D92880256BF4000 3317F?opendocument\&DTC=20040325 [accessed 03/25/04]
} 
David Greenberg, Philip Morris International's senior vice president for corporate affairs said "[t]he company is ready to embrace regulation around the world whether by international institutions and/or at the national level” (Weissman, 2001:6). It must, however, be noted that other companies have expressed misgivings about FCTC. Although Philip Morris International, now a division of Altria Group, public support for FCTC may be suspicious, its support for FCTC is important for global tobacco control. This is because such support tacitly acknowledges the hazards of tobacco use hence the need for regulations to curb the habit. Still, the debate over a global approach to tobacco control continues within the industry. From their submissions made at the FCTC public hearings, many tobacco companies prefer a national approach to a global approach to tobacco control. The strength of the tobacco industry in terms of wealth and political influence in a country will be an obstacle that must be surmounted in the course of implementation of the FCTC.

\subsection{Tobacco Policy Entrepreneurs (TPEs) and Advocates/Activists}

Historically, individuals either in official positions, leaders of organizations, or as ordinary citizens have been involved in the struggle to curb tobacco use. The most prominent person to come out strongly against the use of tobacco is King James I of England. In 1604, James I of England wrote the treatise, "A Counterblaste to Tobacco" in which he pointed out that "Smoking is a custom loathsome to the eye, hateful to the nose, harmful to the brain, dangerous to the lungs, and in the black, stinking fume thereof nearest resembling the horrible Stygian smoke of the pit that is bottomless" (quoted in Borio, 2001). In an attempt to halt tobacco use, James I increased tobacco tax by about 
4,000 percent in the same year. Also, in 1699 Louis XIV and his physician, Fagon, opposed smoking (Borio, 2001). The expression of skepticism and opposition to tobacco use by these individuals even in the earliest phase of the use and spread of tobacco is an indication of the involvement of individuals in the struggle against tobacco use.

The list of known individuals who have been involved in the struggle against tobacco use across the globe is large. However, some of the documented ones who used religion as a tool to preach against tobacco use include Ellen Gould Harmon, the founder of the Seventh Day Adventist Church, 1848, and Evangelist Billy Sunday, 1919 who declared that "prohibition is won; now for tobacco" (Borio, 2001). Individuals such as Lucy Payne Gaston took the initiative to form anti-tobacco groups. In 1899 Lucy Payne Gaston founded the Chicago Anti-Cigarette League, which later became Anti-Cigarette League of the World in 1919. Also, others use their influential positions to call for the halt in the use of tobacco. For instance, Henry Ford published anti-cigarette pamphlet titled "The Case against the Little White Slaver"; and in 1927 Eduard Haas, an Austrian candy executive, invented Pez for those who wanted to stop smoking. In effect, even before the authoritative evidence that tobacco is harmful to human beings in the early 1960s, some individuals had spoken against the habit of tobacco use (Borio, 2001).

In spite of the fact that certain individuals have historically been vocal against tobacco use, the two official publications of the early 1960s provided people not only with the scientific evidence but also with the political backing to come out strongly against tobacco use. Thus, in 1969 Ralph Nader asked the Federal Aviation Administration of the U.S. to ban smoking on airlines. People like Clara Gouin, 1970, Helen Story, 1971, and David Wilson, 1972, in the U.S. took advantage of the political 
mood to establish anti-tobacco groups. In recent times, Stan Glantz and the "tobacco warhorses” in San Francisco and elsewhere in the U.S. have been leading the fight against tobacco use and the tobacco industry in the U.S. in particular, and worldwide (Wolfson, 2001). Thus, within different political and geographical jurisdictions, individual initiatives have been integral part of the tobacco control movement. Individual initiatives also played important role as tobacco control evolves to become an international institution through the FCTC.

\subsubsection{TPEs and Advocates/Activists and the FCTC}

Certain names appear readily in any discussion, analysis, or commentary on the adoption of the FCTC. The names include Allyn Taylor, ${ }^{21}$ Ruth Roemer, ${ }^{22}$ and Judith Mackay. ${ }^{23}$ Some commentators point out that these individuals were the first to conceive the idea of a global convention on tobacco control. The President of American Public Health Association (APHA), Jay Glasser (2003), points out that “The idea of an international convention for tobacco control was born in Los Angeles in July 1993 when Ruth Roemer, ..., past president of APHA; Milton Roemer, ... also an APHA past president; and Allyn Taylor, ..., had lunch together.” Mackay (2003) also states

On 26 October 1993, Ruth Roemer invited me for an unforgettable breakfast during a conference in San Francisco. Had WHO ever considered a convention of tobacco? She asked me. I replied that WHO had meetings all the time - some might say too many! Ruth patiently explained that she meant a UN-style convention and asked me to convey the idea to WHO.

Both Glasser and Mackay acknowledge the value of Allyn Taylor’s 1992 article in American Journal of Law and Medicine calling upon WHO to use legal mechanisms to

\footnotetext{
${ }^{21}$ Health Policy Adviser, World Health Organization; Adjunct Professor, University of Maryland School of Law

${ }^{22}$ Adjunct Professor Emeritus University of California, Los Angeles School of Public Health Department of Health Services
} 
attain its goal of "Health for All by the Year 2000" in the emergence of the FCTC. Also, Holzman (2001) asserts "the idea of FCTC came from a 1992 Article ... in the American Journal of Law and Medicine in which author Allyn L. Taylor ... pointed out that the WHO had within its constitution a theretofore unused right to develop international treaties.” Subsequently, Ruth Roemer's suggestion of the need for an international convention to combat the global tobacco epidemic was adopted as a key resolution at the Ninth WCTOH in Paris, France. Her suggestion laid the foundation for preparation toward the institutionalization of tobacco control at the global level. Although WHO has been concerned with tobacco related issues since 1970, the meeting between these individuals is deemed as the genesis of the FCTC. Ruth Roemer and Allyn Taylor prepared a background document for WHO on the feasibility of an international convention on tobacco control. The document formally directed WHO towards the concept of the FCTC and related protocols (Mackay, 2003).

These individuals worked assiduously to ensure the emergence of the FCTC. Thus between 1993 and 2003 Allyn Taylor and Judith Mackay either solely or with others published articles and wrote commentaries on tobacco control as well as on the issue of global governance in international public health. The 1992 Taylor article, highlighting the constitutional powers of WHO to establish a convention, served as one of the basis for the FCTC. For instance, in a special issue of Bulletin of the World Health Organization, 2002, edited by Allyn Taylor and Douglas Bettcher, ${ }^{24}$ contributors wrote on different issues in "International Law and Public Health.” Different scholars considered the contribution of WHO in the codification and implementation of international law. In

\footnotetext{
${ }^{23}$ The director of the Asian Consultancy on Tobacco Control (ACTC) in Hong Kong
} 
essence, they were and are advocates for the use of legal instruments by WHO to accomplish the goal of global tobacco control. Thus, in terms of agenda setting, these individuals were policy entrepreneurs who helped to push the issue of tobacco control onto the global institutional agenda.

In spite of the fact that the idea of a UN-style convention on tobacco control was conceived in 1993, the idea for an international instrument for tobacco control was initiated in May 1995 by the $48^{\text {th }}$ WHA (WHO, 2003). Subsequently, the $49^{\text {th }}$ World Health Assembly adopted resolution WHA49.17, requesting the Director General to initiate the development of a WHO Framework Convention on Tobacco Control, launching WHO’s first treaty-making enterprise. However, it was not until 1999, a year after the WHO Director General Gro Harlem Brundtland made global tobacco control a priority of WHO, that work on the WHO FCTC began (Mackay, 2003). In this respect, Dr. Gro Harlem Brundtland is not just a bureaucrat of WHO but also a policy entrepreneur. She is one of the main reasons why the issues of global tobacco control that had been within the international systemic agenda for over three decades quickly moved onto the institutional agenda, culminating into a global convention.

Dr. Brundtland's assumption of WHO's leadership in 1998 opened the window for other advocates or activists of tobacco control because she made tobacco control one of the public health priorities of WHO. In addition, many bureaucrats of WHO have worked to promote institutionalization of global tobacco control. For instance Derek Yach, WHO's executive director of noncommunicable disease and mental health and the project director of TFI, falls into such category. Other WHO bureaucrats such as Douglas

${ }^{24}$ Coordinator, Framework Convention on Tobacco Control, World Health Organization, Geneva, 
Bettcher and regional WHO directors such as Judith Mackay of Hong Kong have played lead roles in the promotion of the FCTC around the world.

Also, individuals who were hitherto tobacco control policy entrepreneurs or advocates at the domestic level added an international focus to their concerns. Although the list of such people is large, notable among them are Stan Glantz of USA, Clive Bates of ASH-UK, and Oluwafemi Akinbode of Nigeria’s Environmental Rights Association. Some of these individual advocates or "tobacco war-horses" made submissions during the FCTC public hearings. Their arguments for the support of the FCTC, however, are not different from WHO's. The core argument is on the health consequences of tobacco use. For such people, you cannot sacrifice public health cost of tobacco use for any reason. The FCTC is the result of efforts of both inside and outside initiators and advocates of a global convention of tobacco control. Individual advocates and policy entrepreneurs in the area of tobacco control between 1993 and 2003 contributed to adoption of the FCTC. GlOBALink identifies individuals working either solely or in concert with other individuals, organizations, and institutions at various levels within the international system to see to the adoption of global tobacco control.

The last set of policy entrepreneur and advocates is policymakers and politicians. From Senator Robert Kennedy of the U.S. at First WCTOH in 1967 through Berit A (Member of Parliament of the Norwegian government, 1975) Hedda Lindahl of Sweden (Minister of Health, 1979), George Young of United Kingdom (Health Minister, 1979), Joseph Califano of the U.S. (under Secretary of State in Jimmy Carter's administration), Simone Veil of France (Minister of Social Welfare, 1994) and currently Senator John

Switzerland. 
McCain of Arizona, USA and Congressman Henry Waxman of California, USA individual policymakers and politicians have been involved in the promotion of tobacco control domestically and globally. For instance, the role of Congressman Waxman in persuading the W. Bush administration of the U.S. to support the FCTC has been well documented (Weissman, 2001). Congressman Waxman's case illustrates how these individuals worked with their governments to ensure the institutionalization of tobacco control at the global level.

Policy entrepreneurs and advocates were influential in the emergence of the FCTC. Just like Henry Dunant and the ICRC, these individuals conceived the idea of a global convention to curb tobacco epidemic by working closely with institutions responsible for the issue-area, states, and the civil society organizations. Others championed the course of global tobacco control in their respective countries and influenced their governments to support the FCTC. From this evidence, any analysis of the emergence of the FCTC that does not acknowledge the influence of these individual actors will be limited. Some of these individuals were not just academics or commentators or politicians but also they were active participants in the negotiation of the FCTC. For example, Tom Novotny of University of California in San Francisco led the U.S. delegation to two sessions of the INB meetings. Similarly, Byron Rogers of the Tobacco Control Program of Canada was a member of the Canadian delegation to some of the INB sessions. Thus, the availability of tobacco control policy entrepreneurs and individual advocates facilitated the adoption of the FCTC. 


\subsection{Summary:}

The underlying assumption of this chapter is that the activities of anti-tobacco transnational actors through the mobilization of similar groups around the world to support a global collective effort to curb tobacco use and the education of states about tobacco use and tobacco control, as well as the activities of the tobacco industry around the world, acted as a catalyst for the adoption of the FCTC. The key strategy for the mobilization of support for the FCTC is the formation of alliances and coalitions. This confirms the vitality of the ACF and the TANs in understanding the adoption of the FCTC.

The chapter explores this issue using descriptive and content analysis. From the analysis one of the main reason for the adoption of the FCTC is the worldwide extension of the activities of the transnational companies. The activities of these companies around the world are seen as harmful to public health. The emphasis for the support of the FCTC is public health in spite of the economic, social, and environmental consequences of tobacco use. On the other hand, opposition to the FCTC by pro-tobacco groups is centered on economic concerns. Still, the activities of transnational actors, particularly anti-tobacco advocacy groups and individuals were instrumental in the adoption of the FCTC. After all, individuals initiated the idea of an international convention on tobacco. However, underlying all these processes is familiarity with knowledge, information, and ideas of tobacco use and tobacco control. Thus, although anti-tobacco groups did not have voting rights in the WHA, they were able to educate some states delegates about tobacco use and tobacco control. In the end, familiarity with knowledge about tobacco use and tobacco control proved useful as the FCTC was ultimately adopted unanimously. 
In essence, evidence here supports the liberal-constructivist perspective of the emergence of an international regime in tobacco control. 


\section{Chapter 4}

\section{Global Governance in Tobacco Control}

\subsection{Introduction:}

Although authoritative evidence linking tobacco use and health emerged in the early 1960s, it took about four decades before tobacco control evolved as a global regime. This is consistent with Rosenau's $(1990 ; 1997: 152)$ assertion that in order to acquire legitimacy and support, issues of global governance are more likely to evolve out of a lengthy bottom-up rather than top-down process. This chapter uses the liberalconstructivist approach to analyze the FCTC as form of global governance, an idea consistent with Collin et al.’s (2002) global health governance. Similar to Taylor (1992), the core argument is that the existence of an international institution (WHO) with legitimate authority in an issue area (public health) within the global community can facilitate the emergence of a global regime. The chapter uses descriptive analysis to explore how the activities of WHO and member states of WHO, after familiarity with knowledge, information, and ideas about tobacco use and tobacco control led to the creation of a form of governance on tobacco control at the global level.

The issues discussed and analyzed in this chapter include the conception of global governance under the liberal-constructivist perspective, the contribution of international trade rules under General Agreement on Trade and Tariffs (GATT) and the World Trade Organization (WTO) to the emergence of tobacco control as a global phenomenon, and the contribution of WHO and states to the adoption of the FCTC. In effect, the central argument in this chapter is that in addition to the activities of transnational actors 
(individuals, groups, firms) and knowledge, information and ideas on an issue, one needs states and intergovernmental institutions with legitimate authority in an issue-area are necessary to facilitate the emergence of a system of global governance such as the FCTC.

\subsection{Conceptualization of Global Governance}

While the Commission on Global Governance (1995) categorically pointed out that global governance "does not imply world government or federalism," Rosenau (1997) and Rosenau and Czempiel (1992) refer to the phenomenon as "governance without government." Governance occurs at different levels - national, regional and global - within the international system (Krahmann, 2003). Governance connotes a complex set of structures and processes in both public and private arenas (Weiss, 2000). It refers to structures through which issues that are global and transnational in nature are collectively handled. Attempts to solve transnational issues that emerge from the state level may compel states to institutionalize the issue area at the global level. Decisions taken at the global level then seep down to the different political and geographical jurisdictions in a form of governance.

Although Krahmann (2003) argues that governance can occur at different levels within the international system, this study is particularly interested in governance at the global level. Global governance is conceived as rules, norms, and institutions that govern public and private behavior across national boundaries (Edwards, 2000). It is the sum of regulatory policies and mechanisms that guide the interaction of economies and societies (Krahmann, 2003). It implies an absence of central authority and the need for collaboration or cooperation among governments and others who seek to encourage 
common practices and goals in addressing global issues (Krahmann, 2003; Gordenker and Weiss, 1996; Commission on Global Governance, 1995; Young, 1994). In many cases, it refers to collective actions to establish international institutions and norms to cope with the causes and consequences of adverse supranational, transnational, or national problems (Vayrynen, 1999, Gordenker and Weiss, 1996).

Global governance constitutes the rules and norms that seek to encourage certain 'best practices’ and prohibit others within the global arena. Global governance suggests regulatory policies that guide interaction among economies and societies. This suggests that the FCTC falls under the phenomenon conceived as global governance. The governance in this case is FCTC, a regime on tobacco control. The principles under the FCTC seek to regulate global tobacco use and production, combat marketing and other activities of the tobacco industry, and discourage the export of the tobacco epidemic to medium and low income countries hence the FCTC is deemed as a global regulatory regime (Corrao, 2000, Nadelman, 1990; Studlar, 2002; Taylor, 1996).

Global governance is characterized by the need for greater collaboration among governments and nongovernmental actors as the result of states being faced with new and growing demands on the one hand and shrinking resources on the other (Krahmann, 2003; Gordenker and Weiss, 1996; Young, 1994). As Yach and Bettcher (2000) and others point out, countries cannot handle the tobacco issue alone. For instance, no country can combat the issue of cross-border tobacco smuggling alone. Particularly, low-income countries cannot counteract the activities of a wealthy industry such as the transnational tobacco industry (Frey, 1997; Sklair, 2002, 1998). The actors in this form of global governance go beyond states to include NGOs, individual policy entrepreneurs, MNCs 
(TTCs) and among others. The actors involved in tobacco control governance include the 192 member states of the World Health Organization (WHO), WHO itself, advocacy groups, individuals (policy entrepreneurs) and the tobacco industry. In essence, actors in tobacco control governance could be found from the local/community level to the global level.

Some scholars have attempted to address global governance in some public health issues (Collin et al., 2002). They claim that global health features are directly or indirectly associated with transnational economic, social, and technological changes taking place in the world (Taylor 2002; Taylor et al 2003; Yach and Bettcher1998; Yach 2001; Collin et al. 2002; Brundtland 2003). The boundaries of countries in the world are becoming more permeable. It is very difficult for states to insulate themselves from certain health issues such as the tobacco epidemic. Given the transnational nature of such issues, they are better dealt with through a system of governance that are global in scope.

The tobacco epidemic involves the aggregate number of tobacco users around the globe, the number of people who die annually from tobacco use, and estimated annual number of deaths from tobacco-related diseases if the current trend continues unabated. The tobacco epidemic has been deemed to be a global issue (Taylor et al., 2003). The FCTC as a global regime is an attempt to combat an emerging global problem through bans, taxations, reduction in smuggling, and subsidies for alternative sources of livelihood for people dependent on tobacco cultivation. This is an attempt to intervene in free trade in tobacco that has been guaranteed under the international the trade regime through the World Trade Organization (WTO), the primary international institution governing global trade. An estimated 90 percent of international trade takes place under 
WTO rules (Dunoff, 1994). The concern over free trade is one of the contentious issues in tobacco control in general, and during the negotiation of the FCTC. In 1994, the existing trade regime since 1947 - General Agreement on Trade and Tariffs (GATT) metamorphosed to become the WTO after the conclusion of the Uruguay Round. Tobacco is an issue that first emerged under the Uruguay Round of talks under GATT. Due to this, the tobacco trade is subject to free trade rules under WTO. Thus, this chapter links the Uruguay Round (1986-1994) of the GATT that liberalized agricultural products (including tobacco) and FCTC that seeks to regulate tobacco use in comprehending the formation of the FCTC.

\subsection{From Uruguay Round (Liberalization) to FCTC (Regulation): Global Governance in Tobacco Control}

The general trend of international trade in tobacco is that the percentage of cultivated tobacco that is exported tripled between 1975 and 1995; tobacco trade has increased significantly since 1995; and aggregate tobacco consumption at the global level is on the rise (Taylor et al. 2000; Frey, 1997; Ravenholt, 1990). This trend is attributed to trade liberalization (Callard et al., 2001; Taylor et al. 2000). The Uruguay Round, launched in Punta del Este, Uruguay, in 1986 was termed the most ambitious and important trade negotiation since creation of GATT in 1947 (Ostry, 1990). This is because agriculture, which remained virtually outside GATT discipline for 40 years throughout seven negotiating rounds at the insistence of the United States, became a subject for negotiation (McMichael, 1998; Bhagwati, 1991; Golt, 1988). The efforts at liberalizing agriculture at the Uruguay Round resulted in the liberalization of the tobacco 
trade as well. As an agricultural product, the liberalization of agriculture by the Uruguay Round facilitated the treatment of tobacco as an international commodity subject to the rules of the international trade regime.

Subsequently, the WTO agreements significantly expanded global trade in tobacco by mandating sizable reductions in tariff and non-tariff barriers to trade in tobacco (Chaloupka and Corbett, 1998; Taylor et al. 2000). Such trade agreements encourage the penetration of new markets by tobacco multinationals (Yach and Bettcher, 2000). This resulted in market expansion, brand switching, and traditionally nonsmoking women being disproportionately attracted to Western brands (Campaign for TobaccoFree Kids, 2001:7). In 1990, rejecting contentions over public health, the GATT Council ruled in a dispute between the U.S. and Thailand over its virtual ban on cigarette imports that the government of Thailand's policy was against international trade agreements and that the Thai government should open its market to foreign producers (GATT, 1990; Chaloupka and Nair, 2000). Moreover, the European Union and the U.S. were called upon to remove tariffs on imported tobacco products (Taylor et al., 2000; USDA, 1997). This is evidence in support of how trade liberalization under the international trade regime (GATT/WTO) has facilitated global trade in tobacco.

In some respects, tobacco control policies are deemed as contravening free trade principles. In order to avoid this contradiction, participants at the second WG meeting of FCTC were hesitant to endorse a ban on tobacco subsidies (A/FCTC/WG2/5, p.7). However, Article XX of GATT (1994), specifically section (b) gives room for regulations on grounds of public health. The GATT Council in the Thai case ruled that tobacco control policies do not violate GATT principles as long as they are equally applied to 
both domestic and foreign commodities (GATT, 1990; Taylor et al., 2000). The interpretation of the Article XX and the GATT Council's decision is still a subject of debate among scholars of international jurisprudence. However, the point of the ruling is that public health rules and regulations per se are acceptable under the international trade regime as long as they are not discriminatory (Taylor et al., 2000). The Thai government was required to eliminate restrictions on imported tobacco because it was deemed discriminatory. This suggests that as long as public health rules are not used as protective measures, they are consistent with GATT/WTO rules.

Trade liberalization exacerbated existing concerns about globalization of the tobacco industry and the export of the tobacco epidemic to developing countries. This was especially true after the worldwide publicity incurred by the proposed National Settlement (1997), which led to the eventual Master Settlement Agreement (MSA) (1998) in the United States, and the inability of individual countries to handle problems such as cross border smuggling of tobacco products. Originally the National Settlement was labeled the "Global Settlement," which incurred criticism that it only covered the U.S. Although tobacco companies had been extending their activities into developing countries before the MSA, empirical studies on the effect of the MSA illustrate that it has increased the export of the tobacco epidemic to medium and low income (Weisman, 1998; Frey, 1997). In the face of bans, regulations, and obsolete or declining markets in developed countries, medium and low-income countries have become the target of the tobacco industry (Sklair, 2002, 1998; Satcher, 2001; Frey, 1997). However, many of these countries do not have the ability to assess and manage the risks associated with 
hazardous exports, the export practices of the tobacco industry contribute to the health risks of such countries (Frey, 1997).

Also, the World Bank (1999) and Taylor et al. (2000) provide empirical evidence on the impact of trade liberalization on tobacco consumption. International trade agreements have liberalized global trade in many goods and services (including cigarettes) (World Bank, 1999; Taylor et al., 2000). The removal of trade barriers tends to introduce greater competition that results in lower prices, greater advertising and promotion, and other activities that stimulate demand (World Bank, 1999; Taylor et al., 2000). It leads to increased consumption in the short run and public health problems in the long run (Taylor et al., 200). The World Bank (1999) illustrates this point with a study that concludes that in four Asian economies that opened their markets in response to U.S. trade pressure during the 1980s - Japan, South Korea, Taiwan, and Thailand consumption of cigarettes per person was almost ten percent higher in 1991 than it would have been if these markets had remained closed. Furthermore, econometric models developed to analyze the impact of trade liberalization on tobacco consumption conclude that it contributed significantly to increases in cigarette consumption, particularly in the medium and low- income countries (Chaloupka and Nair, 2000; Taylor et al., 2000; Bettcher et al., 2000; Frey, 1997).

Finally, privatization, a phenomenon associated with trade liberalization, leads to increases in tobacco consumption (Sato et al., 2000). Privatization of state-owned tobacco monopolies usually lead to efficiency in tobacco production and the use of more aggressive strategies, leading to increases in tobacco consumption. For example, Sato et al. (2000) show that privatization of Japanese tobacco products increased the rate of 
prevalence among youth and women. The impact of increased cigarette consumption as a result of liberalization is stronger in developing countries than developed countries (Taylor et al., 2000; Bettcher et al., 2000; Frey, 1997). These are areas where many people generally have lower knowledge about the consequences of tobacco use and larger markets for tobacco; hence the ability of tobacco companies to spread the habit of tobacco use.

This concern of increased global tobacco consumption, particularly in medium and low-income countries contributed to the adoption of the FCTC (Collin et al. 2002; Taylor, 2002; Taylor et al., 2003; Yach and Bettcher, 2000). The per capita consumption of cigarettes goes up after trade liberalization (Taylor et al., 2000). Global governance in tobacco control seeks to regulate worldwide tobacco consumption and to combat the increasing trend of tobacco-related deaths and disease. Thus, Yach and Bettcher (2000:207) argue "the fact that opening of markets and the process of globalization has been linked to increased health risk supports the need for a stronger national regulatory environment for tobacco control and harmonization of national policies between countries,” an approach permissible under the 1990 GATT Panel Report in the Thai case. In effect, the Uruguay Round liberalized tobacco, but the FCTC seeks to regulate its use. Unlike the GATT and WTO, the FCTC is an international institution governing the use of a specific commodity, tobacco. Whereas the WTO is an international institution governing international trade including tobacco trade, the FCTC is an international institution that regulates tobacco use. Thus, the FCTC is a form of global governance in tobacco control. 


\subsection{Models of Global Governance}

There are different approaches to examination of global governance. Young (1999), for instance, identifies intergovernmentalism such as the UN System and regimes (Krasner, 1983). The last falls under the issue of global governance. Thus, we have statecentric - “statist” where governance calls primarily for the management of failures and their consequences on interstate relations (Vayrynen, 1999; Young, 1999; Rosenau, 1990) and the issue-specific - “poststatist” approaches to global governance (Young, 1999). A third variant of global governance is cosmopolitanism that is about political organization in which citizens, wherever they are located in the world, have a voice, input and political representation in international affairs, in parallel with and independent of their own government (Held, 2004 and 1995; Archibugi and Held; 1995). In effect, approaches to global governance go beyond the Westphalian perspective of international relations to include transnational actors such as IGOs, NGOs, MNCs, and individuals. However, the emphasis here is on issue-specific ("poststatist”) approach to global governance.

\section{A Post-Statist Model: A Liberal-constructivist Perspective}

The liberal-constructivist perspective assumes that knowledge, norms, and principles may originate from the local and state levels and through complex processes involving interaction among multiple actors over time, spread through the international system, contributing to transformational shifts in perception of national identity, international agendas, and national interests that foster cooperation at the global level. These complex interactions provide knowledge about the hazards of tobacco use, tobacco 
control, activities of the tobacco industry around the globe, and "best practices" in curbing tobacco use. It brings actors around the world together to embark on a collective action to combat a global problem. Governance occurs through a loosely tied network of multiple actors, states, functional agencies, and non-state actors who interact frequently (Haas, 2002; Keohane and Nye, 2001; Held et al., 2001). Thus, the liberal-constructivist idea contends that global governance in tobacco emerged as a result of activities of domestic and transnational societal actors, WHO, and the spread of knowledge about tobacco, tobacco use, and the tobacco industry.

The emphasis is not just on the interaction of states but also on interaction between advocacy groups and states through WHO structures such as Tobacco Free Initiative (TFI) and international venues such as the "World No Smoking Day," international tobacco conferences (WCTOH and International Conference on Illicit Tobacco Trade - ICITT). Thus, this work argues that interdependence and globalization of tobacco enhanced by the GATT Uruguay Round (1986-1994) resulted in increase in tobacco production and consumption (Taylor et al., 2000, Yach and Bettcher, 2000). It also facilitated the penetration of new markets around the world by the tobacco industry, particularly medium and low-income countries (Taylor et al., 2000; Yach and Bettcher, 2000; Frey, 1997). As Yach and Bettcher (2000:207) argue, "market liberalization and penetration has been linked to greater risk of increased tobacco consumption, especially in low and medium income countries." However, the spread of scientific knowledge about the hazards of tobacco use and effectiveness of tobacco control policies within the international system helped states to define their interests and identities, facilitating cooperation at the global level. The FCTC as a form of global governance emerged as 
states and other transnational actors became familiar with the hazards of tobacco use and the global tobacco epidemic.

Growing interdependence and globalization present both dangers and opportunities for global governance (Desai; 1995). They open arenas of governance within the international society through continued interaction and interconnectedness among actors across national boundaries. Rapid technological advancement has increased the volume and intensity with which those interested in tobacco control at the global level interact. For instance, GLOBALink and other Internet networks connect the tobacco control community around the world. They provide current information about tobacco control for advocates as well as provide for a through for which tobacco control advocates everywhere in the world easily interact. Thus, Yach and Bettcher (2000) point out that since the Washington D.C. based Advocacy Institute's creation of GLOBALink in 1992, it has demonstrated the power of modern information technologies to close the gap between global and local concerns. Advocacy groups worldwide are informed of tobacco control programs, the tobacco industry activities, among others.

The rise of global governance arrangements seems to have been fostered in part by the processes of globalization and in part by national governments themselves through their adoption of liberal ideas that have encouraged greater use of private actors (Krahmann, 2003; Mittelman, 1996). "It is more likely that norms and identities associated with global governance are responses to crisis in the international economy, polity, and environment... institutions of global governance are responses to real and perceived needs of actors in a larger contest” (Vayrynen, 1999; Bryant, 2003; Yach, 2001). The problem in this case is global increase in tobacco consumption and related 
diseases and deaths as a result of the extension of marketing activities of the tobacco industry around the globe (Sklair, 2002, 1998; Yach and Bettcher, 2000; Frey, 1997). Yach and Bettcher (2000) argue, "the transnationalization of marketing and promotion of harmful commodities, such as tobacco, is one important component of globalized public health threats" (p.206). The world's tobacco consumption in developing countries increased from 61 percent in 1986 to 71 percent in 2000 (Yach and Bettcher, 2000). The globalization of public health suggests that policies to combat such an epidemic cannot be handled individually (Taylor, 2002; Taylor et al. 2003; Yach and Bettcher, 2000; Yach and Bettcher, 1998). An important example for such views is the globalization of public health issues through the struggle against HIV/AIDS (Barnett and Whiteside, 2002; Dollar, 2001). For Barnett and Whiteside (2002); AIDS is a good example of an epidemic of globalization. Yet, public health scholars contend that the globalization of tobacco related disease and deaths as a result of extended activities of the tobacco industry throughout the nooks and crannies of the globe is one of the rationales for the FCTC (Collins et al., 2002; Mackay, 2003; Taylor et al. 2003; Taylor et al., 2000; Taylor, 2002; Yach and Bettcher, 2001; Yach and Bettcher, 1998). The tobacco epidemic is considered trans-boundary in scope and that no country can single-handedly solve it. It requires concerted transnational effort through a governance system hence the emergence of global governance in tobacco control (FCTC). 


\subsection{FCTC as a Form of Global Governance}

\subsubsection{Role of the State}

The issue of cooperation is one of the central concerns of liberals. For them, cooperation through collective action is easier in "low politics" issues. Although International Political Economy (IPE) scholars may argue that in many cases states have to respond to both systemic and domestic forces (Gourevitch, 1978; Rogowski, 1989, Putnam, 1988 and 1993; Evans et al., 1993) and that many important actors have emerged on the international stage (Moravcsik, 1997; Keohane, 1989; Keohane and Nye, 1977 and 1972), the state still plays important role in world affairs. For instance, in spite of the forces that may encourage or convince a state to pursue a certain policy direction, the final decision on any issue of cooperation within the international system lies with the state. For instance, throughout the negotiations, NATT and other NGOs prodded and pressurized countries to stand firm in the face of Big Tobacco’s enormous political and economic strength (Lynn, 2003). The state is the final arbiter on issues of cooperation. The FCTC required the signature and ratification by a minimum of 40 countries before it came to force on February 27, 2005. Bilateral and multilateral agreements such as GATT, the WTO Agreement on Technical Barriers to Trade (TBT), the agreement on TradeRelated Aspects of International Property Rights (TRIPS), General Agreement on Trade in Services (GATS), the agreement on Sanitary and Phyto-sanitary Measures (SPS), and others affected tobacco trade are all contracted between states. The FCTC was also adopted by the 192 member states of WHO to render global governance in tobacco control possible. 
In many cases, statesmen must be able to come out with a treaty that will satisfy not only an international audience but also domestic ones as well (Putnam, 1988 and 1993; Evans et al, 1993). There should be a convergence between the global policy and domestic policy. This phenomenon underlies the U.S. and Germany’s position during the negotiation phase of the FCTC. They were hesitant to get on board because of their pessimism of whether the provisions under the FCTC will fit their domestic system. These countries were concerned about whether the FCTC language on advertising, Article 13, was in conformity with the constitutional provisions of their domestic political system (ENSP Report on INB6, 2003).

The centrality of states to the emergence of this tobacco regime suggests that states must reconcile their individuals’ interests with the concerns of global public health. However, as the liberal-constructivist perspective argues, this interest is amenable as a result of the spread of knowledge, norms, and principles about the hazards of tobacco use, the availability of empirically-based effective policies, and the revelation of the marketing and other activities of the tobacco industry by groups such as NATT, as well as multiple interactions with other states and other actors. The intergovernmental technical body set up by WHO - the Working Group (WG) - provided the scientific foundation for the formal negotiation of the FCTC. The first WG meeting took place in Geneva, Switzerland, in October, 1999. One hundred and fourteen WHO member states, the Holy See, the Palestinian, European Union, 10 UN organizations, four other IGOs, and 31 NGOs participated in the meeting. The second WG meeting also took place in March, 2000, in Geneva, Switzerland, with 142 member states in attendance. These 
meetings laid the technical and scientific foundation for the entire FCTC negotiation process.

The information provided as a result of the WG meetings consisted of a variety of scientific and other information meant to educate participants, particularly states, about the global tobacco epidemic. However, an important consensus that emerged among participants was that tobacco control measures were a matter for countries. Section 10 of WHO document A/FCTC/WG2/5 that emerged after the second WG meeting pointed out,

Participants noted that tobacco control measures were a matter for states. Both the convention and possible protocols should allow for the specific circumstances of countries and differences between developed and developing countries; countries of different types should be accountable in different ways. While support should be provided for strong country programs, tobacco growing is highly political and governments needed flexibility (p.2-3).

This put the primacy of the FCTC negotiation and resultant adoption on states. For instance, it has been pointed out that throughout the negotiations, countries of Africa, Southeast Asia, the Middle East, the Pacific and Caribbean made the treaty a reality (Lynn, 2003). Developing countries had a strong role in the emergence of the FCTC. Patti Lynn (2003) from NATT pointed out, "From the beginning of the FCTC process, developing countries pushed for effective measures to reverse the global tobacco epidemic and hold transnational tobacco companies accountable for their abusive practices.” Specifically, Lynn (2003) says, “India, Iran, Palau, Senegal, South Africa and Thailand are few countries that played key leadership roles during the FCTC negotiations.” For Patricia Lambert, a leading member of the South Africa delegation, "Throughout this historic process, the developing world, led by a block of 46 African nations, united around protecting the health of their people from deadly expansion of 
giant tobacco corporations” (cited in Lynn, 2003). Thus, States are at the center of governance in tobacco control. In essence, although non-state actors drive global tobacco control, the influence of states, with respect to governance, has not diminished in the policy arena.

An example of this phenomenon is represented by the role of African states in the negotiation of the FCTC. In spite of the differences in the importance of tobacco to their economies, African states presented a common front. They became advocates for strong provisions of the FCTC (Lynn, 2003). Participants at WHO meeting in Lome, Togo, on October 8, 1999 became alarmed after hearing that tobacco consumption in Africa has increased by 2.3 percent and that most of the estimated 10 million tobacco-related deaths by 2030 will be in developing countries (Ahmad, 1999). As a result, the Ministers adopted the Lome Declaration urging the promulgation of stricter anti-tobacco legislation and support for the WHO’s Tobacco Framework Initiative (TFI) (Ahmad, 1999). In subsequent conferences in South Africa (Johannesburg Declaration) and Algeria (Algiers Declaration) in 2001 African countries declared support of a strong FCTC. The behavior of African states after becoming aware of the scope of the global tobacco epidemic and its trend is evidence to support the argument that knowledge about a phenomenon can alter the identities and interests of states. African states' familiarity with the tobacco epidemic was the key reason why they strongly supported the FCTC. They did away with their separate individual national interests to join the rest of the world to form a regime to combat the global tobacco epidemic. However, the irony is that out of 74 countries that had ratified the FCTC as at July, 2005, nine ${ }^{1}$ out of the 46 countries in the WHO African

\footnotetext{
${ }^{1}$ The seven AFRO countries that had ratified the FCTC are Botswana, Ghana, Kenya, Lesotho, Madagascar, Mauritius, Senegal, Seychelles, and South Africa.
} 
region (AFRO) had done so, an indication that issues of policy adoption at the global level are different from issues of implementation at the unit level (state).

Also, even though the EU already has comprehensive tobacco control policies, the quest to lead the fight against the tobacco epidemic made it to work closely with member states to ensure strong FCTC provisions. ${ }^{2}$ During the fifth round of negotiation of the FCTC, the EU Commissioner for Heath and Consumer Protection, David Byrne said, "The negotiation presents a unique opportunity to create a legal instrument that will be binding worldwide.”3 Byrne further indicates "The negotiations at WHO have become an integral part of EU's tobacco control strategy and ... that our initiatives have already made significant and positive contribution to the important international process. ${ }^{, 4}$ So, in order to present a common front in the negotiation process, the EU had to reach a compromise with Germany (Kapp, 2003). In order to attain consensus among the EU member states, the EU council reached a deal in which members were allowed to tailor provisions under the FCTC to suit their domestic circumstances. In the end, EU unanimously adopted the FCTC, albeit Germany was allowed a reservation based on constitutional grounds (ENSP Report on INB6, 2003). The knowledge about tobacco use encouraged states to adopt the FCTC, the creation of global governance in tobacco control.

The activities of tobacco advocacy groups in general and during the negotiation of the FCTC were geared toward providing education and information for states, individuals, and groups within the international civil society. This was the rationale

\footnotetext{
${ }^{2}$ Information on EURO cooperation with others is available at http://europa.eu.int/comm/dgs/health_consumer/library/press/press272_en.pdf [accessed 05/27/04]

${ }^{3}$ Ibid

${ }^{4}$ Ibid
} 
behind the FCA newsletter - Alliance Bulletin. Many of the non-state actors that participated in the negotiation of the FCTC were granted observer status, as the Constitution of WHO requires. Also, the bylaws governing the negotiation process unambiguously stated that advocacy groups were participating in the process as observers. For instance, resolution WHA52.18 of the $52^{\text {nd }}$ WHA requested the DirectorGeneral "to invite, as observers at the sessions of the working group on WHO framework convention on tobacco control and the intergovernmental negotiating body, representatives of nongovernmental organizations in official relations with WHO, who will attend the sessions of those bodies in accordance with relevant Rules and Procedure and resolutions of the Health Assembly” (A/FCTC/INB1/5, 2000). Although NGOs such as INGCAT (A/FCTC/INB2/6 Add.1), Infact, Commonwealth Medical Association, Consumer International, Soroptomist International and Medical Women's International Association (A/FCTC/INB3/INF.DOC/2) participated in the negotiating process, they did so as observers. On the contrary, tobacco companies did not overtly participate in the INB meetings. Yet, a review of the list of participants in the INB meetings revealed that members of the tobacco industry were on the delegations of some states. Notably in this regard is Malawi, where members of the tobacco industry were part of its delegation.

NGOs participated in the process to educate delegates of states about tobacco use and the scope of the tobacco epidemic and to urge states to approve the FCTC. Thus, when Germany was threatening to block the EU position on the FCTC, NGOs were called upon to aim at influencing Germany's position (ENSP Report on INB6, 2003). ${ }^{5}$ In this respect, if states are reluctant to be party of the treaty, political pressure within the

\footnotetext{
${ }^{5}$ WHO European Ministerial Meeting for a Tobacco-Free Europe, 02/19/02, http://nosmoking.ws/news/newsinb4europe.htm [accessed 05/21/05]
} 
international society and within each political and geographical jurisdiction was used to motivate them to sign on. Yet still, the final and ultimate decision in the creation of the FCTC laid with the state. In essence, despite the proliferation of transnational tobacco advocacy groups around the world, states remain at the center of governance in tobacco control.

\subsubsection{The Role of The World Health Organization (WHO)}

WHO, created in 1947, is the UN agency responsible for international public health. Although official recognition of the hazards of tobacco use occurred in the early 1960s or earlier, WHO took on the tobacco issue for the first time in 1970. This does not suggest that hitherto WHO was not involved in any tobacco control activities. For instance, WHO was involved in the organization of the 1967 WCTOH in New York. Still, the adoption of WHO Resolution WHA23.32 of 1970, with reference to earlier adoption by Pan American Health Organization/Regional Committee for the Americas and the Regional Committee for Europe, was the first official and formal recognition of the health consequences of tobacco use (WCTOH, 1983). It considered the desirability of making the subject for World Health Day "The health consequences of smoking," on the earliest possible occasion (WHA23.32, para 2(a)), convening an expert group to recommend further action that might be taken to discourage smoking (WHA23.32, para. 2(c)), and bringing to the attention of the Food and Agricultural Organization (FAO) the need for studying crop substitution in tobacco producing countries (WHA23.32, para. 2(e)). 
WHO has adopted 20 different resolutions on the health consequences of tobacco use as well as tobacco control at the global level between 1970 and the adoption of the FCTC in May 2003. WHO gathers information on tobacco control through its offices. It gathers information in a bottom-up manner through its local/country and regional offices to the international office. On the other hand, it disseminates information in a top-down faction through the international office to the regional and local/country offices. Thus, at the Ninth WCTOH in 1994, Claire Chollat Traquet signaled the organization's intention to publish a monograph entitled "Evaluation of Tobacco Control Experiences and Guiding Principles,” the first reference text to bring together in a single work an overview and evaluation of tobacco control measures that have been adopted by countries.

New institutionalists argue for the relative autonomy of institutions (March and Olson, 1984). Once established, institutions can exist independent of those who created them. Institutions have their own culture and formative bearing on individuals hence the constitutive notion of institution (Young, 1999; Cook, 1996). Institutions help to shape the interests and identities of actors (Wendt, 1994, 1992, \& 1987). In this respect, WHO has an autonomous and independent identity from the constituent states. It has the constitutional powers to undertake activities independent of the states. This was the underlying argument of Allyn Taylor's 1992 Journal of Law and Medicine article that analyzes the constitutional power of WHO to establish a health regime. Taylor makes it clear that the constitution of WHO provides enough legal backing for such undertaking.

The drive towards the creation of a global tobacco regime started with the recognition of the hazards of tobacco - WHA23.32. However, as FCTC document 
A/FCTC/WG2/5 still acknowledges, WHO was aware that tobacco control measures belong to the realm of states. The tobacco control movement started as a domestic movement with a long history but gained momentum with the publication of the Royal College of Physicians and the U.S. Surgeon General's report in the early 1960s (Borio, 2001; Nathanson, 1999). Both the scientific evidence on hazards of tobacco use and the associated policies to curb tobacco use emerged at the country-level. In this regard, para 4(1) of WHA24.48 of May 1971 requested the Director-General of WHO to "continue to assemble information on the health effects of tobacco smoking and the actions being taken by countries to reduce the habit," a bottom-up approach to the tobacco issue. This resolution required WHO to just "assemble" preexisting information on tobacco use and tobacco control from countries where these were already in existence. Yet, at the same time para 4(5) of WHA24.48 requested the Director-General to "produce a code of practice that can guide governments in the formulation of legislative action relevant to the health consequences of smoking." Thus, while urging WHO to gather information on tobacco use and tobacco control policies from countries where they are in existence (bottom-up), it entrusted WHO with the power to design its own tobacco control policies based on the "assembled" information for implementation in member states (top-down). Subsequent resolutions urged WHO to perform these dual roles.

Analysis of the content of all the resolutions of WHO on tobacco control from 1970 to 2003 revealed that almost all of the WHA resolutions encouraged member states to take actions toward the reduction of tobacco use. At the same, the resolutions assigned certain roles to WHO. Specifically, WHO is usually requested to collaborate with member states, other UN agencies, and NGOs in the formulation, implementation, and 
evaluation of tobacco control policies and programs. In addition, it is usually requested to cooperate with members in development of tobacco control programs. However, resolution WHA33.35 of 1980 urged WHO to take a leading role in coordinating international activities in tobacco control. It further urged WHO to develop an action program on smoking and health, consider problems caused by marketing and consumption of tobacco in developing countries, and mobilize financial and other resources for the implementation of the program.

The first clear mandate for WHO to adopt a global approach to tobacco control came with unanimous adoption of resolution WHA39.14 of 1986. Section 2 of the resolution called for a global public health approach and action to combat the tobacco pandemic. While urging WHO to work closely with member states in the formulation and implementation of tobacco control policies, the resolution requested WHO to continue and strengthen collaboration with NGOs as well as play an effective global advocacy role in tobacco and other health issues. The resolution also called on states to adopt comprehensive strategies to combat tobacco use (Studlar, 2002). Although WHO has been involved in the tobacco control issue for many years, resolution WHA39.14 could be deemed as the genesis of governance in tobacco control. For the first time, WHO was requested to adopt a plan that will treat tobacco use as a global problem. Following resolution WHA39.14, an Advisory Group was set up to advise WHO on its global action plan on tobacco.

The report of the Advisory Group on a WHO Global Action Plan on Tobacco or Health was instrumental in the adoption of a global governance approach to tobacco control. The plan was about the adoption of a global approach to combat the tobacco 
epidemic. One of the ways of making tobacco control a global issue was the adoption of resolution WHA40.38 of 1987. The resolution declared April 7, 1988 as "A World NoSmoking Day,” the first of its kind. Resolution WHA41.25 of 1988 recommended to WHO the content of the Global Action Plan. The plan that emerged covered the period 1988-1995. The plan was approved with resolution WHA42.19 of 1989. Subsequent resolutions dealt with the content of the action plan. However, in order to ensure the successful implementation of tobacco control policies, resolution WHA43.16 of 1990 urged member states to adopt a multisectoral comprehensive tobacco control strategies that involve collaboration with other agencies of the UN system, other IGOs, and important NGOs such as the UICC. Also, WHA45.20 of 1992 urged WHO to seek and facilitate multisectoral collaboration on its program on "tobacco or health" within the UN system. These resolutions laid the legal foundation for the evolution of tobacco control as a form of governance.

The earlier resolutions (WHA33.35 of 1980, WHA39.14 of 1986, WHA43.16 of 1990, and WHA45.20 of 1992) called for comprehensive multisectoral, long-term tobacco strategies and outlined the most important aspects of national, regional, and international policies and strategies in the field. However, resolution WHA48.11 of 1995 clearly encouraged the adoption of international strategy for tobacco control. It urged "Member states that have already successfully implemented all or most of a comprehensive strategy for tobacco control to provide assistance to WHO, working with the United Nations focal point on "tobacco or health" (located in UNCTAD), so that these bodies can effectively coordinate the provision of timely and effective advice and support to Member States seeking to improve their tobacco control strategies, including 
health warnings on exported tobacco products” (WHA48.11, section 2). Furthermore, it requested the Director-General "to report to the Forty-ninth World Health Assembly on the feasibility of developing an international instrument such as guidelines, a declaration, or international convention on tobacco control to be adopted by the UN, taking into account existing trade and other conventions and treaties” WHA48.11, section 2). Accordingly, it was reported that the development of such an institution was feasible. Resolution WHA49.17 of 1996, therefore, gave WHO the green light to initiate the development of a framework convention in accordance with Article 19 of WHO Constitution. The institutionalization of tobacco control sealed global governance in tobacco control.

This is an evidence of a "bubble up” phenomenon. Tobacco control was handled individually by the states. However, it gradually evolved into a global institution with the spread of knowledge about the hazards of tobacco use. It took over three decades - from the recognition of the health hazards of tobacco use in 1970 to the adoption of FCTC in 2003, for governance in tobacco control to emerge. The structures that contributed to the evolution of tobacco control as a form of global governance are discussed below.

\subsubsection{World Health Organization's Partners - UNCTAD, ILO, ECOSOC, FAO, World Bank and IMF, International Civil Aviation}

\section{Organization}

Since the 1970s, WHO has been involved in tobacco control activities at the global level. In addition to establishing two International Clearing-houses on Smoking and Health Information, WHO co-sponsored the Third, Fourth, and Fifth World 
Conferences on Smoking and Health. Also, the WHO Action Program on Smoking and Health was set up in accordance with Resolution WH33.35 to deal with cigarette issues in developing countries (WCTOH, 1983). Moreover, collaboration among various agencies within the UN system has been central to tobacco control at the global level. The WHO Expert Committee on Smoking Control Strategies in Developing Countries expressed the hope that the organization could seek the help of other organizations in the UN system in dealing with the worldwide problem (WCTOH, 1983). In accordance with this, WHO has also collaborated with the FAO on the study of economic benefits and social and medical costs of tobacco production and consumption (WCTOH, 1983).

In order to ensure collaboration with other agencies within the UN system, different resolutions were passed calling on WHO to involve such agencies in its global tobacco control activities. For instance, resolution WHA45.20 of 1992 emphasized the need for multisectoral collaboration on WHO’s program. It requested collaboration within the UN system. It also requested that the ECOSOC to put the subject of "tobacco or health" on its agenda. Furthermore, it requested the Director-General of WHO to bring to the attention of the ECOSOC the WHO concern over socio-economic problems of tobacco production and difficulties associated with assistance to countries dependent on tobacco production, as reflected in the report on the implementation of resolutions WHA42.19 and WHA43.16. Moreover, resolution 48.11 of 1995 requested the WHO to inform ECOSOC of its resolutions. It urged WHO to work with the UN system focal point on “tobacco or health," located in UN Conference on Trade and Development (UNCTAD). Established by the UN Secretary-General in 1998 under the leadership of WHO, the UN Ad-Hoc Inter-Agency Task Force on Tobacco replaced the focal point in 
April 1999. Its purpose was to coordinate tobacco control work carried out by different UN agencies (Yach and Bettcher, 2000). Subsequently, ECOSOC endorsed this task force in July 1999. The task force was to ensure the implementation of multisectoral collaboration on tobacco or health (Yach and Bettcher, 2000). In essence, WHO has been collaborating with other UN agencies to ensure the possibility of governance in tobacco control at the global level. As Yach and Bettcher (2000) point out, fourteen UN organizations were involved in the work of the Task Force on Tobacco.

WHO has been collaborating with other intergovernmental organizations. The 1991 resolution WHA44.26 expressed concern about smoking and travel. While encouraging member states to adopt measures for effective protection from involuntary exposure to tobacco smoke in public transport, the resolution requested WHO to collaborate with the International Civil Aviation Organization (ICAO) and all competent international and national agencies in developing guidelines and recommendations for smoke free travel environment in all types of public conveyances. The ICAO responded that it was going to ban smoking on all international flights beginning from July 1, 1996. Resolution WHA48.11 of 1995 commended the ICAO for its action. In 1994, a multilateral agreement between the U.S., Canada, and Australia on nonsmoking on flights between them became a model for the WHO-ICAO agreement (Studlar, 2002; Kyle 1996, Kyle and Du Melle, 1994). Thus, by working with the ICAO, WHO accomplished the goal of regulating smoking on international flights. States have the power to regulate tobacco use on only domestic flights, hence the involvement of a global institution was needed to regulate smoking on international flights. This reinforces the argument that, 
given the transnational nature of tobacco, a global institution is necessary to combat the associated epidemic.

Also, WHO has been working with the World Bank and International Monetary Fund (IMF). The World Bank and IMF decided not to give loans for investment in tobacco-related projects (World Bank, 1991). In general, the World Bank does not lend directly for, invest in, or guarantee investments or loans, for tobacco production, processing, or marketing, with exceptions for countries heavily dependent on tobacco as source of income (World Bank, 1991). Finally, the issue of trade has been central concern for WHO and other tobacco control advocates due to GATT and WTO rules. (Taylor et al., 2000). However, the GATT Panel's ruling in the Thailand Case suggests that tobacco control policies are not against international trade rules as long as they are not discriminatory. The World Bank, IMF, and WTO are among about 14 UN agencies and organizations that participated in UN inter-agency task force for tobacco or health, expanding the horizon of multisectoral collaboration across the UN system (Yach and Bettcher, 2000). Thus, the transnational nature of tobacco and the globalization of associated health risks have led to collaboration not only between WHO and other organization within the UN system but also between WHO and other IGOs.

These UN agencies and IGOs have been instrumental in the adoption of the FCTC. The 1995 UNCTAD report on tobacco control in developing countries dependent on tobacco production, and the 1999 World Bank’s Curbing the Epidemic, among others, were instrumental in the emergence of tobacco control as a global institution through FCTC. The reports of these institutions provided the basis of the work of the FCTC technical committee and negotiations during the meetings of the intergovernmental 
working group. In this sense, these IGOs contributed to the adoption of FCTC. The familiarity with the hazards of tobacco use, the tobacco epidemic, activities of the tobacco industry, and tobacco control policies allowed organizations to promulgate tobacco control rules for regulation of both tobacco use and production. This is the essence of the liberal-constructivist perspective. Not only were activities of WHO pertinent to governance in tobacco control, but also the spread of knowledge about tobacco use and tobacco control facilitated it. Both phenomena contributed to the adoption of FCTC.

\subsubsection{World Health Organization's Tobacco Control Program: The Tobacco Free Initiative (TFI)}

The TFI was launch in 1994 at the Ninth WCTOH in Paris, France. Organized under the auspices of WHO, International Union Against Cancer (UICC), International Union Against Tuberculoses and Lung Diseases (IUATLD), International Society and Federation of Cardiology (ISFC), International Organization of Consumers’ Unions (IOCU), and International Union for Public Health and Education (IUPHE), the conference adopted an international strategy for tobacco control. Participants from different countries around the globe unanimously adopted a resolution that reducing tobacco consumption requires a global strategy in the face of strong and influential tobacco manufacturers. In response to the adoption of this international approach, resolution WHA 48.11 of 1995 states, "Noting that the Director-General and his staff has contributed to the success of the Ninth World Conference on Tobacco and Health (Paris, October 1994) at which an international strategy for tobacco control was adopted 
covering the essential aspects of WHO policy in that field: ...” and requested the Director-General to report on the feasibility of adopting an international convention on tobacco control by the UN. This began the initiative and efforts at institutionalization of tobacco control at the global level. In an address at the opening ceremony, Hiroshi Nakajima, the Director-General of WHO, pointed out that the initiative requires mobilization of local and national community movements, and international NGOs working alongside WHO to support governments and encourage them to step up the fight against smoking (WCTOH, 1994).

The TFI is WHO's response to the global tobacco epidemic. It was established in July 1998 to focus international action and resources on the global tobacco epidemic. Its main objective is to reduce the global burden of tobacco-related diseases and deaths through the provision of global policy leadership, encouraging mobilization at all levels of society, and the promotion of the FCTC. In essence, the TFI is meant to educate and disseminate information about tobacco use and tobacco control. A process that began with WHA24.48 of 1971, requesting WHO to "assemble” information from states where tobacco control policies and programs were existence has evolved into a system in which WHO is required to provide education and assistance for Member States that need them as well as disseminate information on tobacco control to all Member States.

Structurally, the TFI is part of the Noncommunicable Diseases and Mental Health $(\mathrm{NMH})$ cluster at WHO headquarters (HQ) in Geneva, Switzerland. The NMH is at the top of the TFI's structure. Below the NHM is WHO's regional offices. Regional advisers for tobacco control are based in the six regional offices of WHO in Africa (AFRO), the Eastern Mediterranean (EMRO), Europe (EURO), South Asia (SEARO), and Western 
Pacific (WPRO), and the Americas (PAHO/AMRO). The TFI-HQ works with its regional advisers to plan and implement its activities. The regional advisers in turn, collaborate with the WHO country representatives and liaison officers to facilitate tobacco control at both regional and country levels. This is a form of global governance structure where information flows from the global level to all the units across the global and information flows back from the units to the global level in a form of feedback loop.

The TFI is vertically structured with tobacco and tobacco control information disseminated from the global level (TFI-HQ) through its regional offices to countries located around the globe. Various resolutions of WHO (WHA29.55 of 1976, WHA31.56 of 1978, WHA33.35 of 1980, WHA39.14 of 1986, WHA43.16 of 1990, and WHA45.20 of 1992) called for comprehensive, and long-term strategy for tobacco control. These resolutions required WHO to gather information on tobacco control policies and programs from different countries where they are already in existence and to help and support other member countries to formulate their own policies and programs. In this respect, FCTC is a means of diffusing or transferring tobacco control policies to different political and geographic jurisdiction.

The TFI was very instrumental in the adoption of the FCTC. The major role it played was the organization of pre-negotiation public hearings. It solicited opinions from all interested parties around the world about the drafted FCTC text. The positions of individuals, groups, organizations, and tobacco companies around the world on FCTC were submitted to the TFI during the October 2000 pre-negotiation public hearings. In addition, the TFI was the key WHO organ responsible for the education of the general public and states about the provisions of the FCTC through its regional and state offices. 
In essence, the TFI helped to spread the knowledge about tobacco use throughout the world as well as coordinated the participation of interested parties around the globe in the FCTC process, hence making global governance in tobacco control possible.

\subsubsection{3 “World No-Tobacco Day” - WNTD}

The idea of a world non-smoking day was recommended at the Fifth WCTOH in Winnipeg, Canada. Specifically, the recommendation stipulates, "That a world NONSMOKING DAY be held each year, commencing in 1984 ” $\left(5^{\text {th }}\right.$ WCTOH, 1983:817). However, the idea became a reality when in 1987 the fortieth World Health Assembly passed resolution WHA40.38 to make April 7, 1988 a "World No-Smoking Day" (WNTD). Subsequently, resolution WHA42.19 of 1989 made May 31 of each year the WNTD. The WNTD is an occasion that transcends all national boundaries. Every country in the world is urged to celebrate the day. Since its inception, WHO uses this annual occasion to highlight the nature of the tobacco epidemic and to educate people about tobacco use.

The purposes of the resolution WHA40.38, 1987 include: (a) to encourage the population to desist from smoking and from using tobacco in all others forms; (b) in conjunction with governmental and non-governmental organizations, to use the occasion to launch, or strengthen, anti-smoking campaigns and health-promoting initiatives; and (c) to encourage vendors to refrain voluntarily from selling all forms of tobacco on that day. It is meant to inform the public about dangers of tobacco use, the activities of TTCs, the WHO efforts to curb tobacco use, and the role of people in combating the tobacco epidemic. An important aspect of the resolution is that it called on member states to 
inform the Director-General on action taken in response to the resolution. That is, besides calling upon all member countries to set the day aside for the education of the public about the dangers of tobacco use and promoting tobacco control policies, the resolution requested member states to inform WHO of the actions they were taking. In effect, WHO becomes the venue of coordination of various tobacco control policies around the globe.

Since the first celebration of the occasion in 1988, this phenomenon has become a yearly affair and integral part of WHO strategy to control tobacco use globally. Every year, WHO comes out with new themes, highlighting the dangers of tobacco use to the human health. The themes of the "World No-Tobacco Day" since its inception in 1988 usually cover different aspects of tobacco use, ranging from warning about the dangers of tobacco use, passive smoking, and bans on tobacco advertising. In accordance with resolutions on WNTD, member states of WHO have integrated it into their national legal systems as “National No-Tobacco Day.” The speeches and pronouncements of government officials, officials of WHO, leaders of NGOs, and individual advocates as well as the demonstrations and media coverage throughout the world raises awareness of the dangers of tobacco use and the scope of the tobacco epidemic. Thus, the day is meant to raise awareness of tobacco use and the global nature of the tobacco epidemic and tobacco control.

In the first place, the "World No-Tobacco Day" (WNTD) has contributed to the adoption of tobacco control by states. For instance, at the Seventh WCTOH Azizur Rahman, Minister for Health and Family Planning, Bangladesh, pointed out that On the $2^{\text {nd }}$ WNTD (1989) Bangladesh put into immediate effect measures to help curb tobacco consumption. They include education; ban on smoking in public places, hospitals, and flights; ban 
on ads and sponsorship; rejecting the establishment of new tobacco industries; and research into finding alternative crops for tobacco [ $7^{\text {th }}$ WCTOH, 1990:16]

The WNTD contributed to the adoption of the FCTC, making global governance in tobacco control a reality. In a commentary on 2000 "World No-Tobacco Day” Eryn Brown (2001) points out

Luncheons and bureaucratic edicts are seldom the stuff revolutions are made of, but while World No Smoking Day may sound toothless and irrelevant, it actually signals a big and important phenomenon: The anti-smoking fight is going global. Energized advocates are pooling their efforts into an ambitious long-term push to curb smoking in the wealthy nations where it has flourished and to keep it from catching on in the developing nations where it hasn't. There is more to this than pronouncements and demonstrations: There is education, legislation, and a new heap of litigation. Before long, tobacco opponents should even have a World Health Organizationsanctioned global treaty, the Framework Convention on Tobacco Control (FCTC)—an agreement that promises to influence legislation around the world.

Also, in arguing for local/community involvement in the celebration of 2001 WNTD - Secondhand Smoke Kills. Let's Clear the Air - WHO notes “local action taken by you and your organization to protect people from second-hand smoke are an essential complement to the international negotiation on the FCTC (WHO, 2001).” In effect, inasmuch as the WNTD contributes to global awareness of the tobacco epidemic, it serves as a means of mobilizing the public for the support of the FCTC.

Public support, as Allyn Taylor (1992) earlier pointed out, is vital for the emergence of any global institution and since 1988, the WNTD has been playing this role. The speeches and demonstrations on WNTD had impact on the adoption of the FCTC. This yearly phenomenon has emerged as integral part of global governance in 
tobacco control. WHO sets up the theme for each year and through its regional and local offices, the message is delivered to the average person. WHO, together with government officials, anti-tobacco advocacy groups, and the private sector uses the occasion to build community awareness as well as generate support for tobacco control policies and program. The WNTD provided education and mobilized public support for global governance in tobacco control (FCTC). For instance, a review of over 500 submissions on the FCTC's text from different interests around the globe made during the October 2000 public hearings revealed that majority supported the FCTC after becoming aware of the hazards of tobacco use. Many realized that the tobacco epidemic was global in scope that could be handled better through a global institution, hence the support for the FCTC.

Furthermore, a report on 2003 WNTD in the WHO European region indicated that "World No Tobacco Day provided an important opportunity to build momentum for the Framework Convention on Tobacco Control (FCTC) ... WHO Member States were encouraged to use World No Tobacco Day to draw attention to the FCTC and, in particular, the elements relating to advertising, sponsorship and product placement” ${ }^{\text {6 }}$ (p.2). Thus many activities took place throughout the 27 countries in the EU region to build support for the FCTC. Through the WNTD, the public became aware of the hazards of tobacco use, mobilizing European support for the FCTC. In essence, the WNTD has contributed to the gradual evolution of tobacco use and the tobacco epidemic as a global issue as well as the emergence of a global governance structure to combat it.

\footnotetext{
${ }^{6}$ The EURO 2003 Report of WNTD activities is available at http://www.euro.who.int/document/E82101.pdf [accessed 02/08/05]
} 


\subsection{Globalization and Interdependence, and the FCTC}

There is increasing interaction and interconnectedness among different actors of the world system. Issues such as the environment, smuggling, advertising, and marketing usually spill over national borders. Also, tobacco companies that are primarily based in developed countries depend on tobacco leaves produced in developing countries. The world is described as a "Global Village" where issues in one part of the world reverberate at others (Held, 1995). Policy strategies adopted in one country often have important impacts on policymaking in other countries (Studlar, 2002; Rose, 1993; Heidenheimer et al. 1990). Closely associated with this is the shrinkage of distance facilitated by rapid technological advancement. The result of all these changes within the international system is the realization that many problems are global, and that states cannot deal with these problems all by themselves. An integral part of this trend in the context of public health is described as "globalization of public health” (Yach and Bettcher, 2000). States are not capable of dealing with transnational public health problems alone. They must work together with one another in a collective manner in order to combat such transnational problems. Emerging from the issue of globalization of public health with regards to tobacco is the activities of transnational tobacco companies in developing countries (Sklair, 2002; Frey, 1997). The concern for the expansion of the activities of the tobacco industry into developing countries has remained a big aspect of the global tobacco control movement since the 1970s. 


\subsubsection{The Developing Countries Issue}

Out of the estimated 1.25 billion smokers in the world, about 800 million live in the developing world. Seven hundred million of these smokers in the developing world are men. There are about 300 million Chinese smokers, and 90 percent of them are men. Table 4.0 shows the estimated number of smokers in the world. Also, Table 4.1 shows the trends of adult cigarette consumption over time.

Table 4.0

Estimated Number of Smokers Globally (in millions)

\begin{tabular}{llll} 
Countries & Males & Females & Total \\
\hline Developed & 275 & 150 & 425 \\
Developing & 700 & 100 & 800 \\
World & 975 & 250 & 1225 \\
\hline Source: Taylor and Bettcher (2000) & & &
\end{tabular}

Table 4.1: Estimates and Trends of Cigarette Consumption per Adult Aged 15 and Over, 1970-1972 to 1990-1992

\begin{tabular}{lcllc} 
Countries & $1970-72$ & $1980-82$ & $1990-92$ & Annual \% Change \\
\hline Developed & 2860 & 2980 & 2590 & -0.5 \\
Developing & 860 & 1220 & 1410 & 2.5 \\
World & 1410 & 1650 & 1660 & 0.8 \\
\hline Sources: WHO(1999) & & &
\end{tabular}

The above tables are evidence in support of the declining trend in tobacco use in developed countries and the rising trend in developing countries. The decline of the market share in the developed world has led to the extension of the activities of these companies into developing countries (Satcher, 2001). Sklair (2002:169) points out that Philip Morris, R.J. Reynolds and BAT brand in 1995 had two thirds of the market in 
Barbados, Ghana, Honduras, Hong Kong, Kenya, Morocco, Nicaragua, Sri Lanka, and Turkey; and over one-third in Pakistan, Slovak Republic, and Zaire (Democratic Republic of Congo) (Tobacco Reporter, 1996). Sklair (2002:169) further notes that whereas in the mid-1980s the global tobacco companies had legal access to less than half of the potential world market for cigarettes, by the mid-1990s this has risen to around 90 percent. For example, a BAT document explained:

"We should not be depressed simply because the total free world market appears to be declining. Within the total market, there are areas of strong growth, particularly in Asia and Africa; there are new markets opening up for our exports, such as Indo-China and the COMECON countries” (ASH, 1998).

Other tobacco documents shows that the tobacco industry purposefully targeted developing countries (Sklair, 2002; Frey, 1997). The rationale for this is that relatively, there are fewer smokers of cigarettes in the developing, although the trend is changing (Sklair, 2002:169). In July 1992, Philip Morris signed a contract with Margaret Thatcher, a former Prime Minister of Britain to advise the company on its strategy in the developing world and Eastern Europe (ASH). For instance, in 1992, a Rothmans executive stated:

“Thinking about Chinese smoking statistics is like trying to think about the limits of space” (cited in Yach and Bettcher, 2000:207; ASH, 1998).

Also, a note from BAT tobacco strategy group in September 1994 states:

"It was agreed that China is top priority in terms of size and potential ... in Japan, the strategy is aggressive organic growth” (cited in Yach and Bettcher, 2000:207).

At this meeting, a "revised, more proactive approach to smoking issues" was to be 
"Communicated in clear, credible terms with no time lag around the group. The objectives are to influence opinion and news” (cited in Yach and Bettcher, 2000:207).

The tobacco industry uses different strategies to enter into the new markets in the developing world. One such strategy is the use of international trade rules to tear down protective markets in developing countries. Tobacco companies use international trade rules under GATT and WTO to enter into countries where hitherto they were prevented from entering. An example of this phenomenon is the Thailand Case where the GATT Panel ruled to breakdown Thailand's restriction on importation of and internal taxes on cigarettes (Taylor et al, 2000; Yach and Bettcher, 2000). Further evidence on this issue can be inferred from BAT statement during China’s negotiation into the WTO. Martin Broughton of BAT stated:

"I hope that there will be a successful negotiation of Chinese entry into the World Trade Organization before the commencement of a new round of multilateral trade talks .... We would hope to improve our market access and secure tariff reductions and I will welcome reports that China has offered far-reaching cuts” (cited in Yach and Bettcher, 2000:207).

It happened whenever these TTCs enter into new market, they use sophisticated and effective advertising and effective promotional strategies. The competition for the market results in a general increase in expenditure on advertising. For instance, with the entry of TTCs into the South Korean market in the 1980s, the advertising and promotional expenditure of the Korean national monopoly increased, between 1987 and 1990, and the result is that the smoking rate among Korean male teenagers increased from 18 percent to 30 percent and that of females increased from two percent to nine percent, just one year after the entry of U.S. companies (Roemer, 1993). Other examples of activities of TTCs in developing countries include BAT sponsorship of discos in China 
to advertise the 555 brand, BAT employment of glamorous young girls in their 20s to drive around in 'Play Gold Leaf' cars and jeeps, handing out free cigarettes; distribution of T-shirts with Rothman’s logo ‘Dunhil” to children in Vietnam; Rothman Dunhil brands sponsorship of sporting events in Malaysia; and free distribution of cigarette by BAT employees at sponsored sporting and youth events in Gambia (ASH, 19998). In places where it is difficult to enter the market, the industry uses the idea of an international brand to gain entry (Yach and Bettcher, 2000). Yach and Bettcher (2000) point out that in such places, the industry looks towards the creation of new "global brands" and a "global smoker" as one way of overcoming markets that have resisted the tobacco industry onslaught.

These aggressive marketing strategies of the TTCs in the developing world have been of concern and have facilitated the emergence of global governance in tobacco control. As Yach and Bettcher (2000:207) argue, "The fact that opening of markets and the process of globalization has been linked to increased health risks supports the need for a stronger national regulatory environment for tobacco control and harmonization of national policies between countries.” The developing countries issue was first given due consideration at the Second WCTOH in 1971 in London, U.K. At the conference, the consensus was that, given the tobacco epidemic in the developed countries, steps should be taken to halt the extension of the epidemic into developing countries, where it was yet to start. The emphasis at the conference was on the prevention of diseases caused by smoking. One of the strategies to achieve that was international cooperation (Kaprio, 1971). Particularly, Leo Kaprio, WHO Regional-Director for Europe (1971) pointed out the world has personal and social responsibilities to developing countries to ensure that 
the tobacco industry does not export the tobacco epidemic to developing countries. Since then, the spread of the marketing activities of TTCs in developing countries has been central to the global tobacco movement. The WHO adopted WHA31.56 in 1978 to express its concern over increase in the production and consumption of cigarettes in developing countries due widespread and extensive promotional drives, hence the need for concerted effort to combat the spread of the tobacco epidemic to such countries. The WHO continually cites in its resolutions advocating for a global concerted effort to combat tobacco use. As one of the reasons for the FCTC, it is estimated that 70 percent of about 1.7 million people expected to die every year by 2020 from tobacco related diseases would be from developing countries. As the Togo, Algiers, and Johannesburg's Declarations on tobacco control illustrate, this was particularly a source of mobilization of African countries in support of the FCTC (Ahmed, 1999). Thus, the activities of the TTCs in developing countries have contributed to global governance in tobacco control because combating the activities of a global industry with more wealth than most countries in the world requires global collective effort.

\subsection{Summary, Discussion, and Conclusion}

The consensus about FCTC is that growing knowledge about the hazards of tobacco use as well as the globalization of public health and increasing interdependence led to its emergence (Taylor et al., 2003; Collin et al., 2002; Taylor, 2002; Yach and Bettcher, 1998). The Uruguay Round of GATT negotiation resulted in the liberalization of agricultural commodities (including tobacco). Due to liberalization, increasing restrictions in other developed countries, and the Master Settlement Agreement of 1998; 
the tobacco industry has expanded business into medium and low-income countries (Shafey et al., 2003; Sklair, 2002; World Bank, 1999; Weissman, 1998; Frey, 1997). These fostered the globalization of the tobacco industry. However, the globalization of the industry, facilitated by GATT and WTO, is associated with the globalization of tobacco-related health risks, hence the need for a global governance structure in tobacco control to regulate tobacco use. Globalization has increased awareness of the activities of the tobacco industry in the developing world as well as the linkage between tobacco use and health making a system of governance in tobacco control possible, the essence of the liberal-constructivist perspective.

The emergence of tobacco control as a form of global governance is an evolutionary process. It took over three decades for the tobacco issue to move from the domestic arena to the global arena. The involvement of WHO has been central to this evolutionary process. Beginning with the recognition that tobacco use is a health problem in 1970, WHO contributed to the spread of this knowledge throughout the world, culminating in the adoption of the FCTC in 2003. For about three decades, WHO provided legitimate venue through which global efforts at tobacco control were coordinated.

WHO was initially requested to "assemble" information on tobacco use and tobacco control from member states. However, along the way, it was requested to disseminate the information gathered to Member States and to help other Member States to formulate their own tobacco control policies and program. After the realization that tobacco use was a global problem, the WHO was asked to adopt a multisectoral approach to the problem, collaborating with other UN agencies, other international organizations, 
and nongovernmental actors in its effort to educate states about tobacco use. However, in the early 1990s, WHO was formally asked to adopt a global approach to the tobacco issue. With the advice on the feasibility of establishing a global convention, WHO started with its preparation, resulting in the adoption of the FCTC in 2003. Thus, Collin et al. (2002) conclude, "The breadth of multisectoral collaboration at the national level; the cooperation among comparatively marginalized states to heighten their impact on negotiations; the greater involvement of UN agencies and other international organizations in tobacco control; the opening towards civil society - all indicate the innovation of the FCTC as a move closer to global health governance” (p.279).

The evolution of tobacco control as a form of governance occurred through the activities of WHO. WHO collaborated with other UN agencies and other international organizations to regulate tobacco at the global level. Also, through its own structures, TFI and WNTD, WHO was able to spread the knowledge about tobacco use and mobilized public support for the FCTC. These structures are an integral part of governance in tobacco control. As the above evidence portrays, they contributed to the adoption of the FCTC.

A key concern throughout the three decades was how to combat the export of the tobacco epidemic to developing countries. This has been central to global tobacco control for many years. Even at the Second WCTOH in 1971, it was predicted as one of the most important issues that the world must deal with in the ensuing years. In the face of strong regulations and declining markets in the developed world, developing countries became the target of the tobacco industry (Sklair, 2002; Frey, 1997). This phenomenon has been exacerbated by globalization and interdependence, a situation that forces developing 
countries to open their market, leading to the export of hazardous products into these countries by transnational companies (including tobacco). The irony is that many of these countries cannot assess and manage the risk associated with such exports (Frey, 1997). The result is an increasing trend of tobacco use in these countries. With the aggressive marketing activities of tobacco companies in these countries, the increasing trend will continue if nothing is done. This has been one of the key reasons for the need for global approach to combat the tobacco epidemic.

In nutshell, this chapter reveals that the emergence of global governance in tobacco control is an evolution process. The issue gradually grew from domestic arenas to the global arena. International trade rules, particularly negotiated under the Uruguay Round, facilitated the penetration of new markets by TTCs. The result is general increase in the trend of tobacco use, particularly in developing countries. WHO's adoption of a multisectoral approach; collaborating with other UN agencies, international organizations, and nongovernmental organizations was instrumental in the effort to regulate tobacco at the global level. Also, the creation of the TFI and WNTD resulted in the spread of tobacco use and mobilizing support for the FCTC. Thus, FCTC is a form of global governance that emerged through the activities of WHO on tobacco use and tobacco control. 


\section{Chapter 5}

\section{Diffusion/Transfer of “Best Practices” in Tobacco Control}

\subsection{Introduction}

Since the discovery of tobacco in the Americas, it gradually spread throughout the world. However, it first emerged as a problem in the developed world, and later the developing world. As Eyestone (1977:442), pointed out, people facing problems are usually the first to innovate policies to combat the problem. In this respect, because of widespread use of tobacco in the developed world, knowledge about the hazards of the practice started to accumulate for many years, peaking with the publications of Wynder, Doll, Graham, and others in 1950s and early 1960s [See chapter 1]. As the first to recognize the health consequences of tobacco use, the developed world in general became leaders in the innovation of tobacco control policies and the developing world became laggards. Through transnational activities, these innovaive tobacco control policies and programs or "best practices" spread to different geographic and political jurisdictions around the world, and eventually it became a global issue.

This chapter is a longitudinal and systematic analysis of the evolution of tobacco control from a domestic issue into global issue through an epistemic community, World Conference on Tobacco or Health (WCTOH). The WCTOH is one of the events that occurred in the aftermath of the authoritative recognition of the linkage between tobacco use and health in the early 1960s. The Royal College of Physicians and the U.S. Surgeon General's Reports became reference points for domestic and international debate on tobacco use and tobacco control, and a catalyst for the inception of the WCTOH. The 
WCTOH was one of the earliest attempts at making tobacco use a global problem, and spreading innovative tobacco control policies worldwide. Between 1967 and 2003, twelve WTCOH were held [See Table 5.0].

Table 5.0: World Conferences on Tobacco or Health

\begin{tabular}{|l|l|l|}
\hline Number & \multicolumn{1}{|c|}{ Year } & \\
\hline $1^{\text {st }}$ & 1967 & New York (USA) \\
\hline $2^{\text {nd }}$ & 1971 & London (UK) \\
\hline $3^{\text {rd }}$ & 1975 & New York (USA) \\
\hline $4^{\text {th }}$ & 1979 & Stockholm (Sweden) \\
\hline $5^{\text {th }}$ & 1983 & Winnipeg (Canada) \\
\hline $6^{\text {th }}$ & 1987 & Tokyo (Japan) \\
\hline 7 th & 1990 & Perth (Australia) \\
\hline $8^{\text {th }}$ & 1992 & Buenos Aires (Argentina) \\
\hline $9^{\text {th }}$ & 1994 & Paris (France) \\
\hline $10^{\text {th }}$ & 1997 & Beijing (China) \\
\hline $11^{\text {th }}$ & 2000 & Chicago (USA) \\
\hline $12^{\text {th }}$ & 2003 & Helsinki (Finland) \\
\hline $13^{\text {th }}$ & 2006 & Washington, D.C. (USA) \\
\hline
\end{tabular}

Using opening speeches, papers presented at plenary sessions, closing summaries, and the recommendations of each of these conferences, this chapter analyzes how as an epistemic community, the WCTOH contributed to innovation and diffusion of tobacco control measures and the idea of "best practices" in tobacco control. It also examines the linkage between the WCTOH and global tobacco control in general, and the FCTC in particular. The chapter further discusses the role of NGOs and research institutions in the innovation and diffusion of tobacco control policies through the WCTOH.

The WCTOH began as a meeting of public health practitioners, experts in tobacco control, scientists, and policymakers from the developed world to find a solution to a recognized problem, the health effects of tobacco use. The agenda of the inaugural conference was narrow, and the participants came from primarily the developed countries 
( $1^{\text {st }}$ WCTOH, 1967). However, the most important issue was that for the first time tobacco use was recognized as an international problem that could be addressed through international collaboration and cooperation. The inaugural conference of the WCTOH focused on coordinating tobacco control policies among the developed countries and to exchange and share ideas on finding a less harmful cigarette ( $\left({ }^{\text {st }}\right.$ WCTOH, 1967). Since then, the scope of the conference has expanded to include issues of tobacco use and tobacco control around the world. In addition, not only has the WCTOH has become larger in terms of participation, but also it has become more diversified as participants from around the world, particular the developing countries, have become actively involved in its activities [See Figures 5.0 and 5.1]. Moreover, the WCTOH is linked to global tobacco control through worldwide activities of NGOs, policymakers, and advocates and the involvement of World Health Organization (WHO) in the organization and transformation of the conference resolutions and recommendations into policies for adoption by member states. In effect, this chapter argues that the emergence of tobacco control at the global level is an evolutionary process because it took over four decades (1962-2003) for the issue to be transformed from a domestic matter in a few developed countries into an international issue and then a global institution. 
Figure 5.0: Number of Countries at WCTOH

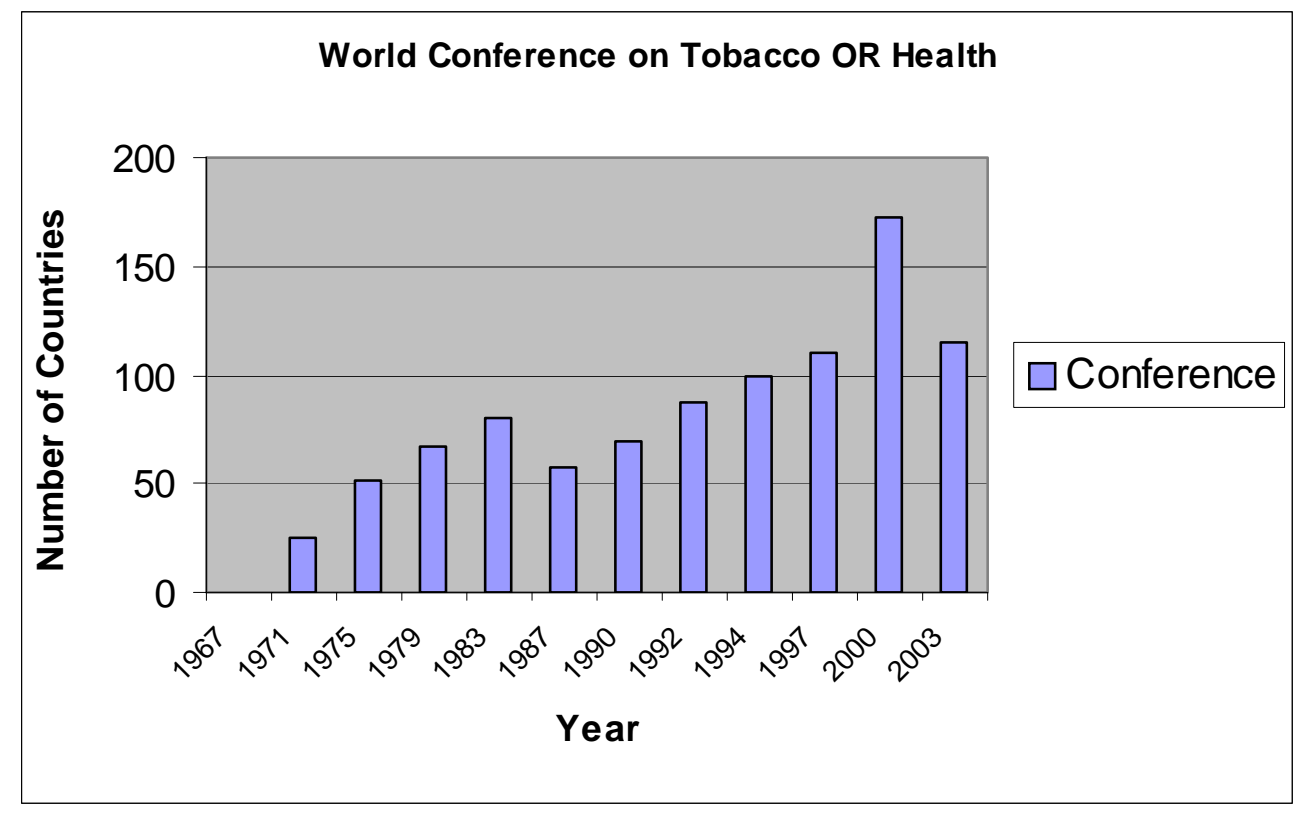

Figure 5.1: Number of Participants at WCTOH

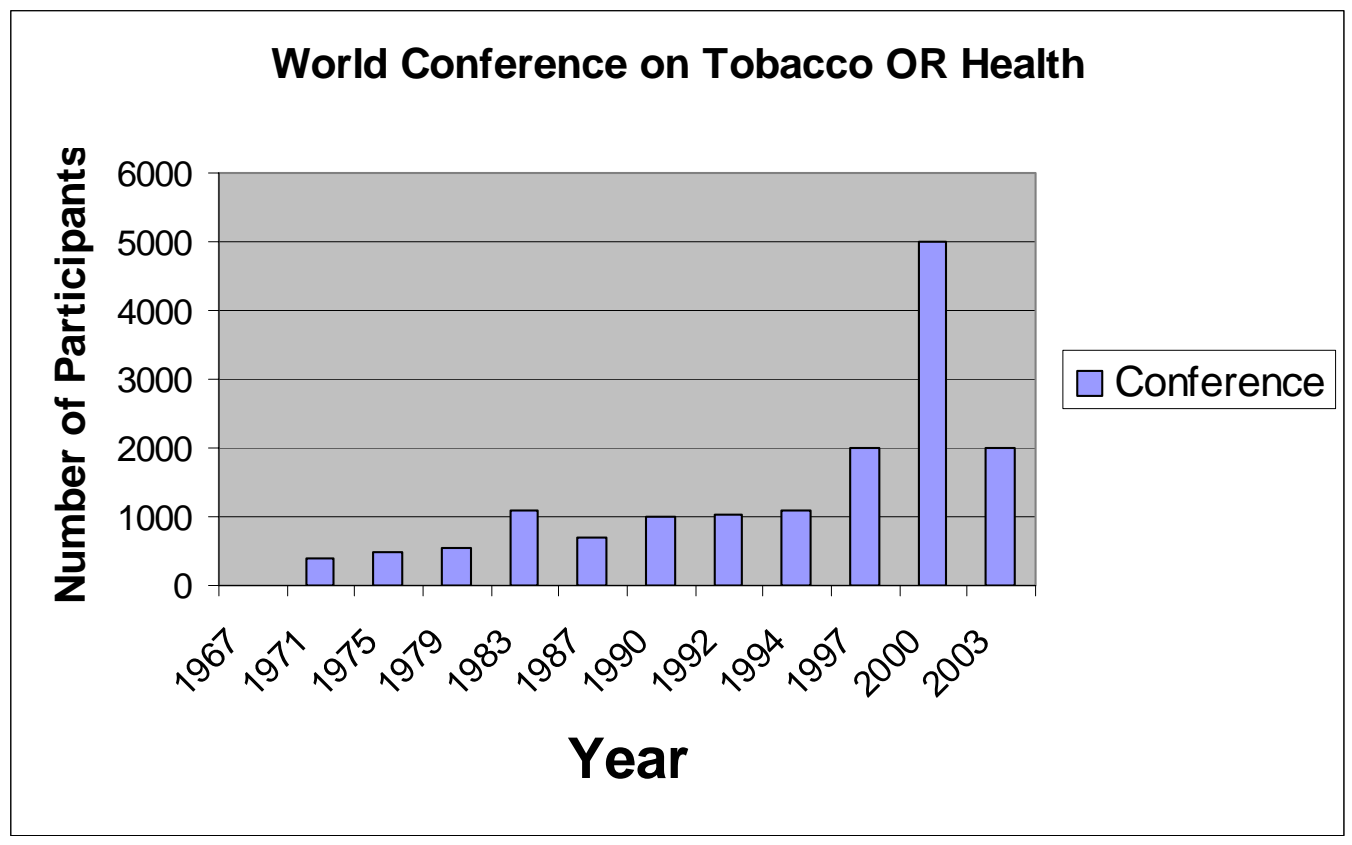




\section{1 “Best Practices” in Tobacco Control}

Studies in diffusion have demonstrated that policies or measures may originate from the ingenuity of an individual, a group, an organization, a firm, or even a state. The innovative policies or measures become models for emulation by others. A model refers to that which is displayed, symbolically interpreted, and copied but usually developed to deal with an issue (Braithwaite, 1994:450, Rose, 2005). It is “a generic description of how a program works” (Rose, 2005:71) The goal for the creation of a model is to "describe a program in terms sufficiently general for it to be portable across national borders, yet sufficiently concrete so that policymakers in the country importing a model will be able to relate each of its parts to activities with which they are familiar” (Rose, 2005:71). The model have been developed to deal with the global tobacco epidemic is known as the "Best Practices" in Tobacco Control (Nathan, 2004; Blanke, 2003; Selin and Bol, 2002; WCTOH, 2000; CDC, 1999).

Although the concept of "best practices" is familiar in other academic fields such as Medicine, Nursing, and Social Work, it is currently gaining grounds in the literature of Political Science in general, especially as public health issues (including tobacco control) are gaining more recognition. "Best practices" are defined as practice activities that are grounded in empirically based paradigms (Potocky-Tripodi, 2002:123; (Nathan, 2004; WCTOH, 2000; CDC, 1999). Borrowing from the Social Work literature, an empirically based paradigm is one that: (a) makes maximum use of research findings; (b) collects data systematically to monitor the intervention; (c) demonstrates empirically whether or not interventions are effective; (d) specifies problems, interventions, and outcomes in terms that are concrete, observable, and measurable; (e) uses scientific methods in 
defining clients’ problems, formulating questions for practice, collecting assessment data, evaluating the effectiveness of interventions, and using evidence; (f) views research and practice as part of the same problem-solving process; and (g)views research as a tool to be used in practice (Siegel, 1984:329; cited in Blythe and Tripodi, 1989:13). In terms of policy, "best practices" are policies and programs that have been empirically tested and proven to be effective in dealing with a problem. Such policies and programs have been promulgated, implemented, and evaluated to be effective and ready for emulation by others.

Organizations and institutions such as the CDC (1999:3-5), the WCTOH (2000), and the WHO, Pan American Health Organization (PAHO), and International Union for Health Promotion and Education (UHPE) (Nathan, 2004) have come out with "best practices” in tobacco control. For instance, the CDC’s (1999:3) manual on “best practices” draws upon evidence-based analyses of comprehensive tobacco control programs in the states of California and Massachusetts in the U.S. Similarly, contributors to the WCTOH (2000) World's Best Practices in Tobacco Control ${ }^{1}$ draw on evidencebased practices from New Zealand, Australia, United Kingdom, the United States, Ireland, Singapore, Canada, Norway, and Sweden as well as sub-national units such as the states of Victoria and Tasmania in Australia and California and Massachusetts in the U.S [see Table 5.1]. In addition, countries such as South Africa and Thailand have currently emerged as models of tobacco control, particularly for developing countries. The bottom line of all these works is that laggards in tobacco control can emulate innovated policies of leaders. These "best practices" in tobacco control have become the

\footnotetext{
${ }^{1}$ You can find the article at http://tc.bmjjournals.com/cgi/reprint/9/2/228 [accessed 07/26/2004]
} 
underlying principles of the FCTC [See Table 5.2]. Thus, in relating "best practices” in tobacco control to the FCTC, Nathan (2004:8) argues that

The Manual addresses the major regulatory topics covered by the FCTC. The FCTC calls upon national authorities to adopt and implement effective legislation, regulations, executive, administrative or other measures to carry out their regulatory obligations under the treaty. The Manuel is a tool for carrying out the FCTC's regulations. Following the Manual should ensure that national tobacco control legislation is FCTC compliant. Article $2^{2}$ of the FCTC encourages Parties to implement measures beyond those required by the Convention and its protocols. The provisions in the Manual help to accomplish that by providing a means for taking a comprehensive approach.

Table 5.1: Model Entities

\begin{tabular}{|l|l|l|l|}
\hline \multicolumn{1}{|c|}{ Countries } & Other Countries & \multicolumn{1}{c|}{ Sub-National } & \multicolumn{1}{c|}{ Regional } \\
\hline Australia & South Africa & California (USA) & The European \\
Canada & Singapore & Massachusetts (USA) & Union (EU) \\
Finland & Thailand & Tasmania (Australia) & \\
New Zealand & & Victoria (Australia) & \\
Norway & & & \\
Sweden & & & \\
United Kingdom & & & \\
United States & & & \\
\hline
\end{tabular}

\footnotetext{
${ }^{2}$ Article 2: Relationship between this Convention and other agreements and legal instruments: (1) In order to better protect human health, Parties are encouraged to implement measures beyond those required by this Convention and protocols, and nothing in these instrument shall prevent a Party from imposing stricter requirements that are consistent with their provisions and are in accordance with international law.
} 
Table 5.2: FCTC Provisions

\begin{tabular}{|l|l|}
\hline Policy & Article \\
\hline Taxation and non-price-related measures to reduce demand & 6 and 7 \\
\hline $\begin{array}{l}\text { Protection of non-smokers from exposure to smoke (“passive } \\
\text { smoking”) }\end{array}$ & 8 \\
\hline Regulation of tobacco contents and packaging & 9 and 11 \\
\hline Public awareness of the consequences of smoking & 12 \\
\hline Restriction on tobacco advertising and sponsorship & 13 \\
\hline Addiction and cessation programs & 14 \\
\hline Illicit trade in tobacco products & 15 \\
\hline Sales to and by minors & 16 \\
\hline Provision of support for economically viable alternative & 17 \\
\hline Tobacco-related research and information sharing among parties & 20,21 , and 22 \\
\hline
\end{tabular}

Source: WHO

The focus of tobacco control is curbing demand by controlling the behavior of tobacco users and curbing supply by controlling the activities of TTCs. It is both about making sure that individuals quit the deadly habit and that the tobacco industry stops promoting and spreading it. The tobacco industry is a transnational enterprise and as such "best practices" in tobacco control are usually designed to ensure harmonization in policies of countries to forestall a situation whereby the it will take advantage of policy differentials to promote and spread the habit worldwide. These "best practices" in tobacco control are meant to serve as guidance in the formulation of tobacco control policies and the design of tobacco control programs in various polities around the globe. This was the rationale behind Ruth Roemer's codification of tobacco control legislations around the world under the auspices of WHO in the 1980s (1982 and 1986) and 1990s (1993). The central purpose of Roemer's codification was identification of effective tobacco control policies and programs around the world worthy for emulation. It was a means of diffusing knowledge about innovated tobacco control policies worldwide. 
The essence of the "best practice" approach is adaptation of these models to suit domestic circumstances, that is, the domestication of tobacco control policies from other jurisdictions (Nathan, 2004:8). The logic here is that instead of countries using scarce resources to design their own unique tobacco control policies and programs, they can adopt and adapt already innovative policies so that they can direct their resources and efforts toward implementation. In this regard, Nathan (2004:7) argues,

The discipline of legal drafting and analysis generally is practiced by examining what has come before. Therefore, it is common when drafting legislation of any type to draw upon previous experiences and examples from other jurisdictions with a track record. Since there are many countries with solid, evidence-based tobacco control legislation, it only makes sense to examine how other countries have done, take what has been successful from around the world and adapt it to meet national needs.

The point here is that the WCTOH has been a critical venue for the emergence and spread of "best practices" in tobacco control at the global level. Before the emergence of the "best practices" concept in the lexicon of global tobacco control, participants at different world conferences had expressed the importance of having some basic policies in tobacco control. For instance, Mike Daube, a professor at the Department of Community Medicine of the University of Edinburgh, U.K. warned at the $4^{\text {th }}$ WCTOH in Stockholm, Sweden that policies must be designed to avoid the problem of fragmentation. Daube pointed out, “A basic policy has been agreed by WHO, UICC, IUAT and other health agencies, and this at least is one of the areas where we do not need to reinvent the wheels” ( $4^{\text {th }}$ WCTOH, 1979:335). Joseph Cullen $\left(7^{\text {th }}\right.$ WCTOH, 1990), 
Director of AMC Cancer Research Center, California, U.S.A also said at the $7^{\text {th }}$ WCTOH that

The time has come to discontinue fragmented, random and duplicative activities. National plans are imperative. The world (each country) must become organized, dedicated and highly focused on its goals to reduce tobacco-related diseases as the tobacco industry has been and continues to be” ( $7^{\text {th }}$ WCTOH, 1990:48).

In addition, Cullen called on that the International Advisory Body (IAB) to solicit advice from experts and codify what constitutes core of strategies in tobacco control, those that have been proven to work under clinical trial conditions and those that are policy directed and have a demonstrated high probability of payoff $\left(7^{\text {th }}\right.$ WCTOH, 1990:48). It is through the codification of tobacco control legislations around the world that "best practices" in tobacco control are determined and marked as models for emulation. Moreover, at the $8^{\text {th }}$ WCTOH, Chollat-Traquet of WHO announced the organization’s monograph, “Evaluation of Tobacco Control Experiences and Guiding Principles," the first reference text to bring together in a single work an overview and evaluation of all the major tobacco control measures that have been adopted by countries. All these are illustrations of the use of $\mathrm{WCTOH}$ as a venue for raising awareness about innovative tobacco control measures worthy of worldwide adoption. For about four decades, the WCTOH contributed to raising global awareness about the existence of innovated policies that countries everywhere in the world could use to solve their own tobacco problems. For this reason, the WCTOH has contributed in the transformation of tobacco control into a global issue. 


\subsection{An Epistemic Community in Tobacco Control: World Conference on Tobacco or Health (WCTOH)}

As indicated earlier [See Chapter 2], the WCTOH qualifies as an epistemic community (Haas, 1992, 1989; Alderman and Haas, 1992). The participants in the conference include experts in medicine and public health, policymakers, academics and researchers, specialized NGOs, and representatives from intergovernmental organizations - a resemblance of epistemic community (Haas, 2001, 1992, 1989; Alderman and Haas, 1992) [See Figure 5.2]. First, the deep core belief of participants at the WCTOH is that there is an unquestioned linkage between tobacco use and health hazards. They had a common fundamental belief about the science and evidence of tobacco use, and the $1^{\text {st }}$ WCTOH marked a gradual shift from emphasis on science to policy.

Moreover, the central purpose of the WCTOH has been to influence policy changes both domestically and internationally through individual participants, NGOs, states, and WHO. For instance, the purpose of the meeting of experts at the $1^{\text {st }}$ WCTOH conference was to find a way of reducing tar and nicotine volume in cigarettes in order to reduce the harm caused by tobacco use in the developed countries. In essence, the WCTOH has an underlying deep core belief, and it has being oriented towards policy change at different levels within the international system. In addition, it has played influential role in innovation of global tobacco control. 


\section{Figure 5.2: $\quad$ Tobacco Control Epistemic Community: WCTOH}

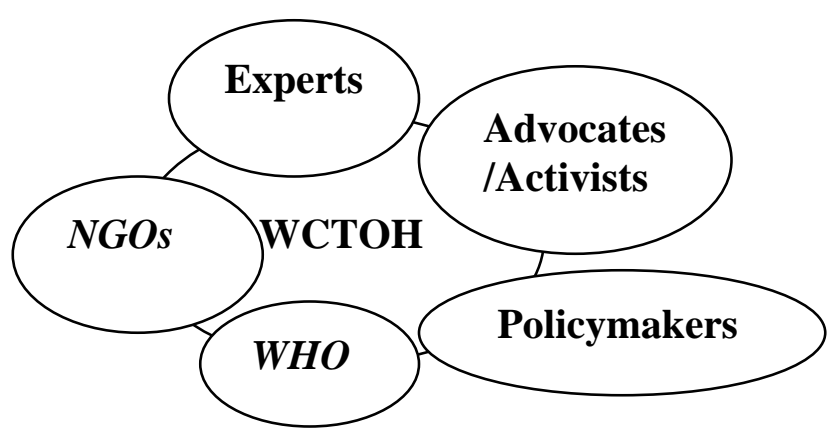

A review of the publications of the world conferences on tobacco (1967-2003) revealed that most of these "best practices" originated from developed countries. They innovated tobacco control policies to combat the rising trend of tobacco consumption and tobacco-related within their jurisdictions. For instance, at the Fourth WCTOH, Sir George Godber, Chairman, WHO Expert Committee on Smoking and Health, noted the spread of tobacco restrictions in industrialized countries. He indicated that only 13 industrialized countries had prohibited tobacco advertising by 1979 ( $4^{\text {th }}$ WCTOH, 1979:17). On the contrary, Julie Sulianti Saroso $\left(4^{\text {th }}\right.$ WCTOH, 1979) indicated the paucity of epidemiologic information on smoking associated morbidity and mortality in developing countries. Saroso emphasized the point that "anti-smoking programs are almost non-existing in developing countries" (4th WCTOH, 1979:22). However, in 1994, Ruth Roemer noted at the Ninth WCTOH that tobacco control legislation had been enacted in 91 countries, up from 57 in 1982. Out of the countries with tobacco control legislations, 28 had ban on advertising of tobacco products, 77 had health warnings, and 27 had a system of strong, rotating warnings pioneered by Sweden and perfected by Iceland with pictographs ( $9^{\text {th }}$ WCTOH, 1994:979). Particularly, Australia and Canada were identified as having the strongest health warnings in the world ( $9^{\text {th }}$ WCTOH, 
1994:979). Roemer ( $9^{\text {th }}$ WCTOH, 1994: 980) further indicated that developing countries have joined the campaign to protect their people from the ravages of tobacco use, with Thailand and African countries as examples (Roemer, 1993; Yach and Harrison, 1993).

A review of worldwide tobacco control legislations using the $2003 \mathrm{WHO}$ Tobacco Control Country Profiles revealed that more than 90 percent of the countries in the world have some form of tobacco control legislation. Almost all the industrialized countries, using OECD membership as baseline, have tobacco control legislation. The few countries in the world without any form of tobacco control legislation are located in the developing world. The evidence from the Tobacco Control Country Profiles reinforces the assertion that tobacco control in general originated from developed countries. However, the recognition by people such as Berit As, a member of Norwegian Parliament and Sir George Godber, at the Second and Third world conferences that tobacco use was gradually emerging as a problem in the developing countries due to the activities of tobacco companies resulted in the inclusion of the developing countries in the agenda of the Fourth WCTOH.

Between the Fourth and Ninth WCTOH (1979-1994), tobacco control became an international issue because tobacco use transcended all national boundaries regardless of the level of development. In addition, the worldwide activities of TTCs and the increasing trend of tobacco use received attention. Eventually, the recognition that states could not handle the tobacco issue individually led to the recommendation at the Ninth WTCOH in Paris, France in 1994 that there should be an international strategy to combat tobacco use through a form of convention [See Table 5.3]. This is consistent with the policy selection role of epistemic communities (Alderman and Haas, 1992:381). In this 
respect Alderman and Haas point out, "If no institutions yet exist in which responses to be given to a problem can be pursued internationally, the community can provide a new institutional framework for dealing with the problem” (p.381). The WCTOH urged WHO member states to adopt a global convention on tobacco control. In effect, the WCTOH contributed to the provision of a new institutional framework for dealing with the problem of global tobacco epidemic.

Consequently, in 1995, WHO member states adopted Resolution WHA48.11, urging the Director-General of WHO to prepare grounds for a global convention on tobacco control, resulting in the formation of the FCTC. In this respect, the foundation of the FCTC was laid at the Ninth WCTOH. In fact, WHO resolution WHA48.11 of 1995 made reference to the $1994 \mathrm{WCTOH}$ resolution on development of an international convention on tobacco control. Also, it was made clear at the ICITT that no country could single-handedly combat the problem of cross-border smuggling; hence the resolution at the conference became basis of FCTC negotiation. For this reason, this chapter discusses the contribution of international conferences (WCTOH and ICITT), NGOs, and international tobacco control research institutions in the evolution of tobacco control as a global issues as well as transfer and diffusion of "best practices" in tobacco control to different jurisdictions in the world. For about four decades, these activities within the international system laid the foundation of global tobacco control; hence the assertion that the emergence of the FCTC was an evolutionary process, and international conferences on tobacco control have been part of this process. The persistency of the WCTOH throughout the period (1962-2003) and beyond makes it an example of epistemic community (Alderman and Haas, 1992:384). 


\subsubsection{First Phase: - Tobacco Control as a Developed Countries Issue}

The new phase of tobacco control began with the First WCTOH. Also, the First WCTOH began the transformation of tobacco control into a global issue through international conferences. The conference began an era of action to combat the use and spread of tobacco through international collaboration. This was due to the recognition that the main culprit in the tobacco epidemic is the tobacco industry. For instance, Senator Robert Kennedy said at the opening session of the First WCTOH that we cannot seriously expect to make major inroads in people’s smoking habits while 30 million dollars a year is spent to increase the number of those addicted (WCTOH, 1967). This new phase of tobacco control was not only about finding measures to curb tobacco use but also finding ways to limit the ability of the tobacco industry to promote tobacco use. Under this situation, one could observe policy following problem. For instance, three years after the First WCTOH reinforced the scientific evidence on hazards of tobacco use and raised awareness about the international nature of the problem, WHO officially recognized the linkage between tobacco use and health. In addition, WHO became a cosponsor of the Second WCTOH. This is an illustration of how the WCTOH is linked to international tobacco control.

In spite of the fact that the WCTOH began internationalization of collaborative efforts to curb the use and spread of tobacco, the scope of the First, Second, and Third conferences was limited. This is because the earliest conferences were meant to find solutions to tobacco use in developed countries. However, at the Third WCTOH, people like Sir George Godber and Berit As forcefully drew attention during plenary sessions to 
an emerging problem of tobacco use in developing countries. This culminated in the purposive expansion of the scope of the conference and inclusion of participants from developing countries and around the world. At the same conference, it was recommended that WHO should constantly collect and evaluate information on smoking and health in all the countries of the world and to distribute the information to member states, as well as cooperate with the FAO and ILO to let them be aware of the health implications of tobacco use. Moreover, the conference endorsed the 1974 WHO Expert Committee on Smoking Report that reinforced the linkage between tobacco use and health (Akhmeteli, 1975). Furthermore, the conference recommended that the right of nonsmokers should be protected. It urged states to use education and legislation to curb tobacco use. Finally, it recommended that states should find a way of phasing out tobacco growing in favor of more useful crops. The endorsement of the Expert Committee Report was recognition that tobacco control goes beyond the developed world, and as such subsequent conferences integrated tobacco control in developing countries into the agenda. In this respect, the Fourth WCTOH began another phase of tobacco in the evolutionary process.

\subsubsection{Second Phase: - Tobacco Control as a Worldwide Issue}

At the Fourth WCTOH, tobacco use in developing countries was included in the agenda of the conference for the first time. In addition, people from developing countries were sponsored to participate in the conference. Hedda Lindahl, the Swedish Minister of Health, noted in the inaugural speech that the 1974 WHO Expert Committee report confirmed that the best preventive measure for improving the health of industrial countries was preventing tobacco use. At the same time, Lindahl pointed out that tobacco 
use was spreading very fast in developing countries where it was formerly less common, hence the conference was mainly set up to help solve this complicated problem $\left(4^{\text {th }}\right.$ WCTOH, 1979:2). The main rationale was that becoming aware of the hazards of tobacco is a big step towards curbing the habit ( $4^{\text {th }}$ WCTOH, 1979:2). Olle Hillerdal also said in the welcoming speech to the $31^{\text {st }}$ World Health Assembly in May 1978 that there was serious concern at the alarming increase in production and consumption of cigarettes during the last two decades in some countries, particularly developing countries, in which it had previously not spread ( $4^{\text {th }}$ WCTOH, 1979:6). Since the Fourth WCTOH, curbing tobacco use and combating the activities of the tobacco industry in developing countries have been underlying issues in all the subsequent world conferences. Thus, the Fourth to Eight conferences (1975-1992) are categorized as the second phase of the evolution of global tobacco control.

A review of the publications of all the conferences for the second phase portrayed that besides finding the scientific basis for tobacco control policies, the two main underlying issues the conferences addressed were the international collaborative strategy for tobacco control and tobacco use in developing countries. The quest to achieve these goals gradually propelled tobacco control onto the global agenda.

First, the main consensus from the Fourth WCTOH onwards was that combating worldwide tobacco use required international collaboration. Olle Hillerdal argued, “substantial reduction of smoking-related problems in some countries, and prevention of similar problems in others will take a lot of effort and development in many areas and process will be facilitated by international collaboration” (4 ${ }^{\text {th }}$ WCTOH, 1979:7). Also, Halfdan Mahler, the Director General of WHO, reiterated the point that solutions to 
problem of tobacco use require the promotion of international collaboration $\left(4^{\text {th }} \mathrm{WCTOH}\right.$, 1967:10). According to George Godber, the international collaboration requires WHO, Food and Agricultural Organization (FAO), International Labor Organization (ILO), United Nations Conference on Trade and Development (UNCTAD), and the World Bank working to stop supporting schemes for tobacco growing, processing, and marketing $\left(4^{\text {th }}\right.$ WCTOH, 1979:17). However, for R. Masironi of WHO Cardiovascular Disease Unit, the collaboration requires not only UN agencies working together in the field of tobacco control but also WHO collaborating with NGOs such as the UICC, IUPHE, and International Union Against Tuberculosis (IUAT) $\left(4^{\text {th }}\right.$ WCTOH, 1979:310). This was realization that combating tobacco use at the global level requires collaboration among different intergovernmental organizations and nongovernmental organizations. As such, subsequent conferences attempted to find ways of involving individuals, groups, and WHO and other organizations in an international collaborative efforts to halt the use and spread of tobacco worldwide.

In the case of the second issue - tobacco use in developing countries, Mahler argued at the $4^{\text {th }}$ WCTOH that developing countries, whose peoples are largely unaware of the consequences of tobacco use, have become target of a vast campaign to promote the habit by the tobacco industry, and WHO and the Conference have duty to sound the alarm bell to such countries ( $4^{\text {th }}$ WCTOH, 1979:13). In addition, Leo Kaprio, WHO European Regional Director, argued that the responsibility of the international community keeps on increasing with the spread of tobacco use worldwide and it is becoming a problem in many developing countries, where previously it was unknown, hence the need for international collaboration $\left(4^{\text {th }}\right.$ WCTOH, 1979:298). Halting the 
extension of activities of TTCs in developing countries was deemed as the moral duty of WHO and participants in the world conference. With regard to this issue, Kaprio said, "As we all know, pressures against the reduction of tobacco-smoking are such that for proper preventive action there must be international moral support, as well as a continuous flow of information on how to combat the habits and traditions which underlie the tobacco-caused diseases" ( $4^{\text {th }}$ WCTOH, 1979:298). Daube also argued elaborately at the Fifth WTCOH that the struggle to halt the spread of tobacco to developing world should be seen as a "war," given the determination of the tobacco industry to export the habit to such countries $\left(5^{\text {th }}\right.$ WCTOH, 1983:48). These instances illustrate the interest of the WCTOH in limiting the spread of tobacco to developing countries.

The main concern after the $4^{\text {th }}$ WCTOH was how to stop the observed trend in developing countries of an increasing number of tobacco users and activities of the tobacco industry. Since tobacco control measures were primarily non-existing in developing countries ( $\left.4^{\text {th }} W C T O H, 1979\right)$, the consensus in subsequent conferences was to spread knowledge, information, and ideas about tobacco use and tobacco control policies innovated in developed countries into developing countries. For instance, Mahler indicated at the Fourth WCTOH that innovated tobacco control measures had already been taken in countries such as Canada, Australia, and Finland, and they are models for emulation by countries (including developing ones) $\left(4^{\text {th }}\right.$ WCTOH, 1979:11). According to Godber, "the strategies that will resist marketing of cigarettes in the West should resist the enlargement of the cigarette market in the East. The same strategies will resist the change of culturally entrenched smoking habits towards more sophisticated western 
smoking habits” (5 $5^{\text {th }}$ WCTOH, 1983:84). Thus, diffusion and transfer of tobacco control measures became integral part of the process of transformation of tobacco control as a domestic issue into international issue.

Between 1979 and 1994, those interested in the use of international collaborative efforts to combat worldwide tobacco consumption called at different world conferences for transfer of innovative policies in developed countries to developing countries. First, Godber said at the Fifth WCTOH "our objective ... is to resist the transfer of Western smoking pattern to the developing world. The strategy to do this are well developed and much the same in India as they are in America” (5 $5^{\text {th }}$ WCTOH, 1983:84). Second, D. Femi-Pearse from University of Lagos (Nigeria) College of Medicine also said, “A series of actions that have been taken with success [in developed countries] can be repeated in the Third World" (5 $5^{\text {th }}$ WCTOH, 1983:66). Third, in the closing address of the Fifth WCTOH, N.C. Delarue from Canada argued that the transfer of information that has been generated by those in "advantaged” positions to the "disadvantaged' becomes an international imperative for the 1980s ( $5^{\text {th }}$ WCTOH, 1983:804). Finally, Mahler said, “It seems the industrialized countries which, unknowingly at first, helped to sell a bad habit to the world, are now making amends. In this day of rapid communication of ideas and images from country to another, industrialized countries are spreading the word that a smoke-fouled society is yesterday's fashion, out-of-date. A smoke-free society is the trend, the new fashion, the latest, the smartest, worthy of emulation" ( $6^{\text {th }}$ WCTOH, 1987:12). These illustrate how participants at different world conferences called for deliberate transfer of innovative tobacco control policies in developed countries to developing countries. 
The adopted approach to combat the spread of tobacco to developing countries entailed informing the public at large about the hazards of tobacco use. It was pointed out that a public information program is one of the keys to counter the activities of the tobacco industry ( $5^{\text {th }}$ WCOTH, 1983:47). Just like other world conferences, it was realized that information and knowledge about tobacco use is necessary for combating the activities of the tobacco industry. Lack of knowledge about tobacco use was seen as the reason why people in developing countries continue to be vulnerable to the activities of the tobacco industry (5 $5^{\text {th }}$ WCTOH, 1983:59-69). As Mahler pointed out, the power of the tobacco industry lies in the fact that it is transnational in nature; the health enterprise should also be transnational so that it can spread ideas on tobacco use across the world ( $5^{\text {th }}$ WCTOH, 1983:101). In addition, tobacco control measures recommended by WHO Expert Committee, WHA, the UICC, the IUAT and other international bodies were deemed as comprehensive program for adoption, albeit needing slight changes to meet domestic situations ( $5^{\text {th }}$ WCTOH, 1983:50).

In spite of the conference's efforts at international collaboration, the emphasis was on acting through national governments, WHO, and other UN agencies. For this, Godber said, "at the end of the day, governments must make this campaign effective and it may be WHO and this conference that will shame them into doing it" ( $5^{\text {th }}$ WCTOH, 1983:75). Femi-Pearse also said, "the exponential growth of the habit of cigarettesmoking [in developing countries] can be controlled only when government, the tobacco industry and the populace subscribe to a moratorium to reduce the scourge of tobacco smoke" ( $5^{\text {th }}$ WCTOH, 1983:67). Moreover, in talking about the adoption of policies that emerged at the $5^{\text {th }}$ WCTOH, Daube, Executive Director, Health Promotion and Education 
Services, Health Department of Western Australia said, "I hope that major development by the time of the next conference is that governments and major health agencies will recognize, take over, and claim they invented this approach” (5 ${ }^{\text {th }}$ WCTOH, 1983:58). In essence, until the $9^{\text {th }}$ WCOTH, national governments, WHO and other UN agencies were identified as the main bodies that could ensure the realization of the recommendations and resolutions ("best practices" in tobacco control) of the world conference. Still, NGOs such as the UICC conducted workshops in 20 developing countries $\left(5^{\text {th }}\right.$ WCTOH, 1983).

From the fourth to the fifth conferences, the scope of the conference was expanded to engulf the rest of the world. Issues of concern to countries with special characteristics and circumstances became the focus of the sixth, seventh, and eighth world conferences. For instance, tobacco control in countries dependent on tobacco production was given elaborate consideration at the $6^{\text {th }}$ WCTOH in Tokyo, Japan in 1987. The conference reviewed effectiveness of transferring tobacco control measures into developing countries. Among the programs reviewed were WHO studies on tobacco use in China and the Philippines as well as collaboration with Fiji, French Polynesia, Papua New Guinea, Tonga, and Egypt (6 $6^{\text {th }}$ WCTOH, 1987:28 and 64). Other activities included the Western Pacific Regional Committee's effort to curb tobacco use in the region $\left(6^{\text {th }}\right.$ WCTOH, 1987:29-30). All these programs in developing countries were deemed effective. For this reason, at the $7^{\text {th }}$ WCTOH in Perth, Australia, in 1990, efforts were geared towards perfecting this trend. As a result, a smoking control program developed by the UICC in 1975, under the chairmanship of Nigel Gray, and accepted by other international organizations (including WHO) was identified as the basis for comprehensive tobacco control program $\left(7^{\text {th }}\right.$ WCTOH, 1990:4). 
Also, the WHO's “World No Tobacco Day” program was identified at the $7^{\text {th }}$ WCTOH as a global strategy to combat tobacco use ( $7^{\text {th }}$ WCTOH, 1990:9). In addition, research and other tobacco control activities in developing countries were examined. It was established at the conference that a number of key African individuals and organizations are arming themselves with the tools and strategies that have emerged from years of efforts around the world, and that they were well reflected at World Conferences on Smoking and Health (7 $7^{\text {th }}$ WCTOH, 1990:169). Between 1983 and 1990, the UICC supported site visits and planning meetings in Sudan, Kenya, Tanzania, Uganda, Botswana, Ethiopia, Zimbabwe, Zambia, Nigeria, Cameroon, and Senegal. The impact of such activities ranged from formation of anti-tobacco groups, legislative actions, data collection, and dissemination of information to stimulation of interest in tobacco control ( $7^{\text {th }}$ WCTOH, 1990:175-177).

The evolution of the conference on tobacco into a global conference became complete with the $8^{\text {th }}$ WCTOH in 1992 in Buena Aires, Argentina, the first in a developing country. It ended the developed countries' dominance of the conference. Not only was the number of participants diversified and countries from all regions of the world represented, but also the World Bank, UNICEF, and UNESCO participated in the conference for the first time. However, issues deliberated at the conference were similar to earlier ones. The emphasis was on strategies to curb the worldwide activities of the tobacco industry. On this, the WHO Director-General, Hiroshi Nakajima, emphasized the importance of an international coalition on tobacco control in the face of a strong and wealthy tobacco industry, the virtue of the "best practices" approach to tobacco control, and the effectiveness of diffusion and transfer of tobacco control measures to different 
parts of the world, particularly developing countries ( $8^{\text {th }}$ WCTOH, 1992:6). Still, the emphasis of global tobacco control was on national governments despite UICC's successful tobacco control workshop in Nigeria in November 1992, the beginning of tobacco control in West Africa ( $8^{\text {th }}$ WCTOH, 1992:12), and the Canadian International Development and Research Center's decision to fund research programs in certain countries in Africa. Through the contribution of the WCTOH, by the $8^{\text {th }}$ conference, tobacco control had gradually evolved into a global issue.

\subsubsection{Final Phase: - Development of a Global Tobacco Control Regime}

A new phase of tobacco control started with the $9^{\text {th }}$ WCTOH in 1994 in Paris, France. At the conference it was realized that reducing tobacco consumption requires a global strategy. This strategy requires uniting all those engaged in tobacco control activities around the world under the auspices of the international alliance of public health led by WHO, UICC, IUATLD, International Systemic Functional Congress (ISFC), International Organization of Consumers Unions (IOCU), and IUPHE. As a result of the global focus of the conference, it was resolved that all nations should adopt and implement the International Strategy for Tobacco Control [see Table 5.4]. The uniqueness of the conference was that it called on national governments, Ministers of Health, and WHO to immediately initiate action to prepare and achieve an International Convention on Tobacco Control to be adopted by the UN as an aid to the enforcement of the International Strategy for Tobacco Control adopted by the $9^{\text {th }}$ WCTOH $\left(9^{\text {th }}\right.$ WCTOH, 1994:1017). This resolution was subsequently integrated into WHA48.11, becoming the basis for negotiation of the FCTC. The subsequent conferences - the $10^{\text {th }}$ in Beijing, 
China in 1997, the $11^{\text {th }}$ in Chicago, USA in 2000, and the $12^{\text {th }}$ in Helsinki, Finland in 2003 were all geared toward strengthening scientific evidence on hazards of tobacco use, identification and diffusion of more "best practices" in tobacco control, and the realization of the first global regime on health, the FCTC.

\section{Table 5.3: International Strategy of Tobacco Control}

Strategies

1. Legislation to ban all direct and indirect advertising and promotion of tobacco products

2. Legislation to protect young people from tobacco promotion and sales

3. Policies to discourage the onset and maintenance of tobacco use, including a. Intensive health education and information to young people and adults;

b. Wide availability of support for tobacco users who wish to stop

4. Economic policies to discourage production and use of all tobacco products taxation, abolition of tobacco subsidies, alternative sources of livelihoods etc

5. Warning and regulation of tobacco product packaging

6. Regulation of tar and nicotine content

7. "Smoke-free" public policies

8. Blocking future marketing initiatives of TTCs

9. Monitoring of the tobacco pandemic and enforcement of these control measures

Source: 9th WCTOH, 1994:1018

\subsubsection{Impact of WCTOH on Global Tobacco Control}

In nutshell, the key purpose of WCTOH has been accumulation of evidence on tobacco use and policies for combating the practice around the world. Harold Diehl, deputy Executive Vice-President for Research and Medical Affairs of American Cancer Society, pointed out that not only was the First WCTOH meant to examine the available knowledge on tobacco use and tobacco control, but also to deal with the practical 
application of the knowledge ( $1{ }^{\text {st }}$ WCTOH, 1967:XIII). There is a strong consensus within the WCTOH about the hazards of tobacco use. In addition, it has been involved in innovation and diffusion of "best practices" in tobacco control and helping to define decision-makers' interests. Thus the WCTOH perform roles of epistemic community (Haas, 1992, 1989; Alderman and Haas, 1992).

First, in summarizing the importance of the WCTOH in the spread of knowledge about tobacco use and tobacco control, George Rosemond, President of American Cancer Society, and Gio Gori of the National Cancer Institute noted at the Third WCTOH that the volume produced on the proceedings of the conference summarizes the important research on the health consequences of tobacco use, contains a review of worldwide governmental and social efforts to restrict smoking and regulate tobacco production, and presents recommendations for future action $\left(3^{\text {rd }}\right.$ WCTOH, 1975:xvi). For instance, recommendations at the Second WCTOH included a call on all governments to consider as matter of urgency the recommendations of the Executive Board of the WHA on limitation of smoking, call on WHO to consider the formation of an international depository of information of education material and national activities, and call on WHO regional directors to consider appropriate arrangements for further international conferences on smoking and health $\left(2^{\text {nd }}\right.$ WCTOH, 1971:162). The accumulation of knowledge on tobacco use has had an impact on curbing the practices. In this case, George Godber, said at the $4^{\text {th }}$ WCTOH at Stockholm, Sweden in 1979 that the impact of the accumulation of knowledge about tobacco use and tobacco control is that "After nearly 30 years of knowledge in Britain things have begun to move in a way [decreasing trend of tobacco use] that it did not seem possible even in 1970 (4h WCTOH, 1979:18). 
The WCTOH has contributed to accumulation of knowledge about tobacco use and tobacco control, the ultimate catalyst for the adoption of the FCTC.

Second, the WCTOH has been a venue of lesson drawing and diffusion of tobacco control measures, especially to developing countries. This issue was first considered at the Second WCTOH (1971:157). However, people like Charles Fletcher, Vice-Chairman of the Health Education Council (HEC) of United Kingdom, considered it unsafe to transfer policies in the West to developing countries $\left(2^{\text {nd }}\right.$ WCTOH, 1971:157). The main rationale for the caution was that most of the information on tobacco control has been derived from Western nations. This view was rebutted at the Fourth WCTOH. At the $4^{\text {th }}$ WCTOH, Mike Daube argued, "In the past our opponents have sometimes ... asked whether the lessons learned from studies in Britain and the U.S. are applicable to different countries and continents. ... It is of particular importance that nearly one-third of cancer in men was observed to be attributable to cigarette smoking in Japan, the US, and the UK" $\left(4^{\text {th }}\right.$ WCTOH, 1979:326). Also, in talking about tobacco control and tobacco use in developing countries, Julie Sulianti Saroso, a medical doctor from Indonesia, noted that the conference and other relevant sciences would help developing countries to develop realistic tobacco control programs ( $\left.4^{\text {th }} W C T O H, 1979: 23\right)$. From then onwards, policy transfer from developed countries to developing countries was deemed as appropriate policy approach towards combating tobacco use around the world.

In fact, based on the adoption of a memorandum on a smoking ban in public places by Arab Gulf Health Ministers Conference in Muscat and UICC successful workshop on smoking control in Egypt, developing countries were encouraged to draw on the experiences of Norway, Finland, and other developed countries to develop 
comprehensive tobacco control programs $\left(4^{\text {th }}\right.$ WCTOH, 1979:333). In this regard, Mike Daube pointed out, “one of the most encouraging developments since Stockholm $\left(4^{\text {th }}\right.$ WCTOH) is that more of us have gone to war in countries ranging from Hong Kong and Austria, to China Kuwait and Australia” (5 $5^{\text {th }}$ WCTOH, 1983:48). This was an illustration of translation of the resolutions and recommendations of the WCTOH into actions

Third, the WCTOH acquainted participants with knowledge of tobacco control. This could be discerned from comments made by participants at the Twelfth $\mathrm{WCTOH}^{3}$ in 2003 in Helsinki, Finland. For instance, a Gambarian summed up participants’ hopes for the conference itself. “Communication, communication, communication!” she said with a smile, adding that the WCTOH is "different from other conferences in that it brings together all aspects of tobacco control from different perspectives.” Alexis-Thomas, a participant said, "I want to network more and find more resources I can use in my home country and region. The main problem we're dealing with there is apathy. We have to move to a realization that it's a public health problem that must be dealt with like SARS, very aggressively.” "So far there hasn’t been much coming out of the Caribbean on tobacco control. I hope that someday there can be a conference in our neck of the woods,” adds the Tobagonian health official. These comments illustrate that participants usually learn from the experiences of others. However, due to the fact that the conference has no permanent agency or direct link to any specific organization, the support from IOs such as WHO and FAO and governments was deemed as necessary for the diffusion and transfer of tobacco control measures to developing countries ( $4^{\text {th }}$ WCTOH, 1979:298). Thus, since the $4^{\text {th }}$ WCTOH there have been conscious efforts to diffuse and transfer tobacco control measures to developing countries through WHO, other IGOs, and NGOs. 
Finally, the use of international strategy in the effort to combat tobacco use has been a key aspect of the WCTOH. This is due to the transformation of tobacco control into an international issue. For instance, Kaprio, WHO Regional Director for Europe noted at the $3^{\text {rd }}$ WCTOH that he has witnessed the gradual growth of the tobacco issue into an international issue since the 1950s publications on the hazards of tobacco use because of the importance international organizations have placed on the area $\left(3^{\text {rd }}\right.$ WCTOH, 1971:16-17). IOs, particularly WHO, usually adopt the conference resolutions and recommendations. At the $3^{\text {rd }}$ WCTOH, George Godber pointed out that in 1974 , WHO’s Expert Committee went through the evidence and endorsed all that had been said by Doctors Fletcher and Horn in their 1970 report ( $3^{r d}$ WCTOH, 1975:28). The report has earlier been adopted by the $23^{\text {rd }}$ WHA in May 1970, calling the attention of member states to the dangers of tobacco use and urging them to take action. Moreover, the Fifth WCTOH recommendation on the need for "World Non-Smoking Day" was eventually adopted as resolution WHA40.38 in 1987 by the member states of WHO. Similarly, WHO adopted the 1994 WCTOH resolution on the development of an international convention on tobacco control at the $48^{\text {th }}$ WHA, leading to the formation of FCTC. In this sense, the WCTOH has been influential in setting the agenda for tobacco control at the global level. Thus, it has contributed to the evolution of tobacco control from a domestic phenomenon into a global phenomenon.

\footnotetext{
${ }^{3}$ http://www.tupakka.org/images/WCTOH_dailynews2.pdf [accessed 8/14/2004]
} 


\subsection{International Conference on Illicit Tobacco Trade ${ }^{4}$ (ICITT)}

The ICITT was held from July 30 to August 1, 2002 in New York, with the specific goal of finding appropriate policies ("best practices”) for combating cross-border smuggling and other illicit trade in tobacco and tobacco products around the world. The Conference was meant to provide delegates with the opportunity to share experiences and identify "best practices" to combat illicit trade in tobacco and tobacco products at the national, regional, and global level (ICITT Report, 2002:1-2). Representatives of law enforcement, taxation and revenue, and custom agencies from 142 countries and government observers, as well as about 50 NGOs in official relations with WHO, members of civil society, industry, news media, and the public participated in the conference - a form of epistemic community. The final report of the Conference was made available to everyone, especially those participating in the FCTC negotiating process.

In general, illicit trade in tobacco involves bootlegging, large-scale organized smuggling involving criminal organizations, and counterfeiting. Bootlegging occurs in situations where there are substantial price differentials between neighboring states. In this case, tobacco products are purchased in a low tax area and sold illegally in high tax area. The usually cited example of bootlegging is the illegal traffic of hand-rolled tobacco between Belgium and the United Kingdom. A 50g pack of hand-rolling tobacco costs 1.80 pounds sterling in Belgium but 7.80 pounds sterling in the United Kingdom in 1998. For this reason, gangs buy the tobacco in Belgium and transport them to United Kingdom, making a daily profit of about 2000 pounds (Groom, 1998). However, in the

\footnotetext{
${ }^{4}$ Co-Chairpersons' Report, Executive Summary, www.atf.gov/tobacco/icitt/index.htm [accessed 8/17/2004]
} 
absence of big price differentials between countries, bootlegging is regarded as small part of the entire problem of illicit trade in tobacco and tobacco products (Joossens, 2000).

Counterfeiting refers to illegal manufacture of cigarettes. It is a problem regarding illicit tobacco trade in developing countries. For instance, it has been estimated that more than 50 billion of cigarettes in China are manufactured illegally (Yuan, 1997:32). Still, counterfeiting is a lesser problem in global illicit trade in tobacco compared to large-scale smuggling. As such, it is not a significant threat to global tobacco control.

The largest form of illicit trade in tobacco and tobacco products that threatens global tobacco control is large-scale smuggling. This is because the phenomenon has increased in all regions of the world, regardless of tax rates (World Tobacco File, 1998; Joossens et al. 1992). It is estimated that trade in contraband sales of tobacco around the globe grew by 110 percent between 1990 and 1997 (World Tobacco File, 1998). About 400 billion cigarettes or one-third of all legally exported cigarettes are smuggled across international borders every year (Joossens and Raw, 1998). Smuggling has been identified as important feature of the cigarette market that depresses legitimate sales in future (World Tobacco File, 1998:1322). Given the enormity of this form of illicit trade in tobacco, it emerged as one of the issues of concern during the second working group meeting on FCTC in March 2000 in Geneva, Switzerland. Many countries expressed support for protocols to eliminate tobacco smuggling. ${ }^{5}$

One of the key players in the large-scale smuggling of tobacco and tobacco products is the tobacco industry. The first indicator of the involvement of the industry in smuggling is that there has been several court cases and official investigations in different parts of the world, accusing the industry of smuggling. Examples include: (a) a BAT 
executive was found guilty by Hong Kong's High Court for his role in an operation that smuggled cigarettes to China; (b) an affiliate of RJ Reynolds International pled guilty to charges of helping smugglers illegally reroute export cigarettes in Canada; and (c) the UK Government Department of Trade and Industry's investigation of BAT over tobacco smuggling. Another indicator of the tobacco industry's involvement in smuggling is the uncovering of code words or euphemisms used to refer to smuggling in the tobacco industry documents. These identified code words include: (a) Transit - "With Regards to the definition of transit it is essentially the illegal import of brands from Hong Kong, Singapore, Japan, etc., upon which no duty has been paid"6; (b) Duty Not Paid (DNP) "Is the volume of cigarettes produced in Venezuela, exported (mainly to Aruba) and reentering Venezuela as transit plus transit cigarette produced elsewhere (mainly Ecuador and Brazil)"; ; (c) General Trade - "The imported segment [in Taiwan] has increased each year and penetration reached 32.6\% in 1993. This figure includes legal imports which accounted for 6.7 bns in 1993... plus GT imports estimated at 7.6 bns (17.4\% SOM [share of market]) (Campaign for Tobacco-Free Kids, p.6)." ${ }^{, 8}$ In the internal document of BAT, the Global Five-year Plan 1994-1998, it is estimated that about six percent of the total world cigarette sales of 5.4 trillion were DNP sales in 1993. ${ }^{9}$ East Europe and Asian Pacific account for majority of the DNP (c85blln each). The estimated DNP shares of the total market in the following regions are: Eastern Europe (c13\%), Africa/Middle East (c12\%), Latin America (c9\%), and Western Europe (c7\%). In addition to the

\footnotetext{
${ }^{5}$ WHO document, A/FCTC/WG2/3, http://www.who.int/gb/fctc/PDF/wg2/ef23.pdf [accessed 04/15/2005],

${ }^{6}$ BAT letter dated August 25, 1989; BAT Bates No. 302000021

${ }^{7}$ BAT internal document, file owner Keith Dunt, "Venezuelan Market Definitions and Assumptions." Undated, Bat Bates No. 500025647

${ }^{8}$ BAT internal document entitled “Review of Asia-Pacific Market,” January 1995, BAT Bates No. 502628801

${ }^{9}$ BB0153/DEP0274/500018206/ www.ash.org.uk/smuggling/048.pdf
} 
euphemisms, the tobacco industry documents revealed that tobacco companies use terms such as "wholesaler," "distributor," "buyer," "transit," or "agent” to refer to others involved in the smuggling business (Campaign for Tobacco-Free Kids, p.6). It is through these that the tobacco industry has been identified as a participant and beneficiary of global smuggling in tobacco and tobacco products (Jha and Chaloupka, 1999).

The major effect of illicit trade in tobacco and tobacco products is that it depresses the price of tobacco and thereby stimulates consumption, indirectly (pressure to reduce taxes) and directly (sale of cheap cigarettes) (Jha and Chaloupka, 1999). For example, Canada and Sweden reduced tobacco taxes in response to the issue of smuggling in 1994 and 1998, respectively (Sweanor, 1997; Wendleby and Nordgren, 1998). From 1979 to 1991, the real price of cigarettes in Canada increased by 159 percent and cigarette consumption among the teenagers fell from 42 percent to 16 percent. However, in 1994, due to concerns over smuggling, Canada reduced tobacco taxes that resulted in a one-third fall in price cigarettes, leading to an increase in teenage cigarette consumption rate from 16 percent to 20 percent (Health and Welfare Canada, 1991; Health Canada, 1994). Furthermore, smuggling leads to loss of revenue. In this case, the revenue that may have been accrued to government is lost because smuggling circumvents tariffs and non-tariff barriers to trade. For example, it is estimated that approximately 1000 freight containers of Imperial Tobacco (UK) cigarettes were diverted into the black market in 2000, each one causing a tax loss of about US\$2 million to the UK government (Bates, 2002). In addition, governments lose revenue through tax reductions on tobacco. For example, it is estimated that the February 1994 tobacco tax cut in Canada resulted in a combined federal and provincial revenue loss of over CAN\$1.2 
billion in 1994-1995 fiscal year (Sweanor, 1997). The Canadian federal government loss of CAN\$656 million was more than twice the prediction of the government (Nonsmokers’ Right Association, 1996).

The impact of smuggling on tobacco control policies and programs was one of the concerns of the FCA a briefing to NGOs before the ICITT conference. ${ }^{10}$ According to the FCA, smuggling reduces average prices, increases demand and, as a result, harms health. Also, for WHO that illicit trade in tobacco products contributes to the global death and disease burden caused by tobacco consumption (WHO, 2002). In essence while smuggling boosts consumption of tobacco by depressing prices, it reduces government revenue due to either duties circumvented or tax cuts on tobacco products. Finally, the threat of smuggling is used to break down trade barriers and to force open new markets (Joossens, 2000). For the fear of contraband tobacco products flooding their markets leading to loss of revenue, governments legitimize the tobacco trade by tearing down forms of trade barriers.

In spite of the concern over the effects of taxation on smuggling, taxes on tobacco have historically been proven to be effective in curbing tobacco use and, as such, constitute one of the key "best practices" in tobacco control. For instance, evidence to demonstrate the effectiveness of taxation in curbing tobacco use recurred in world conferences on smoking and health, especially throughout the 1980s and 1990s. It has also been pointed out that taxes per se are not detrimental to tobacco control because of their effectiveness in generating revenue and reducing consumption (Jha and Chaloupka, 1999). It has been pointed out that the level of tobacco smuggling tends to rise with the

\footnotetext{
${ }^{10}$ http://fctc.org/about_FCTC/ICITT/ISM_smuggling_briefing.pdf [accessed 08/14/2004]
} 
degree of corruption in the country and that according to Transparency International, ${ }^{11}$ countries with high levels of cigarette smuggling (more than 30 percent of total sales) are not those with the highest prices or taxes, but rather those with high corruption scores (Transparency International, 1999). Thus, the recommended response to smuggling is not reducing taxes but rather cracking down on smuggling (Jha and Chaloupka, 1999). Still, smuggling in tobacco and tobacco products has be identified as a major problem for global tobacco control, hence it acted as a catalyst for the 2002 ICITT with the aim of finding “best practices' to combat it.

Three working groups were set up at the ICITT to address issues organizers identified as effectively measures of combating illicit trade in tobacco and tobacco products (ICITT Report, 2002:3). It was agreed among the delegates that an effective international response to the illicit tobacco trade encompasses strong domestic action tailored at the circumstances of each country, and communication and cooperation among arms of governments and ministries as well as regional and international cooperation through intergovernmental organizations such as WHO, World Customs Organization (WCO), Interpol, and the European Anti-Fraud Office (OLAF) (ICITT Report, 2002:4). The emerged "best practices" is summarized in Table 5.3

\footnotetext{
11 Transparency International, the only international non-governmental organization devoted to combating corruption, brings civil society, business, and governments together in a powerful global coalition.
} 
Table 5.4: $\quad$ ICITT Policy Recommendations

\begin{tabular}{|c|c|c|}
\hline Working Group I & $\begin{array}{l}\text { Working Group II } \\
\text { Tracking and Tracing }\end{array}$ & $\begin{array}{l}\text { Working Group III } \\
\text { Information Sharing - } \\
\text { Mutual Assistance - } \\
\text { International Cooperation }\end{array}$ \\
\hline $\begin{array}{l}\text { (a) Licensing to address a } \\
\text { person's qualification to } \\
\text { participate in tobacco } \\
\text { trade } \\
\text { (b) Record keeping }\end{array}$ & $\begin{array}{l}\text { (a) Labeling } \\
\text { (b) Monitoring, document } \\
\text { and control the } \\
\text { movement of tobacco } \\
\text { products } \\
\text { (c) Capacity building } \\
\text { (d) Monitoring and } \\
\text { assessment } \\
\text { (e) Cooperation and } \\
\text { collaboration } \\
\text { (f) Domestic } \\
\text { legislation/policy } \\
\text { framework }\end{array}$ & $\begin{array}{l}\text { (a) Multilateral Agreement } \\
\text { (b) Bilateral Agreement } \\
\text { (c) Information sharing } \\
\text { (d) Mutual Assistance } \\
\text { (e) International } \\
\text { Cooperation }\end{array}$ \\
\hline
\end{tabular}

Source: ICITT, 2002

The measures in Table 5.3 were identified at the ICITT as "best practices" in curbing illicit trade in tobacco. A review of papers presented at the conference revealed that the majority of the delegates at the conference urged WHO to integrate the conference resolutions and recommendations into the FCTC protocols on smuggling. Accordingly, WHO pointed out "The New York International Conference on Illicit Tobacco Trade will develop approaches, and recommendations on effective measures or best practices to address the illicit tobacco trade. These recommendations will inform the next negotiating session on the FCTC to be held in Geneva, Switzerland in October 2002.”"12 The cornerstone of "best practices” in combating smuggling of tobacco products involves elimination of perverse incentives to smuggling and securing the distribution

\footnotetext{
${ }^{12}$ Ibid
} 
line. ${ }^{13}$ It must also be noted that smuggling was extensively discussed at the Eleventh WCTOH in Chicago, USA. The Article 15 of the FCTC highlights "best practices" in tobacco control similar to those discussed at the Eleventh WCTOH and the ICITT. In this respect, international conference has contributed to development of global norms on tobacco smuggling hence the formation of a global regime on tobacco control, the FCTC.

\subsection{Key International Nongovernmental Organizations in Global Diffusion of Tobacco Control Measures}

Historically, civil society groups have been involved in international issues such as tobacco control Tobacco control (Nadelman, 1990). The leading actors in this policy arena are non-state transnational actors. This study describes the activities of American Cancer Society (ACS) and the International Union against Cancer (UICC) to illustrate the involvement of non-state actors in global tobacco control. Whereas the ACS has the financial strength to organize and support other anti-tobacco groups around the world, the UICC has the global reach and the power to mobilize affiliated groups around the world. Since the First WCTOH in 1967, the ACS and UICC have been involved in the activities and organization of the conference, helping to update scientific knowledge on tobacco use and tobacco control, and spreading the knowledge around the world. These organizations were among the strongest supporters of the idea of a global convention on tobacco control during the negotiation phase of the treaty. The submissions they made to the public hearings in October 2000 showed a strong support for the FCTC.

\footnotetext{
${ }^{13}$ http://fctc.org/about_FCTC/ICITT/ISM_smuggling_briefing.pdf [accessed 08/14/2004]
} 


\subsubsection{The International Union Against Cancer (UICC)}

The UICC is one of the leading independent, non-profit, international nongovernmental associations with a unique focus on cancer, a disease linked to tobacco use. In October 1933, delegates at an international conference on cancer in Madrid, Spain held under the auspices of French authorities voted to establish a permanent UICC. It was officially launched in Paris, France in 1934. It aims at coordinating international cancer research and control. It is estimated that about 30 percent of all cancers are attributable to tobacco use and as such, the UICC has been one of the leading actors in global tobacco control. It is composed of cancer fighting organizations around the world. Currently, it has over 260 member organizations in over 80 countries. It brings together a wide range of organizations and advocacy groups around the world. Through its partners, experts, and affiliated local organizations, the UICC disseminates information and foster "best practices” nationally and globally.

The mission of UICC includes: (a) sharing and exchanging cancer control knowledge and competence equitably; (b) transferring scientific findings to clinical settings; (c) systematically reducing and eventually eliminating disparities in prevention, early detection, treatment and care of cancers; and (d) delivering the best possible care to all cancer patients. In order to accomplish its goals, it focuses on prevention and early detection of cancer, tobacco control, knowledge transfer, and capacity building. The pertinent issues to this study are tobacco control and knowledge transfer. For instance, with respect to tobacco control, Yusuf Saloojee, the UICC Strategic Leader for Tobacco Control, stipulates, "UICC tobacco control activities focus on sharing information, providing leadership training and establishing networks for tobacco control organizations, 
advocates and advocacy groups. ${ }^{, 14}$ It has been involved in propelling tobacco control from a domestic phenomenon into a global issue. Currently, its tobacco control network, GLOBALink, is a cyber community of over 4,700 tobacco control professionals worldwide. The GLOBALink has been recognized as promoting dialogue and facilitating collective action between the tobacco control professionals.

It advances global tobacco control through gathering of new evidence-based data and identifying research needs, establishing standards for international "best practices" in tobacco control, encouraging and facilitating collaboration, shared learning and collective action amongst its members; developing consensus positions on key policy maters and to influence the policy debate; and representing cancer organizations in relations with intergovernmental bodies. The focus has been transfer of knowledge to different political and geographic regions. With respect to this, Kenneth Nilsson, an UICC Strategic Leader on Knowledge Transfer stipulates, "UICC knowledge transfer activities include a comprehensive range of preclinical and clinical research, as well as clinical training and care activities focusing on aspects of translation, behavior, policy, epidemiology, registries, carcinogenesis, environmental factors, prevention, detection, diagnosis and treatment. ${ }^{\nexists 15}$ For instance, under the chairmanship of Nigel Gray in 1975, an Australian physician, the UICC Program on Smoking and Cancer developed a consensus manual on Tobacco Control. Some advocates at the Fourth WCTOH argued that this UICC manual should be the guiding principles for all tobacco control policies and programs around the world. Also, the UICC has been collaborating with WHO and other NGOs in the development of "best practices" in tobacco control.

\footnotetext{
${ }^{14}$ The information is available at http://www.uicc.org/index.php?id=645 [accessed 05/27/05]

${ }^{15}$ The information is available at http://www.uicc.org/index.php?id=646 [accessed 05/27/05]
} 
The activities involved in the transfer of existing knowledge from those who have and to those who do not include research and training, accessibility to international networks of experts, providing fora for exchange, dialogue, and learning among professionals through international conferences (World Conference for Cancer Organizations (WCCO), World Cancer Congress (WCC), and World Conference on Tobacco or Health (WCTOH), publication of scientific journals and manuals, and data collection ("Tobacco Control Country Profiles"), among others. Thus, through its activities around the world, the UICC has been able to spread the knowledge about tobacco use and tobacco control around the globe. From its involvement in the organization of international conferences on cancer and tobacco control to workshops in countries in Africa, Asia, and Latin America in the 1980s and the 1990s and the steadfast support for the FCTC, it has contributed to the emergence of tobacco control as a global issue $\left(5^{\text {th }}\right.$ WCTOH, 1983:130). From the review of the WCTOH publications and the UICC website, it has been realized that the UICC contributed immensely in propelling tobacco control unto the global institutional agenda.

\subsubsection{American Cancer Society (ACS)}

The ACS is another leading nongovernmental organization in the tobacco control policy arena. Fifteen physicians and business leaders in New York City founded the American Society for the Control of Cancer (ASCC) in 1913. It was later reorganized as American Cancer Society in 1945. The ACS has evolved to become a nationwide community-based voluntary health organization of both domestic and international importance. Currently, it is made up of a national Society, with chartered Divisions 
throughout the country, more than 3,400 local Units, and over two million volunteers. It has a broad range of networks and it has influence at the grassroots level. Its central goal is elimination of cancer and improvement in the quality of life of those facing the disease.

The ACS has been involved in tobacco control since the 1950s. For instance, it sponsored some of the first research into tobacco and cancer, including the famous report in 1954 (see Studlar, 2002). Also, in 960 it played a leading role in challenging and eliminating tobacco advertising. Moreover, it was one of the three organizations ${ }^{16}$ that wrote letter to President John F. Kennedy to set up a presidential commission to investigate the hazards of tobacco use, and it led to the first U.S. Surgeon General's Report of 1964 (Borio, 2001). It quickly recognized the need for action against smoking ( $7^{\text {th }}$ WCTOH, 1990:968). Internationally, it concentrates on capacity building in developing cancer societies and collaboration with other cancer-related organizations throughout the world in carrying out shared strategic directions. For instance, its relationship with the UICC dates back to 1954 when the ACS Board of Directors established a special Committee to Advance the Worldwide Fight Against Cancer and to aid and stimulate the creation of cancer societies in other countries. Since then, the ACS has been a staunch supporter of the UICC and has been providing funds for some of its worldwide activities. Also, it has been supporting international initiatives such as funding the First and Third WCTOH. Evidence from the publication of WCTOH indicates that it has been involved in the organization of other conferences.

Examples of ACS involvement in tobacco control at the domestic and international levels are enormous. First, in 1970, the U.S. Surgeon General concurred with findings of the Society research irrefutably linking cigarette smoking to cancer. 
Second, in 1977, it held its first annual Great American Smokeout to publicize the dangers of smoking to the media and the general public. Third, it joined the American Heart Association and the American Lung Association to form the Coalition on Smoking or Health to advocate for federal tobacco control policy in 1982. Fourth, it pushed for legislation for clean indoor air acts in local communities, tobacco taxation, and elimination of tobacco industry advertising targeting children in 1990. In the same year, it launched the "Trade for Life" program to fight the aggressive marketing of cigarettes in developing countries at the Seventh WCTOH. Fifth, in 1991, it launched the American Stop Smoking Intervention Study for Cancer Prevention. Sixth, it asked the U.S. Food and Drug Administration (FDA) to reconsider regulation of tobacco products, prompting a congressional hearing in 1994. Seventh, it played an influential role in the 1998 Master Settlement Agreement. Eighth, in 2000, it helped secure \$300 million in new funds for comprehensive tobacco control. Lastly, it was one of the leading supporters of the FCTC. These examples are indications of the depth of ACS involvement in tobacco control from the grassroots to the global levels. It has been responsible for much of the progress in tobacco control $\left(7^{\text {th }} W C T O H, 1990: 968\right)$. It is also recognized as the largest charitable organization in the world.

The activities of the ACS include research, education, patient services, and advocacy. With respect to research, it has funded US\$2.5 billion in cancer research, since 1946. Specifically, it has funded 38 Nobel Prize winners. Also, the ACS educational and advocacy program focuses on tobacco control. It aims at not only raising awareness about the hazards of tobacco use but also striving to influence public policies through its advocacy efforts at the grassroots. Specifically, it emphasizes regulation of the use, sale,

\footnotetext{
${ }^{16}$ The other two organizations were American Heart Association and American Lung Association.
} 
distribution, marketing, and advertising of tobacco products by countries around the world. At the Twelfth WCTOH in Helsinki in 2003, the ACS and UICC announced a joint publication of an advocacy book entitled Tobacco Control Strategy Planning. The book provides guidelines and serves as a basic tool designed for tobacco control advocates whose countries are in the early stages of tobacco control. In essence, the ACS has been involved in the spread of knowledge about tobacco use around the world through its activities and helped to make tobacco control a global issue.

\subsection{Research Institutions in Diffusion of Global Tobacco Control Measures}

Although there are many tobacco related research institutions around the world, this study briefly describes the activities on only two - the U.S. Centers for Disease Control and Prevention and the Research International on Tobacco Control (RITC) of the International Development Research Center (IDRC) in Canada as an illustration of their contribution to global tobacco control. These two research institutions have contributed to the accumulation of scientific knowledge on tobacco use and tobacco control. In addition, they usually disseminate discovered information on tobacco use and tobacco control around the world. In fact, the CDC in particular has helped to solidify the scientific bases of the hazards of tobacco use since the onset of the contemporary phase of tobacco control in the early 1960s.

\subsubsection{The U.S. Centers for Disease Control and Prevention (CDC)}

The CDC is one of the leading research institutions in the world. It was established on July 1, 1946 as the Communicable Disease Center (CDC) with the original 
purpose to help control malaria. In 1970, CDC changed its name to Center for Disease Control. In October 1992, Congress changed the name again to the Center for Disease Control and Prevention to recognize its leadership role in prevention. The CDC has remained at the forefront of public health efforts to control infectious and chronic diseases. As one of the 13 operating components of the U.S. Department of Health and Human Services (HHS), the CDC's core objectives include health promotion and prevention of disease, injury, and disability. One of the key areas of concern has been tobacco control. The 1964 U.S. Surgeon General report and other subsequent reports have been published under its auspices. In effect, the CDC has remained one of the authoritative sources of scientific knowledge on tobacco use and tobacco control.

In general, it has been one of the global leaders in public health. With regards to tobacco control, the CDC has been involved in research, and collaboration with other institutions and organizations in research into tobacco control. For instance, the CDC allied with other groups to advance comprehensive approach to tobacco control. This approach entails building state capacity through funding and guidance. One of such guidance for tobacco control programs is the "Best Practices for Comprehensive Tobacco Control Programs." As already discussed above, the CDC "Best Practices" is meant for emulation by countries around the world. Also, the CDC, UNICEF, World Bank, WHO and representatives from the six WHO regions had a meeting in December 1998 at Geneva on the development of the school-based Global Youth Tobacco Survey (GYTS). The project is meant to track tobacco use among young people in over 140 countries using a common methodology and a core questionnaire. By August 2004, 129 countries had participated in the GYTS. In addition, the CDC's National Tobacco 
Information Online System (NATIONS) provide country level data on tobacco use and its health effects, laws and regulations, and economics. Furthermore, the CDC, RITC, and the World Bank funded research projects on tobacco control in six countries (de Beyer and Bridgen, 2003). In effect, the CDC researches, develops, and distributes tobacco and health information nationally and internationally through media, schools, and communities.

Finally, it facilitates both domestic and global action through partners. Domestically, it coordinates and promotes tobacco prevention and control activities with the ACS and allied groups. Globally, it is the WHO Collaborating Center on Global Tobacco Prevention and Control in North America, and as such, it implements international studies, conducts epidemiological research, and provide international assistance on reducing tobacco use. In this sense, the CDC is a domestic research institution with global impact. Since the 1990s, the CDC has undertaken more internationally oriented projects. The research information of CDC funded projects is disseminated worldwide. Due to this fact, the CDC is one of the architects of the contemporary era of tobacco control (Nathanson, 1999; WCTOH). The 1964 U.S. Surgeon General report, one of the catalysts for the inception of the WCTOH, and other publications of the CDC have been authoritative source of knowledge on tobacco use and tobacco control worldwide. The awareness of knowledge on tobacco use and tobacco control worldwide was one of the catalysts for the FCTC, and as such, the CDC was instrumental in the emergence of the FCTC. 


\subsubsection{Research for International Tobacco Control (RITC)}

Originally known as the International Tobacco Initiative, it was introduced at the $9^{\text {th }}$ WCTOH in Paris, France in 1994 and as such is an integral part of the entire WCTOH phenomenon. It was announced at the $9^{\text {th }}$ WCTOH that an international initiative funded by the International Development Research Center (IDRC) and Canada's federal Ministry of Health would provide a funding base for policy relevant research, capacity building, and information dissemination in support of effective tobacco control in developing countries $\left(9^{\text {th }}\right.$ WCTOH, 1994:1015). The Initial resources for the program were CAN\$2.15 million (ibid). The initiative was based at the headquarters of the IDRC in Ottawa, Canada, and it was later renamed as RITC. The main activity of the FCTC is shown in Figure 5.3.

Figure 5.3: Activities of the RITC ${ }^{17}$

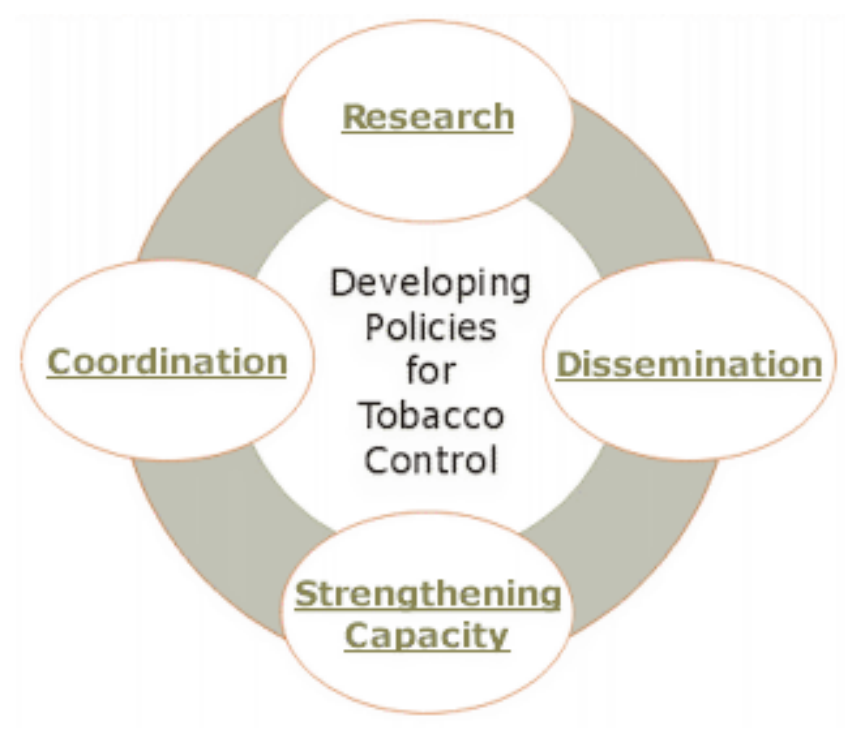

Source: RITC

\footnotetext{
${ }^{17}$ http://archive.idrc.ca/ritc/en/activities/index.html (accessed April 25, 2005)
} 
The RITC was established with a focus on the issue of tobacco control in developing countries. Organizationally, it is made up of individuals from NGOs, IGOs, and WHO as well as experts in tobacco control. Its main sources of funding include Health Canada, IDRC, Swedish International Development Cooperation Agency (Sida), and Canadian International Development Agency (CIDA). Its mission is to "create a strong research, funding and knowledge base for the development of effective tobacco control policies and programs that will minimize the threat of tobacco production and consumption to health and human development in developing countries."18 $\mathrm{It}$ accomplishes this mission through a combination of research, information dissemination, capacity building, and research coordination. ${ }^{19}$ In this regard, an idea that emerged at a world conference on tobacco became instrumental in the diffusion of knowledge about tobacco use and transfer of tobacco control policies to developing countries, a "best practices” approach.

Since the Initiative was launched in 1994, it has undertaken numerous tobacco control research projects in developing countries around the globe. The main areas of research include health and social implications of tobacco use; economics of tobacco; legislative and policy analysis; and tobacco farming and alternative livelihoods. ${ }^{20}$ Currently, it is funding a research project on the implementation of the protocols and principles underlying the FCTC, particularly in developing countries. In the course of realization of its mission, it has funded research projects in South Africa, Brazil, Argentina, Turkey, China, Poland, Vietnam, Lebanon, India, Nepal, Colombia, Cuba, Trinidad and Tobago, Vietnam, and Zimbabwe. For instance, the RITC funded research

${ }_{19}^{18}$ http://archive.idrc.ca/ritc/en/about/mission.html [accessed 04/19/05]

19 Ibid 
project on tobacco control in six countries (Bangladesh, Brazil, Canada, Poland South Africa, and Thailand) in conjunction with the Human Development Network of the World Bank, Office of Smoking and Health of the U.S. Center for Disease Control and Prevention, and the Tobacco Free Initiative of WHO (de Boyer and Brigden, 2003). In this sense, the RITC has been concerned primarily with increasing knowledge of tobacco use and tobacco control in developing countries. By so doing, it is contributing to the transfer of tobacco control measures from developed, countries where they have been established for many years, to developing countries.

The RITC also engages in research in tobacco control at regional levels of the developing world. In the effort to accomplish this task, it convened three regional meetings from 1998 to 1999 in Latin America and the Caribbean, Middle East, South and South East Asia, and Eastern, Central and Southern Africa to launch a bottom-up strategy for formulating a global tobacco control research agenda based on regional research agendas. ${ }^{21}$ The results of these meetings were published in Tobacco Control, 2000. By the adoption of this bottom-up approach, the RITC has been influential in the gradual transformation of tobacco control as a domestic issue into a global issue.

Globally, the RITC synthesizes the results of regional meetings and research results. ${ }^{22}$ Among the emerging themes during global symposia over a decade of the existence of the Initiative is lack of standardization and comparable data as well as the absence of a network for communication of information, data and best practices. ${ }^{23}$ Thus, for about a decade, the RITC has been working to harmonize tobacco control measures

\footnotetext{
${ }^{20} \mathrm{http} / / /$ archive.idrc.ca/ritc/en/activities/research.html [accessed 04/19/2005]

${ }^{21} \mathrm{http://archive.idrc.ca/ritc/en/activities/coordination1.html} \mathrm{[accessed} \mathrm{04/19/2005]}$

22 http://archive.idrc.ca/ritc/en/activities/coordination2.html [accessed 04/19/2005]

${ }^{23}$ Ibid
} 
around the world and to diffuse and transfer best practices in tobacco control. In the effort to accomplish this goal, the RITC and WHO-TFI published Confronting the Epidemic: A Global Agenda for Tobacco Control Research, in 1999. The agenda set out in this publication was endorsed by participants at the Global Forum for Health Research in June 1999 in Geneva, and by a meeting on Global Research Priorities for Tobacco Control co-hosted by RITC and WHO in March $1999^{24}$ (RITC and WHO-TFI, 1999). Central to this publication is the development of the FCTC. The publication was meant to provide technical assistance for the development and implementation of the protocols and principles of the FCTC. ${ }^{25}$ In essence, since the emergence of the Initiative at the $9^{\text {th }}$ WCTOH in 1994, RITC has worked to ensure the evolution of tobacco control as a global issue through the search for knowledge and information, and the diffusion and transfer of best practices in tobacco control to developing countries. Its activities in developing countries resulted in uncovering evidence that tobacco control is not an individual country issue or an issue of importance to only the developed; hence the appropriate approach is global collective action, the FCTC.

\subsection{Summary and Conclusion}

The chapter discussed the issue of "best practices" in tobacco control and the role of an epistemic community, WCTOH in the evolution of tobacco control. "Best practices” in tobacco control refers to evidence based tobacco control policies, and as such, they are usually prescribed for adoption by all states around the world, albeit modifications to meet domestic circumstances. Currently, it has emerged as an important

\footnotetext{
${ }_{25}^{24} \frac{\mathrm{http} / / / \mathrm{www} . \text { who.int/tobacco/research/en/print.html [accessed 04/19/2005] }}{\text { Ibid }}$
} 
concept in the lexicon of tobacco control. However, the underlying notion has been in existence since the inception of the First WCTOH in 1967. The WCTOH is identified as an epistemic community in tobacco control because it meets it criteria (Haas, 1992, 1989; Alderman and Haas, 1992). This occasional meeting of experts usually aim at sharing and exchanging knowledge, information, and ideas about tobacco use and tobacco control. In so doing, the various conferences identified effective tobacco control policies around the world and marked them for worldwide adoption. The conferences also contributed to the identification of model states or policies in tobacco control, and the encouragement of others to emulate them. This is the rationale behind the "best practices" approach in tobacco control.

In addition, the WCTOH has been involved in conscious transfer of innovated tobacco control policies from primarily developed countries to developing countries. Also, it has been involved in the transformation of tobacco control because of expansion of its scope and inclusion of peoples around the world. Moreover, WHO has adopted resolutions and recommendations of the conferences. It has been a critical venue for the development of international collaborative strategies (including international convention) to combat worldwide tobacco use and activities of the tobacco industry. In this sense, the WCTOH has performed the role of an epistemic community in the transformation of tobacco control into a global institution (Alderman and Haas, 1992). The chapter ends with brief description of the global activities of two NGOs and two research institutions as illustrations of how such organizations and institutions contributed to the evolution of tobacco control. 


\section{Chapter 6}

\section{Preliminary Analysis}

\subsection{Introduction:}

This study began with the argument that the recognition of a problem, the existence of institutions with legitimate powers in the issue area, the spread of knowledge, information, and ideas about the issue, and activities of actors with interest in the issue facilitates collaboration and cooperation that can lead to collective action. This is the logic behind the liberal-constructivist perspective of this study that draws ideas from Advocacy Coalition Framework (Sabatier and Jenkins-Smith, 1999, 1993; Wieble et al. 2004), transnational advocacy networks (Keck and Sikkink, 1998) and epistemic communities (Haas, 1992, 1989). This chapter is a preliminary analysis of the validity of the theory, the hypotheses, and the conclusions of the descriptive segments of this study using data gathered through interviews. The chapter also describes the data collection processes and analyzes the information gathered through interviews. The final segment of the chapter is a summary and discussions of findings.

\subsection{The Interviewing Process}

The interview process began with the identification of the population of study. The population is composed of participants in the negotiation process described above. This was followed by questionnaire design. Due to the absence of pre-existing questionnaires on the subject, new questions were formulated on the basis of theory and hypotheses of this study. 
The next stage was securing the approval of the West Virginia University's Institutional Review Board for the permission to go-ahead with surveys and interviews. The Board approved the questionnaire and the cover letter. This began an active search for interviewees.

The search for interviewees who are dispersed around the world started with compilation of list of participants involved in the country-level conferences, the regional conferences, public hearings, and Working Group (WG) and Intergovernmental Negotiating Body (INB) meetings in Geneva, Switzerland [See Table 6.0]. The sources of the list of participants include World Health Organization, the regional branches of WHO that held conferences on the FCTC, and select countries that held country-level conferences such as the U.S. For instance, Center for Disease Control and Prevention (CDC) provided the list of participants in the U.S. conferences.

Initially, faxes were sent to embassies, diplomatic missions, government offices, and organizations for direct access to prospective interviewees. However, due to difficulties in gaining direct access to select interviewees, this method was changed for the snowballing method of data collection. In general, the snowballing method of data collection was significantly useful in gaining access to participants in Africa, Europe, North America, and Oceania. The tables below illustrate the categories of people interviewed for this study. 
Table 6.0: Interviewees by Type of Conference/Meeting ${ }^{1}$

Type of Participation

Country-level conferences

WHO regional conferences

FCTC public hearings

FCTC working group meetings

FCTC intergovernmental negotiating body meetings

*Preparatory Meetings ${ }^{2}$
Interviewees

5

1

$6+5$

4

13

\subsubsection{Interviewees by Region}

According to Jacob (2004), a phenomenon that emerged during the negotiation process was the tendency of states to form regional blocs. WHO encouraged these regional meetings so that each region can have a common stand on some of the issues that were being negotiated (Jacob, 2004). Other interviewees confirmed this claim. For this reason, efforts were made to interview at least one person from each of these WHO regions. Unfortunately, nobody from the Eastern Mediterranean (EMRO) and the Southeast Asia (SEARO) regions was interviewed due to time constraints and inability to gain access to prospective interviewees. Only people from AFRO, EURO, PAHO, and WPRO regions were interviewed for this study. The summary of the interviewees by region is shown in the Table 6.1 below.

\footnotetext{
${ }^{1}$ It must be noted that participation in the FCTC overlaps because some interviewees participated in one or more of the meetings and conferences organized throughout the negotiation process.

${ }^{2}$ These were background meetings before the idea FCTC got unto the agenda of WHO.
} 
Table 6.1: Interviewees by Region $($ Total $=21)$

Region

African (AFRO)

Eastern Mediterranean (EMRO)

Europe (EURO)

Pan America (AMRO/PAHO)

Southeast Asia (SEARO)

Western Pacific (WPRO)

World Health Organization (WHO)
Number of People Interviewed

2

0

1

13

0

4

1

\subsubsection{Interviewees by Country}

A total of 192 countries were involved in the negotiation of the FCTC, even though the number fluctuated from one INB to another. However, given the difference in size, resources, and population, the number of delegates sent to the negotiating meetings in Geneva differs from country to country. Jacob (2004) notes this fact in the account on the negotiation process. Whereas developed countries in particular could afford to send as many delegates as possible to the negotiation meetings, many developing countries sent a handful of delegates to the meetings. In addition, as a result of the underlying principles throughout the interviewing process - accessibility and convenience, the emphasis was on getting as many interviewees as possible regardless of region or country of origin. Still, efforts were made to ensure that interviewees were as diverse as possible. Also, due consideration was given to the importance of the country to global tobacco control within the literature of tobacco control. Table 6.2 below is a breakdown of the interviewees according to countries of origin. 
Table 6.2: Interviewees by Country of Origin $($ Total = 21)

\section{Country}

Australia

Canada

New Zealand

Nigeria

South Africa

United Kingdom

United States

*Switzerland (WHO)
Number of Interviewees

1

4

3

1

1

1

9

\subsection{Actors and Stakeholders in FCTC Negotiation Process}

Although states are the core actors and ultimate decision-makers in many international issues such as the FCTC, the negotiation process gave ample room for civil society groups around the world to play major and influential roles. As one interviewee said, “as far as I know, the FCTC was primarily driven by civil society groups.” This is consistent with Jacob’s (2004) account of his involvement in the FCTC negotiations in which he indicated the strength of NGOs in the entire process. Whereas group such as UICC and INGCAT had official relations with WHO, groups such as the FCA did not. Yet, all of them had opportunity to be involved in the process. Such a phenomenon allowed interested parties or stakeholders from around the world to play major role(s) in the negotiation of the treaty. The table below summarizes the categories of actors or stakeholders interviewed for this study. 
Table 6.3: $\quad$ Interviewees by Activity $($ Total $=21+6)$

Activity

Intergovernmental Organization (WHO)

Nongovernmental organizations (NGOs)

Business Nongovernmental organizations (BINGOs)

Public Officials

Policy entrepreneur

*Tobacco Industry ${ }^{3}$
Number of Interviewee

1

11

3

5

1

6

\subsubsection{Intergovernmental Organization (WHO)}

As neo-institutionalists and constructivists (Jacobsen, 2003; Zehfuss, 2002; March and Olson, 1984) point out, institutions could exist independent of the component parts. The central argument of these scholars is that institutions do have some degree of autonomy and as such they are capable of acting independently. The key institution in this case is World Health Organization. WHO is an intergovernmental organization made up of states. Yet, as an organization, it has the ability to take the leadership in some issues in its constitutional arena. Thus, since 1970, WHO has been actively involved in global tobacco control issues. Besides providing venue for tobacco control activities for over three decades, it helped propelled the issue of tobacco control unto the agenda of the World Health Assembly. For instance, an interviewee said, “it was Dr. Brundtland, the Director-General of WHO, that forced the FCTC unto the agenda of WHO.” As such, one expert from WHO was interviewed for this study. 


\subsubsection{Nongovernmental Organizations (NGOs)}

As Jacob (2004) admits, NGOs had tremendous influence in the negotiation of the FCTC. This was because from the state to the global levels, NGOs had opportunity to make their views and positions on FCTC known. Particularly, the state-level conferences and the FCTC preliminary public hearings provided opportunity for NGOs to influence the negotiation process. However, as stated earlier, pro-tobacco groups such as smokers’ right, hospitality, and other allied groups were only visible during the public hearings. Beyond that, the negotiation process was dominated by anti-tobacco NGOs. Due to flexibility and easy accessibility, eleven people around the world from the anti-tobacco NGO community were interviewed.

\subsubsection{Business International Nongovernmental Organizations}

\section{(BINGOs)}

Business groups became interested in the FCTC process mainly because of the perceived influence of global collective action on tobacco control on the flow of international trade. An interviewee who attended one of the FCTC conferences in the USA said,

"I was there to represent business interest. I just want them to know of the opinion of our members. We were there to make sure that they do not do anything that will hurt trade.”

However, beyond trade, they were little interested in many aspects of tobacco control. They were present at the state-level and the FCTC public hearings. Three people from

\footnotetext{
${ }^{3}$ Because of the inability to get any interviewee from the tobacco industry, I relied on the submissions made by British American Tobacco, Philip Morris, Imperial Tobacco, Japan International Tobacco, R.J. Reynolds, and Reemtsa during the FCTC public hearings in October 2000.
} 
BINGOs were interviewed for this study. One of the interviewees represents a tobacco interest, and the other two represent general business interests.

\subsubsection{Policy Entrepreneurs and Individual Advocates/Activists}

Policy entrepreneurs are individuals who, among others, were not happy with the global trend of tobacco use pursued the idea of a global convention on tobacco control. As one interviewee said,

"In the 1970s and 1980s, I was upset when I realized the tobacco companies were moving to developing countries as tobacco regulations became stricter in developed countries. I then, said 'we have to do something about this problem.' Until the FCTC was adopted, I had been fighting for some form of international convention on tobacco control.”

These are people who dedicated their entire life or career to make sure that tobacco is regulated at the global level and eventually helping to propel the issue unto the agenda of WHO. The study categorizes these people as policy entrepreneurs. They were involved in different preparatory meetings on a global convention on tobacco even before the WHA gave WHO the green light to state the preparation for the development of FCTC. One policy entrepreneur was interviewed.

Individual advocates or activists are experts and consultants in tobacco control who, because of their knowledge and experience have been leading the fight against tobacco use. They are usually members of NGOs as well. In spite of this fact, there is still a line between the organizations they belong, and their activities as experts and consultants. Although they are treated as part of anti-tobacco NGOs, it must be noted that four people who could be separately identified as advocates or activists were interviewed. 


\subsubsection{Public/Government Officials}

These are states delegates that participated directly and actively in the negotiation of the FCTC. They formed the core of states delegations during the negotiations, and as such their positions were reflection of the position of their countries on any provision under the FCTC. For this reason, they had to liaise with their governments and other interested parties within their countries to develop a position on the FCTC. Five government official who were part of state delegations were interviewed for this study.

\subsubsection{The Tobacco Industry (TTCs)}

The uniqueness of the tobacco epidemic from other public health concern stems from the involvement of a multi-billion dollar industry in the promotion of tobacco use around the world. When asked, "why is it that states agreed to develop a global institution on tobacco control in spite of the fact that there are many other international public health concerns?” An interviewee said,

"First, there is a multi-billion dollar transnational enterprise involved in this issue. Mosquito causes malaria. A virus causes HIV/AIDS. A germ causes tuberculosis. But, tobacco use is consciously spread by an industry, and we need group effort to stop it.”

This illustrates the importance of the tobacco industry to global tobacco control. In spite of this, their "overt" involvement in the FCTC negotiation process was limited to the FCTC public hearings. Efforts to interview any person from the tobacco industry on their involvement in global tobacco control and the negotiation of the FCTC were in vain. For this reason, this study relied on submissions made by Philip Morris, British American Tobacco, Japan Tobacco International, Imperial Tobacco, R. J. Reynolds, and Reemtsa 
during the public hearings and information on tobacco control from their Internet websites for the analysis.

\subsection{Methods of Data Collection}

One form of data collecting is interview (Patton, 2002; Merriam, 1998; Rubin and Rubin, 1995; Biagi, 1986). The topical interviewing approach was used. This approach was meant to piece together from different people a coherent narrative that explains puzzling outcomes, FCTC (Rubin and Rubin, 1995:196). One reason for the use of this approach was that some information is available only from people who have limited time for an interview (Rubin and Rubin, 1995:2000). Also, interviewees had different levels of participation in the negotiation process, hence questions were tailored in accordance with the background information they provided [See Table 6.0]. During interviews, three kinds of questions were asked. These include main questions that began the conversation, probe questions for clarifications, and follow-up questions to pursue the implications of answers to the main question (Rubin and Rubin, 1995:145).

\subsubsection{The Face-to-Face Interview}

This form of interview was conducted in Washington, D.C. between May 15 and 18, 2005. The interview date and time were scheduled through telephone. A reminder telephone call was made one week before the scheduled date. All interviews started after establishing rapport with the interviewee and securing the consent of the person to record the interview. The most important aspect of the process was assuring interviewees that their identities would remain anonymous. 


\subsubsection{The Telephone Interview}

The option was chosen because not all participants could have time for a face-toface interview. In addition, participants in the FCTC negotiation process are spread around the world and they are accessible through the telephone. In effect, time constraints and distance were the key motivating factors the choice of this method. Still, the procedure used for the interview was similar to the face-to-face interviews. However, interruptions and lack of concentration were the key drawbacks of this approach.

\subsection{Analysis of Data}

This is the final stage and it began with listening to what was said (Rubin and Rubin, 1995; Riessman, 1993; Antaki and Leuder, 1992; Tesch, 1990; Antaki, 1988; Strauss, 1987). Many hours were spent listening to the tapes in order to make sense of the arguments, comments, and opinions of interviewees. This section attempts to organize the information gathered throughout the interviews into a coherent whole, and to determine whether the theory and hypotheses of the study were confirmed or not. This analysis begins with discussion of how the various concepts underlying this study were measured.

\subsubsection{Measurement of Theoretical Concepts}

First, transnationalism was measured with two sets of questions. The first set contains two questions and it is about whether tobacco control is a national or transnational issue, and why? The second set contains five questions on general influence of transnational advocacy groups in the negotiation of the FCTC, and specific questions 
on activities and strategies of three NGO coalitions and alliances (FCA, NATT, and INGCAT) during the FCTC negotiating process [See Appendix].

Second, policy transfer and diffusion was also measured with two sets of questions. The first set contains two questions on the kind of knowledge about tobacco use that drove the debate on global tobacco control and the necessity for a global institution. The other set contains two questions as well. The questions are on how people around the world become familiar or acquainted with knowledge on tobacco use. These questions identify specific modes of transferring knowledge about tobacco use and interviewees were allowed to comment on their usefulness in transferring and diffusing knowledge about tobacco use and tobacco control worldwide. In addition, interviewees were allowed to identify other modes of transferring and diffusing knowledge about tobacco use and tobacco control worldwide [See Appendix].

Third, globalization and interdependence were measured with three sets of questions [See Appendix]. The first set contains five questions on whether increasing interactions and interconnectedness facilitated the adoption of the FCTC. In addition, it considers the most prominent actor in the negotiation process and the relationship between WHO and the tobacco industry. The second set contains three questions on issues on interdependence, specifically trade. The last set contains one question on the extension of the activities of transnational tobacco companies into developing countries and how it influenced the adoption of the FCTC.

Fourth, “best practices” was measured with three questions [See Appendix]. The essence of these questions was to assess the scientific basis of the FCTC and how it will facilitate the transfer of innovated policies to other political and geographic jurisdictions. 
Fifth, "low politics" was measured with two questions [See Appendix]. The first question is about whether there is comparison between tobacco and other issues classified as "low politics" in international relations literature (Kegley and Wittkopf, 2004:19; Dougherty and Pfaltzgraff, 2001:511). The other question is on the level of government that handles tobacco control issues in a country. This is attempt to determine whether the alacrity with which the FCTC came to being is because it is a "low politics" issue in international relations.

Sixth, policy entrepreneurs and advocates/activists were measured with two questions [See Appendix]. This was an attempt to determine whether individual efforts have been influential in the transformation of tobacco control into a global issue, and especially the negotiation of the FCTC. In this respect, interviewees were asked to identify influential individuals they know, and the role they played in the adoption of the FCTC and global tobacco control in general.

Finally, miscellaneous questions were asked to determine the contribution of the various WHO regions to the adoption of the FCTC [See Appendix]. In addition, interviewees were asked to comment on the role of individual countries in the adoption of the FCTC. This was an attempt to understand the role of states in the entire negotiation process.

\subsection{The Adoption of FCTC: Analysis}

As the first public health treaty under the auspices of WHO, interviewee were asked to indicate whether they support, oppose, or neither. However, in the case of the transnational companies, their positions were deduced from the submissions they made 
during the public hearings and information on their Internet websites. Table 6.4 summarizes the positions of the various stakeholders on FCTC.

Table 6.4: $\quad$ Position on FCTC $($ Total $=21+6)$

\begin{tabular}{lccccc}
\hline & NGOs WHO & BINGOs & TTCs & P/GOs PE \\
Support & 11 & 1 & 1 & 1 & 5 \\
Neither support nor oppose & & & 3 & \\
Oppose & 2 & 2 \\
P/GO refers to public or government officials, and PE refers to policy entrepreneurs.
\end{tabular}

First, the NGOs from the public health community, experts from WHO, policy entrepreneurs/advocates and public officials interviewed were unanimous in their support for the FCTC. Although interviewees from anti-tobacco NGOs preferred a stronger FCTC text, they expressed satisfaction with the treaty, given the nature of negotiation. For instance, an interviewee opined, “Given the nature of the negotiation, I am astonished that we were even able to get such a treaty out. For that reason, I am pretty much satisfied with it.” The degree of satisfaction varies, but the support for a global institution on tobacco control is strong.

Second, interviewees from business NGOs were split on their positions on the FCTC. Even though the FCTC has become enforceable treaty at the time of the interviews, two out of the total of three interviewees from this group oppose it. The interviewee who expressed support for the FCTC argues,

"Whilst solution to the tobacco problem lies in national governments, the issue is severe enough and globally in its impact. There's a good case for having an international institution to raise 
awareness, bring together best practices, and even to assist governments that are not far from the learning curve with the science, with the best practice, with the range of alternatives, and even with resources if they want to implement certain remedy for what has been known as a global problem, a serious one.”

On the other hand, the two interviewees emphatically oppose the FCTC because, as one said,

"Government responsibility is to educate the people about the risk involved in the commodity they are consuming, and the individual should be allowed to make his or her own choice.”

However, they support educational programs under the FCTC, but not the actual collective action geared towards regulating the choices of individuals.

Finally, the tobacco companies expressed mixed positions on the FCTC. For instance, Philip Morris is in favor of some form of international regulation on tobacco, and as such, they favor the FCTC. On the other hand, Japan Tobacco International (JTI) and Reemtsa were in opposition to the FCTC. However, British American Tobacco (BAT), Imperial Tobacco Limited (ITL) and R. J. Reynolds expressed ambivalence in their positions. On one hand they pointed out that they were ready to cooperate with WHO on some specific policy issues. But on the other hand, they think that regulation of tobacco products is a domestic issue and should remain as such. In essence they did not express support for FCTC nor did they oppose it.

The entire positions of the various actors and stakeholders in global tobacco control are summarized in Table 6.5 below. The table summarizes the percentage of interviewees in each category of actors that favor the various issues. For instance all NGOs, WHO, government officials, and policy entrepreneur interviewed agree that 
tobacco control is a transnational issue. Also, 66 percent of interviewees from BINGOs agree that tobacco is a transnational issue [See below for further descriptions].

Table 6.5: Percentage of Interviewees $($ Total $=21+6)$

NGOs WHO BINGOs TTCs GOs PE

Policy Transfer/Diffusion

$\begin{array}{llllll}100 & 100 & 100 & - & 100 & 100\end{array}$

Transnationalism

$100 \quad 100 \quad 66$

$100 \quad 100$

Globalization and interdependence Interconnectedness

$\begin{array}{lll}100 & 100 & 100\end{array}$

Trade

$100 \quad 100 \quad 100$

$\begin{array}{lll}- & 100 & 100\end{array}$

LDC’s Issue

$100 \quad 100 \quad-$

$\begin{array}{lll}100 & 100 & 100\end{array}$

"Low Politics"

100

"Best Practices"

$\begin{array}{lllrlll}\text { Harm of tobacco usage } & 100 & 100 & 100 & 83 & 100 & 100 \\ \text { Policy } & 100^{4} & 100 & 33 & 20 & 100^{5} & 100\end{array}$

Policy Entrepreneurs and

$91 \quad 100 \quad 100$

$80 \quad 100$

Advocates

Miscellaneous

Regional Influence

$100 \quad 100 \quad-$

$\begin{array}{lll}- & 100- \\ - & 100 & -\end{array}$

Role of Countries

$100 \quad 100 \quad-$

Mean

(99) (100) (85)

(68) (98) (100)

\subsubsection{FCTC and Knowledge, Information, and Ideas about Tobacco Use and Tobacco Control}

Knowledge, information, and ideas about tobacco use and tobacco control have been fundamental issues in the evolution of tobacco control as a global phenomenon. In

\footnotetext{
${ }^{4}$ Despite the agreement that the policies under FCTC are evidence based, 27 percent of the interviewees expressed skepticism over specific policies.
} 
this study, knowledge was divided into two components. The first component is knowledge about health hazards of tobacco use (science), and the other component is knowledge about the availability of measure that have been empirically proven as effective in curbing tobacco use (policy). Whereas there is almost a unanimous consensus among the various stakeholders and actors on the scientific evidence linking tobacco use to health, some interviewees, from BINGOs in particular, questioned the scientific basis of the policy recommendations for curbing tobacco use. Similarly, TTCs raised skepticism about effectiveness of some of the tobacco control measures under the FCTC in their submissions to the public hearings.

In the first place, all interviewees agreed there is a link between tobacco use and diseases such as lung cancer, emphysema, and bronchitis, among others. This is the deep core belief of the tobacco control community and it has been the driving force of the tobacco control movement since the 1960s. As one interviewee said, "this is no longer a subject of debate. I think it was settled forty years ago.” Even 83 percent of TTCs that made submissions to the FCTC public hearings accepted the scientific evidence on the hazards of tobacco use. The TTCs that raised doubts about the evidence on the health risks of tobacco use did not dismiss the evidence outright. They admit that tobacco is a 'controversial' product. As a result of believe in the science of tobacco use, all interviewees agreed that throughout the four-year duration of the FCTC negotiation process, debates were primarily driven by health concerns, hence the dominance of the public health groups in the process (Jacob, 2004). This was a source of frustration for other professionals during the negotiating process, an interviewee opined. Still, with the exception of the TTCs and the BINGOs, all the others acknowledged that the social,

\footnotetext{
${ }^{5}$ Forty percent of public officials interviewed expressed skepticism on some specific policies.
} 
economic, and environmental consequences of tobacco use was in the background. The interviewee from WHO pointed out that the organization took time to explain the socioeconomic consequences of tobacco use to the delegates to make them aware that in the long-run tobacco use is a loss to the economy.

The issue is: was the familiarity with the knowledge about the health consequences of tobacco use able to transform the identities and interests of states? The answer was unanimously in the affirmative, with respect to anti-tobacco NGOs. An interviewee who has been involved in tobacco control at the local/community and national levels, prosecution of the tobacco industry, and participated in the FCTC public hearings and all the six INB sessions said,

"The three or more years of the negotiating process served as a university for the delegates.

Overtime, by virtue of things said and education surrounding the negotiations, you could feel the level of knowledge and understanding of these issues increase. The effect was that the more you learn about the science and evidence, the more willing you tend to support stronger tobacco control policies. So, the center of gravity shifted to stronger tobacco control policies. This was because the delegates had deeper understanding of tobacco control by INB6.”

This is an illustration of the transformational effect of familiarity with knowledge on the consequences of tobacco use on the delegates. The delegates arrived in Geneva for the negotiation of an international convention on tobacco control with varied degrees of knowledge on the consequences of tobacco use. However, as the degree of knowledge on tobacco use among the delegates converged, they started to advocate for a stronger treaty. This is a confirmation of the liberal-constructivist theory that knowledge about tobacco use has been central to the evolution of tobacco control as a global phenomenon. The second component of this knowledge, policy, is discussed under "best practices" below. 


\subsubsection{FCTC and "Best Practices"}

"Best practices” in tobacco control, as pointed out earlier, are evidence-based policies that have being proven empirically to be effective in curbing tobacco use (Nathan, 2004; CDC, 1999). These are policies innovated at a particular political or geographic jurisdiction but they have been proven effective; hence they are regarded as models for emulation worldwide. For instance, all of the NGOs, WHO, government/public officials, and advocates interviewed, agreed unanimously that taxation is a typical example of such "best practices.” On the other hand, TTCs pointed out in their submission that taxation could exacerbate smuggling, hence it is not an ideal tool for curbing tobacco use. Also, 66 percent of people from BINGOs pointed out that taxation is just a tool used by government to generate revenue, and it has nothing to do with curbing tobacco use. In effect, there is division among actors and stakeholders when it comes to the second component of knowledge about tobacco use and tobacco control, policy.

The division over effectiveness of specific policy recommendations under the FCTC can be seen within both public health community, on the one hand, and business NGOS and the tobacco industry on the other. TTCs indicated in their submissions that they were willing to cooperate with WHO in areas such as combating youth smoking. Yet they disagree with measures such as taxation, advertising and sponsorship bans. Also, many of the interviewees from the public health community noted that tobacco control policies are not equally effective. That is, some policies are more effective than others. One interviewee pointed out that "this is why we support only a handful of tobacco control measures, and we were against the U.S. buyout policy for tobacco farmers.” 
Another interviewee pointed out, "No single tobacco control measure is a silver bullet." For this reason, over 90 percent of the interviewees from the public health community argued that the best approach to combat tobacco use is a comprehensive approach as suggested under the FCTC. The approach is about concurrent implementation of both demand side and supply side policies under the FCTC.

In spite of the division at the policy level, all the interviewees (including those from BINGOs) accepted that familiarity with knowledge about innovative policies,

primarily from the developed world, was a key factor that urged many states to cooperate to bring the FCTC into being. For instance, in an answer to why many developing countries joined the FCTC, an interview from a BINGO said, "the developing world is adopting practically everything prominent in the developed world when it comes to tobacco control and tobacco use.” Moreover, all the interviewees from the public health community pointed out that awareness of the pictogram cigarette packages from Canada, Brazil, and Thailand was influential in the adoption of the 30 percent health warnings on cigarette packages during the FCTC negotiations. This further attests to the power of knowledge, information, and ideas about tobacco use and tobacco control in the evolution of tobacco control into a global issue.

\subsubsection{FCTC and Policy Transfer/Diffusion}

This section attempted to answer how individuals, groups, organizations and states become familiar with innovated policies in tobacco control. In general, interviewees identified California in the U.S., Canada, New Zealand, Australia, and Norway as models for tobacco control from the developed world. In addition, South 
Africa and Thailand were identified as models of tobacco control from the developing world. These are widely known leaders in global tobacco control, and it is a confirmation of findings of the descriptive sections of this study. However, in specific policies other countries have been leaders. For instance, an interviewee from Canada indicated,

"Even though we have been known as leaders in tobacco control around the world, we also have to learn from others. We have to follow European Union's lead to eliminate the language of “mild” and "light" from cigarette sales. We also have to learn from others."

This confirms an earlier study on tobacco control by Studlar (2002). In specific policy areas, model states do learn from others. This, however, does not change the widespread perception among interviewees and within the literature that these few countries and geographic jurisdictions symbolize models of tobacco control.

The FCTC encourages policy learning, diffusion and transfer of tobacco control policies from one jurisdiction to another. With respect to this, one interviewee from Africa said,

"We do not need to reinvent the wheels. Tobacco is not an African phenomenon. It was moved to this part of the world. So, if there are tools working elsewhere we can import and use them in our own countries. This is because the corporations are not designing any new strategies. So, if there are policies working in Norway, we can import them and they will work.”

Another interviewee said,

"It took developed countries 30 or more years to develop these policies. Developing countries should not wait for another 30 or more years to develop their own policies. They can simply borrow these policies.” 
The impact of the spread of recognized tobacco control policies has been central to this study. It suggests the importance of the means through which knowledge about tobacco use and tobacco control is spread globally.

The first identified medium for the spread of about tobacco control is the international conference - World Conference on Tobacco or Health (WCTOH) and the International Conference on Illicit Tobacco Trade (ICITT). Although interviewees agreed that these are very important conferences, their ability to spread knowledge about tobacco use and tobacco control to the local/community level is limited. This is because they are predominantly seen as elite conferences in the sense that most attendees are tobacco control professionals. People who are already familiar with the issues at stake usually attend them. However, for interviewees from public health groups, such conferences are vital for the sake of sharing and exchanging information as well as updating knowledge on tobacco use and tobacco control among the elites from around the world. About 90 percent of the interviewees from the public health community agree that international conferences have contributed to the perception of tobacco control as a global issue. Whether the knowledge acquired by the participants can be disseminated to the local/community level is an issue many interviewees could not answer. The consensus is that at the elite level, international conferences have been very useful medium for the diffusion of knowledge on tobacco use and tobacco control. Other elite mechanisms of tobacco policy transfer or diffusion include academic publications such as the Tobacco Control and Nicotine and Tobacco Research, and the Internet community, such as GLOBALink. Interviewees see these as important media for diffusion of knowledge about tobacco use and tobacco control but primarily at the elite level. 
The linkage between these conferences and the FCTC lies in their recommendations and resolutions. For instance, 36 percent of interviewees from antitobacco NGOs are familiar with the fact that Ruth Roemer was one of the earliest individuals to suggest the need for an international convention on tobacco control. A former employee of the WHO indicated that in the early 1990s, whilst working as an employee of the organization, Roemer and others brought the issue to his attention and they began preparing grounds for the development of the FCTC. Even one interviewee was able to vividly recollect that it was at the Ninth WCTOH in Paris in 1994 where she made the suggestion for such a global convention. This is confirms an earlier finding of this study. It also confirms earlier finding in this study that WHO has been adopting resolutions and recommendations of the WCTOH since its inception in 1967.

Besides the above, the WHO tobacco control programs, the "World No Tobacco Day” (WNTD) and the Tobacco Free Initiative (TFI) were noted as very influential in spreading knowledge about tobacco use around the world. Only 9.5 percent of the interviewees were not aware of these programs at the point they got involved in the FCTC negotiation process. All the interviewees from the public health community are aware of these programs. However, the impact of the program in the diffusion of knowledge of tobacco use around the world differs.

The WNTD was identified by interviewees as been very instrumental in transmitting message about tobacco use and tobacco control to the grassroots level. However, the activities during WNTD and its impact are more notable in medium and low-income countries than in developed countries. For instance, an interviewee from Nigeria pointed out the in 2004 after public speeches and conferences highlighting the 
attitude of the country's Ministry of Health toward the FCTC, the minister as forced to respond to the accusation that Nigeria was not doing enough to ensure the adoption of the FCTC the same day. Thus, whereas interviewees from developing countries see the WNTD as very important program in raising awareness and educating people about tobacco use and tobacco control, those from developed world do not see it as very important. Some interviewees from developed world see it as important only when it is used in conjunction with other tobacco control programs. Yet all the interviewees agree that it has contributed to the growing perception of tobacco control as a global issue.

The TFI, on the other hand, was seen not only as influential in spreading knowledge about tobacco use and tobacco control around the world through its regional and local offices, but also through the organization of the FCTC negotiations and the mobilization of support for the FCTC. For instance, all the stakeholders (including the TTCs) credited the TFI for giving the entire world the opportunity to participate in the FCTC negotiation process through the public hearings. Also, interviewees who were at Geneva expressed appreciation for the education and information the TFI provided throughout the negotiation process. Finally, one important strategy that according to all the interviewees from anti-tobacco NGOs that ensured the successful negotiation of the FCTC was the involvement of civil society groups in the negotiation process. As a result, they agree that the FCTC was a civil society driven treaty. The activities of the civil society throughout the negotiation are described in the following sections.

In sum, diffusion of knowledge, information and ideas about tobacco control has contributed to the evolution of tobacco control as a global issue. However, based on the interviews, international conferences, academic publications, and the Internet are widely 
seen as tools for spreading information primarily among the elites of tobacco control. The only medium that is widely seen as having grassroots impact is the WHO WNTD. The WNTD is seen as limited because it is a one-day event. The TFI is also seen as influential in spreading knowledge about tobacco use around the world. But, its influence was particularly felt during the FCTC negotiation process when it took on the task of educating the country delegates about tobacco use and tobacco control. It must be noted that some interviewees pointed that country-to-country, organization-to-country, global activities of tobacco control NGOs have been relevant in the spread of knowledge about tobacco use and tobacco control around the world.

\subsubsection{FCTC and Transnationalism}

The issue as to whether tobacco control is a national or transnational phenomenon has been a subject of debate between the public health community and the tobacco industry. The tobacco companies argued in their submissions that tobacco control belongs to the domestic realm and it must be left to the national governments to handle. On the other hand, the public health groups perceive tobacco control as an ideal transnational issue. Thus, interviewees were asked to reconcile these two contending positions.

Approximately, 95 percent of the interviews agreed that tobacco use and tobacco control are a transnational issues. An interviewee who perceives tobacco control as a national issue argues,

“The FCTC was probably misconceived. It involves measures that may do more harm than good. Measures that induce government to follow international organization guidelines may not be good. 
For instance, tobacco control has been more successful in Sweden than in EU, partly because of opposition from tobacco control organizations.”

In spite of this stand, the interviewee still acknowledges that tobacco use is a global phenomenon. Yet, the interviewee explained that tobacco control is best handled by national governments.

Interviewees from the public health community strongly believe this issue should not even be a subject of argument. One interviewee said,

“There are so many aspects of tobacco that are trans-boundary. We can talk about advertising. In Nigeria, we read Newsweek. These magazines carry tobacco adverts, and how do we regulate it without international cooperation?”

Another said, "people around the world watch Formula 1 with cigarette adverts on the cars. This should tell everyone about the need for global cooperation in tobacco control.” Beyond the issues of smuggling and cross-border advertising, the dominant reason why tobacco control is deemed as a transnational issue is the nature of the tobacco industry. All the interviewees, especially those from public health community, pointed out that the industry itself is transnational in scope, hence the measures to control its activities should be transnational in nature as well. For instance, an interview said, "the political and transnational nature of the tobacco industry demands that we have a transnational organization for tobacco control.” Another interviewee said, “From the industry's documents, they organize video conferences for tobacco executives around the world. So, if they see the world as a global market place, then tobacco control should also be global.” Internet sales is another reason cited for the consideration of tobacco as a transnational issue. Thus, generally, issues of tobacco use and tobacco control are considered transnational in scope. 


\subsubsection{FCTC and Globalization and Interdependence}

The idea that increasing levels of interaction and interconnectedness foster cooperation in certain issue areas within the international system such as tobacco control is one of the underlying hypotheses of this study. All the interviewees agreed that recent technological advancements have contributed not only to increase in the awareness of the science and evidence of tobacco use and tobacco control but also the mobilization of global support for the FCTC. Interviewees agreed that the idea that the world is a "global village" has affected the transformation of tobacco control into a global phenomenon. An interviewee said, "of course, tobacco control is a global issue because it is affecting people all over the world.” Another interviewee argued, "The tobacco industry is global, so tobacco is a global problem. It is a problem for every country around the world. The solutions are global, and international organization will facilitate global cooperation.” From this, interviewees from public health groups argue that tobacco control on a country-by-country basis will not be successful against of a global industry that spends millions of dollars in the promotion of its products around the world. One interviewee compared the drive towards smoking bans on all international flights with the FCTC negotiation process, and she pointed out that advancement in communication facilitated the mobilization of advocates from around the world to be involved in the FCTC process in a manner that has never happened before. Also, an interviewee indicated that the mobilization of civil society groups around the world to support the FCTC would not have been possible 15 years ago, and she attributed it to globalization. In effect, increasing interaction and interconnectedness among individuals, groups, organizations 
and states has been noted as an important determinant for the successful negotiation of the FCTC.

Associated with globalization is interdependence in trade. All the interviewees who were present at the INB sessions acknowledge that trade was one of the most contentious issues in the FCTC negotiation process. An interview said he opposes the FCTC because it inhibits international free trade and does not allow the market to flow freely. All the TTCs expressed concern about the adverse effect of global regulations on trade in tobacco.

On the other hand, interviewees from the public health community suggested that liberalization of international trade rather led to the concern for an international regulatory regime. One government official interviewed said,

“Certainly there are many benefits of international trade liberalization. But unfortunate side effects of more liberalized international trade is that some products do not bring any benefits like tobacco are also treated the same. The existence of the FCTC is the only defense we have against tobacco trade.”

Thus, with trade in tobacco booming and associated consumption rate increasing at the aggregate level, it was deemed necessary that global collective action was the solution to the problem. Although the Preamble of the FCTC point out that in all aspects of international relations health should be given priority, all the interviewees pointed out that the trade versus health issue in international relations was perhaps the only issue not resolved under the FCTC. It is now left to the conference of parties to come out with protocols governing the relations between international trade and global tobacco control. In essence, interviewees who supported the FCTC pointed out that concern over international trade in tobacco was a key determinant for their position. 
A third component of globalization has been the extension of the activities of $t$ the transnational tobacco companies into the developing world. In this respect, one interviewee suggested that one reason why countries in Southeast Asia, particularly Thailand, supported a strong tobacco treaty could be due to its experience with the U.S. Another interviewee indicated that this concern was a source of mobilization of developing countries, especially those from Africa.

The extension of the activities of the tobacco companies into developing countries has been integral part of the evolution of tobacco control into a global issue. A policy entrepreneur said,

“Throughout the 1970s, I saw what was happening worldwide. These tobacco companies, once they were faced with legislations in the industrialized countries, they turned with an assault on the developing world. And therefore I realized that we had to have some international action that match the international assault of the international companies on countries in the developing world.”

This was the main reason why she fought throughout her life and career to help transform tobacco control into a global issue. Also, all the interviewees from anti-tobacco groups acknowledge that this has been a reason why tobacco control has become a global issue. Although it was not extensively discussed during the negotiation sessions, one interviewee indicated that most of the delegates were already aware of the marketing activities of the tobacco companies in the developing world. Another said that those who were not aware at the beginning of the negotiations become aware later because of the information provided them and as they head more stories on the global activities of the TTCs from their fellow delegates and anti-tobacco groups. This is another confirmation of the results of descriptive analysis of this study. 


\subsubsection{FCTC and States}

States remained the leading actors throughout the negotiation of the FCTC because the ultimate decision lies in their hands. Of course, states were the contracting parties to the FCTC under international law and not any other entity within the international system. For instance, in comments on the activities of NGOs during the negotiation sessions, one public official said, “They were present, but they attended plenary session and not more detailed discussions. They were on the periphery talking with state delegates. But in the end, states had to make the final decision.” In spite of the centrality of state during the negotiation process, only five percent of the interviewees accept the assertion that they were the dominant actors in the negotiation process. However, interviewees pointed out some influential contributions of certain individual states. Whereas some countries wanted a weak or watered-down treaty, others wanted a stronger treaty. In all, the countries interviewees pointed out as favoring strong FCTC provisions included Australia, Brazil, Canada, India, New Zealand, Palau, Ireland, South Africa, and Thailand. On the other hand, countries that favored watered-down treaty were China, Germany, Japan, U.S., and to a lesser degree Cuba and tobacco-dependent countries such as Malawi and Zimbabwe. This tells use that states played different roles in the negotiation process.

With regards to the role of states in the negotiation of the FCTC, interviewees pointed out that a phenomenon that occurred during the negotiations, and which may be new in treaty negotiation, was bloc voting. Jacob (2004), for instance, acknowledged this phenomenon in his account, but criticized the system undermining the ability of 
individual states to negotiate on many issues. The WHO regions, particular Africa (AFRO), Southeast Asia (SEARO), and Western Pacific (WPRO) developed common stand on certain policies and voted on them as blocs. All the interviewees who participated in the INB sessions agree that the AFRO region was the most influential in this respect. An interviewee pointed out that through the leadership of South Africa, the African countries organized as a bloc after INB1, and they held inter-session meetings to develop a common position on some of the negotiated provisions under the FCTC. This transformed the entire process because regional inter-session meetings became integral part of the negotiation process. Evidence from the interviews indicates that the Pacific islands region of WPRO and the SEARO emulated this, making them the second and third most influential regions in the negotiation process. The Caribbean states and the Eastern Mediterranean regions (EMRO) followed in that order. However, interviewees pointed out that the European region (EURO) was weakened throughout the negotiation because of division in its ranks. Germany was single out as being the main culprit for weakness of EU in the negotiation process. The idea that the 15 members of the European Council must reach consensus on every issue was seen as a hindrance on the ability of EU countries that have strong tobacco control programs to contribute to the negotiation of the FCTC. This made the EURO the fifth most influential WHO region in the negotiating process. The region with the least influence on the process was the Pan American Health Organization (PAHO or AMRO). This is because the AMRO literally did not negotiate as a bloc. Whereas countries in North America, in particular, participated in the process as individual countries, those in Latin America bounded together (Jacobs, 2004). This removed their regional impact on the process. In the end, 
some interviewees argued that the FCTC is one of the treaties that developing countries played influential roles in bring it into being.

\subsubsection{FCTC and NGOs}

All the interviewees agreed that civil society groups dominated the entire FCTC negotiation process. Whereas participation of pro-tobacco groups such as smokers' rights groups were limited to the public hearings, anti-tobacco groups participated in entire

process. They were involved in activities concerning the FCTC from the country level to the global level. An interviewee from WHO said,

“The anti-tobacco groups were very involved even before the treaty was under negotiation. They helped in mobilizing interest at the country level for states to send delegates. The treaty would have failed without the support of civil society."

Whereas at the country and regional levels they participated in the process more as individual organizations, at the global level, they participated in the process in the form of alliances and coalition.

The identified alliances and coalition include the Framework Convention Alliance (FCA), the Network for the Accountability of Tobacco Transnationals (NATT), and the International Nongovernmental Coalition against Tobacco (INGCAT). Although all the interviewees from anti-tobacco community are familiar with these groups, the FCA was overwhelmingly identified as the most influential coalition during the negotiation of the FCTC. The NATT was the second most visible and influential group. The group that was least influential and visible during the negotiation process was INGCAT. The main reason, an interviewee indicates, was that the FCA was formed primarily with a focus on the convention, but the others have broader goals than that. 
The activities of the FCA, as the interviewees that participated in the INB meetings agreed, contributed to the strength of the civil society in the negotiating process. From the interviews, these activities include education of delegates through lunchtime briefings, media advocacy through news conferences and news releases, publication of the Alliance Bulletin, symbolic protests, holding countries accountable through awards, and contacting other advocates in the country of delegates. The most effective tool was the publication of the Alliance Bulletin. It was more or less the newspaper of record throughout the negotiation process. As one interviewee pointed out, the negotiation was big and unwieldy for states with small delegates; thus the Alliance Bulletin was the main source of news for such countries during the negotiations. Another interviewee said, "every morning you could observe the delegates rushing for the newsletter, so that they can understand the issues and know what was going on.” Through the newsletter, the anti-tobacco groups provided information about tobacco use and tobacco control to the delegates, and thereby helping to influence the course of the negotiations. The influence of the Alliance Bulletin in the negotiation process is also consistent with the findings the descriptive sections of this study.

The other influential tool was the award. The Dirty Ashtray Award went to country or countries that were deemed as obstructing the process towards a stronger treaty. The Orchid Award went to country or countries whose contributions in previous day deliberations were deemed as favoring stronger tobacco control treaty. Interviewees pointed out that initially some of the states were dismissive of the awards. However, the impact of the awards came to light when some of the participants were using it to criticize others. From then on, the awards became a valuable part of the entire process. No country 
wanted the Dirty Ashtray Award, so countries were careful with the positions they hold on some of the provisions. The influence of the FCA awards in the negotiation of the FCTC is one of the new findings of this study. Until the interviews, the influence of the awards in the process was underestimated.

In spite of the above activities of the FCA, its most important contribution to the negotiation of the FCTC was the ability to convince delegates with varied degrees of knowledge that tobacco control was not a North-South issue. Especially, the FCA was able to educate developing countries that tobacco was not a developed world issue. This was accomplished in part with the creation of the FCA itself, with crosscutting membership around the world. Thus, the ability of the delegates from developing countries to understand that the treaty was not one of the North-South issues in world politics is widely seen as one of the reasons for the general strong support for the FCTC. This is another new finding of this study. Although this has been one of the underlying arguments of this study, it only came up in the interviews that the FCA took up the responsibility of educating the delegates not to perceive tobacco control as a North-South issue. This could a reason for the unanimous approval of the treaty.

It must, however, be noted that the influence of the FCA in the negotiation process varied from country to country and from region to region. In this regard, one public official pointed out, "Each country had instructions from their home governments. Whilst some came in with strong instructions, others had flexibility. In that sense, the influence of the anti-tobacco NGOs varied from country to country.” Another said, "The NGOs were very influential particularly, with respect to developing countries where the governments themselves are not experts in the field of tobacco control and the NGO were 
very important for them.” These comments by these public officials are indications of the variation in the influence of NGOs on positions of states.

\subsubsection{FCTC and the Tobacco Industry}

In the first place, TTCs had the opportunity to contribute to the FCTC through the preliminary public hearings, hence their submissions. However, they were sidelined from participating in the WG and the INB meetings. For instance, R. J. Reynolds lamented in its submission that "the WHO has excluded the entire tobacco industry from participation in the process of developing the Framework Convention of Tobacco Control. Neither the manufacturers of tobacco products nor any association representing tobacco farmers, retailers, advertising agencies, or consumers have had the opportunity to participate in a meaningful way." Yet, interviewees from anti-tobacco NGOs, public officials, advocates, and WHO still harbor the perception that tobacco industry was influential in the process.

Many argue that the tobacco industry covertly influenced the negotiation process in two ways. One of the means through which the industry sought to influence process was lobbying delegates. For instance, an interviewee said, "during the negotiations, even directors of BAT as far away as Nigeria were in Geneva. As the NGOs were talking to the delegates, they were also talking.” In addition, members of the industry participated in the process as state delegates. Some interviewees pointed out that there were identifiable members of the tobacco industry on the delegations of Turkey, China, Japan, Russia, and Malawi. One interviewee queried, "if you find members of the International Tobacco Growers’ Association (ITGA) on state delegations, what will you say about the

involvement of the tobacco industry in the process?” Another interviewee said, “yes, they 
tried to influence the process, but they failed.” Many perceive the adoption of FCTC as evidence that the efforts of the tobacco industry to undermine the process did not work.

WHO deliberately designed the process to reduce the participation of the tobacco industry. Still, there is a widespread belief, particularly among public health groups, that the industry tried to covertly influence the process through membership on state delegations. On this issue, the tobacco industry claims that they were sidelined from the process, but the public health community claims that the industry covertly participated it. This is one of the irreconcilable issues when it comes to participation in the FCTC negotiation process.

\subsubsection{FCTC and Policy Entrepreneurs and Advocates/Activists}

Through the interviews, three groups of individuals have been identified. These include policy entrepreneurs as explain by Mintrom (1997) and others, experts of WHO, and advocates. In general, the policy entrepreneurs identified in the interviews include Ruth Roemer, Allyn Taylor, and Judith Mackay. An interviewee pointed out that these three individuals actually laid down the idea of an international convention on tobacco control. Roemer, in particular, is seen as the main architect of the FCTC. She explained her tobacco control activities since the 1970s in an interview with the author. Also, an interviewee identified Taylor's 1992 article as helping to explain the constitutional power of WHO to develop a convention. These people who were identified in the interviews as architects of FCTC are consistent with the literature and findings of the descriptive sections of this study. 
In the case of the experts of WHO, Neil Collishaw of Canada was identified for working together with Taylor, Roemer, and Mackay to get the idea of an international convention unto WHO's agenda, when he was working with the organization in the early 1990s. In addition, Collishaw was identified as influential in encouraging the International Union Against Cancer (UICC) to start GLOBALink. Although other individuals at WHO had been involved in the transformation of tobacco control into a global institution, the most important individual credited for getting the development of a convention on course and making it a WHO priority is Gro-Harlem Brundtland, the Director-General during the era of the negotiation. One interviewee argued, "Without the Director-General's leadership, we may not have FCTC. She made tobacco control one of the top priorities of WHO.” Another interviewee said, "The FCTC is actually the treaty of Brundtland.” These are indications of how her leadership facilitated the successful negotiation of the FCTC. Other individuals whose names were mentioned in the interviews include Vera Luria Da Costa e Silva, Derek Yach and Douglas Bettcher. Da Costa e Silva was mentioned for her role as the Project Manager of the TFI. Yach and Bettcher were identified for the various roles in the Tobacco Free Initiative (TFI). Once again, this confirms findings in the descriptive section of this study.

Finally, identifiable advocates who were influential in the negotiation process include Yusuf Saloojee and Patricia Lambert of South Africa for getting the African position together, Ross Hammond of U.S. and Clive Bates of United Kingdom for devising the FCA lobbying strategy, and Laurent Hubert (USA) of FCA for the assistance to French speaking countries from West Africa. Many interviewees from anti-tobacco NGOs acknowledged that Hubert's ability to speak multiple languages was of immense 
help to many delegates to the negotiation process. Other names that were mentioned for the influential role in the FCTC negotiation include Mary Assunta of Malaysia, Caleb Otto of Palau, Shabba Juan of India, Judith Wilkenfeld of the U.S., Luk Joossens of Belgium, and Margaretta Haglund of Sweden. In addition, individuals such as Doug Blanke of Tobacco Law Center (USA), Murray Laugessen of ASH-New Zealand, and Anne Jones of ASH- Australia who were interviewed for this study have been influential in global tobacco control in general, and the FCTC negotiations in particular. The point here is that even though some of these individuals were members of organizations, interviewees named them for their outstanding individual roles in the entire FCTC negotiation process. In effect, individual activities were influential in the transformation of tobacco control into a global phenomenon, a confirmation of one of the hypotheses of this study.

\subsubsection{FCTC and "Low Politics"}

The ease and speed with which the FCTC came into being raised the question why states were able to easily cooperate on the tobacco issue? Why was cooperation on global tobacco control relatively easy? For instance, a public official from Canada said, "It is quite amazing that we signed and ratified the treaty less than 18 months. That's amazing for an international treaty.” All the advocates, NGOs, and public official interviewed agreed that tobacco is a unique public health issue. An interviewee said, “Tobacco use ultimately affects pretty much everybody on the planet. People are either smokers themselves or are exposed to other people who smoke.” Another reason interviewees pointed out for its uniqueness is the involvement of a corporate agent in the 
spread of the disease. As a result, states were ready to cooperate on tobacco control when they became familiar with the science and evidence of the issue.

In spite of its uniqueness, interviewees agree that in some ways it is comparable to other public health issues. Advocates, NGOs, and government officials agree that tobacco control is also comparable to other trans-boundary issues such as the environment and human rights. In fact, one interviewee said, "tobacco is being spread by an industry that makes billions of dollars by spreading the disease. Tobacco control is really a political human rights issue. This is why we have other groups coming on board.” Also, an interviewee from an environmental group said, "tobacco is a developmental issue that is linked to poverty and social justice.” Other interviewees compared tobacco control to different issues within the international system. However, none of the interviewees compared tobacco to issues of national security, sovereignty or conflicts among states.

Also, despite the differences in the domestic political structures of interviewees, all of them indicated that issues of tobacco control in their countries are handled at the lower executive or ministerial, the congressional or parliamentary, the provincial/state, the local/community, and the nongovernmental levels. None of the interviewees indicated that tobacco is handled at the presidential or prime ministerial level. It must, however, be pointed out that interviewees from New Zealand indicated that the involvement of the current prime minister, Helen Clark in issues of tobacco control in the country is due to her special interest in the issue (Studlar, 2005). From all these, it can be deduced that the ease and speed with which countries cooperate on tobacco control at the global level is 
because it is a "low politics" issue in world politics, a confirmation of an hypothesis of this study.

\subsection{Summary, Conclusion, and Discussion}

This is the empirical chapter meant to test the hypotheses and to examine the tentative conclusions of the descriptive chapters of the study. The chapter analyzed of interviews conducted with actors and stakeholders involved or interested in global tobacco control around the world. The categories of interviewees include policy entrepreneurs/advocates, anti-tobacco NGOs, business NGOs (BINGOs), and government/public/state officials. The interviews were complemented with tobacco industry submissions at the FCTC public hearings. The focus of the interviews was to understand the politics behind the evolution of tobacco control into a global phenomenon and the institutionalization of FCTC.

First, the whole idea of tobacco control hinges on familiarity with knowledge, information, and ideas about tobacco use and tobacco control. The more people around the world who become familiar with the science and evidence of tobacco control, the more easily they can to embark on collective action. Second, with the exception of the tobacco industry that decries the global institutions of tobacco control as an infringement on the sovereignty of states, all the other stakeholders view the issue as primarily a transnational phenomenon. Thus, the more tobacco use is seen as a transnational phenomenon, the more people are ready to cooperate in the establishment of a global institution on tobacco control. Third, increasing interconnectedness and interaction within the international system has contributed to the progressive awareness that tobacco use 
and tobacco control is a global issue, making cooperation on the issue easier. Fifth, the "low politics" nature of tobacco control and the crosscutting nature of the tobacco problem reduce points of tensions and conflicts, making collective action possible. Finally, activities of transnational actors such as policy entrepreneurs, advocates, and anti-tobacco NGOs propelled the issue unto the agenda of the World Health Organization. The continued involvement of the global civil society in the negotiation of the treaty resulted in the institutionalization of tobacco control as FCTC.

The findings of this analysis are consistent with the underlying hypotheses of this study and the conclusion of the descriptive chapters. One new fact coming out of the interviews is the indirect and covert participation of the tobacco industry in the negotiations process. The tobacco companies criticize WHO for sidelining them in the FCTC process. Yet they directly participated in the process through their submissions to the public hearings. In addition, they found alternative ways of participating in the negotiation process as state delegates and as lobbyists. The only difference is that attempts to influence the process did not succeed because the FCTC has been adopted. In addition, the influence of the FCA awards in the negotiation process was underestimated in politics. Finally, North-South divisions hinder many global collective actions. However, the ability of the FCA to overcome this problem through education of the delegates is one important finding of this study.

In summary, transnationalism, globalization and interdependence, policy diffusion and transfer, and "low politics" explain the evolution of tobacco control into a global regime. These phenomena have contributed to the spread of knowledge about tobacco use and tobacco control, making collective action easier. The involvement of global civil 
society in the negotiation of the treaty facilitated the adoption of the FCTC. In essence, when the scientific evidence on an issue is very strong, the issue is crosscutting such that it affects everyone, when the issue is transnational and global in scope, and the involvement of the global civil society in the process of getting cooperation among states could lead to global collective action. 


\section{Chapter 7}

\section{Conclusion}

\subsection{Introduction:}

Since tobacco was discovered in 1492, the habit of tobacco use spread around the world. Although individuals, groups, and organizations had protested against this trend, their actions were in vain as tobacco continued to spread worldwide. This is due in part, to the strength of the tobacco industry. It was also due to governments' support for the industry at certain points in history. A typical example of this was the inclusion of cigarettes in the ration of American servicemen during the first and second World Wars. However, by the 1950s and early 1960s scientific knowledge and evidence about the hazards of tobacco had become widespread. In 1962 and 1964, the Royal College of Physicians and the U.S. Surgeon General published reports on the linkage between tobacco and health respectively. The two reports began a new era of tobacco control [See chapters 1, 3, and 5]. The scientific reports encouraged the need for tobacco control at both domestic and international levels, but little was done (Studlar, 2004). Until recently, tobacco control was more of a domestic issue.

Between the early 1960s and 2003, tobacco control gradually spread to other parts of the world, and eventually evolved into a global institution, the FCTC. In May 2003, it was unanimously adopted by the 192 member states of WHO after approximately four years of negotiations (1999 to 2003). It became an enforceable international treaty on February 27, 2005. At the time of writing this section of the paper, July 2005, 168 countries had signed the treaty and 74 had ratified. Now, the focus has changed towards its implementation. The analysis of this phenomenon brings Public Health and Political 
Science together in a single study. This is because the idea of tobacco control is about policies and programs needed to curb the habit of tobacco use domestically and internationally.

Today, tobacco use and tobacco control have spread around the world [See Figure 7.0]. An issue that started as a domestic concern and later, the concern of developed countries about four decades ago has become a worldwide issue. From Canada, the U.S., and Cuba (PAHO); to France, Ireland, Montenegro, Netherlands, Norway, Sweden and UK (EURO); Bhutan and India (SEARO); Iran (EMRO); Kenya, Tanzania, and Uganda (AFRO); and Australia (WPRO); countries around the world are instituting tobacco control policies and programs (BBC, May 5, 2001). This work generally analyzed the politics behind this evolution, but with emphasis on institutionalization of global tobacco control. The main question this study tried to answer was: given numerous other public health concerns, why should tobacco be the first international public health issue institutionalized in treaty form? The entire study was geared towards this analysis. This chapter summarizes the study, highlights the key findings, discusses the contribution of the study to general Political Science theory, and lays down directions of future research.

\subsection{Summary of Study}

This study is a bottom-up analysis of the development of global norms on tobacco using the liberal-constructivist perspective of international relations. This perspective draws on theories of regimes such as transnational advocacy networks (Keck and Sikkink, 1998), advocacy coalition framework (Sabatier and Jenkins-Smith, 1999, 1993), and epistemic communities (Haas, 1992, 1989; Alderman and Haas, 1992). It relies, first

and foremost, on the existence of an international organization with constitutional powers 
in a given issue-area in the international system, such as WHO in international public health. The World Health Organization has provided the policy arena through which issues of international tobacco control had been handled, since it officially recognized the problem in 1970. In the ensuing years, it became a leader in global tobacco control, creating a policy venue for anti-tobacco activities. In addition, the theory emphasizes the transformational effect of knowledge, information, and ideas on the interests and priorities of states and other non-state actors in the issue-area. Similar to certain development of international prohibition regimes (Nadelman, 1990), familiarity with knowledge about tobacco use and tobacco control served as tools for mobilization of antitobacco individuals, groups, and organizations around the world for a global collective action to combat the practice of tobacco use and worldwide activities of the tobacco industry. These are the prerequisite conditions for this liberal-constructivist perspective. The perspective was used to explore why, among all other public health issues, we have the first ever treaty in tobacco control. The emphasis, however, was on the processes and procedures that led to the emergence of this global regime.

The first argument is on the transnational nature of tobacco. First, tobacco use is a practice that goes beyond any national boundary. Second, the industry involved in the spread of the habit is transnational in nature [See chapter 4]. Many issues involved in tobacco such as advertising and smuggling spill over national borders. This suggests that no country can single-handedly curtail tobacco use hence the need for international collective action.

Associated with the above is the issue of globalization and interdependence. First, the tobacco industry, over time, extended its activities throughout the world. Second, with 
increasing interconnectedness and interactions in the world, tobacco has emerged as an issue that affect many people around the world (both smokers and non-smokers). This implies that to curtail the global activities of the tobacco industry and to curb the global tobacco epidemic, there is the need for the harmonization of national policies through international collective action [See chapter 4].

Another argument of this study is on policy transfer/diffusion. As the liberalconstructivist theory indicates, knowledge has transformational effect on actors within the international system. The study argues that activities of actors within the international system resulted in the spread of knowledge about tobacco use and tobacco control over time, and acted as a catalyst for mobilization for international collective action to curb the use and the spread of tobacco [See chapter 5].

The study theoretically argues that knowledge about tobacco use and tobacco control originated through the ingenuity of individuals, groups, organizations, and states at the domestic level. However, over time, these ideas spread throughout the international system through the activities of different transnational actors, conferences, and institutions. In addition, societal actors and transnational societal interaction helped to shape the preferences of states to embark on such international collective action. This is facilitated by the fact that tobacco is a "low politics" and transnational issue. Furthermore, the global extension of the activities of the tobacco industry on one hand, and increasing interactions and interconnectedness on the other facilitated the mobilization of forces against the use and spread of tobacco. All these activities on tobacco control around the world eventually converged at one governance arena, WHO. 
It used its constitutional power to provide the arena for global tobacco control activities and the negotiation of the FCTC. This argument is represented in figure 7.1 below.

Figure 7.0: The Evolution of Global Tobacco Control

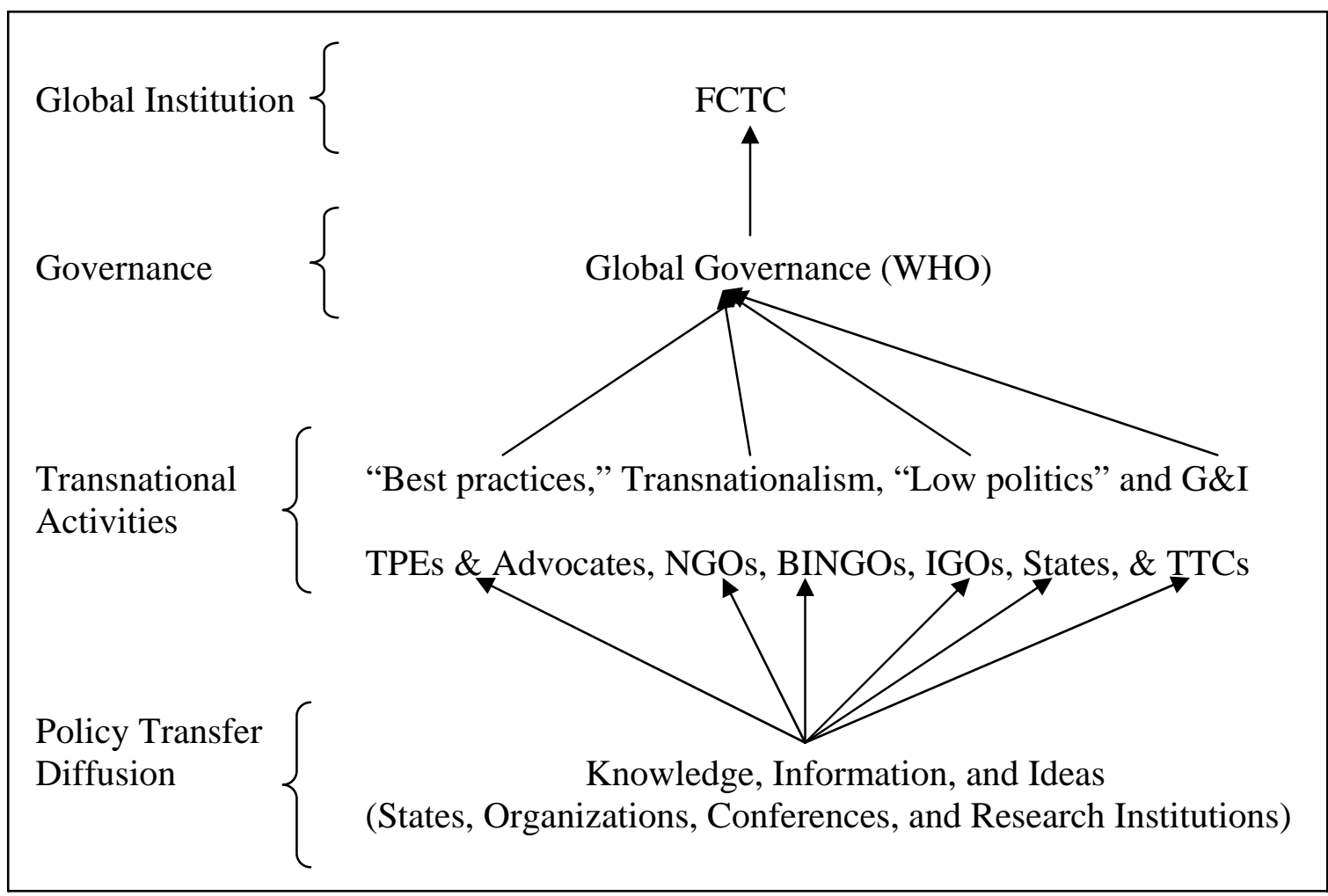

This is a longitudinal study that covered the period between the early 1960s (the emergence of authoritative recognition of the hazards of tobacco use) and 2003 (the adoption of FCTC). However, the study put more emphasis on the period between 1999 and 2003, that is, the beginning to the end of active negotiation of the FCTC. The analysis of the study was done through triangulation. This method combines qualitative and quantitative methodologies of research. Specifically, the study combined elite interviews and content analysis of archival data. Because of the multimethod nature of this study, it has three descriptive chapters on transnationalism, global governance, and "best practices" in tobacco control, and one empirical chapter. 
Each of the three chapters covers an aspect of the politics involved in the gradual evolution of tobacco control into a global phenomenon. First, the chapter on tranasnationalism analyzed the contribution of transnational actors (pro-tobacco groups, anti-tobacco groups, tobacco policy entrepreneurs and advocates, and transnational tobacco companies) to the emergence of the global institution in tobacco control. Second, the chapter on global governance shows the contribution of states and the intergovernmental organization responsible for public health to the emergence of global institution on tobacco control. Due to the fact that the extension of the activities of the tobacco industry into developing countries contributed immensely towards the treatment of tobacco as a global issue, special attention was given to why and how these developing countries issue aroused the necessity for a global collective action. Third, the chapter on "best practices" analyzed how an epistemic community in tobacco control, World Conference on Tobacco and Health (WCTOH) since its inception in 1967, has contributed to the development of new tobacco control policies, facilitated the spread of tobacco control policies from developed countries to developing countries, and helped in the development of global collective strategies to combat the worldwide activities of the tobacco industry. In essence, these three chapters cover virtually all aspects of the politics behind in the evolution of tobacco control into a global regime. Finally, the empirical chapter is analysis of interviews of actors who were involved in the negotiation of FCTC for confirmation of the key hypotheses and tentative conclusions in the descriptive chapters. 


\subsection{Findings}

The descriptive chapters and the empirical chapter complement each other. This is because virtually all the key arguments were confirmed. However, the findings of this study are divided into three categories - general, unique, and unexpected. The general findings are those that were expected from the onset of the study. The first general finding is on transnational argument. The key point is that the tobacco industry has historically remained a transnational enterprise and as such, regulation of its activities must be transnational as well. This multibillion-dollar corporate agent has been spreading the habit of tobacco use through its worldwide activities for many years hence the effort to curtail such activities through international collective action. Also, globalization and interdependence of the world was found to be very important issue in the evolution of global tobacco control. The most important finding here is that the extension of the activities of the tobacco industry into developing countries throughout the period of study has been one of the reasons why tobacco is treated as a global issue. Moreover, with respect to the issue of "best practices" in tobacco control, the study found that there has been purposive effort to transfer tobacco control policies from one jurisdiction to another. Transferring tobacco control policies from developed countries to developing countries in particular was an issue consciously and deliberately discussed at different world conferences on tobacco [See chapter 5].

Also, one underlying principle under the FCTC is for countries to borrow tobacco control policies from each other and as such, countries like Australia, Canada, Finland, New Zealand, Norway, Sweden, Singapore, South Africa, and Thailand, and the states of Massachusetts and California of the U.S. are repeatedly identified as models for 
emulation by other jurisdictions around the world. The phenomenon has blurred the gap between International Relations and Comparative Public Policy sub-fields of Political Science, as internal policies of these model countries have become international norms on tobacco control. The availability of these innovated tobacco control policies was found to a central rationale behind the emergence of the FCTC.

Finally, the "low politics" nature of tobacco control was found to be a reason why cooperation is easier in the policy arena. The most important point is that tobacco is one of the less divisive issues in international relations that affect everyone equally hence the ease with which it evolved into a global regime. Interestingly, with the exception of New Zealand, all interviewees indicated that tobacco control issues in their countries are handled at the lower executive, congressional/parliamentary, and nongovernmental levels. Behind all these is the powerful influence of knowledge, ideas, and information on tobacco use and tobacco control. Also, with the exception of a few tobacco companies, the vast majority of actors in the international system no longer question the linkage between tobacco use and health. This is the reason why since the 1960s, and particularly during the FCTC, numerous efforts were used to educate actors and stakeholders about the science and evidence on tobacco use and tobacco control.

The first unique finding of this study is that tobacco control in general has been a civil society driven issue. Since 1970, all resolutions of the WHA have called for the involvement of civil groups in tobacco control activities domestically and internationally. Also, from the beginning of the FCTC negotiations, deliberate efforts were made to involve the entire world in the debate for the necessity of a convention on tobacco control through the FCTC public hearings. Tobacco control has been an area in international 
relations dominated by non-state actors. Of course, the tobacco industry is a non-state actor within the international system. Civil society groups have led the fight to combat the spread of the habit since the authoritative recognition of the hazards of tobacco use (Nathanson, 1999). Even during the negotiation of the FCTC, civil society groups, particularly the anti-tobacco ones, dominated the entire process. Evidence gathered portrays that although states were the ultimate decision-makers in FCTC process, civil society groups were the most influential actors.

Furthermore, the study found the transformational effect of symbols on the interests and identities of actors in a process of negotiation. During the FCTC negotiation, the FCA awards became very effective mechanisms in modifying the stands of different actors. A Majority of interviewees (including state delegates) pointed out that the awards were very influential in the negotiation process. This was because no state wanted to be seen as derailing global efforts to protect the health of peoples around the world. In this case, symbolism influenced some states to support the FCTC.

Finally, the study identified an epistemic community in global tobacco control. In 2006, the $13^{\text {th }}$ World Conference on Tobacco or Health would be held in Washington, D.C., USA. This meeting of experts and policymakers in tobacco control since 1967 has a shared a deep core belief of the linkage between tobacco use and health. In addition, the conference is policy oriented in the sense that it aimed at transforming tobacco control policies both domestically and internationally. For about for decades, the WCTOH has performed the roles of innovation and diffusion of tobacco control policies around the world. This study found that the WCTOH contributed to the transformation of tobacco control into a global phenomenon and the eventual emergence of the FCTC. 
The first unexpected finding is regional approach to the negotiation of the FCTC. During the negotiation process, some WHO regions, notably AFRO and the Pacific island states of WPRO voted as bloc. In effect, these regions presented a common front in the negotiation of the FCTC although the importance of tobacco to them varies from one country to another. The other unexpected finding is about the origin of the idea of an international convention on tobacco. From the onset of this study, Allyn Taylor was deemed as the originator of the idea because of her 1992 article on the power of WHO to establish a regime on public health. However, through the interviews, it came to light that Ruth Roemer is rather the originator of the idea, although she has been working closely with Taylor and Judith Mackay. Roemer has been working in the area of global tobacco control since the 1970s and was influential in laying the foundation of the FCTC.

\subsection{Contribution to Theory}

First, this study makes contribution to liberal and constructivist theories of world politics. This is an issue-area whereby non-state entities had not only dominated the arena for over four decades and continue to do so, but also they helped to shape preferences of states within the international system. Non-state entities have led the development of international norms that are influencing the behavior of states and other actors within the international system. This is consistent with Nadelman's (1990) analysis of international prohibition agreements. From UICC tobacco control workshops in Africa in the 1980s and 1990s [See chapter 5] to FCA involvement in the negotiation of the FCTC [See chapters 3 and 6], non-state entities have been influential in changing the behavior of states and global norms in the tobacco control policy arena. Today, anti-tobacco NGOs 
around the world have formed global coalitions and alliances [See chapter 3 and 6 ] to strengthen their influence on the behavior of states. The dominance of non-state actors in this policy arena within the international system strengthens the argument of liberal international relations theory (Moravcsik, 1997).

Secondly, this study bridges the gap between international relations and comparative politics. Global tobacco control is a bottom-up evolutionary phenomenon. This is because it originated from within specific jurisdictions, and spread to others. As indicated above, currently there are states that are marked as models of tobacco control. Although these countries have advanced forms of tobacco control programs, the actions of individual countries are insufficient in the face of a multibillion dollar enterprise, hence the need for international cooperation and collaboration. A typical example was the rift between Thailand and the U.S. over the Thailand's government ban on imported tobacco [See chapter 4]. In addition, tobacco control is an issue area in which unique features of states are relatively less significant in the policy-making process. This was a widespread opinion among interviewees. For instance, one interview said, "When it comes to tobacco control, the most important thing is the political will.” In this sense, the line between comparative politics and international relations is blurred.

Thirdly, for the tobacco control policy arena, this study demonstrates that it is not just the outcome but also the politics behind it that matters. In this sense, it brings Political Science and Public Health together in a single study. It took several years for tobacco control to be transformed from a domestic phenomenon into a global regime. Throughout the period, more scientific evidence linking tobacco use to health has been gathered, and knowledge, information, and ideas about tobacco use and tobacco control 
have spread to different parts on the world. This strengthens constructivist perspective of world politics. Familiarity with the science and evidence motivated states to institute tobacco control policies even before the emergence of the FCTC. For example, an interviewee from New Zealand pointed out that it was easier for the country to sign unto the FCTC because that country has an advanced form of tobacco control policies and programs. In this respect, the FCTC did not occur overnight, and the cumulative politics behind the evolution of global tobacco control within the four decades (1962-2003) accounts for why it is the first ever-global public health treaty.

Finally the study is also relevant to agenda setting within the international system. It helps us to understand how issues within the international systemic agenda are either kept off or propelled unto the international institutional agenda. In this issue-area, the process began with official recognition of the hazards of tobacco use in the early 1960s. However, the strength of the tobacco industry kept the issue off the agenda of many states. For instance, until the MSA in 1998, where the tobacco industry admitted the hazards of their products, they had continually denied it. Even now, companies such as JTI only see tobacco as a 'controversial' product rather than harmful one [See chapter 6]. In spite of this, a combination of strong scientific evidence and activities of anti-tobacco transnational actors propelled the issue unto WHO's agenda. This study illustrates that over time a combination of strong science and sustained commitment can propel issues unto an institutional agenda. 


\subsection{Limitations of Study}

The key drawback of the study is biasness of the sample. The study did not only over-sampled interviewees from certain WHO regions, particularly PAHO, but it also over-sampled certain actors, particularly NGOs. This problem limits the generalizability of the conclusions of the study hence the preliminary analytical nature of the interview data. This problem arose because of the difficulty in gaining access to participants in the FCTC process. The snowballing method of data collection contributed to the oversampling of certain types of interviewees. In spite of this drawback, the findings of the study are consistent with the conclusions of the descriptive segments of this study, firsthand account of the FCTC negotiation process, and the literature on tobacco control.

\subsection{Research Agenda}

This is one of the few studies in Political Science in general, and in International Relations in particular that examines how a domestic issue becomes an international institution (Nadelman, 1990). As one of the few Political Science works in a Public Health arena that analyzes issues behind the scenes, future study will try to interview as many participants as possible. Larger and wider variety of interviewees will strengthen the arguments and findings of this study.

Second, since the adoption of the FCTC, there have been different rates of ratification. Future studies will attempt to investigate why some states ratified the treaty very quickly and others are even yet to ratify. For instance, developing countries in

general, and African countries in particular spearheaded the development of the FCTC, 
yet only a handful of them had ratified the treaty. Yet, only half ${ }^{1}$ of the 74 countries that had ratified the treaty come from developing regions. Why? What are transnational tobacco companies doing in the process of ratification of the treaty? What evidence can be adduced from the tobacco industry documents to account for why tobacco control is lagging in developing countries in general and how that relates to the lag in the ratification of the treaty?

Finally, future studies will investigate development component of global tobacco control and how the tobacco industry capitalizes on this to sustain its profitability. As one African interviewee said, “Tobacco control here is a development and social justice issue.” Many tobacco growers are some of the most impoverished people in the world, yet they are stuck in tobacco farming. Why? What is the tobacco industry doing to keep them in tobacco farming?

In sum, future studies will combine tobacco industry documents and other archival data with surveys and interviews to explore issues in ratification and compliance at the country-level. Such works will analyze the feedback loop of the development of FCTC.

\footnotetext{
${ }^{1}$ The number of ratified countries includes AFRO - 9; EMRO - 5; SEARO - 10; and WPRO - 14. Latin American countries were not counted because they belong to PAHO.
} 


\section{Appendix}

\section{Interviewees}

Anti-Tobacco NGOs

Amanda Sanford, Action against Smoking and Health (ASH) - UK

Anna Jones, Essential Action, USA

Anne Jones, ASH - Australia

Cassandra Welch, American Lung Association, USA

Clare Dougherty, Campaign for Tobacco-Free Kids, USA

Doug Blanke, the Tobacco Law Center, USA

Gary Ewart, American Thoracic Society, USA

Murray Laugessen, ASH - New Zealand

Neil Collishaw, Physicians for Smoke-Free Canada, Canada

Oluwafemi Akinbode, Environmental Rights Action, Nigeria

Yusuf Saloojee, Tobacco Action Group, South Africa

Business International NGOs (BINGOs)

Jack Calfee, American Enterprise Institute, USA

John Gavin, the United States Council for International, USA

Norman Sharp, Cigar Association of America, USA 
Government/Public Officials

Byron Rogers, the Tobacco Control Program, Health Canada

Denis Choiniere, the Tobacco Control Program, Health Canada

Helene Goulet, the Tobacco Control Program, Health Canada

John Stribbling, Ministry of Health, New Zealand

Mathew Allen, Formerly of Ministry of Health, New Zealand

Policy Entrepreneurs

Ruth Roemer, Academic Expert of Tobacco Control Legislation, University of California, Los Angeles (UCLA), USA

World Health Organization (WHO)

Gemma Vestal

Transnational Tobacco Companies

British American Tobacco (BAT)

Imperial Tobacco Limited (ITL)

Japan Tobacco International (JTI)

Philip Morris International (PMI) 
Reemtsa

R. J. Reynolds 


\section{QUESTIONNAIRE}

\section{BACKGROUND:}

On May 21, 2003, the 192 members of World Health Organization (WHO) unanimously voted at the $56^{\mathrm{TH}}$ World Health Assembly (WHA) to adopt the Framework Convention on Tobacco Control (FCTC), the first global public health treaty under the auspices of WHO. Between 1999 and 2003, different people around the globe participated in the negotiation of the FCTC. This work is an investigation into the adoption of the FCTC. Your help would be appreciated.

(1) In what capacity did you participate in the negotiation of the FCTC?

(1) As a representative of a state

(2) As a member of advocacy group

(3) As a representative of a tobacco company

(4) As an official from an intergovernmental organization (IGO)

(5) As individual

(6) Others

(7) Did not participate

(21) Don’t know

(2) Can you briefly describe activities of the organization you represented?

(3) How many years have you been a member of your organization?

(4) What kind of preliminary negotiating body did you participate in?

(1) The Intergovernmental Working Group (WG)

(2) The Intergovernmental Negotiating Body (INB)

(3) World Health Organization's regional conference on FCTC

(4) State/country-level conference on FCTC

(5) Preparatory Meetings

(6) None

(21) Don’t know

(5) If you participated in the Intergovernmental Working Group sessions, how many of them?
(1) 1
(2) 2
(3) None
(21) Don’t know

(6) If you participated in the Intergovernmental Negotiating Body sessions, how many of them?
(1) 1
(2) 2
(3) 3
(4) 4
(5) 5 (6) 6 (7) None
(21) Don’t know

(7) How many years have you been involved in tobacco-related issues at the international level? 
(8) How did you become aware of global tobacco control issues?

(1) Working in a state health institution(s)

(2) Member of tobacco advocacy group

(3) Working in a transnational tobacco company

(4) As an official of WHO

(5) As a representative at World Conference on Tobacco or Heath (WCTOH)

(6) "World No Tobacco Day"

(7) Tobacco Control Journal

(8) GLOBALink (Internet)

(9) Individual interest

(10) Other(s):

(9) What is your preferable level of approach to the tobacco epidemic?

(a) Individual behavioral/attitudinal approach

(b) Local/community approach

(c) State/country approach

(d) Global approach

(e) Others:

(11) How satisfied are with the FCTC text?

(12) Did the final FCTC text meet your expectation?

(13) To what degree do you support for FCTC as a global institution?

(14) Can you comment on the degree of influence of the following during the negotiations of the FCTC?

(a) Pro-tobacco advocacy groups

(b) Anti-tobacco advocacy groups

(c) Tobacco companies

(d) Officials of World Health Organization

(e) Individual advocates/activists

(f) The European Union

(g) Transnational Tobacco Companies (TTCs)

(h) Others:

(15) Beside the above (14a-g), name any known individual(s), NGO(s), state(s), and IGO(s), or particular WHO region(s) that you believe played important role(s) in the negotiation of the FCTC.

(16) Give specific reason(s) why you think that the individual(s), state(s), or organization(s) you have just mentioned in (15) were important player(s) in the FCTC negotiation? 
(17) Can you comment on the extent to which knowledge about health, social, economic, and environmental impact of tobacco use and tobacco production affect the adoption of the FCTC?

(18) Comment on the degree of importance of the following in the spread of knowledge about tobacco use as well as norms and principles of tobacco control around the globe.

(a) World Conference on Tobacco OR Health (WCTOH)

(b) International Conference on Illicit Tobacco Trade (ICITT)

(c) GLOBALink (the tobacco Internet network)

(d) Tobacco Control (Journal)

(e) "World No Tobacco Day"

(f) World Health Organization

(i) The European Union

(j) Non-governmental organizations

(k) Individual advocates/activists

(l) Others:

(19) To what extent should tobacco control be considered as the following?

(a) A national issue

(b) A transnational issue

(c) Global issue

(20) Can you comment on the degree of influence of transnational advocacy groups or NGOs in the negotiation of the FCTC?

(21) Are you familiar with the Framework Convention Alliance (FCA)?

(22) If yes, how important was the FCA in the negotiation of the FCTC?

(23) Are you familiar with the Network for Accountability of Tobacco Transnationals (NATT)?

(24) If yes, how important was the NATT in the negotiation of the FCTC?

(25) If yes to 21 and 23, indicate the degree to which the emergence of the Framework Convention Alliance and Network for Accountability of Tobacco Transnationals contributed to the strength of anti-tobacco advocacy groups in the negotiation of the FCTC.

(26) Indicate the extent to which the Framework Convention Alliance Newsletter swayed states to support the FCTC

(27) Is your organization a member of Framework Convention Alliance or Network for Accountability of Tobacco Transnationals?
(1) Yes
(2) No
(21) Don’t know 
(28) If no, what role(s) did your organization or institution play in the negotiation of the FCTC?

(29) Does your advocacy group favor global tobacco control institution?

(30) If yes or no, why?

(31) How would you describe the relationship between the transnational tobacco companies and World Health Organization?

(32) How would you rank the level of participation of the following transnational actors in the negotiation of the FCTC?
(a)__States
(b)
Pro-tobacco advocacy groups
(c) _ Individuals
(d) __Anti-tobacco advocacy groups (5) _ The tobacco industry

(33) To what extent should the tobacco issue be considered global?

(34) How did the consideration of the world as a "Global Village" influence the negotiation of the FCTC?

(35) Do you know about the activities of transnational tobacco companies in developing countries?

(36) Describe the extent to which the extension of the production and marketing activities of the transnational tobacco companies into developing countries influenced the adoption of the FCTC.

(37) Do you think interdependence of the world in terms of trade, communication, food delivery, finance etc has influenced the way we perceive the tobacco issue as global in scope?

(38) How did liberalization of international tobacco trade influence the negotiation of the FCTC?

(39) Do you think that FCTC was adopted because the tobacco issue is similar to issues such as the environment, education, culture, human rights, HIV/AIDS, and women's right?

(40) At which level is the tobacco issue usually handled in your country?

(1)__ The executive level (foreign and national security policy managers of a state)

(1) _ The lower-level executive branch officials

(2) _ The congressional/parliamentary committees and subcommittee levels

(4) __ State/provincial and local levels

(5) _ The non-governmental level 
(41) Are the protocols and principles of FCTC based on empirical evidence about the effectiveness of such policies?

(42) If yes, in what way(s)?

(43) What is the best approach(s) to curbing tobacco use?
(1) Behavioral education
(2) Legislative restrictions
(3) (1) and (2)
(4) Other(s). List:

(44) Indicate the degree to which the FCTC document supports the following tobacco control practices

(a) Public information on tobacco use and consequences

(b) Health education

(c) Cessation programs

(d) Legislation

(e) Curbing supply

(f) Others:

(45) In what way(s) does the FCTC play a role in the transfer of empirically proven and effective tobacco control policies to other geographical jurisdictions?

(46) Were efforts of individual officials and activists instrumental in the adoption of the FCTC?

(47) If yes, name specific individual(s) you know whose activities were instrumental in the emergence of the FCTC.

(48) What role(s) did the various regions of WHO played in the Negotiation of the FCTC?

(49) Can you identify states that favored strong treaty? Why?

(50) Can you identify countries that wanted a weak treaty during the negotiations of the FCTC? Why?

(51) Do you have any comment on the adoption of FCTC and compliance of the underlying principles?

(52) If yes, what are they?

Thank You!!! 


\section{References}

Action on Smoking and Health (ASH). Key Dates in the History of Anti-Tobacco Campaign. Website: http://www.ash.org.uk/html/schools/keydates.html. (Accessed 09/20/2004)

Action on Smoking and Health (ASH). 1998. “Tobacco: Global Trends.” Web: http://www.ash.org.uk/html/international/html/globaltrends.html (accessed January 17, 2005) - From Talk to TMDP, Chelwood 1990

Ahmad, Khabir. 2000. “WHO Calls for Public Hearing on Tobacco Control.” Lancet Vol. 355 Issue 9210

Ahmad, Khabir. 1999. “African Ministers Call for Tighter Tobacco Control Legislation.” Lancet Vol. 354 Issue 9187

Alder, Emanuel. 1991. “Cognitive Evolution: A Dynamic Approach for the Study of International Relations in Their Progress.” In Emanuel Alder and Beverly Crawford (eds.). Progress in Postwar International Relations. New York: Columbia University Press

Alder, Emanuel, and Peter M. Haas. 1992. “Conclusion: Epistemic Communities, World Order, and the Creation of a Reflective Research Program.” International Organization, 46(1): 367-390

Antaki, C. (ed.). 1988. Analyzing Everyday Explanation. Newbury Park, CA: SAGE

Antaki, C. and Leuder, I. 1992. "Explaining Conversation: Towards an Argument Model.” European Journal of Social Psychology 22:181-194

Apperson, G.L. 1916. The Social History of Smoking. New York: G.P. Putnam’s Sons 
Archibugi, Daniele and David Held (eds.). 1995. Cosmopolitan Democracy: An Agenda for a New World. Cambridge: Polity Press

Ashraf, Haroon. 2002. “European Tobacco Control Reaches a Critical Phase.” The Lancet 359:585-586

Barnum, H. 1994. “The Economic Burden of Global Trade in Tobacco.” Tobacco Control, 3:358-361

Barnett, Michael. 1990. "High Politics is Low Politics.” World Politics, 42: 530-562

Bates, Clive. 2002. “Could Someone Please Acknowledge the Alligator?” Alliance Bullet July 30, Issue 24

Baumgartner, Frank R., and Bryan D. Jones. 1993. Agendas and Instability in American Politics. Chicago: Chicago University Press

Benford. R.D. and D. A. Snow. 2000. "Framing Processes and Social Movements: An Overview and Assessment.” Annual Review of Sociology 26:611-639

Bennett, Colin J. 1992. Regulating Privacy. Ithaca: Cornell University Press

Bennett, Colin J. 1991. “A Review Article: What is Policy Convergence and What Causes It?” British Journal of Political Science 21: 215-233

Bennett, LeRoy. 1980. International Organizations: Principles and Issues, $2^{\text {nd }}$ ed. New Jersey: Prentice-Hall

Bhagwati, JS. 1991. “Jumpstarting GATT.” Foreign Policy Issue 83:105-118

Biagi, Shirley. 1986. Interviews that Work. Belmont, California: Wadsworth Publishing Company

Blanke, Doug. (Ed). 2003. Tobacco Control Legislation: An introductory Guide. Geneva, Switzerland: World Health Organization 
Blythe, B., and T. Tripodi. 1989. Measurement in Direct Practice. Newbury Park, CA: Sage

Borio, Gene. 2001. Tobacco BBS. Web Page: http://www.tobacco.org

Braithwaite, John. 1994. "A Sociology of Modeling and the Politics of Empowerment.” British Journal of Sociology 45(3):445-475

British American Tobacco. 2005. “Our Company.” Website:

http://www.bat.com/OneWeb/sites/uk_3mnfen.nsf/vwPagesWebLive/C7E1095B

B1D02C3B80256BF40003313D?opendocument\&SID=4C96394D21F5DCA2D4 $\underline{\text { 64DA0030246FD2\&DTC }=20050505}$

British Broadcasting Corporation. March 19, 2004. "Smoke Ban 'Would Save Thousand."” Website: http://news.bbc.co.uk/1/hi/health/3546025.stm. Accessed March 10, 2004

Brown, Eryn. 2001. “The World Health Organization Talks on Big Tobacco (But Don’t Hold Your Breath).” Action on Smoking and Health. September 2001. Website: http://nosmoking.ws/news/newstobaccoglobal091001.htm. Accessed February 8, 2005

Brundtland, Gro Harlem. 2003. "Global Health indicates International Security.” Global Governance 9:417-423

Bryant, Ralph C. 2003. Turbulent Waters: Cross-Border Finance and International Governance. Washington D.C.: Brookings Institute Press

Buechler, S.M. 1995. “New Social Movement Theories.” Sociological Quarterly 36:441464

Bulletin of World Health Organization. 2003. 81(8) 
Callard, Cynthia, Neil Collishaw, and Michelle Swenarchuk. 2001. “An Introduction to International Trade Agreements and their Impact on Public Measures to Reduce Tobacco Use.” Canada: Physicians for a Smoke-Free Canada

Campaign for Tobacco-Free Kids. Illegal Pathways to Illegal Profits: The Big Cigarette Companies and International Smuggling. Website:

\section{http://www.tobaccofreekids.org/campaign/global/framework/docs/Smuggling} .pdf. (Accessed 08/15/04)

Campaign for Tobacco-Free Kids. 2001. Public Health, International Trade and the Framework Convention on Tobacco Control. Washington, D.C.: Campaign for Tobacco-Free Kids

Caporaso, James A., 1997, “Across the Great Divide: Integrating Comparative and International Politics,” International Studies Quarterly, 41:563-592

Cassese, Antonio, and Andrew Clapham. 2001. "International Law.” in Joel Krieger et al (eds.). The Oxford Companion to Politics of the World. $2^{\text {nd }}$ edition. Oxford: Oxford University Press, pp.408-424

Castles, Francis G. 1998. Comparative Public Policy. Northampton, MA: Edward Edgar Centers for Disease Control and Prevention (CDC). Best Practices for Comprehensive Tobacco Control Programs-August 1999. Atlanta GA: U.S. Department of Health and Human Services, Centers for Disease Control and Prevention, National Center for Chronic Disease Prevention and Health Promotion, Office on Smoking and Health, August 1999 
Chaloupka, Frank J, and Rima Nair. 2000. "International Issues in the Supply of Tobacco: Recent Changes and Implication for Alcohol.” Addiction 95 (Supplement 4), S477-S489

Chaloupka, F.J., and M. Corbett. 1998. “Trade Policy and Tobacco: Towards an Optimal Policy Mix.” In The Economics of Tobacco Control: Towards an Optimal Policy Mix. I. Abedian, R. van der Merwe, N. Wlikins, and P. Jha (eds.) Cape Town, South Africa: University of Cape Town, Applied Fiscal Research Center

Chandler, A.D. Jr. 1977. The Visible Hand: The Managerial Revolution in American Business. Cambridge (MA): Harvard University Press

Checkel, Jeffrey T., 1999, “Norms, Institutions, and National Identity in Contemporary Europe,” International Studies Quarterly 43:83-114

Coleman, James S. 1990. Foundation of Social Theory. Cambridge, MA: Harvard University Press

Coleman, William D., and Anthony Perl. 1999. "International Policy Environments and Policy Network Analysis.” Political Studies, (XLVII) 47:691-709

Collin, Jeff, Kelley Lee, and Karen Bissell. 2002. “The Framework Convention on Tobacco Control: The Politics of Global Health Governance.” Third World Quarterly 23:265-282

Commission on Global Governance. 1995. Our Global Neighborhood: Report of Commission on Global Governance. Oxford: Oxford University Press Cook, Brian J., 1996, Bureaucracy and Self-Government, Baltimore: The John Hopkins University Press 
Cooper, Richard C. 1972. "Economic Interdependence and Foreign Policy in the Seventies.” World Politics, 24: 158-181

Cooper, Richard C., 1968, the Economics of Interdependence: Economic Policy in the Atlantic Community, New York: McGraw-Hill Book Company

Corrao, Marlo Ann, G. Emmanuel Guindon, Namita Sharma, Dorna Fakhrabadi Shokoohi (eds.). 2000. Tobacco Control Country Profiles. Atlanta, Georgia: American Cancer Society

Crane, George T., and Alba Amawi, (eds.). 1997. The Theoretical Evolution of International Political Economy. New York: Oxford University Press

de Boyer, Joy and Linda W. Brigden (eds.). 2003. Tobacco Control: Strategies, Successes, and Setbacks. Washington, D.C., USA: World Bank; Ottawa, Canada: International Development Research Center

Desai, Meghnad. 1995. “Global Governance.” In Global Governance: Ethics and Economics of the World Order. In Meghnad Desai and Peter Redfern (eds.). New York: Pinter. Pp. 6-21.

Doll, Richard and A. Bradford Hill. 1950. "Smoking and Carcinoma of the Lung: Preliminary Report.” British Medical Journal 2:739-748

Dolowitz, David P.2003. “A Policy-maker’s Guide to Policy Transfer”. Political Quarterly 74:101-108

Dolowitz, David P. 1997, "British Employment Policy in the 1980s: Learning from the American Experience.” Governance 10:23-42

Dolowitz, David P. and D. Marsh. 2000. "Learning from Abroad: The Role of Policy Transfer in Contemporary Policy-Making.” Governance 13:5-24 
Dolowitz, David P. and D. Marsh. 1996. “Who Learns What From Whom: A Review of Policy Transfer Literature.” Political Studies 44:343-357

Dougherty, James E. and Robert L. Pfaltzgraff, Jr. 2001. Contending Theories of International Relations: A Comprehensive Survey. $5^{\text {th }}$ Edition. USA: Longman Edwards, Michael. 2000. “Civil Society and a Global Norm.” United Nations Chronicle, Vol.37, Issue 4.

ENSP Report on INB6. 2003. “Negotiations for the FCTC.” Geneva. Website: http://64.233.161.104/search?q=cache:QeV6FWfrmLAJ:www.ensp.org/files/Miss ion_Report_INB6.doc+germany,+eu,+and+adoption+of+fctc\&hl=en (accessed May 21, 2005).

European Region of WHO Report. 2003. World No Tobacco Day 2003 in European Region. EUR/03/5041374 (Website: http://www.euro.who.int/document/E82101.pdf)

Evans, Peter B., H. K. Jacobson, and R. D. Putnam (eds.). 1993. Double-Edged Diplomacy: International Bargaining and Domestic Politics. Berkeley, CA: University of California Press

Eyestone, Robert. 1977. “Confusion, Diffusion, and Innovation.” American Political Science Review 71(2):441-447

Farquharson, Karen. 2003. "Influencing Policy Transnationally: Pro- and Anti-Tobacco Global Advocacy Networks” Australian Journal of Public Administration 62(4): 80-92 
Faulkner, Robert R. 1982. “Improvising on a Triad.” In John Van Maanen, James M. Dabbs, Jr., and Robert R. Faulkner. Varieties of Qualitative Research. Beverly Hills: SAGE Publications

Finnemore, Martha, 1996, National Interests in International Society, Ithaca: Cornell University Press

Fontana, Andrea, and James H. Frey. 2000. “The Interview: From Structured Questions to Negotiated Text.” Pp.645-672. In Handbook of Qualitative Research. $2^{\text {nd }}$ Edition. Norman K. Denzin and Yvonne S. Lincoln (ed.). Thousand Oaks, CA: SAGE

Framework Convention Alliance. 2001. “FCTC Negotiations.” Website: http://fctc.org/archives/inb1.shtml. (Accessed 03/19/2004)

Frey, Scott R. 1997. “The International Traffic in Tobacco.” Third World Quarterly 18(2): 303-319

Gamson, W.A. and D.S. Meyer. 1996. “Framing Political Opportunity.” In Comparative Perspective on Social Movements. New York: Cambridge University Press, pp. $275-290$

GATT. 1990. Thailand - Restriction on Importation of and Internal Taxes on Cigarette, Report of Panel. Geneva: GATT

Giddens, Anthony, 1984, the Constitution of Society, Berkeley: University of California Press

Glantz, A. Stanton, John Slade, Lisa A. Bero, Peter Hanauer, and Deborah E. Barnes. 1996. The Cigarette Papers. Berkeley: University of California Press 
Glasser, Jay. August 2003. “Global Tobacco Treaty will be remembered as Year’s Success.” The Nation's Health

Golt, Sidney. 1988. "The GATT Negotiations 1986-90: Origin, Issues and Prospects.” National Planning Association Report. United Kingdom: British-North American Committee

Gordenker, Leon, and Thomas Weiss. 1995. "Pluralizing Global Governance: Analytical Approaches and Dimensions.” Third World Quarterly 16:357-387

Gourevitch, Peter, 1978, “The Second-Image Reversed: International Sources of Domestic Politics,” International Organization, 32:881-912

Gray, Virginia. 1973. "Innovation in the States: A Diffusion Study.” American Political Science Review 67:1175-1185

Grieco, Joseph M., 1990, Cooperation among Nations: Europe, America, and Non-Tariff Barriers to Trade, Ithaca and London: Cornell University Press

Groom, B. 1998. “Battling Bootleggers Disturb Dover’s Calm.” Financial Times, March 18

Haas, Ernst B. 1990. When Knowledge is Power: Three Models of Change in International Organization. Berkeley: University of California Press

Haas, Ernst. 1983 “Words Can Hurt you; Or, Who Said What to Whom About Regimes.” In Stephen D. Krasner (ed.) International Regimes. Ithaca: Cornell University Press

Haas, Ernst B., 1968, “Technology, Pluralism, and New Europe” in Joseph Nye Jr., ed., International Regionalism, Boston: Little, Brown 
Haas, Ernst B., 1964, Beyond the State: Functionalism and International Organization, Stanford: Stanford University Press

Haas, Peter. 2002. "UN Conferences and Constructivist Governance of the Environment.” Global Governance 8:73-91

Haas, Peter. 2001. "Policy Knowledge and Epistemic Communities.” Encyclopedia of Social and Behavioral Sciences. London: Elsevier Science

Haas, Peter, 1992, “Introduction: Epistemic Communities and International Policy Coordination,” International Organization, 46:1-35

Haas, Peter, 1989, “Do Regimes Matters? Epistemic Communities and Mediterranean Pollution

Haggard, Stephan, and Beth A. Simmons, 1987, "Theories of International Regimes,” International Organization 41:491-517

Hammond, E. Cuyler. 1967. “Quantitative Relationship Between Cigarette Smoking and Death Rates.” In World Conference on Smoking and Health ( $1^{\text {st }}$ : 1967). Toward a Less Harmful Cigarette. New York: National Cancer Institute

Health and Welfare Canada. 1991. Canadians and Smoking: An Update. Ottawa: Health and Welfare Canada

Health Canada. 1994. Survey on Smoking in Canada. Cycle 1 Fact Sheets. Ottawa: Health Canada

Heidenheimer, Arnold J., Hugh Heclo, and Carolyn Teich Adams. 1990. Comparative Public Policy: The Politics of Social Choice in America, Europe, and Japan. $3^{\text {rd }}$ (ed.). New York: St. Martins Press

Held, David. 2004. "Democratic Accountability and Political Effectiveness from a Cosmopolitan Perspective.” Government and Opposition. Vol. 39 Issue 2 
Held, David. 1995. Democracy and Global Order. Stanford: Stanford University Press

Held, David, and Anthony McGrew with David Golbatt and Jonathan Perraton.

2001.“Managing the Challenge of Globalization and Institutionalizing

Cooperation through Global Governance.” In Charles W, Kegley and Eugene R.

Wittkopf (eds.) The Global Agenda: Issues and Perspectives, 6th ed. USA:

McGraw Hill Companies

Hoberg, George, Keith Banting, and Richard Simeon. 1999. “North America Integration and the Scope of Domestic Choice: Canada and Policy Sovereignty in a Globalized World,” paper presented at Association of Canadian Studies in the United States, Pittsburgh, November 1999

Holzman, David C., 2001, “Stopping the Scourge Tobacco Control Goes Global,” Environmental Perspectives, Vol. 109 Issue 4

International Conference on Illicit Tobacco Trade (ICITT). 2002. Co-Chairpersons

[David L. Benton and Arthur J. Libertucci] Report. Website:

www.atf.treas.gov./tobacco/icitt/index.htm

Jacob, Gregory. 2004. “Without Reservation.” Chicago Journal of International Law, Summer

Jacobsen, John Kurt. 2003. “Dueling Constructivism: A Post-Mortem on Ideas Debated in IR/IPE.” Review of International Studies, 29:39-60

Jenkins, J.C. 1983. "Resource Mobilization Theory and the Study of Social Movements.” Annual Review of Sociology 9:527-553

Jervis, Robert. 1983. “Security Regimes.” In Stephen Krasner (ed.). International Regimes. Ithaca: Cornell University Press 
Jha, P. and Frank Chaloupka (eds.). 2000. Tobacco Control in Developing Countries. Oxford: Oxford University Press

Jha, Prabhat, and Frank J. Chaloupka. 2000b. “The Economics of Tobacco Control.” British Medical Journal 321:358-361

Jha, Prabhat, and Frank J. Chiloupka (eds.). 1999. Curbing the Epidemic: Government and the Economics of Tobacco Control. Washington, D.C.: World Bank

Joossens, Luk. 2000. “Tobacco Smuggling.” International Union Against Cancer (UICC), WHO. Website: http://factsheets.globalink.org/en/smuggling.shtml. Accessed March 4, 2005

Joossens, Luk. and M. Raw. 1998. "Cigarette Smuggling in Europe: Who Really Profits?” Tobacco Control 7:66-71

Joossens, Luk., C. Naett, and C. Howie. 1992. Taxes on Tobacco Products: A Health Issue. Brussels: European Bureau for Action on Smoking Prevention Kampala, Badru D. Mulumba. 2004. “Government Signs Global Anti-Smoking Law.” http://no-smoking.org/march04/03-12-04-6.html. (Accessed March 15, 2004)

Kapp, Clare. 2003. "World Health Assembly Approves Historic Tobacco Accord.” Lancet Vol. 361 Issue 9371

Kaprio, Leo. 1975. "Possibilities for International Action in Europe.” World Conference on Smoking and Health ( $3^{\text {rd }}$ : 1975: New York: N.Y). Health Consequences, Education, Cessation Activities, and Governmental Action; [Proceedings]. Jesse Steinfield, William Griffiths, Keith Ball, and Robert M. Taylor (eds.) USA: U.S. Department of Health, Education, and Welfare. Pp.148-151 
Katzenstein, Peter J., ed. 1996. The Culture of National Security: Norms and Identity in World Politics, New York: Columbia University Press

Keck, Margaret E. and Kathryn Sikkink. 1998. Activists Beyond Borders: Advocacy Networks in International Politics. Ithaca: Cornell University Press

Kegley, Charles, and Eugene Wittkopf. 2004. World Politics: Trend and Transformation. $9^{\text {th }}$ Ed. U.S: Thomson/Wadsworth

Keohane, Robert O. 1989. International Institutions and State Power: Essays in International Relation Theory, Boulder: Westview Press

Keohane, Robert O. 1988. “International Institutions: Two Approaches,” International Studies Quarterly 32:379-396

Keohane, Robert O., 1984, After Hegemony: Cooperation and Discord in the World Political Economy, Princeton: University of Princeton Press

Keohane, Robert. 1983. “The Demand for International Regimes.” In Stephen Krasner (ed.). International Regimes. Ithaca: Cornell University Press

Keohane, Robert O., Joseph Nye, 2001, “Globalization: What’s New? Not (And so What?),” in Power and Interdependence: World Politics in Transition, New York: Longman

Keohane, Robert O., Joseph Nye, 1977, Power and Interdependence: World Politics in Transition, Boston: Little Brown

Keohane, Robert O., Joseph Nye, 1972, Transnational Relations and World Politics, Cambridge: Harvard University Press

Kerr, Clark. 1983. the Future of Industrial Societies. Cambridge: Harvard University Press 
King, Gary, Robert O. Keohane, and Sidney Verba. Designing Social Inquiry: Scientific Inference in Qualitative Research. Princeton, New Jersey: Princeton University Press

Kingdon, John W. 1984. Agendas, Alternatives, and Public Policies. Boston: Little Brown and Company

Kluger, Richard. 1996. Ashes to Ashes: America's Hundred-Year Cigarette War, The Public Health, and the Unabashed Triumph of Philip Morris. New York: Alfred A. Knopf

Kowalewski, David. 1992. “Transnational Organizations and Actors.” In Mary Hawkesworth and Maurice Kogan (eds.) Encyclopedia of Government and Politics, Vol. 2, New York: Routledge, pp.944-956

Krahman, Elke. 2003. “National, Regional, and Global Governance: One Phenomenon or Many?” Global Governance 9:323-346

Krasner, Stephen. 1995. “Compromising Westphalia.” International Security Vol. 20 No. 3

Krasner, Stephen. 1988. "Sovereignty: An International Perspective.” Comparative Public Policy Study, 21:77-80

Krasner, Stephen (ed.). 1983 International Regimes. Ithaca: Cornell University Press Kyle, Ken. 1996. "Engineering an International Coup-Smoke-Free Skies in 1996.” Speaking notes for presentation at Tobacco-Free Canada: Second National Conference on Tobacco or Health, Ottawa

Kyle, Ken and Fran Du Melle. 1994. "International Smoke-Free Flights: Buckle Up for Take-Off.” Tobacco Control 3:3-4 
Lancet. 2003. “Agents of Mass Destruction found in USA.” Vol. 361 Issue 9369

Levin, Morton, Hyman Goldstein, Paul R. Gerhardt. 1950. “Cancer and Tobacco Smoking. A Preliminary Report.” Journal of the American Medical Association $143: 336-338$

Ling, Pamela M., and Stanton A. Glantz. 2002. "Why and How the Tobacco Industry Sells Cigarette to Young Adults: Evidence from Industry Documents.” American Journal of Public Health, Vol. 92 Issue 6

Lipschultz, Ronnie D. 1996. Global Civil Society and Global Environmental Governance. Albany: State University of New York Press

Lofland, John. 1971. Analyzing Social Settings. Belmont, CA: Wadsworth

Lowi, Theodore J. 1964. “American Business and Public Policy.” World Politics 16:677715

Lumsdaine, David. 1993. Moral Vision in International Politics: The Foreign Aid Regime 1949-1989. Princeton, NJ: Princeton University Press

Lynn, Patti. May 2003. “Adoption of Global Tobacco Treaty Marks Historic Milestone in Public Health and Corporate Accountability.” Website: http://www.infact.org/052103whaadopt.html. (Accessed 11/24/2004)

Mackay, Judith.2003. "The Making of a Convention on Tobacco Control.” Bulletin of the World Health Organization 81 (8)

Maanen, John Van. 1982. “Introduction.” In John Van Maanen, James M. Dabbs, Jr., and Robert R. Faulkner. Varieties of Qualitative Research. Beverly Hills: SAGE Publications, pp.11-29 
Maanen, John Van James M. Dabbs, Jr., and Robert R. Faulkner. 1982. Varieties of Qualitative Research. Beverly Hills: SAGE Publications

March, James G. and Johan P. Olson. 1984. “The New Institutionalism: Organizational Factors in Political Life.” American Political Science Review 78(3): 734-749

McAdam, Doug., John D. McCarthy, and Mayer N. Zald. 1996. “Introduction: Opportunities, Mobilizing Structures and Framing Processes - Toward a Synthesis, Comparative Perspective on Social Movements.” In Comparative Perspectives on Social Movements, edited by McAdam, Doug., John D. McCarthy, and Mayer N. Zald. New York: Cambridge University Press, pp.1-20 McAdam, Doug . 1996. “Conceptual Origins, Current Problems, Future Directions.” In Comparative Perspectives on Social Movements, edited by McAdam, Doug., John D. McCarthy, and Mayer N. Zald. New York: Cambridge University Press, pp.2340

McCarthy, John D. and Mayer N. Zald. 1977. Resource Mobilization and Social Movements: A Partial Theory.” American Journal of Sociology 82(6): 1212-1241 McCormick, James M. and Eugene R. Wittkopf. 1992. “At the Waters’ Edge.” American Political Science Quarterly, 20: 26-53

McMichael, Philip. 1998. “Global Food Politics.” Monthly Review: An Independent Socialist Magazine. Vol. 50 Issue 3

Merriam, Sharan B. 1998. Qualitative Research and Case Study Applications in Education. San Francisco, CA: Jossey-Bass Publishers

Merton, R.K., M. Fiske, and P.L. Kendall. 1990. The Focused Interview: A Manual of Problems and Procedure. $2^{\text {nd }}$ Edition. New York: Free Press 
Meyer, John W., David John Frank, Ann Hironaka, Evan Schofer, Nancy Brandon Tuma, 1997, “Towards an International Environmental Regime,” International Organization 51:623-651

Mingst, Karen and Margaret P. Karns. 1995. The United Nation in Post-Cold War Era. Boulder, Co: Westview Press

Mintrom, Michael, 1997, "Policy Entrepreneurs and the Diffusion of Innovation,” American Journal of Political Science 41:738-770

Mitrany, David. 1966. Working Peace System. Chicago: Quadrangle Mittelman, James H. 1996. 'Rethinking the 'New Regionalism' in the Context of Globalization.” Global Governance Vol. 2 No. 2

Moravcsik, Andrew. 1997. “Taking Preferences Seriously: A Liberal Theory of International Politics.” International Organization, 51:513-553

Morse, Edward S., 1970, “The Transformation of Foreign Politics: Modernization, Interdependence, and Externalization, World Politics, 22:371-392

Multinational Monitor, June 2001

Nadelman, Ethan A. 1990. “Global Prohibition Regimes: The Evolution of Norms in International Society.” International Organization 44: 479-526

Nathan, Rose. 2004. Model Legislation for Tobacco Control: A Policy Development and Legislative Drafting Manuel. $1^{\text {st }}$ Ed. France: International Union for Health Promotion and Education (IUHPE)

Nathanson, Constance A. 1999. "Social Movements as Catalysts for Policy Change: The Case of Smoking and Guns.” Journal of Health Politics, Policy and Law 24:421488 
Neuman, Mark, Asaf Bitton, and Stanton Glantz. 2002. “Tobacco Industry Strategies for Influencing European Community Advertising Legislation.” Lancet, Vol. 359 Issue 93

Non-Smokers’ Right Association. 1996. “Two Years Later: The High Cost of the 1994 Tobacco Tax Cuts.” Press Release. Toronto, February 18

Onuf, Nicholas, 1989, World of Our Making, Columbia: University of South Carolina Press

Ostry, Sylvia. 1990. "Europe 1992 and the Evolution of the Multi Trading.” Case Western Reserve Journal of International Law, Spring/Summer 1990, Vol. 22 Issue $2 / 3$,

Oye, Kenneth. 1986. Cooperation Under Anarchy. Princeton, N.J.: Princeton University Press

Pan American Health Organization. 2003. "The Framework Convention on Tobacco Control: Strengthening Health Globally. Website: http://www.paho.org/English/HPP/HPM/TOH/tobacco.pdf. (Accessed March 15, 2004)

Patton, Michael Quinn. 2002. Qualitative Research and Evaluation Methods. $3^{\text {rd }}$ Edition. Thousand Oaks, CA: SAGE publications

Pertschuk, Michael. 2001. Smoke in Their Eyes: Lessons in Movement Leadership from Tobacco Wars. Nashville, Tennessee: Vanderbilt University Press

Peters, Guy B. 1998. Comparative Politics: Theory and Methods. New York: New York University Press 
Pichardo, N.A. 1997. “New Social Movements: A Critical Review.” Annual Review of Sociology 23:411-430

Philip Morris International. “Our Business.” http://www.philipmorrisinternational.com/pages/eng/ourbus/Our_business.asp. (Accessed 05/05/05)

Polsby, Nelson W., 1984, Political Innovation in America: The Politics of Policy Initiation, New Haven: Yale University Press

Potocky-Tripodi, Miriam. 2002. Best Practices for Social Work with Refugees and Immigrants. New York: Columbia University Press

PR Newswire. 2003. "First Global Public Health Treaty to Take Effect: Despite Years of Intense Industry Lobby, Tobacco Treaty Becomes International Law Sunday, February $27^{\text {th }}$.” Website: http://sev.prnewswire.com/health-carehospitals/20050224/NETH01324022005-1.html. (Accessed 05/21/05)

Proctor, Robert N. 1999. The Nazi War on Cancer. Princeton: Princeton University Press Puchala, Donald J. and Raymond F. Hopkins. 1983. “International Regimes: Lessons from Inductive Analysis.” In Stephen Krasner (ed.) International Regimes. Ithaca: Cornell University Press

Putnam, Robert D. 1988. "Diplomacy and Domestic Politics: The Logic of Two-Level Games.” International Organization 42:427-460; Also in P. Evans, H.K. Jacobson, and R.D. Putnam (eds.) Double-Edged Diplomacy: International Bargain and Domestic Politics. Berkeley, CA: University of California Press Ravenholt, R. T. 1990. “Tobacco’s Global Death March.” Population and Development Review 16(2): 213-240 
Ramstrom, L., M. Raw and M. Wood (ed.). 1988. Guidelines on Smoking Cessation for the Primary Health Care Team. Geneva: WHO/UICC

Report of Committee of Experts on Tobacco Industry Documents. 2000. Tobacco Company Strategies to Undermine Tobacco Control Activities at the World Health Organization. Geneva, Switzerland: World Health Organization

Riessman, C.K. 1993. Narrative Analysis. Qualitative Research Methods Series No.30. Newbury Park, CA: SAGE

RITC and WHO-TFI. 1999. Confronting the Epidemic: A Global Agenda for Tobacco Control Research. Geneva, Switzerland: WHO

Roemer, Ruth. 1993. "Legislative Action to Combat the World Tobacco Epidemic.” Geneva: World Health Organization

Roemer, Ruth. 1986.Recent Developments in Legislation to Combat the World Smoking Epidemic. Geneva: WHO

Roemer, Ruth. 1982. Legislative Action to Combat the World Smoking Epidemic. Geneva: WHO

Rogowski Ronald. 1989. Commerce and Coalitions: How Trade Affect Domestic Political Alignment. Princeton: Princeton University Press

Rose, Richard. 2005. Learning from Comparative Public Policy. New York: Routledge Rose, Richard. 1993. Lesson Drawing in Public Policy. Chatham, NJ: Chatham House Rosenau, James N. 1997. Along the Domestic-Foreign Frontier: Exploring Governance in a Turbulent World. Cambridge: Cambridge University Press.

Rosenau, James N. 1990. Turbulence in World Politics: A Theory of Change and Continuity. London: Harvester Wheatsheaf. 
Rosenau, James N., and Ernst-Otto Czempiel (eds.) 1992. Governance without Government: Order and Change in World Politics. Cambridge: Cambridge University Press

Royal College of Physicians. 1962. Smoking and Health: A Report on Smoking in Relation to Cancer of the Lung and Other Diseases. London: Pitman Medical Publishing Co.

Rubin, Herbert J. and Irene S. Rubin. 1995. Qualitative Interviewing. Thousand Oaks, CA: SAGE Publications

Ruggie, John Gerard. 1983. “Continuity and Transformation in the World Polity: Towards a Neorealist Synthesis.” World Politics, 35: 261-285

Ruggie, John Gerard. 1982. “International Regimes, Transactions, and Change: Embedded Liberalism in Postwar Economic Order.” International Organization, 36: $195-231$

Ruggie, John Gerard. 1975. “International Responses to Technology: Concepts and Trends.” International Organization 34: 557-583

Sabatier, Paul A. and Hank C. Jenkins-Smith,.1999. “The Advocacy Coalition Framework.” in Theories of the Policy Process. Paul A. Sabatier (ed.) Boulder: Westview Press, pp.117-166

Sabatier, Paul A. and Hank C. Jenkins-Smith. 1993. Policy Change and Learning: An Advocacy Coalition Approach. Boulder, San Francisco, and Oxford: West View Press

Satcher, David. 2001. "Why We Need an International Agreement on Tobacco Control.” American Journal of Public Health Vol. 91 Issue 2 
Sato, H., S. Araki, and K. Yokoyama. 2000. “Influence of Monopoly Privatization on Smoking Prevalence in Japan: Trends of Smoking Prevalence in Japan in 19751995.” Addiction, 95(7): 1079-1088

Schrek, Robert et al. 1950. “Tobacco Smoking as an Etiologic Factor of Disease. I. Cancer.” Cancer Research 10:49-58

Seeliger, Robert. 1996. “Conceptualizing and Researching Policy Convergence.” Policy Studies Journal 24:287-306

Selin H, and Bols M. 2002. Developing Legislation of Tobacco Control: Template and Guidelines. Washington, DC: Pan American Health Organization (PAHO)

Singer, J. David. 1969. “The Global System and its Subsystems: A Developmental View.” in James N. Rosenau (ed.). Linkage Politics: Essays on the Convergence on National and International Systems. New York: Free Press

Singer, J. David. 1961. “The Level of Analysis Problem in International Relations.” World Politics 14:

Sklair, Leslie. 2002. “The Transnational Capitalist Class and Global Politics: Deconstructing the Corporate-State Connection.” International Political Science Review, 23(2): 159-174

Sklair, Leslie. 1998. “The Transnational Capitalist Class and Global Capitalism: The Case of the Tobacco Industry.” Political Power and Social Theory, 12: 3-43

Smith, Roger K. 1987. "Explaining the Non-Proliferation Regime: Anomalies for Contemporary International Relations Theory.” International Organization, 41(2): 253-281 
Staruss, A.S. 1987. Qualitative Analysis for Social Scientist. Cambridge, UK: Cambridge University Press

Stein, Arthur A.1983. "Coordination and Collaboration: Regimes in an Anarchic World." In Stephen Krasner (ed.). International Regimes. Cornell University Press

Stewart, G.G. 1967. “A History of the Medicinal use of Tobacco, 1492-1860.” Medical History 11(3): 228-268

Stone, Diane, 2003, “Transnational Transfer Agents and Global Networks in 'Internationalization’ of Policy,” (Unpublished), presented at “Internationalization and Policy Transfer” Workshop, Tulane University, New Orleans, April $11^{\text {th }}-12^{\text {th }}$

Strange, Susan. 1983. “Cave! Hic Dragones: A Critique of Regime Analysis.” In Stephen Krasner (ed.). International Regimes. Ithaca: Cornell University Press Studlar, Donley T. 2005. "The Political Dynamics of Tobacco Control in Australia and New Zealand: Explaining Policy Problems, Instruments, and Patterns of Adoption.” Australian Journal of Political Science, 40:255-274

Studlar, Donley T. 2004. "Tobacco Control Policy Instruments in a Shrinking World: How Much Policy Learning? " In D. Levi-Faur and E. Vigoda-Gadot (eds.). International Public Policy and Management Policy Learning Beyond Regional, Cultural, and Political Boundaries, (Marcel and Dekker, 2004), pp. 189-209.

Studlar, Donley T. 2002. Tobacco Control: A Comparative Politics in the United States and Canada. New York: Broadview Press

Swank, Duane, 1998, “Funding the Welfare State: Globalization and the Taxation of Business in Advanced Market Economies,” Political Studies 46:671-692 
Sweanor, D. 1997. “The Smuggling of Tobacco Products.” Ottawa: Smoking and Health Foundation

Taylor, Allyn L. 2002. “Global Governance, International Law and WHO: Looking Towards the Future.” Bulletin of World Health Organization 80 (12)

Taylor, Allyn L. 1996. “An International Regulatory Strategy for Global Tobacco Control.” Yale Journal of International Law 21: 257-304

Taylor, Allyn L. 1992. “Making the World Health Organization Work: A Legal Framework for Universal Access to Conditions for Health.” American Journal for Law and Medicine 18:301-346

Taylor, Allyn L., Douglas W. Bettcher, and Richard Peck, 2003, “International Law and International Legislative Process: The WHO Framework Convention on Tobacco Control,” in Richard D. Smith et al (eds.), Global Public Goods for Health, pp.212-229

Taylor, Allyn L., Frank J. Chaloupka, Emmanuel Guindon, and Michaelyn Corbett. 2000. “The Impact of Trade Liberalization on Tobacco Consumption.” In Prabhat and Frank Chaloupka (eds.). Tobacco Control in Developing Countries. Oxford: Oxford University Press

Taylor, Peter. 1985. The Smoking Ring: Tobacco, Money and Multinational Politics. New York: New American Library

Tesch, R. 1990. Qualitative Research: Analysis Types and Software Tools. New York: Falmer

Thun, Michael J., Derek Yach, and Michael Eriksen. 2000. “Tobacco Control Country Profiles” In Marlo Ann Corrao, G. Emmanuel Guindon, Namita Sharma, Dorna 
Fakhrabadi Shokoohi, (eds.) Tobacco Control Country Profile., Atlanta, GA: American Cancer Society, Inc.

Transparency International. 1999. Corruption Perception Index. Berlin, Germany: TI

Underhil, Geoffrey R.D. 2000. "State, Market, and Global Political Economy: A

Genealogy of an Inter(-?) Discipline.” International Affairs 76: 805-824

UICC. 2003. "Tobacco Control Strategy Planning Guides: Learning From the Strategic Lessons of 40 Years of Tobacco Control Advocacy Triumph - and Failures Across the Globe.” Website: http://strategyguides.globalink.org/. (Accessed 05/13/2004)

United State Department of Agriculture. 1997. Tobacco: World Markets and Trade. Washington, D.C.: United States Department of Agriculture, Foreign Agricultural Service

U.S. Department of Health, Education and Welfare. 1964. Smoking and Health: Report of the Advisory Committee of the Surgeon General of the Public Health Service. Princeton: D. Van Nostrand Co., Inc.

U.S. Department of Health and Human Services. 2004. The Health Consequences of Smoking: What it Means to You. U.S. Department of Health and Human Services, Center for Disease Control and Prevention, National Center for Chronic Disease Prevention and Health Promotion, and Office on Smoking and Health

U.S. Department of Health and Human Services. 2000. Reducing Tobacco Use. Center for Disease Control and Prevention, National Center for Chronic Disease Prevention and Health Promotion, and Office on Smoking and Health. Website: http://www.cdc.gov/tobacco/sgr/sgr_2000/ackntoc.pdf. (accessed June 13, 2004) 
Vayrynen, Raimo. 1999. “Norms, Compliances, and Enforcement in Global Governance.” In Raimo Vayrynen (ed.). Globalization and Global Governance. New York: Rowman \& Littlefield. Pp.25-46

Walker, Duncan. March 10, 2004. “The Hunt for the Pro-Smokers.” British Broadcasting Corporation. http://news.bbc.co.uk/1/hi/magazine/3497170.stm. Accessed March 10,2004

Walker, Jack L. 1969. "The Diffusion of Innovation Among the American States.” American Political Science Review 63:880-900

Waltz, Kenneth N. 1979. Theory of International Politics. Reading, Massachusetts: Addison-Wesley

Waltz, Kenneth N. 1959. Man, State, and War. New York: Columbia University Press

Wapner, Paul. 1997. “Governance in Global Civil Society.” In Oran D. Young (ed.). Global: Drawing Insights from the Environmental Experience. Cambridge: MIT Press, 65-84

Weible, Christopher, Paul A. Sabatier, and Mark Lubell. 2004. “A Comparison of a Collaborative and Top-Down Approach to the Use of Science in Policy: Establishing Marine Protected Areas in California.” Policy Studies Journal, 32(2): $187-207$

Weiss, Thomas, 2000. "Governance, good governance and global governance: Conceptual and Actual Challenges.” Third World Quarterly 21:795-814 Weissman, Robert. 2001. “The Taste of the U.S.A.” Multinational Monitor, Vol. 22 Issue 6 
Weissman, Robert. 1998. “IV. Big Tobacco Goes Global,” Multinational Monitor, Vol. 19 Issue $7 / 8$

Wendleby, M. and P. Nordgren. 1998. "Balancing the Prices: Sweden.” In Lipponen S., Hara M., Waller M., and Piha T (eds.). Non-taxable Imports of Tobacco. Helsinki: Ministry of Social Affairs and Health

Wendt, Alexander. 1994. "Collective Identity Formation and the International State.” American Political Science Review, 88:384-396

Wendt, Alexander, 1992, “Anarchy is What States Make of it - the Social Construction of Power-Politics,” International Organization 46:391-425

Wendt, Alexander, 1987, “The Agent-Structure Problem in Internal Relations Theory,” International Organization, 41: 335-370

White, Ann A. 2004. “Controlling Big Tobacco.” Multinational Monitor Vol. 25 Issue 1/2

Wolfson, Mark. 2001. The Fight Against Big Tobacco. New York: Aldine De Gruyter

World Bank. 1999. Curbing the Epidemic: Governments and Economic of Tobacco Control. Washington, DC: World Bank

World Bank. 1991. Policy on Tobacco (R91-225). Washington, D.C.: The World Bank World Conference on Tobacco or Health. 2003. (12 ${ }^{\text {th }}$ : Helsinki, Finland). Global Action for Tobacco Free Future. Website: http://www.congcreator.com/wctoh2003/content.html. Accessed February 10, 2004

World Conference on Tobacco or Health. 2000. (11 ${ }^{\text {th }}$ : 2000: Chicago, Illinois, USA). Promoting a Future Without Tobacco. Boston, MA, USA: Sappi Fine Paper, and Atlanta, Georgia, USA: Williams Printing 
World Conference on Tobacco or Health. 2000. (10 ${ }^{\text {th }}: 1997:$ Beijing, China). Tobacco:

The Growing Epidemic: Proceedings of the Tenth World Conference on Tobacco or Health. Ju-shan Lu (ed.). London; New York: Springer

World Conference on Tobacco and Health. 1995. ( $9^{\text {th }}: 1994$ : Paris, France). Tobacco \& Health: Proceedings of the Seventh World Conference on Tobacco and Health. Karen Slama (ed.). New York and London: Plenum Press

World Conference on Tobacco or Health. 1994. ( $8^{\text {th }}:$ 1992: Buenos Aires, Argentina).

Building a Tobacco-Free World. Atlanta, GA: American Cancer Society

World Conference on Tobacco and Health. 1990. ( $7^{\text {th }}: 1990$ : Perth, Australia). Tobacco \& Health 1990, The Global War: Proceedings of the Seventh World Conference on Tobacco and Health. Betty Durston and Konrad Jamrozik (eds.) Australia: Lamb Printers Pty Ltd.

World Conference on Smoking and Health. 1988. (6 $6^{\text {th }}: 1987:$ Tokyo: Japan). Smoking and Health 1987. Masakazu Aoki, Shigeru Hisamichi, and Suketami Tominaga (eds.) Amsterdam - New York - Oxford: Excerpta Medica World Conference on Smoking and Health.1985. (5 ${ }^{\text {th }}: 1983$ : Winnipeg, Manitoba, Canada). Proceedings of the Fifth World Conference on Smoking and Health. William f. Forbes, Richard C. Frecker, and David Nostbakken (eds.). Canada: Canadian Council on Smoking and Health World Conference on Smoking and Health. 1980. (4 $4^{\text {th }}: 1979:$ Stockholm, Sweden). The Smoking Epidemic: A Matter of Worldwide Concern: Proceedings of the Fourth World Conference on Smoking and Health. Lars M. Ramstrom (ed.). Sweden: Almqvist and Wiksell International 
World Conference on Smoking and Health. 1976. ( $3^{\text {rd }}: 1975:$ New York: N.Y). Smoking and Health. [Proceedings]. Jesse Steinfield, William Griffiths, Keith Ball, and Robert M. Taylor (eds.) USA: U.S. Department of Health, Education, and Welfare, Public Health Services, National Institutes of Health, and National Cancer Institute.

World Conference on Smoking and Health. 1972. ( $2^{\text {nd }}$ : 1971: London, England). The Second World Conference on Smoking and Health: the Proceedings of a conference organized by the Health Education Council at Imperial College, London, September 20-24, 1971. Robert G. Richardson (ed.). Pitman Medical World Conference on Smoking and Health. 1968. (1 $1^{\text {st: }}$ 1967: New York: N.Y). Toward a Less Harmful Cigarette; [Proceedings]. Ernest L. Wynder and Dietrich Hoffmann (eds.) National Cancer Institute

World Conference on Tobacco or Health (WCTOH). 2000. "World’s Best Practices in Tobacco Control.” Tobacco Control 9:228-236

World Health Organization. 2005. "Why is Tobacco a Public Health Priority.” Website: http://www.who.int/tobacco/health_priority/en/index.html. (Accessed 09/13/2004) World Health Organization. 2005b. “About Us: The World Health Organization’s Response to the Tobacco Epidemic.” Website: http://www.who.int/tobacco/about/en/. (Accessed March 23, 2004)

World Health Organization. 2004. Basic Texts. $44^{\text {th }}$ Edition. Website: http://policy.who.int/cgibin/om_isapi.dll?hitsperheading=on\&infobase=basicdoc\&record= $\{9 \mathrm{D} 5\} \&$ softpag e=Document42. (Accessed September 29, 2004) 
World Health Organization. 2004b. "International Consultation on Environmental Tobacco Smoke (ETS) and Child Health Background Papers.” Website: http://www.who.int/tobacco/fctc/consultation/ets2/en/. (Accessed March, 15, 2005)

World Health Organization. 2003. "An International Treaty for Tobacco Control.” Website: http://www.who.int/features/2003/08/en/. (Accessed March 15, 2004)

World Health Organization. 2003b. " $12^{\text {th }}$ World Conference on Tobacco or Health.” August 4, 2003. Website: http://www.who.int/dg/lee/speeches/2003/helsinki/en/. (Accessed November 15, 2004)

World Health Organization. 2002. "Illicit Tobacco Trade Contributes to Global Disease Burden.” Website: http://www.who.int/mediacentre/news/releases/who62/en/. (Accessed 8/14/2004)

World Health Organization. 2001. "World No Tobacco Day 2001: Second-hand Smoke Kills. Let’s Clear the Air.” WHO. Website: http://www.who.int/tobacco/communications/events/wntd/2001/en/. Accessed February 8, 2005

World Health Organization. 2000. "Health and Health Behavior among Young People.” In Currie C., Hurrelmann K., Settertboulte W., Smith R., and Todd J. (eds.) Denmark: WHO Regional Office for Europe WHO. 2000b. A/FCTC/WG2/5. Website: http://www.who.int/gb/fctc/PDF/wg2/et25.pdf WHO. 2000c. "Public Hearings on the Framework Convention on Tobacco Control." Website: http://www3.who.int/whosis/fctc/fctc.cfm. Access February 2004 through July 2005 
World Health Organization. 1999. The World Health Report 1999. Geneva: WHO

World Health Organization. 1947. Chronicle of World Health Organization:

Development and Constitution of the World Health Organization. New York, USA and Geneva, Switzerland. Retrieved October 11, 2004 from the World Wide Web: http://whqlibdoc.who.int/chronicles/chronicles_1947.pdf Vol. 1, No. 1-2

WHO Committee of Experts Report on Tobacco Industry Documents. 2000. "Junking Science to Promote Tobacco.” Website: http://www.tobaccoscam.ucsf.edu/pdf/9.6-JunkScience-Yach.pdf. Accessed February 12, 2005

World Tobacco File, 1998

Wynder, Ernst L. and Evarts A. Graham. 1950. “Tobacco Smoking as Possible Etiology in Bronchogenic Carcinoma.” Journal of the American Medical Association $143: 329-336$

Yach, Derek. 2001. "Economics and Public Health - Reflections from the Past and Challenges for the Future.” Scand J Public Health 29:241-244

Yach, Derek and Douglas Bettcher. 2000. "Globalization of the Tobacco Industry Influence and New Global Response." Tobacco Control 9:206-216

Yach, Derek and Douglas Bettcher. 1998. "The Globalization of Public Health.” American Journal of Public Health 88:735-741

Yach, Derek, S. Harrison (eds.). November 14-17, 1993. Proceedings of All Africa Conference on Tobacco or Health. Harare, Zimbabwe

Young, Oran R. 1999. Governance in World Affairs. Ithaca, NY: Cornell University Press 
Young, Oran R., 1994, International Governance: Protecting the Environment in a Stateless Society, Ithaca: Cornell University Press

Young, Oran. 1983 “Regime Dynamics: The Rise and fall of International Regimes.” In Stephen Krasner (ed.). International Regimes. Ithaca: Cornell University Press

Yuan, Hu An. 1997. “Cigarette Production Down; Contraband and Counterfeits Flourish.” Tobacco Reporter, April

Zehfuss, Maja. 2002. Constructivism in International Relations: The Politics of Reality. New York: Cambridge University Press 